Universidad de Lima

Facultad de Ingeniería y Arquitectura

Carrera de Ingeniería Industrial

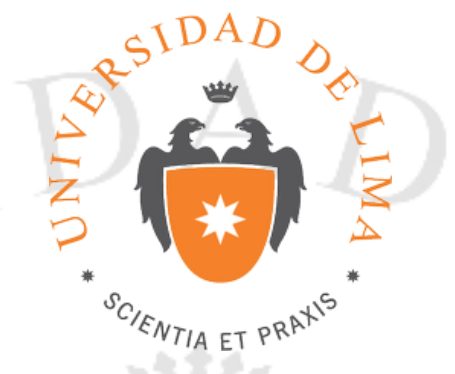

\title{
ESTUDIO DE PRE-FACTIBILIDAD PARA LA INSTALACIÓN DE UNA PLANTA DE PRODUCCIÓN DE BOLSAS FILTRANTES DE MANZANILLA COMÚN (Chamomilla recutita $(\mathrm{L}$. Rauschert)
}

Trabajo de investigación para optar el título profesional de Ingeniero Industrial

Elio Luis Aliaga Paredes

Código 20042408

José Antonio Acevedo Jara

Código 20041475

Asesor

Rafael Mauricio Villanueva Flores

Lima - Perú

Noviembre del 2017 


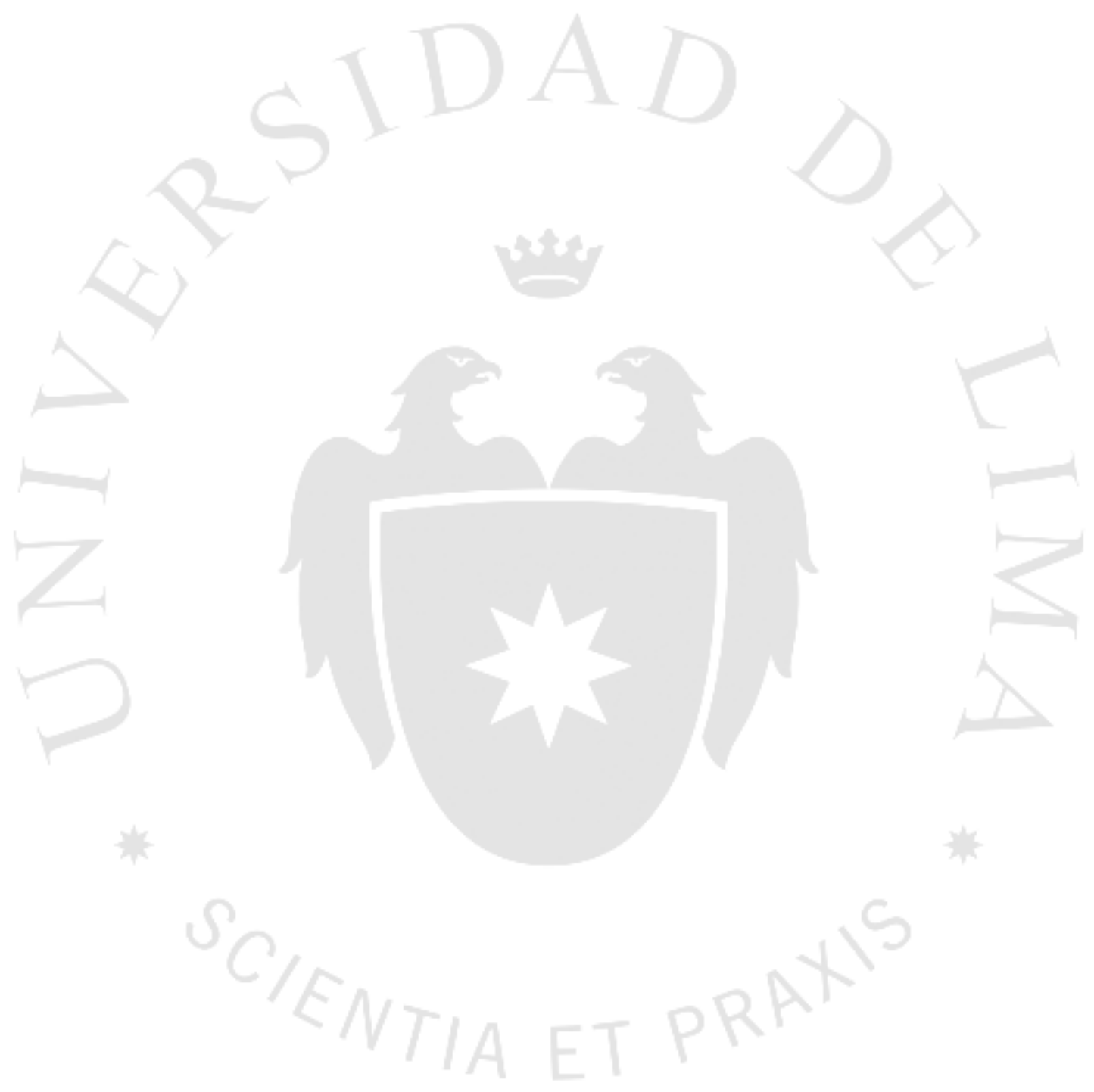




\section{ESTUDIO DE PRE-FACTIBILIDAD PARA LA}

INSTALACIÓN DE UNA PLANTA DE PRODUCCIÓN DE BOLSAS FILTRANTES DE MANZANILLA COMÚN (Chamomilla recutita (L.) Rauschert) 


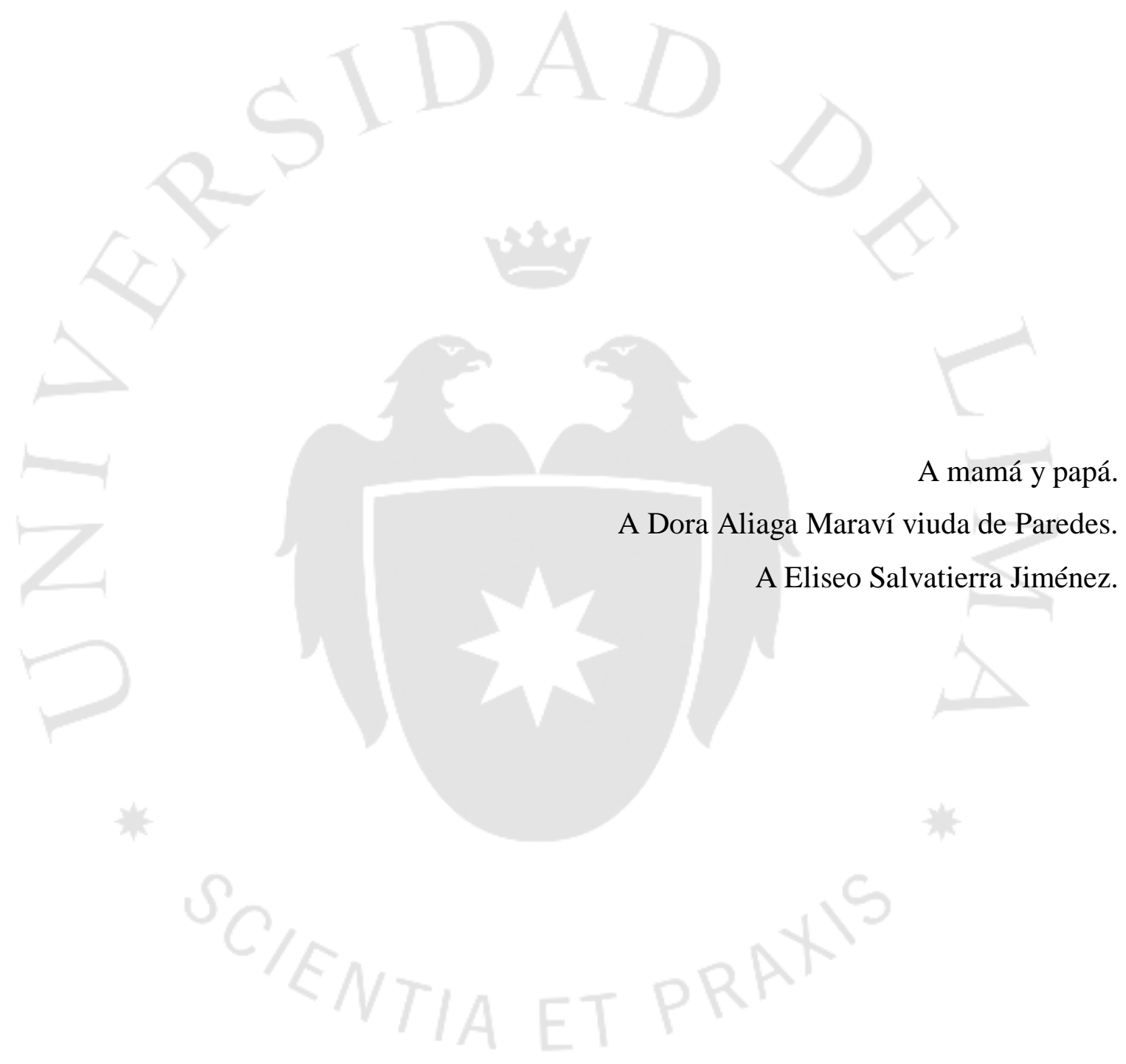




\section{TABLA DE CONTENIDO}

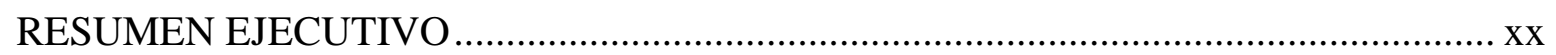

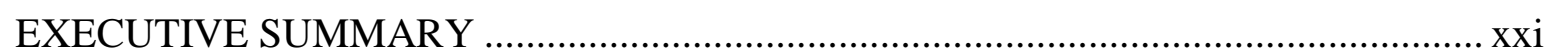

CAPÍTULO I: ASPECTOS GENERALES ........................................................... 1

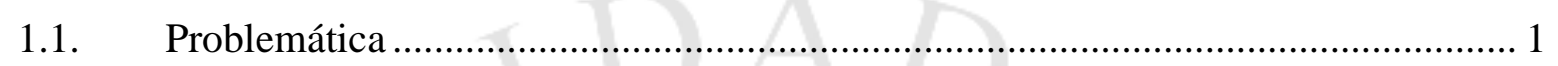

1.2. Objetivos de la investigación.................................................................. 2

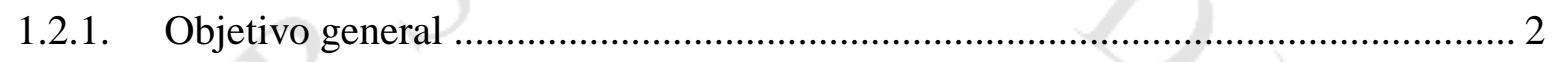

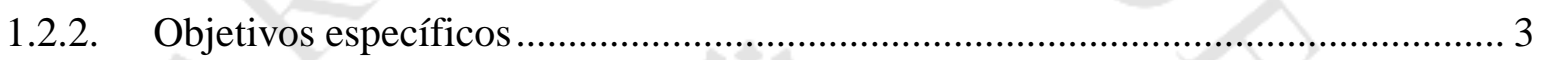

1.3. Alcance y limitaciones de la investigación...................................................... 3

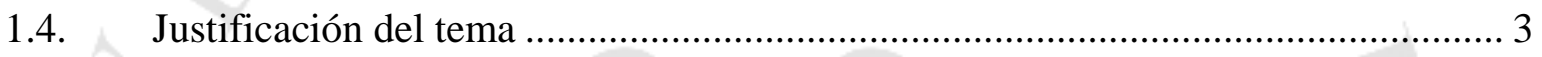

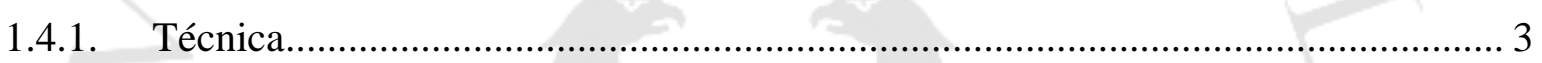

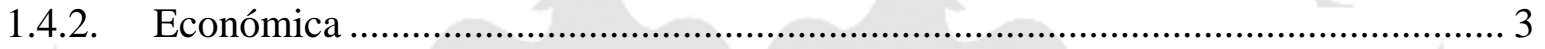

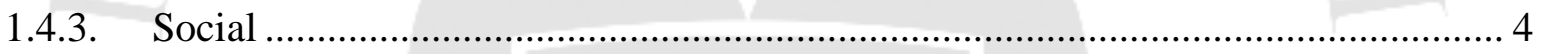

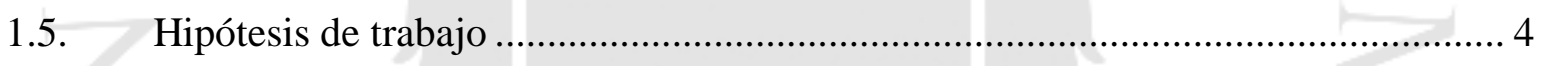

1.6. Marco referencial de la investigación ........................................................ 5

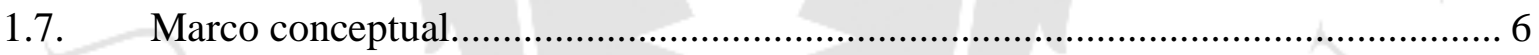

1.7.1. Sustento teórico de la propuesta del estudio ................................................ 6

1.7.2. Información de la materia prima y sus propiedades ......................................... 7

1.7.3. Nombre común de la materia prima ….............................................................. 7

1.7.4. Proceso y tecnología de fabricación propuestos ............................................... 8

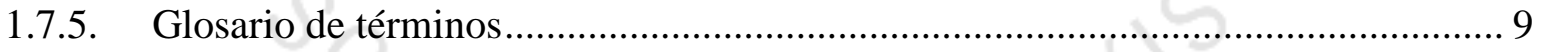

CAPÍTULO II: ESTUDIO DE MERCADO ............................................................ 12

2.1. Aspectos generales del estudio de mercado................................................... 12

2.1.1. Definición comercial del producto ......................................................... 12

2.1.2. Principales características del producto....................................................... 14

2.1.2.1. Usos y características del producto........................................................... 14

2.1.2.2. Bienes sustitutos y complementarios.......................................................... 15

2.1.3. Determinación del área geográfica que abarcará el estudio .............................. 16

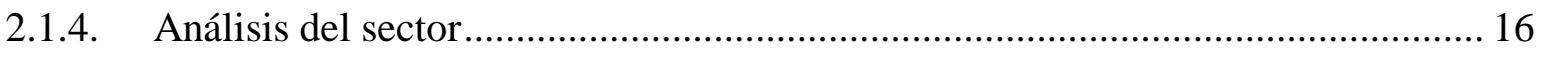


2.1.5. Determinación de la metodología que se empleará en la investigación de mercado 18

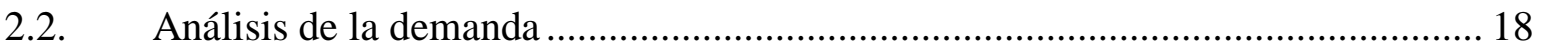

2.2.1. Demanda histórica ........................................................................................ 18

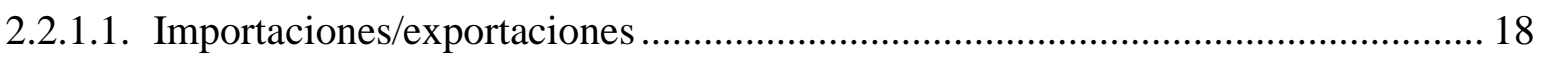

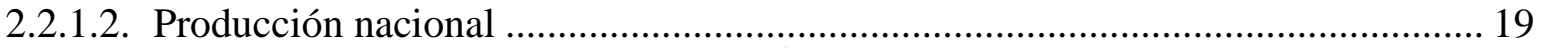

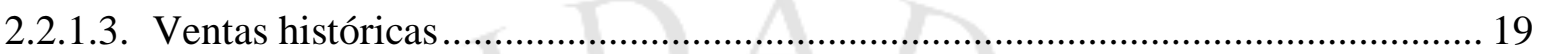

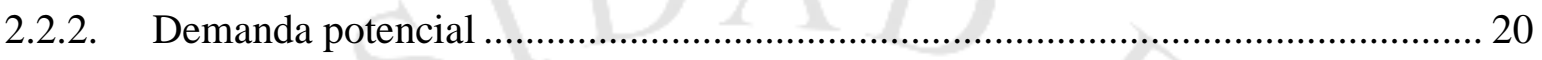

2.2.2.1. Patrones de consumo: incremento poblacional, consumo per cápita, estacionalidad 20

2.2.2.2. Determinación de la demanda potencial........................................................... 20

2.2.3. Demanda mediante fuentes primarias........................................................... 20

2.2.3.1. Diseño y aplicación de encuestas u otras técnicas................................................ 20

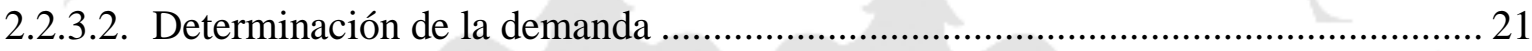

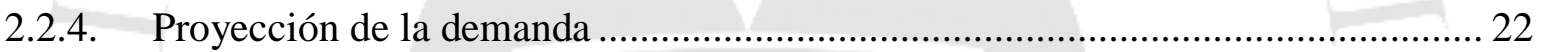

2.2.5. Consideraciones sobre la vida útil del proyecto .................................................. 23

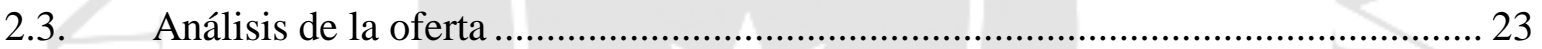

2.3.1. Empresas productoras, importadoras y comercializadoras................................... 23

2.3.2. Competidores actuales y potenciales …………................................................. 26

2.4. Determinación de la demanda para el proyecto...................................................... 28

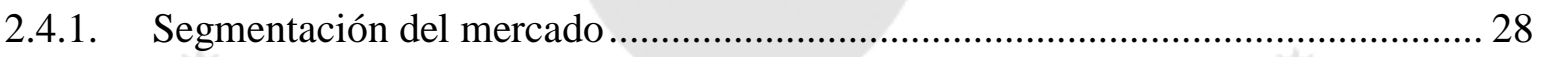

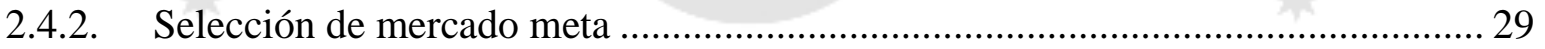

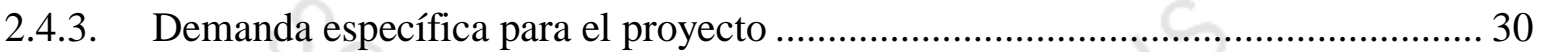

2.5. Definición de la estrategia de comercialización .................................................... 32

2.5.1. Políticas de comercialización y distribución ........................................................ 32

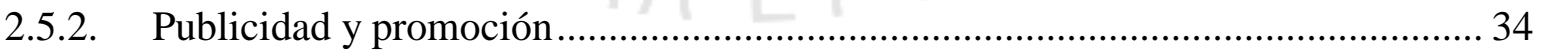

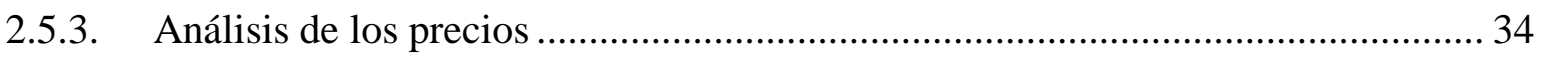

2.5.3.1. Tendencia histórica de los precios.................................................................... 34

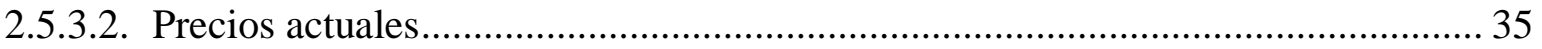

2.6. Análisis de disponibilidad de los insumos principales .......................................... 36

2.6.1. Características principales de la materia prima ………………………………....... 36 
2.6.2. Disponibilidad de la materia prima..................................................................... 41

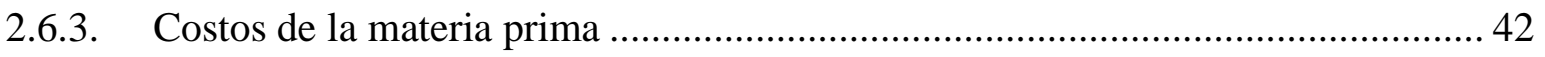

CAPÍTULO III: LOCALIZACIÓN DE PLANTA ………………………………………….. 43

3.1. Identificación y análisis detallado de los factores de localización .......................... 43

3.2. Identificación y descripción de las alternativas de localización ............................... 44

3.3. Evaluación y selección de localización ................................................................. 49

3.3.1. Evaluación y selección de la macro localización ...................................................... 49

3.3.2. Evaluación y selección de micro localización ..........................................................51

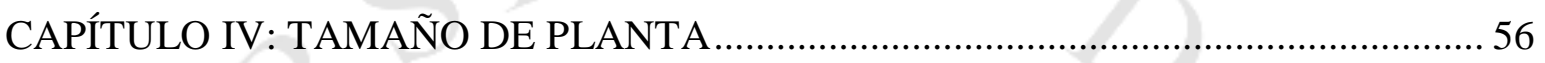

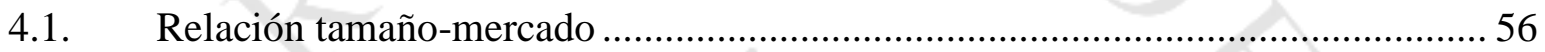

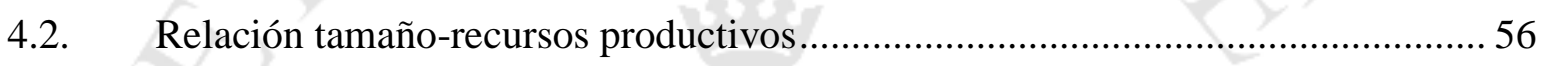

4.3. Relación tamaño-tecnología ………………………………………………..... 57

4.4. Relación tamaño-punto de equilibrio................................................................ 57

4.5. Selección del tamaño de planta........................................................................ 57

CAPÍTULO V: INGENIERÍA DEL PROYECTO........................................................ 59

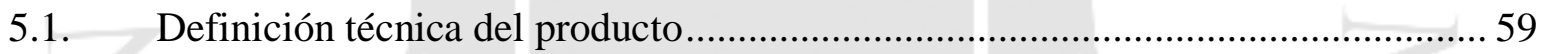

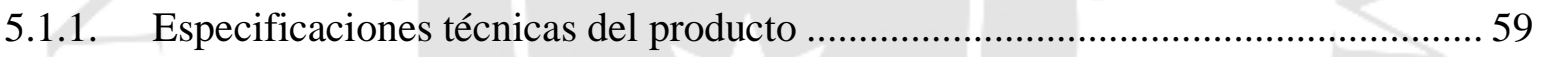

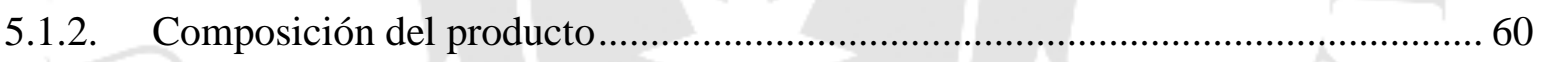

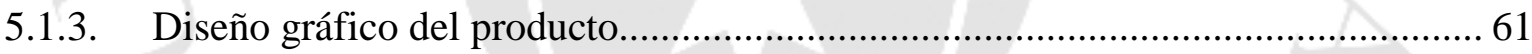

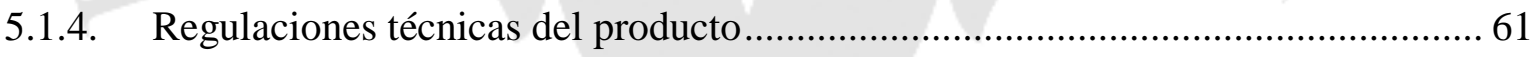

5.2. Tecnologías existentes y procesos de la producción ............................................... 62

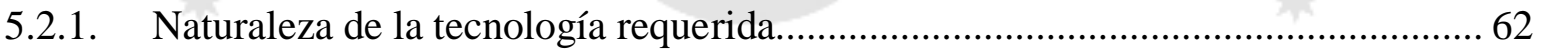

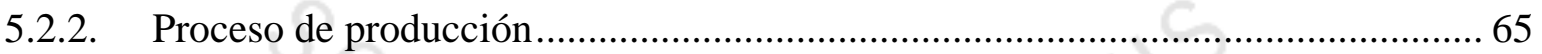

5.3. Características de las instalaciones y equipos .................................................... 72

5.3.1. Selección de la maquinaria y equipos................................................................. 72

5.3.2. Especificaciones de la maquinaria.................................................................... 72

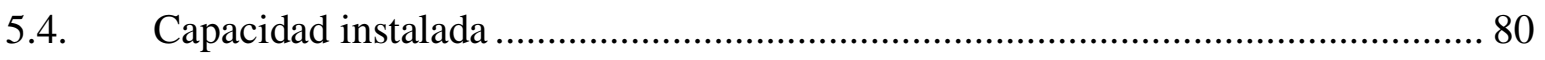

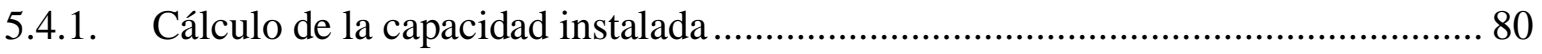

5.4.2. Cálculo detallado del número de maquinaria requerida ......................................... 82

5.5. Resguardo de la calidad e inocuidad del producto ............................................. 82

5.5.1. Calidad de la materia prima, de materiales, del proceso y del producto ................ 82 


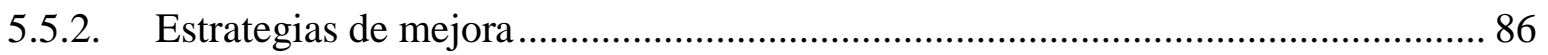

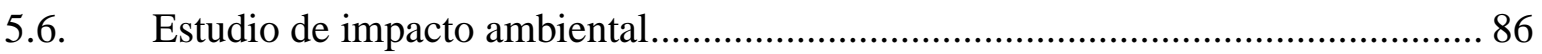

5.7. Seguridad y salud ocupacional ………………….......................................... 89

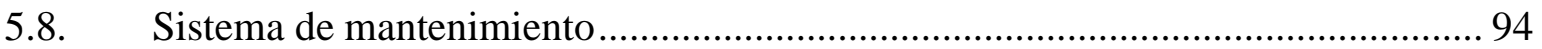

5.9. Programa de producción ................................................................................. 95

5.9.1. Factores para la programación de la producción .................................................... 95

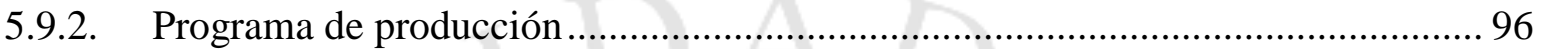

5.10. Requerimiento de materiales, servicios y personal................................................ 96

5.10.1. Materia prima, materiales y otros …………………………………………......... 96

5.10.2. Servicios: energía eléctrica, agua, vapor, combustible, etc................................. 101

5.10.3. Determinación del número de operarios y trabajadores indirectos ....................... 103

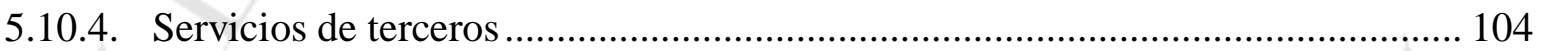

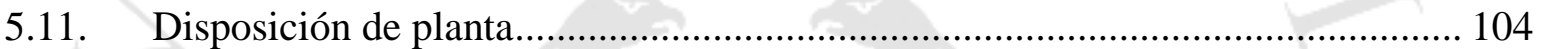

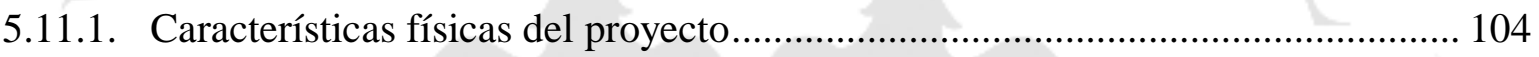

5.11.2. Determinación de las zonas físicas requeridas .................................................. 105

5.11.3. Cálculo de áreas para cada zona .................................................................. 105

5.11.4. Dispositivos de seguridad industrial y señalización ........................................... 109

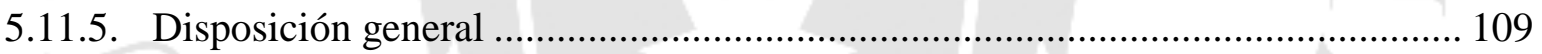

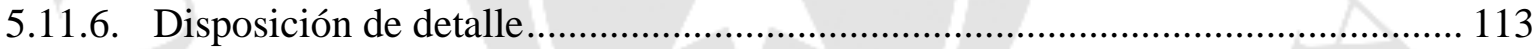

5.12. Cronograma de implementación del proyecto ..................................................... 116

CAPÍTULO VI: ORGANIZACIÓN Y ADMINISTRACIÓN ………………………...... 117

6.1. Formación de la organización empresarial ........................................................ 117

6.2. Requerimientos de la personal directivo, administrativo y de servicios ............. 119

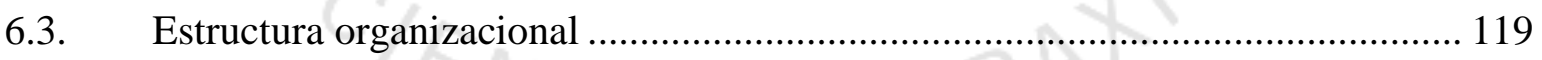

CAPÍTULO VII: ASPECTOS ECONÓMICOS Y FINANCIEROS ................................. 120

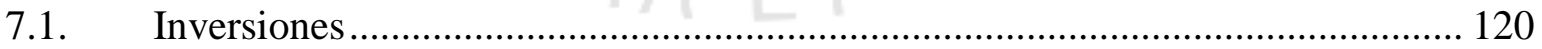

7.1.1. Estimación de las inversiones de largo plazo (tangibles e intangibles) ................ 120

7.1.2. Estimación de las inversiones de corto plazo (capital de trabajo) ....................... 122

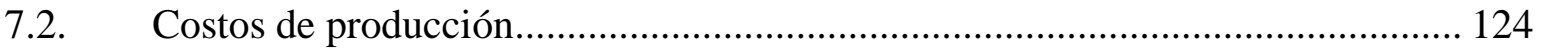

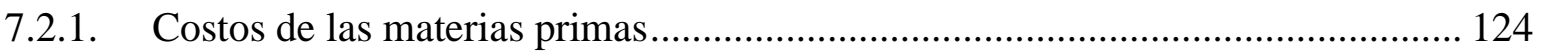

7.2.2. Costos de la mano de obra directa ..................................................................... 128 
7.2.3. Costos indirecto de fabricación (materiales indirectas, mano de obra indirecta y

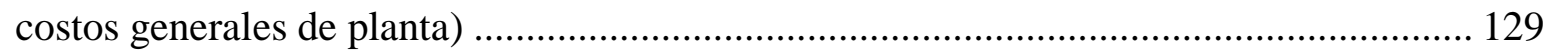

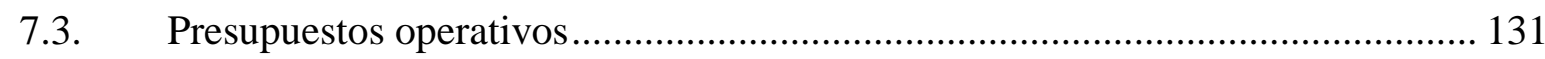

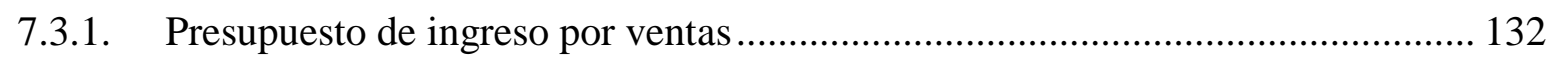

7.3.2. Presupuesto operativo de costos ..................................................................... 133

7.3.3. Presupuesto operativo de gastos ....................................................................... 135

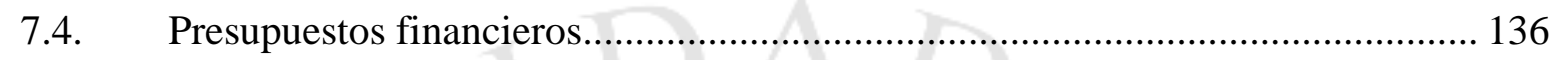

7.4.1. Presupuesto de servicio de deuda .................................................................. 136

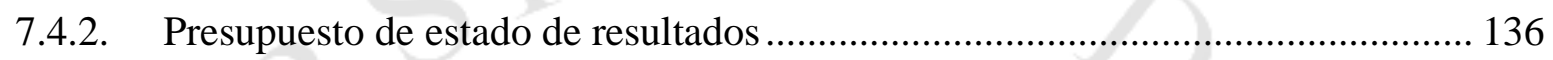

7.4.3. Presupuesto de estado de situación financiera..................................................... 138

7.4.4. Flujo de caja de corto plazo ............................................................................... 139

7.5. Flujo de fondos netos.................................................................................. 140

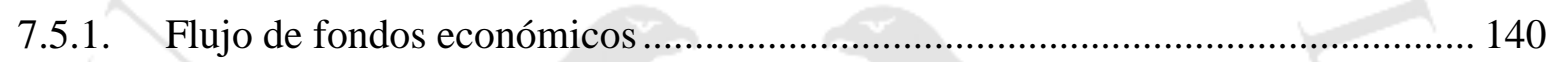

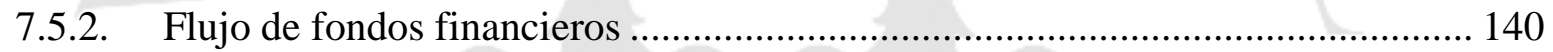

CAPÍTULO VIII: EVALUACIÓN ECONÓMICA Y FINANCIERA DEL PROYECTO 141

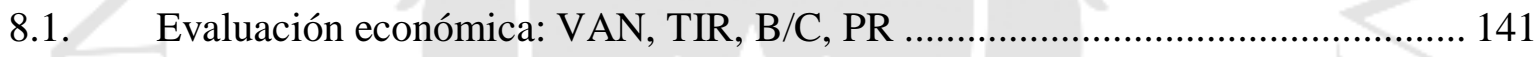

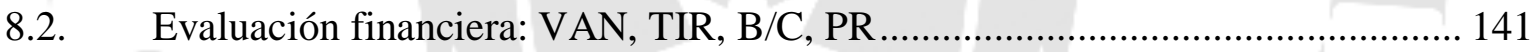

8.3. Análisis de ratios (liquidez, solvencia, rentabilidad e indicadores económicos y financieros del proyecto) ........................................................................................ 142

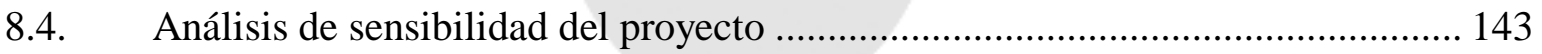

CAPÍTULO IX: EVALUACIÓN SOCIAL DEL PROYECTO......................................... 144

9.1. Identificación de las zonas y comunidades de influencia del proyecto ................ 144

9.1.1. Análisis de indicadores sociales (valor agregado, densidad de capital, intensidad de

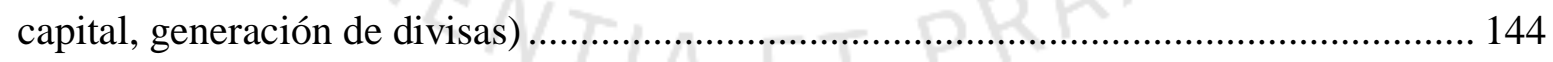

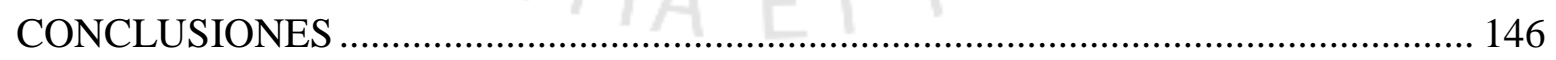

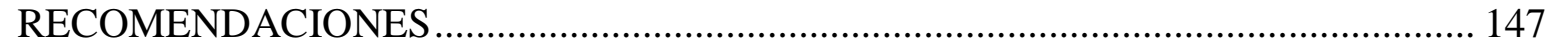

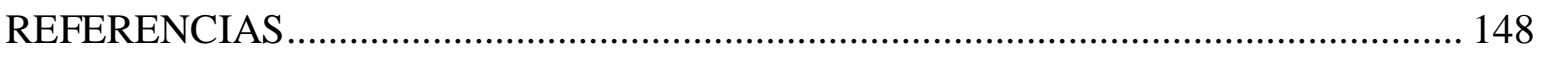

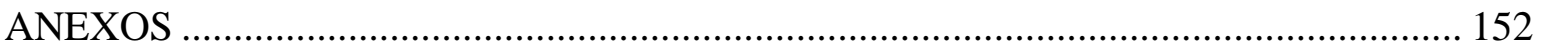




\section{ÍNDICE DE TABLAS}

Tabla 2. 1. Importaciones y exportaciones de infusiones del 2009 al 2013 hechas por Perú

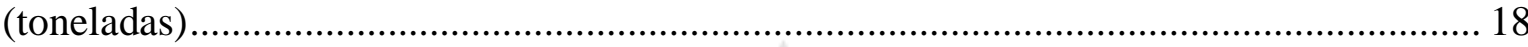

Tabla 2. 2. Producción de infusiones filtrantes del 2009 al 2013 (toneladas) .................. 19

Tabla 2. 3. Ventas históricas de infusiones en el Perú del 2005 al 2014 (toneladas) ......... 19

Tabla 2. 4. Demanda potencial de infusiones filtrantes a base de manzanilla común en Perú

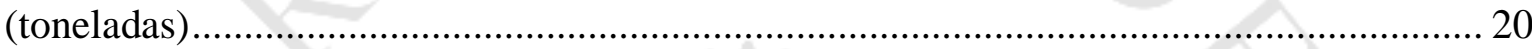

Tabla 2. 5. Intención e intensidad de compra de bolsas filtrantes de manzanilla común entera 21

Tabla 2. 6. Intención e intensidad de compra de bolsas filtrantes de sólo flores de manzanilla

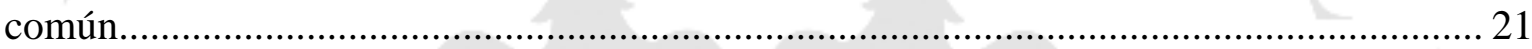

Tabla 2. 7. Población y venta de infusiones en el Perú del 2005 al 2014 (toneladas) ........ 22

Tabla 2. 8. Correlación entre la población histórica y las ventas históricas de infusiones en

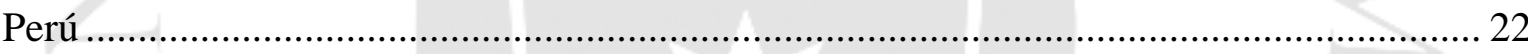

Tabla 2. 9. Proyección de la demanda de infusiones en el Perú del 2016 al 2025 (toneladas)

Tabla 2. 10. Ventas off-trade porcentuales de empresas de infusiones del 2005 al 2014 en

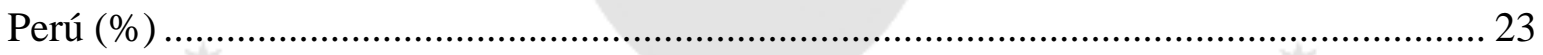

Tabla 2. 11. Ventas off-trade de principales empresas de infusiones al 2014 en Perú

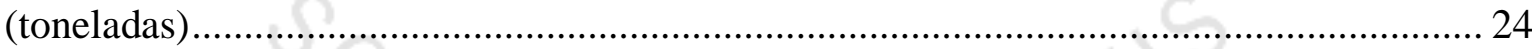

Tabla 2. 12. Participación de las empresas que importan infusiones del 2005 al 2014 en Perú $(\%)$

Tabla 2. 13. Ventas de infusiones en canal off-trade del 2005 al 2014 en Perú (toneladas)

Tabla 2. 14. Competidores directos de infusiones filtrantes a base de manzanilla común al

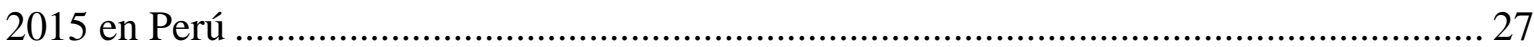

Tabla 2. 15. Competidores indirectos a base de partes de plantas para infusiones............ 28

Tabla 2. 16. Competidores indirectos a base de solubles para infusiones ....................... 28 
Tabla 2. 17. Estratificación de Lima Metropolitana por NSE al 2015 30

Tabla 2. 18. Lugares más frecuentes de compra de infusiones filtrantes en Lima Metropolitana por NSE 30

Tabla 2. 19. Proporción por intervalos de edad de la población en Lima Metropolitana al 2014 30

Tabla 2. 20. Demanda específica del proyecto para producto de planta entera de manzanilla común del 2016 al 2025 (toneladas) 31

Tabla 2. 21. Demanda específica del proyecto para producto de sólo flores de manzanilla común del 2016 al 2025 (toneladas) 31

Tabla 2. 22. Lugares usuales de ubicación de infusiones filtrantes de manzanilla común el 2015 en Perú 33

Tabla 2. 23. Leyenda de la Tabla 2.22. .33

Tabla 2. 24. Precios de infusiones filtrantes a base de manzanilla común el 2015 en Perú 35 Tabla 2. 25. Producción de manzanilla común en el Perú según zonas de mayor producción al 2014 (toneladas). 42

Tabla 2. 26. Disponibilidad de manzanilla común en Tarma del 2016 al 2025 (toneladas) 42 Tabla 3. 1. Disponibilidad de manzanilla común en verde al 2015 en regiones productoras (toneladas). .45

Tabla 3. 2. Escala de calificación de disponibilidad de materia prima 45

Tabla 3. 3. Distancia y tiempo hacia Lima Metropolitana desde regiones a evaluar (kilómetros y horas) .45

Tabla 3. 4. Escala de calificación de cercanía al mercado meta. 46

Tabla 3. 5. Costo promedio de terrenos en zonas industriales en regiones a evaluar al 2015 (soles) .46

Tabla 3. 6. Escala de calificación de costo de terreno 46

Tabla 3. 7. Nivel de remuneración a pagar en las regiones a evaluar al 2015 (soles) ........ 47

Tabla 3. 8. Escala de calificación de costo de mano de obra. 47

Tabla 3. 9. Costo medio de energía eléctrica para manufacturas en regiones a evaluar al 2015 (soles) 47

Tabla 3. 10. Escala de calificación de costo de energía.......................................................... 48

Tabla 3. 11. Costo de flete entre Lima Metropolitana y regiones a evaluar (soles) ........... 48 
Tabla 3. 12. Escala de calificación de costo de transporte terrestre 48

Tabla 3. 13. Costo medio de agua potable al 2015 en regiones a evaluar (soles)............... 49

Tabla 3. 14. Escala de calificación de costo de agua potable ............................................... 49

Tabla 3. 15. Abreviación de los factores de localización para evaluación de macro

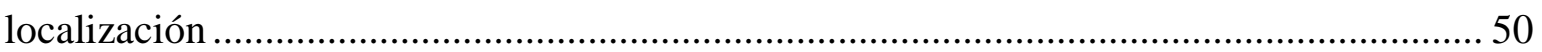

Tabla 3. 16. Ponderado de factores de evaluación para macro localización ........................ 50

Tabla 3. 17. Escala de calificación ............................................................................. 50

Tabla 3. 18. Resultados de la evaluación a nivel de macro localización ................................ 51

Tabla 3. 19. Porcentaje de producción de manzanilla común en los distritos a evaluar..... 51

Tabla 3. 20. Escala de calificación de porcentaje de producción de manzanilla común .... 51

Tabla 3. 21. Tarifas de energía eléctrica de tipo BT5B no residencial de distritos a evaluar

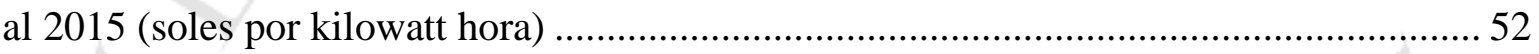

Tabla 3. 22. Escala de calificación de energía eléctrica de tipo BT5B ………………….... 52

Tabla 3. 23. Costo de terreno en los distritos a evaluar (soles por metro cuadrado) .......... 52

Tabla 3. 24. Escala de calificación de costo de terreno ......................................................... 53

Tabla 3. 25. Disponibilidad de GLP para consumidores directos en los distritos a evaluar al

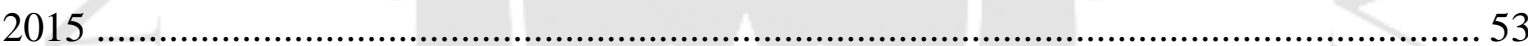

Tabla 3. 26. Escala de calificación de disponibilidad de GLP.............................................. 53

Tabla 3. 27. Vías de acceso a evaluar desde la Oroya hacia los distritos a evaluar............ 54

Tabla 3. 28. Escala de calificación de vías de acceso desde la Oroya .................................. 54

Tabla 3. 29. Abreviación de factores de evaluación a nivel de micro localización............. 54

Tabla 3. 30. Ponderado de factores de evaluación a nivel de micro localización ............... 54

Tabla 3. 31. Resultados de la evaluación a nivel de micro localización................................ 55

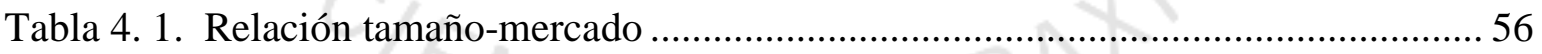

Tabla 4. 2. Relación tamaño-recursos productivos........................................................... 56

Tabla 4. 3. Relación tamaño-tecnología ……………………………………………........ 57

Tabla 4. 4. Relación tamaño-punto de equilibrio............................................................ 57

Tabla 4. 5. Selección del tamaño de planta........................................................................ 58

Tabla 5. 1. Especificaciones técnicas del producto de planta entera de manzanilla común59

Tabla 5. 2. Especificaciones técnicas del producto de flores de manzanilla común ........... 60

Tabla 5. 3. Composición del producto de planta entera de manzanilla común .................... 60 
Tabla 5. 4. Composición del producto de flores de manzanilla común 60

Tabla 5. 5. Selección de tecnología de las operaciones o procesos ....................................... 65

Tabla 5. 6. Resumen de cantidad y tipo de maquinaria para el proceso productivo............ 72

Tabla 5. 7. Especificaciones técnicas de balanza de plataforma ……………………......... 72

Tabla 5. 8. Especificaciones técnicas de coche de traslado .................................................. 73

Tabla 5. 9. Especificaciones técnicas de mesa de selección ................................................. 73

Tabla 5. 10. Especificaciones técnicas de peine de selección ............................................... 73

Tabla 5. 11. Especificaciones técnicas de cestos .................................................................. 74

Tabla 5. 12. Especificaciones técnicas de picadora ................................................................ 74

Tabla 5. 13. Especificaciones técnicas del lavadero ……………………………….......... 74

Tabla 5.14. Especificaciones técnicas de la centrífuga.................................................... 75

Tabla 5. 15. Especificaciones técnicas del deshidratador ..................................................... 75

Tabla 5. 16. Especificaciones técnicas del molino de martillos ………………………..... 76

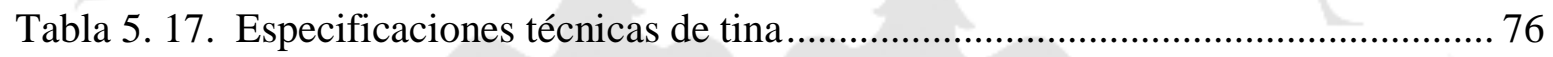

Tabla 5. 18. Especificaciones técnicas de jarra de medida .................................................... 76

Tabla 5. 19. Especificaciones técnicas de balanza de sobremesa ........................................ 77

Tabla 5. 20. Especificaciones técnicas de la mezcladora ………………………................ 77

Tabla 5. 21. Especificaciones técnicas de selladora …………………………………....... 77

Tabla 5. 22. Especificaciones técnicas de la envasadora ..................................................... 78

Tabla 5. 23. Especificaciones técnicas de tanque de GLP ................................................... 78

Tabla 5. 24. Especificaciones técnicas de horno de mufla .................................................. 79

Tabla 5. 25. Especificaciones técnicas de balanza de humedad .......................................... 79

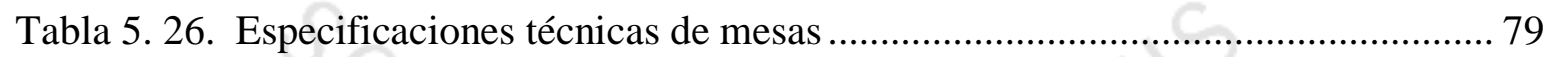

Tabla 5. 27. Capacidades en producto terminado de las operaciones por el método de balance

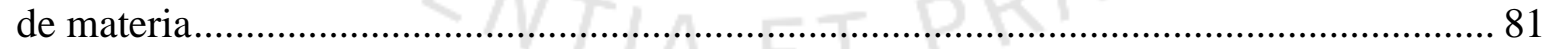

Tabla 5. 28. Requerimiento de maquinaria u operarios ....................................................... 82

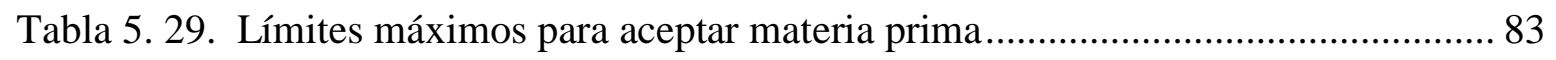

Tabla 5. 30. Análisis de Peligros y Puntos Críticos de Control............................................ 85

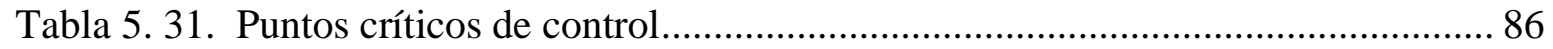

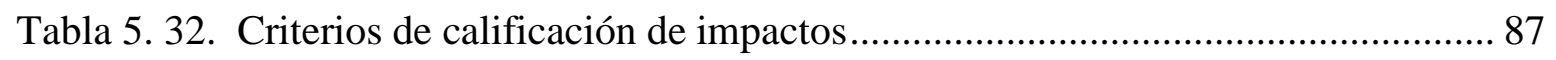

Tabla 5. 33. Rangos de significancia de impactos .............................................................. 87 


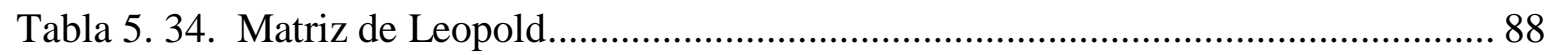

Tabla 5. 35. Índice de probabilidad de ocurrencia de un evento ........................................ 89

Tabla 5. 36. Índice de severidad al ocurrir un evento ........................................................... 90

Tabla 5. 37. Nivel de riesgo de un evento y su significancia ............................................ 90

Tabla 5. 38. Matriz de identificación de peligros y evaluación de riesgos (IPER) ............. 91

Tabla 5. 39. Plan de mantenimiento preventivo aplicada a la maquinaria y equipos ......... 94

Tabla 5. 40. Programa de producción del proyecto ............................................................ 96

Tabla 5. 41. Requerimiento de materia prima..................................................................... 96

Tabla 5. 42. Requerimiento de papel filtro termosellable .................................................... 97

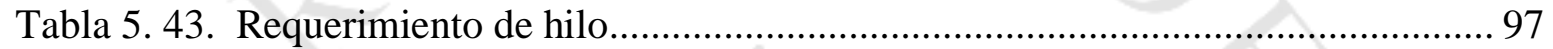

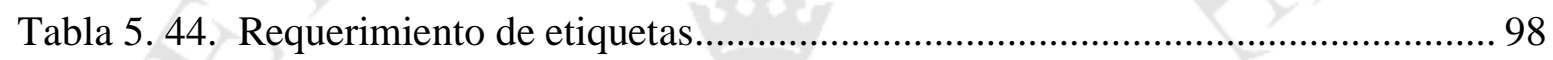

Tabla 5. 45. Requerimiento de adhesivo...................................................................... 99

Tabla 5. 46. Requerimiento de sobres de envoltura.......................................................... 99

Tabla 5. 47. Requerimiento de cajas para ambos productos............................................. 100

Tabla 5. 48. Requerimiento de etiquetas adhesivas ....................................................... 100

Tabla 5. 49. Requerimiento de envolturas de cajas, bolsas de polietileno y cintas de embalaje 101

Tabla 5. 50. Requerimiento de agua potable y desinfectante para operación de lavado .. 102

Tabla 5. 51. Requerimiento de energía eléctrica............................................................. 102

Tabla 5. 52. Requerimiento de gas licuado de petróleo (GLP) ........................................... 103

Tabla 5. 53. Tipo de industria en función de los usos permisibles .................................... 104

Tabla 5. 54. Área mínima del área de producción por el método de Guerchet ................. 106

Tabla 5. 55. Espacio mínimo de almacén de materia prima ................................................ 107

Tabla 5. 56. Espacio mínimo para materiales que cubran seis meses de producción el último

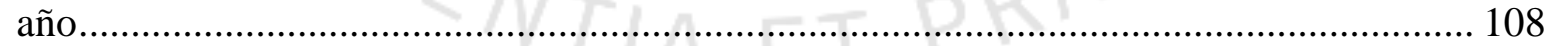

Tabla 5. 57. Espacio mínimo de productos terminados para rotación cada dos semanas el último año 109

Tabla 5. 58. Tabla de motivos para análisis relacional ...................................................... 110

Tabla 5. 59. Códigos de análisis relacional ................................................................. 110

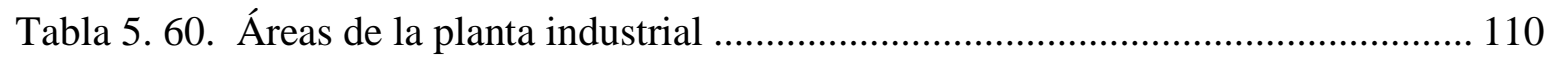

Tabla 5. 61. Valores de proximidad de las áreas de la instalación ...................................... 111 
Tabla 5. 62. Superficies mínimas de las principales áreas de la planta industrial 112

Tabla 5. 63. Cronograma de implementación del proyecto ............................................ 116

Tabla 6. 1. Cantidad total de personal de planta industrial al último año........................ 119

Tabla 7. 1. Costos de maquinaria y equipos .............................................................. 120

Tabla 7. 2. Costo de equipos complementarios asociados a la producción ...................... 121

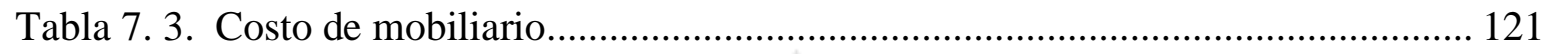

Tabla 7. 4. Costos de implementos de seguridad y salubridad ...................................... 122

Tabla 7. 5. Costo de terreno y edificación construida .................................................... 122

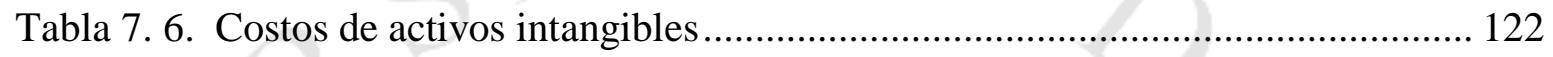

Tabla 7. 7. Capital de trabajo del proyecto ............................................................... 123

Tabla 7. 8. Inversión total del proyecto ..................................................................... 123

Tabla 7. 9. Costo de materia prima ....................................................................... 124

Tabla 7. 10. Costo de papel filtro termosellable .......................................................... 124

Tabla 7. 11. Costo de hilo ...................................................................................... 125

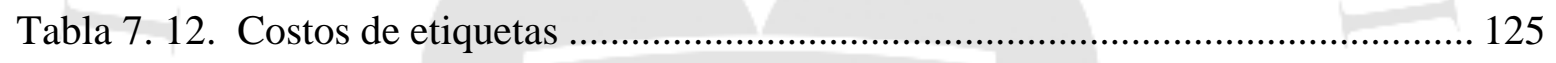

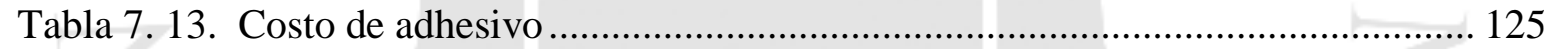

Tabla 7. 14. Costo de sobres de envoltura para bolsas filtrantes .................................. 126

Tabla 7. 15. Costos de cajas para producto de planta entera ........................................ 126

Tabla 7. 16. Costo de cajas para producto de flores .................................................. 126

Tabla 7. 17. Costo de etiquetas adhesivas .............................................................. 127

Tabla 7. 18. Costo de envoltura de cajas .................................................................... 127

Tabla 7. 19. Costo de desinfectante ...................................................................... 127

Tabla 7. 20. Costo de bolsas para empaque de cajas ................................................ 128

Tabla 7. 21. Costo de cinta de embalaje ................................................................. 128

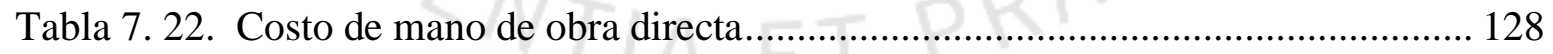

Tabla 7. 23. Costo de mano de obra indirecta y personal administrativo ....................... 129

Tabla 7. 24. Costo de personal de limpieza ................................................................. 129

Tabla 7. 25. Costo de personal de vigilancia .......................................................... 130

Tabla 7. 26. Costo de agua potable y desagüie ......................................................... 130

Tabla 7. 27. Costo de energía eléctrica ...................................................................... 130

Tabla 7. 28. Costo de gas licuado de petróleo (GLP) .............................................. 130 


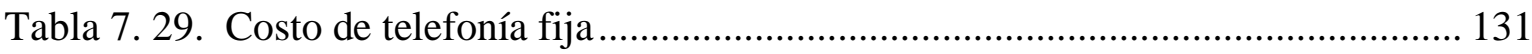

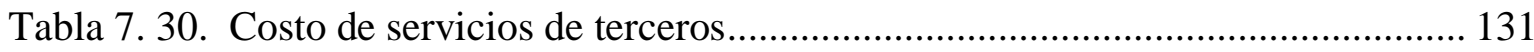

Tabla 7. 31. Presupuesto de ingreso por ventas ............................................................. 132

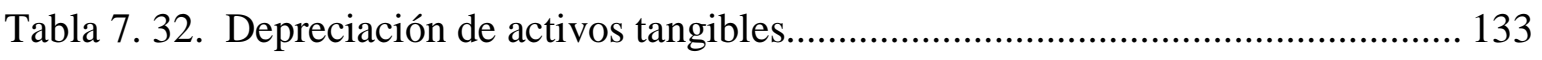

Tabla 7. 33. Depreciación de activos intangibles ........................................................... 133

Tabla 7. 34. Presupuesto operativo de costos .................................................................... 134

Tabla 7. 35. Presupuesto operativo de gastos ................................................................ 135

Tabla 7. 36. Estructura de financiamiento del proyecto ……………………………….... 136

Tabla 7. 37. Servicio de deuda del proyecto .................................................................. 136

Tabla 7. 38. Presupuesto de estado de resultados del proyecto ......................................... 137

Tabla 7. 39. Presupuesto de estado de situación financiera............................................. 138

Tabla 7. 40. Flujo de caja de corto plazo ..................................................................... 139

Tabla 7. 41. Flujo de fondos económicos .................................................................. 140

Tabla 7. 42. Flujo de fondo financiero..................................................................... 140

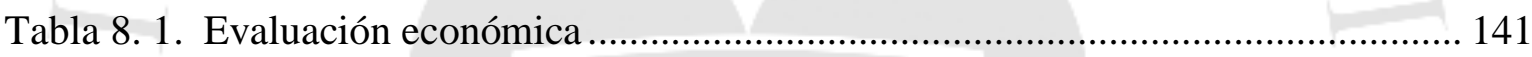

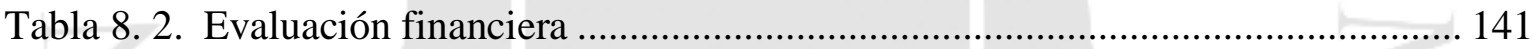

Tabla 8. 3. Análisis económico de sensibilidad del proyecto ............................................. 143

Tabla 9. 1. Valor agregado acumulado del proyecto …………………………………... 144

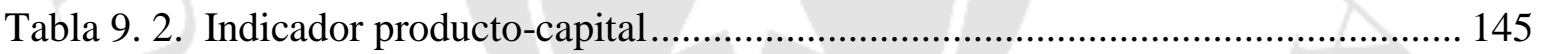

Tabla 9. 3. Indicador densidad de capital ............................................................... 145

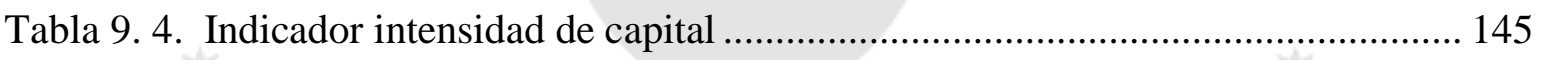




\section{ÍNDICE DE FIGURAS}

Figura 1. 1. Elemento extraño en el acopio de manzanilla común entera secada al sol en Tarma 2

Figura 1. 2. Manzanilla común entera acopiada en Tarma lista para proceso de infusiones filtrantes 2

Figura 1. 3. Proyección de ventas al por menor de infusiones en Perú al 2021 (millones de soles) 4

Figura 1. 4. Esquema explicativo de la tecnología propuesta por el presente estudio...... 9

Figura 2. 1. Modelo de sobre de envoltura y bolsa filtrante de planta entera de manzanilla común 13

Figura 2. 2. Modelo de sobre de envoltura y bolsa filtrante de sólo flores de manzanilla común... 13

Figura 2. 3. Ventas de infusiones en canal off-trade del 2014 en Perú (\%) ..................... 26

Figura 2. 4. Canal de distribución de productos para el presente estudio.......................... 32

Figura 2. 5. Tendencia histórica de precios minoristas de infusiones del 2005 al 2014 en

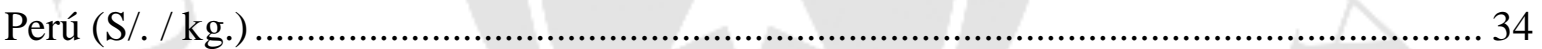

Figura 2. 6. Descripción de la manzanilla común y sus partes ....................................... 37

Figura 2. 7. Posición de las flores liguladas (blancas) como indicativo para su cosecha ... 39 Figura 2. 8. Producción promedio mensual de manzanilla común en Tarma provincia el 2007 $(\%)$ 40

Figura 3. 1. División política de Tarma provincia 55

Figura 5. 1. Diseño frontal y lateral de caja de 20 bolsas filtrantes de planta entera de manzanilla común 61

Figura 5. 2. Diseño frontal y lateral de caja de 15 bolsas filtrantes de flores de manzanilla común 61

Figura 5. 3. Diagrama de flujo del proceso productivo 68

Figura 5. 4. Diagrama de operaciones del proceso de bolsas filtrantes de manzanilla común 
Figura 5. 5. Balance de materia del proceso de fabricación de bolsas filtrantes de manzanilla común. 70

Figura 5. 6. Balance de energía de la operación de deshidratado de manzanilla común.... 71

Figura 5. 7. Distribución de extintores y señalización en primer piso.............................. 92

Figura 5. 8. Distribución de extintores y señalización en segundo piso ........................... 93

Figura 5. 9. Diagrama Hombre- Máquina de las operaciones ....................................... 103

Figura 5. 10. Tabla relacional de áreas de la planta industrial..................................... 111

Figura 5. 11. Diagrama de análisis relacional......................................................... 112

Figura 5. 12. Diagrama relacional de espacios de la planta industrial........................... 113

Figura 5. 13. Plano de disposición de planta del primer piso ...................................... 114

Figura 5. 14. Plano de disposición de planta del segundo piso .................................... 115

Figura 5. 15. Diagrama de Gantt de implementación del proyecto ............................... 116

Figura 6. 1. Esquema de organización de personal del proyecto.................................. 119 


\section{ÍNDICE DE ANEXOS}

ANEXO 1: Producción materia prima y diseño de producto ....................................... 153

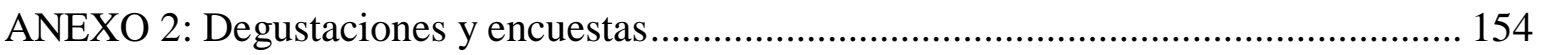

ANEXO 3: Participación y margen de filtrantes en supermercados .............................. 160

ANEXO 4: Cálculos para el capítulo de ingeniería ................................................... 161

ANEXO 5: Cálculo de consumo de GLP .................................................................... 170

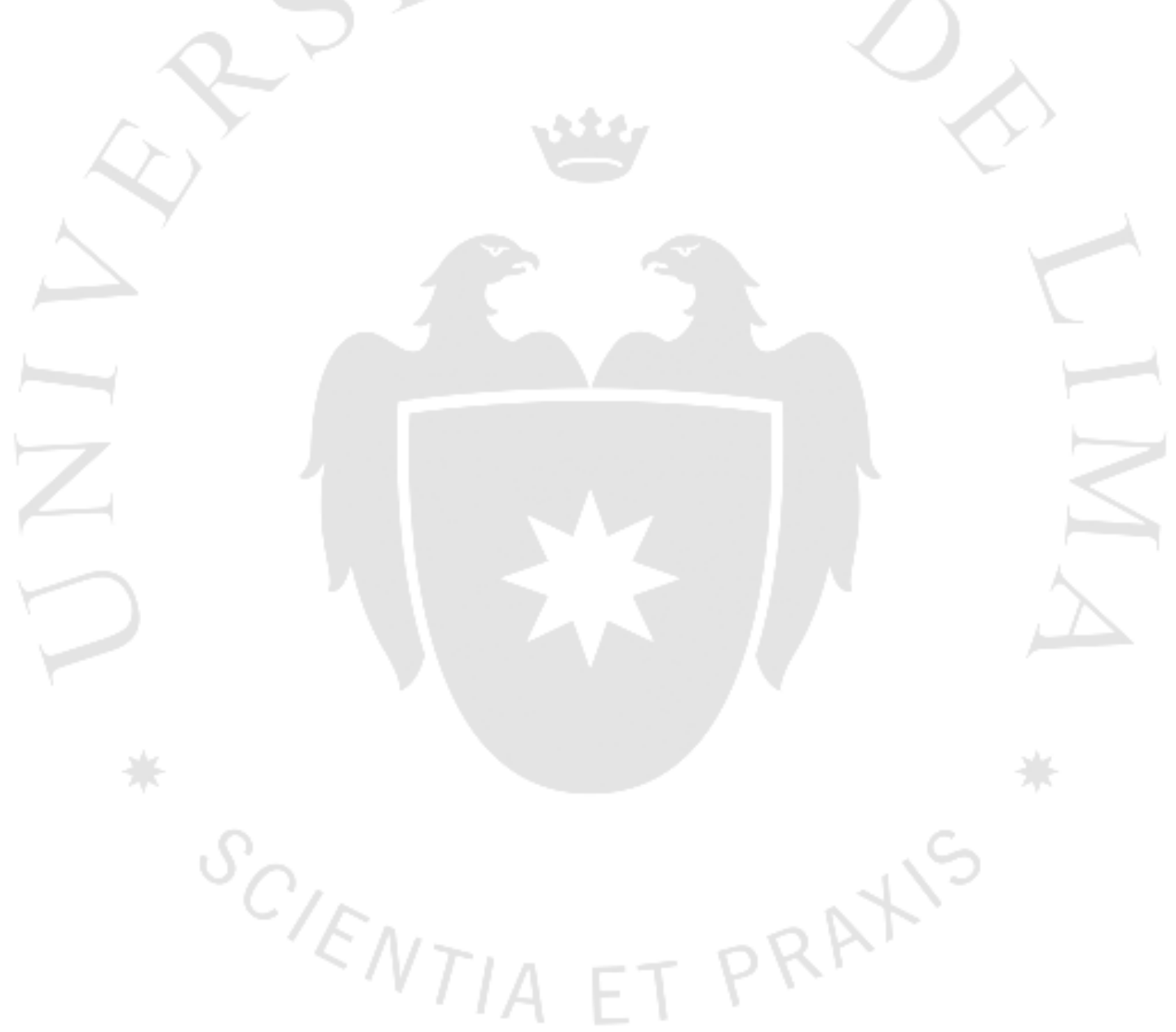




\section{RESUMEN EJECUTIVO}

El objetivo del presente estudio es determinar la viabilidad de mercado, tecnológica, económica, financiera y social de la instalación de una planta de producción de bolsas filtrantes de manzanilla común.

Se producirán dos tipos de producto, uno a base de planta entera de manzanilla común y otro a base de sólo flores de la misma planta. Ambos tendrán como mercado meta Lima Metropolitana, por ser el lugar donde se concentra, aproximadamente, el $70 \%$ de las ventas de infusiones envasadas a base de té, de plantas aromáticas y de frutas del Perú. Asimismo, ambos productos serán vendidos en supermercados. Los valores de venta a estos establecimientos serán de 1,87 S/./caja con 20 bolsas filtrantes y 3,20 S/./caja con 15 bolsas filtrantes, de los productos de planta entera y sólo flores, respectivamente.

La planta de producción se instalará en el distrito de Acobamba, provincia de Tarma y región Junín. El tamaño de planta es de 1,36 kg/h de producto final. Por otro lado, la tecnología requerida para la elaboración de los productos es factible de adquirirse y emplearse.

En cuanto a inversión, los activos totales ascienden a S/. 485.885,67 y el capital de trabajo a S/. 153.545,99, resultando así una inversión total de S/. 639.431,66. Se consideró un financiamiento del 44,46\% de la inversión, con un horizonte de 6 años, 1 año de gracia parcial y 15,00\% de tasa efectiva anual. La evaluación económica arroja S/. 224.097,33 de valor actual neto, 23,63\% de tasa interna de retorno, 1,35 de relación beneficio-costo y un periodo de recupero de 4 años y 2 meses. La evaluación financiera establece S/. 279.008,83 de valor actual neto, 29,00\% de tasa interna de retorno, 1,79 de relación beneficio-costo y 3 años y 10 meses de periodo de recupero. 


\section{EXECUTIVE SUMMARY}

The objective of the present research is determinate the market, technical, economic, financial and social viability for the installation of a chamomile tea bags plant.

Two types of products will be produced, one based on the whole chamomile plant and the other based on only flowers of the same plant. Both are intended for Lima Metropolitana as the target market, since it is the place that concentrates, approximately, the $70 \%$ of the Peruvian sales of packaged teas based on tea, herbals and fruits. Likewise, both products will be sold in supermarkets. The sale value to supermarkets will be $1,87 \mathrm{~S} / . /$ box with 20 tea bags and 3,20 S/./ box with 15 tea bags, of the products of whole plant and flowers only, respectively.

The plant will be located in Acobamba, Province of Tarma and Region of Junín. A plant size is $1.36 \mathrm{~kg} /$ hour of finished product. On the other hand, the technology required for the production of both products is feasible to be acquired and used.

The investment in assets amounts to S/. 485.885,67 and the working capital to S/. $153.545,99$, resulting in a total investment of S/. 639.431,66. It is considered a finance of $44,46 \%$ of the investment, with a horizon of 6 years, 1 year of partial grace and 15,00\% annual effective rate. The economic evaluation shows S/. 224.097,33 net present value, $23,63 \%$ internal rate of return, 1,35 ratio of benefit-cost and a recovery period of 4 years and 2 months. The financial evaluation shows S/. 279.008,83 net present value, 29,00\% internal rate of return, 1,79 cost-benefit ratio and 3 years and 10 months recovery period. 


\section{CAPÍTULO I: ASPECTOS GENERALES}

\subsection{Problemática}

Al día de hoy la industria peruana de infusiones filtrantes a base de plantas medicinales y aromáticas no está suficientemente desarrollada. En primer lugar, debido a métodos inadecuados de elaboración, con incidencia en la calidad y salubridad de los productos finales. En segundo lugar, por un "limitado dominio de la tecnología requerida" (Gupta, Handa, Longo y Rakesh, 2013, p. 162), limitación que restringe la implementación de procesos adecuados. Ambos problemas se verifican al investigar la cadena productiva de infusiones filtrantes. En especial las operaciones previas al envasado, como la del secado, que pese a ser la más crítica por el control de sus parámetros, es la menos tecnificada.

En el caso de la manzanilla común, el secado de esta planta aromática ${ }^{1}$ se realiza generalmente en las mismas áreas de cosecha al exponerlas directamente al sol hasta que pierdan humedad, como se ve en las figuras 1.1 y 1.2, requiriendo luego un mayor secado mediante otras tecnologías hasta llegar a una humedad óptima. El secado por radiación solar, a la intemperie, no es conveniente por el nulo control del ambiente, de los parámetros de secado y de la higiene. Esto genera productos potencialmente insalubres y sobrecostos. Un ejemplo es el costo del servicio de irradiación para bajar la carga bacteriológica hasta niveles mínimos exigidos según normas sanitarias para productos de consumo humano. Es así que, un secado para plantas (sólidos), que sea rápido, mejor controlado, más salubre y que no dependa del medio ambiente, requiere de un deshidratador. Este mejora tanto la competitividad, al deshidratar en una sola fase sin sobrecostos, como la salubridad y calidad del producto al controlar las condiciones de secado.

El método de secado que propone el presente estudio es el de deshidratado por flujo de aire calentado mediante combustión de gas licuado de petróleo (GLP), ya que este combustible presenta ventajas frente a otros, como se espera demostrar más adelante.

\footnotetext{
${ }^{1}$ La Ley peruana $N^{\circ} 27300$ define qué es una planta medicinal y hace referencia a un inventario de
} las mismas, la manzanilla común no está incluida. El punto de glosario de términos trata sus definiciones. 
Figura 1. 1

Elemento extraño en el acopio de manzanilla común entera secada al sol en Tarma

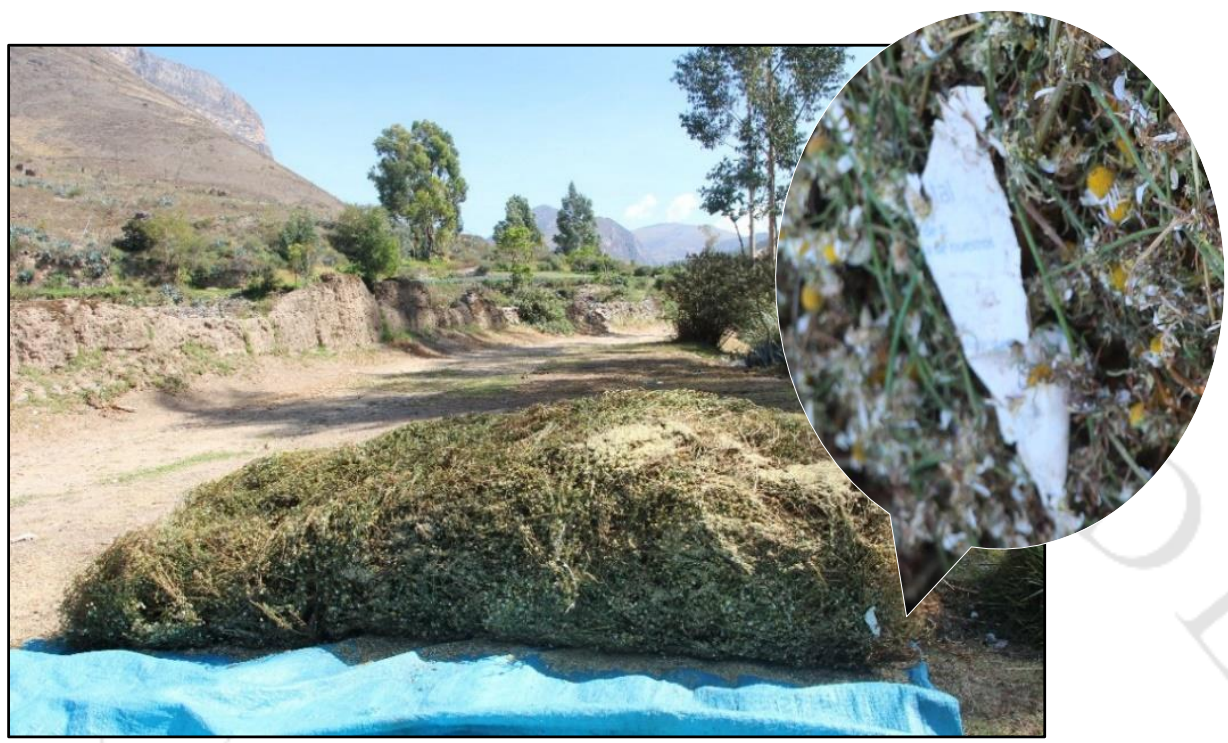

Elaboración propia

Figura 1.2

Manzanilla común entera acopiada en Tarma lista para proceso de infusiones filtrantes

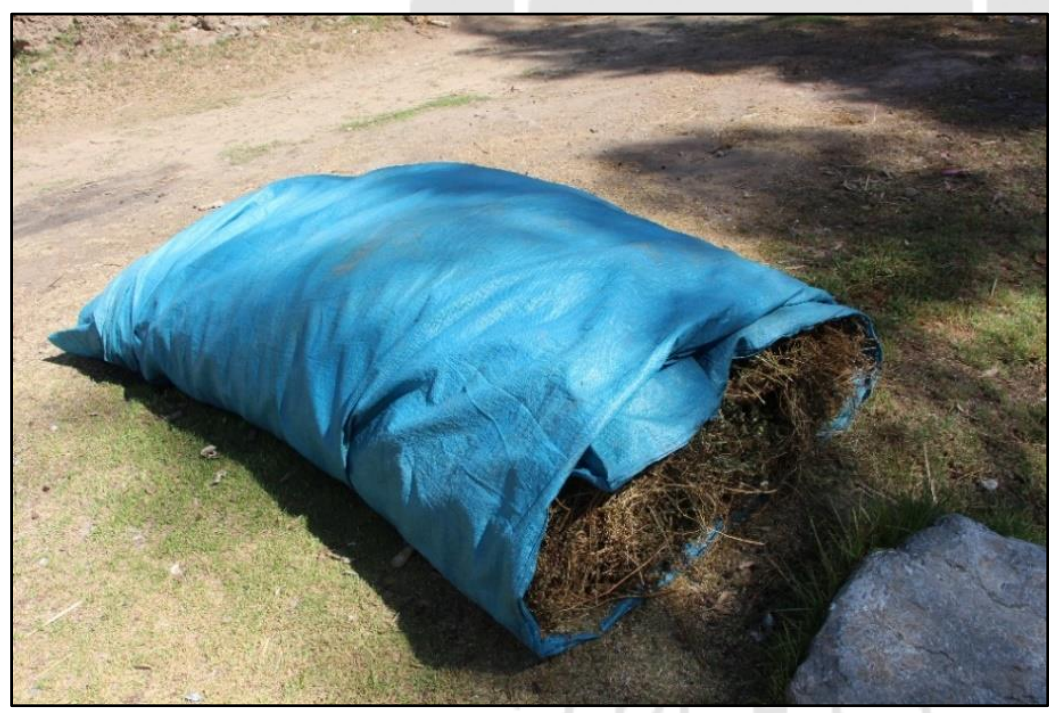

Elaboración propia

\subsection{Objetivos de la investigación}

\subsubsection{Objetivo general}

Determinar la viabilidad de mercado, tecnológica, económica, financiera y social para la instalación de una planta de producción de bolsas filtrantes de manzanilla común. 


\subsubsection{Objetivos específicos}

- Estimar la demanda de infusiones filtrantes a base de manzanilla común que sea viable de cubrir.

- Cuantificar la materia prima disponible para el proceso de producción.

- Definir el tamaño y la localización de planta adecuadas para el proyecto.

- Definir el proceso de fabricación en la planta de producción.

- Realizar la evaluación económica, financiera y social del proyecto.

\subsection{Alcance y limitaciones de la investigación}

El presente estudio finalizará cuando se hayan llevado a cabo los objetivos específicos.

Asimismo, dentro de las limitaciones del presente estudio se señala la escaza información a nivel nacional respecto a la materia prima, como la cantidad cosechada y su rendimiento. De igual modo, pocos datos respecto a las infusiones filtrantes, como la demanda, lugar, cantidad e intervalos de compra por tipo de producto.

\subsection{Justificación del tema}

\subsubsection{Técnica}

La tecnología para la producción de infusiones filtrantes a base de manzanilla común existe y es factible de aplicarse en el Perú. Además de eso, específicamente en la operación de secado se propone utilizar un deshidratador por aire calentado mediante combustión de GLP.

\subsubsection{Económica}

Según un estudio de liderazgo de productos comestibles de Ipsos Perú (2014) las infusiones filtrantes son de "primera necesidad" y se clasifican como "productos de alta penetración" en Lima Metropolitana (p. 6). Asimismo, como muestra la Figura 1.3, la categoría 
Frutas/Hierbas ${ }^{2}$, donde se incluye a la manzanilla común, tendrá un crecimiento sobresaliente en ventas al por menor, proyectando hasta el 2021, en comparación a las demás categorías.

Figura 1. 3

Proyección de ventas al por menor de infusiones en Perú al 2021 (millones de soles)

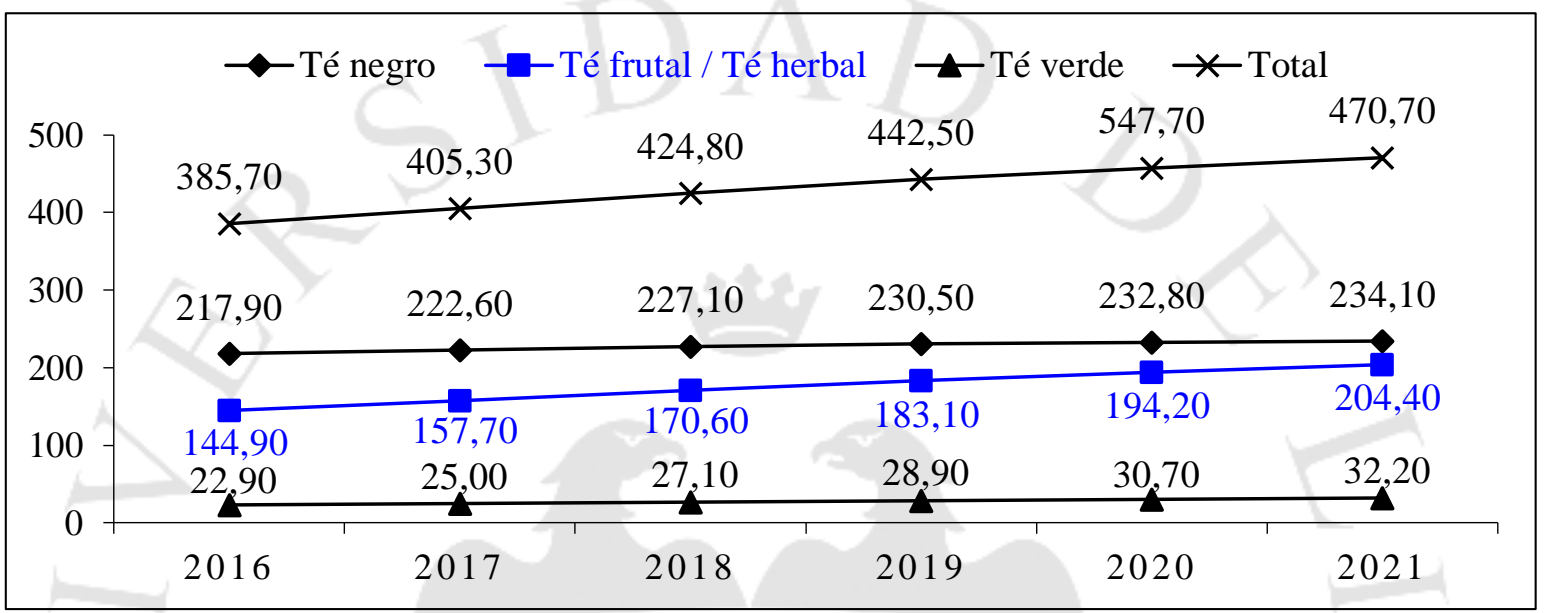

Fuente: Euromonitor Internacional, (2015).

\subsubsection{Social}

El proyecto generará nuevos puestos de trabajo, tanto en el ámbito de la localidad donde se instalará la planta, como en las zonas próximas a esta. Del mismo modo, se incrementará el número de agricultores dedicados a sembrar manzanilla común lo cual fortalecerá la capacidad organizativa de los agricultores, aumentando su poder de negociación. Po último, se precisa que la tecnología y los métodos propuestos en el presente estudio generan un mínimo impacto ambiental.

\subsection{Hipótesis de trabajo}

La instalación de una planta de producción de bolsas filtrantes a base de manzanilla común (Chamomilla recutita (L.) Rauschert) para ser consumidas en infusiones es factible, ya que

\footnotetext{
2 Euromonitor International denomina Hot Drinks a las infusiones en general, las divide en tres categorías: coffee (de café), tea (de té, de plantas aromáticas y de frutas) y others hot drinks (otras bebidas calientes). La segunda categoría puede ser clasificada según el tipo de producto en: té, hierbas (a base de plantas aromáticas o medicinales), frutas (secas para infusión) y otros.
} 
existe un mercado con demanda a atender, tecnología para su producción y viabilidad económica, financiera y social.

\subsection{Marco referencial de la investigación}

Las siguientes investigaciones se relacionadas con el tema del presente estudio:

- Autor(es): Marco Antonio Pérez Castro, Año: 2010, Título: Estudio de prefactibilidad para la instalación de una planta de producción de bolsitas filtrantes a base de orégano, llantén y hierba buena. (Tesis para optar el título de Ingeniero Industrial). Universidad de Lima, Perú.

Aporta datos históricos de producción, ventas, precios de principales marcas, demanda y oferta proyectadas de infusiones filtrantes en Lima. Además de no haber pasado más de cinco años desde su elaboración a la fecha. Se diferencia del presente estudio en que emplea varias materias primas.

- Autor(es): Rolf Franke y Heinz Schilcher, Año: 2005, Título: Chamomile: Industrial Profiles. Estados Unidos de América: Taylor \& Francis.

Aporta una recopilación de estudios interdisciplinarios de distintas realidades a nivel científico sobre la manzanilla común (Chamomilla recutita (L.) Rauschert) y la manzanilla romana (Anthemis nobilis L.). Se diferencia del presente estudio en que es una recopilación de varios autores.

- Autor(es): Juan Fernando López Fierro, Eva Margarita Meneses Florián, Patricia Beatriz Ortíz Rodríguez y Nancy Yovana Vásquez Valverde, Año: 1997, Título: Elaboración de un manual de calidad para la empresa Tecno Food S.A. y una propuesta de un plan HACCP para la línea de infusiones a base de té, canela y clavo de olor. (Tesis para optar el título de Ingeniero en Industrias Alimentarias). Universidad Nacional Agraria La Molina. Perú.

Aporta un manual de procedimientos para el control de calidad en la elaboración de infusiones. Asimismo, su plan HACCP muestra los lineamientos para la inocuidad en infusiones. No aporta más que el tema de calidad. 
- Autor(es): Hernán Percy Celiz Castillo, Año: 1991, Título: Estudio de factibilidad para la instalación de una fábrica de bolsitas filtrantes de plantas medicinales. (Tesis para optar el título de Ingeniero Industrial). Universidad de Lima. Perú.

Aporta algunos cálculos, principalmente sobre las curvas de secado de la manzanilla común, como son: porcentaje de humedad versus tiempo y velocidad de secado versus porcentaje de humedad. Sin embargo, emplea otras materias primas aparte de la manzanilla común, emplea esta última como planta entera.

- Autor(es): Marcial Ibo Silva Jaimes, Año: 1985, Título: Determinación de los parámetros de procesamiento para la obtención de la manzanilla Común (Matricaria chamomilla L.) deshidratada por el método del Aire Caliente. (Tesis para optar el título de Ingeniero en Industrias Alimentarias). Universidad Nacional Agraria La Molina. Perú.

Aporta cálculos importantes para la determinación de los parámetros de deshidratado de manzanilla común por el método de aire caliente, tales como: temperatura del aire, velocidad del aire y tiempo de secado. Se destaca la realización de experimentos con flores de manzanilla común de origen tarmeño. No obstante, solo profundiza en la operación de deshidratado.

\subsection{Marco conceptual}

\subsubsection{Sustento teórico de la propuesta del estudio}

El presente estudio evalúa la producción de bolsas filtrantes a base de manzanilla común. Según Franke y Schilcher (2005), las flores de manzanilla común son las que producen más aceite esencial ( p. 56). En consecuencia, son las que contienen mayor cantidad de principios activos de la planta. Sin embargo, debido a que en Perú se usa la planta entera de manzanilla común, se propone dos productos: el primero a base de la planta entera (partes verdes y flores), y el segundo a base de sólo flores de la misma planta.

Asimismo, como ya se mencionó, las operaciones previas al envasado de infusiones filtrantes no están suficientemente tecnificadas y no utilizan los métodos adecuados. Teniendo en cuenta que la operación de secado tiene mayor incidencia en la calidad del producto final. 


\subsubsection{Información de la materia prima y sus propiedades}

La manzanilla común (Chamomilla recutita (L.) Rauschert) ${ }^{3}$, según Páez (1943), es una planta anual que crece entre 20 y $100 \mathrm{~cm}$, altura máxima observada en plantaciones experimentales en Perú (p. 4). Además, se debe sembrar de preferencia sobre los 3.000 metros sobre el nivel del mar (m.s.n.m.) para obtener mejores rendimientos de acuerdo con el Centro de Innovación y Desarrollo Rural (Cender, 2013). Asimismo, la planta tiene raíces delgadas y ramificadas que penetran profundamente el suelo. El tallo de color verde tiene posición vertical, muy ramificado, desnudo y con forma cilíndrica. Por otro lado, en los extremos de las ramificaciones del tallo se desarrollan unas cabezuelas cónicas conformadas por flores tubulares de color amarillo, estas cabezuelas además están circundadas, por la parte inferior, por flores liguladas de color blanco. Es así que al decir flores se hace referencia tanto a las tubulares como a las liguladas, ambas son parte de la cabezuela, llamada también capítulo.

Asimismo, Tabernaemontanus distingue seis tipos de variedades de la planta de manzanilla (como se citó en Franke y Schilcher, 2005, p. 40). No obstante, en el Perú la manzanilla común o alemana es la que más abunda y sobre la que trata el presente estudio. Según un informe de la Agencia Agraria de Tarma (2008), esta planta entera en verde rindió entre los años 2001 y 2007 en la provincia del mismo nombre, en promedio, $40000 \mathrm{~kg} / \mathrm{ha}$ al año como indica el Anexo 1. Asimismo, el Cender (2012) y Franke y Schilcher (2005) coinciden en que la "relación promedio de secado" de la planta es de 1:5 (p. 146).

Por último, según Franke y Schilcher (2005), en base a estudios comparativos en personas, señalan que los principios activos presentes en las flores de manzanilla común tienen los siguientes efectos: antiinflamatorio, antiespasmódico y como cicatrizante de heridas (p. 26).

\subsubsection{Nombre común de la materia prima}

Español: Manzanilla común, dulce o alemana; Flores de manzanilla común.

\footnotetext{
${ }^{3}$ A esta especie se le atribuyen otros nombres como Matricaria recutita L. o Matricaria chamomilla L., sin embargo, el presente estudio adopta el nombre de Chamomilla recutita (L.) Rauschert en base a lo explicado más adelante en el punto 2.6.1.
} 
Inglés: German chamomile; German chamomile flowers.

Francés: Camomille allemande; Fleurs de camomille allemande.

Alemán: Deutsche Kamille; Deutsche kamillenblüten.

Italiano: Camomilla comune; Fiori di camomilla comune.

Portugués: Camomila alemã; Flores de camomila alemã.

\subsubsection{Proceso y tecnología de fabricación propuestos}

El proceso comienza con la recepción y pesado de las plantas enteras de manzanilla común. Luego, estas pasan a la selección, donde se separan las flores, con un máximo de $2 \mathrm{~cm}$ de tallo, de las partes verdes, así como elementos extraños o dañados. A continuación, las flores pasan a ser lavadas por inmersión en pozas de agua potable, se debe usar algún recipiente con orificios para facilitar el lavado y las operaciones posteriores. Antes de enjuagar se deja reposar en una solución de agua con algún desinfectante que no afecte la composición de la materia prima. Después del lavado se centrifugan y se colocan en bandejas para iniciar la operación de deshidratado hasta llegar a una humedad de bulbo húmedo de 6,5\%. Los parámetros como velocidad de aire, tiempo y temperatura de secado deben ser controlados. Una vez deshidratadas las flores se procede a la molienda y tamizado. Después se pone el producto tamizado en la tolva de la envasadora para ser dosificado en bolsas filtrantes de 1 gr. La máquina coloca automáticamente el papel filtro termosellable, el hilo, la etiqueta y el sobre de envoltura. Por último, se empacan en cajas de 15 unidades y se embolsan en paquetes de 24 cajas.

Las partes verdes seleccionadas siguen la misma secuencia de operaciones, con la diferencia que se pican antes de lavar. Y que al final se mezclan con una parte de las flores molidas y tamizadas, se envasan y se empacan en cajas de 20 unidades y se embolsan en paquetes de 24 cajas.

Finalmente, la tecnología propuesta para el deshidratado se explica en la Figura 1.4. En líneas generales, consiste en dirigir un flujo de aire caliente continuo que entre en contacto con una carga para absorber su humedad. El presente estudio propone un flujo de aire horizontal, es decir, el aire previamente calentado por combustión de un quemador a GLP, se dirigirá horizontalmente hacia la carga de manzanilla común durante el tiempo que dure la operación. 
Figura 1. 4

Esquema explicativo de la tecnología propuesta por el presente estudio

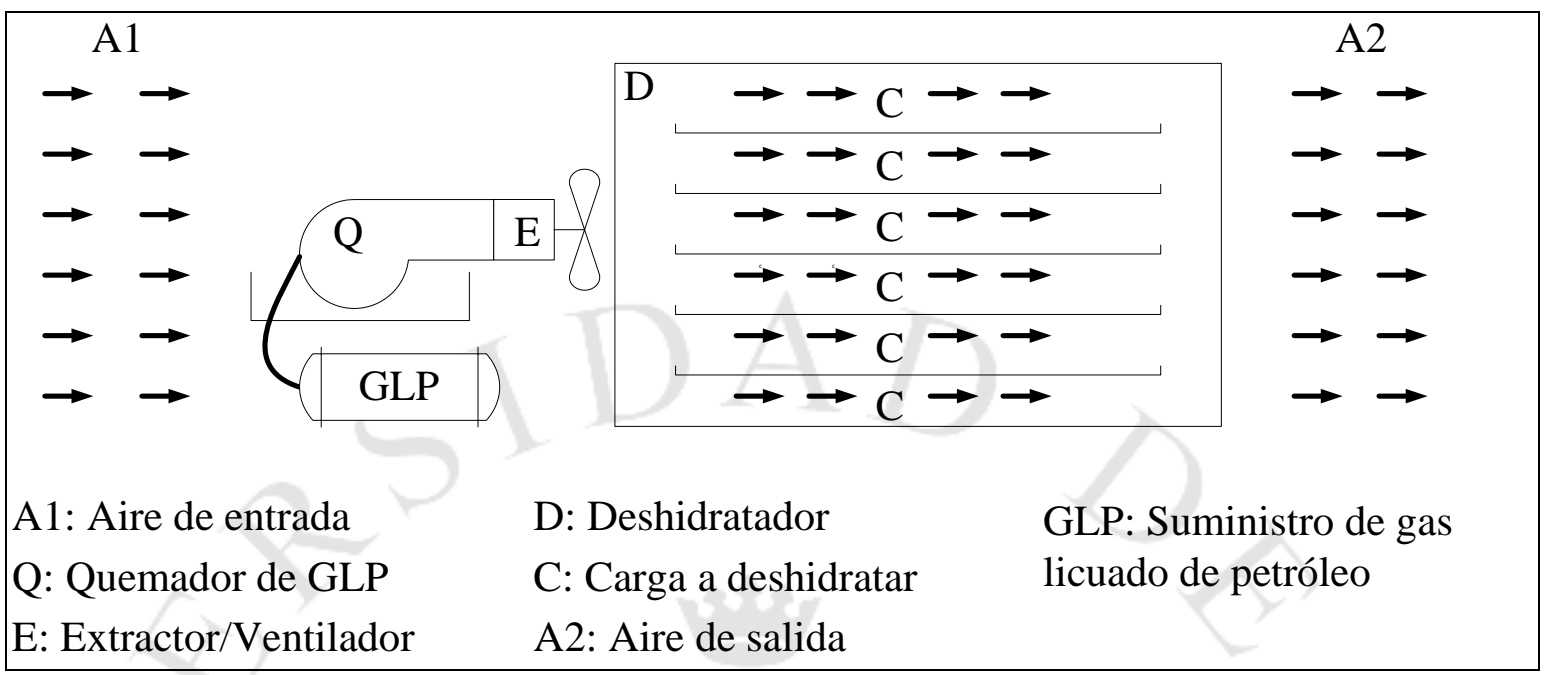

Nota: La Figura 1.4 no está representada a escala, es solamente representativa.

Elaboración propia

\subsubsection{Glosario de términos}

- Aceite esencial.- Líquido no miscible con agua, concentrado y que contiene compuestos aromáticos volátiles que portan la esencia, sabor y aroma, además de las propiedades de las planta según Martínez (2003).

- Cender.- Centro de Innovación y Desarrollo Rural creado por la Universidad de Lambayeque, tiene por misión reducir la pobreza en los rubros agropecuario, forestal, ambiental y turístico a través de innovación tecnológica y comercial en la región Lambayeque.

- Deshidratación.- Secado controlado por el que el agua contenida en un sólido o una disolución (generalmente concentrada) se transfiere a la fase fluida que lo rodea (generalmente el aire) debido a los gradientes de actividad de agua entre el producto y el fluido de acuerdo con Fito, Andrés, Albors y Barat (2001). En consecuencia es una operación ampliamente utilizada para la conservación de alimentos.

- Gas licuado de petróleo (GLP).- Mezcla de gases licuados, principalmente propano $\left(\mathrm{C}_{3} \mathrm{H}_{8}\right)$ y butano $\left(\mathrm{C}_{4} \mathrm{H}_{10}\right)$. Por su facilidad de licuefacción se transporta y almacena en estado líquido. Según el Organismo Supervisor de la Inversión en Energía y Minería 
(OSINERGMIN) posee un poder calorífico superior de 49,15 MJ/kg a condiciones normales $\left(25^{\circ} \mathrm{C}\right.$ y $\left.1 \mathrm{~atm}\right)$.

- HACCP.- Hazard Analysis and Critical Control Points, en español Análisis de Peligros y Puntos Críticos de Control (APPCC), es un plan sistemático para garantizar la inocuidad de los alimentos.

- Infusión.- Según Handa, Singh Khanuja, Longo y Rakesh (2008) es cualquier bebida que se prepara echando en agua caliente hojas, flores, frutos u otras partes de plantas, de preferncia dejándolas reposar antes de ser consumidas.

- Irradiación de alimentos.- Método físico de conservación y esterilización mediante radiaciones ionizantes u ondas electromagnéticas aplicadas a alimentos en dosis controladas.

- Molienda.- Operación unitaria cuya función es reducir el volumen de un sólido de acuerdo a McCabe, Smith y Harriot (2007).

- Normas técnicas peruanas.- Son estándares orientados a elevar la calidad de los productos de acuerdo a las exigencias de un mercado, buscan desarrollar la competitividad de las empresas peruanas. La calidad de un producto debe ser definida por cada fabricante, por eso no son obligatorias. No confundir con Reglamentos Técnicos.

- Plantas anuales.- De acuerdo con Handa, et al. (2008) son las plantas que viven solo durante una temporada, por lo general un año. Tienen un ciclo vital veloz: nacen, se desarrollan y florecen, luego producen sus frutos (mismos que contienen sus semillas) para finalmente morir.

- Plantas aromáticas.- Son plantas que poseen un aroma ligero o intenso, en su mayoría agradable para el olfato humano. Según Handa, et al. (2008) por lo general son usadas en alimentos o bebidas; sin embargo, también pueden ser usadas para otros fines industriales. 
- Plantas medicinales.- Según la ley peruana $\mathrm{N}^{\circ}$ 27.300, en su artículo 2 señala textualmente "Se consideran plantas medicinales a aquéllas cuya calidad y cantidad de principios activos tienen propiedades terapéuticas comprobadas científicamente en beneficio de la salud humana peruana". El Centro Nacional de Salud Intercultural (Censi, 2015) computa 305 plantas de este tipo.

- Principios activos.- Según Handa, et al. (2008) es toda materia, ya sea de origen humano, animal, vegetal, químico o de otro tipo al que se considera apropiado para prevenir o curar una enfermedad. En estado bruto y acompañado de otros componentes o principios activos se considera una droga. Si se logra aislar y dosificar por tipo de principio se denomina fármaco. Y si se combina uno o más principios activos con otros componentes que faciliten su administración se denominan medicamentos.

- Registro sanitario.- Documento expedido por la Dirección General de Salud Ambiental (DIGESA) que autoriza a una persona natural o jurídica a comercializar cualquier alimento o bebida de tipo industrial. Tiene una vigencia de cinco años.

- Reglamentos técnicos.- Son normas jurídicas que reglamentan las características de un producto, los procesos o métodos de producción relacionados con este, son de cumplimiento obligatorio.

- Tamizado.- Método físico para separar mezclas de sólidos en función del tamaño de acuerdo con McCabe, et al. (2007). 


\section{CAPÍTULO II: ESTUDIO DE MERCADO}

\subsection{Aspectos generales del estudio de mercado}

\subsubsection{Definición comercial del producto}

Un producto de planta entera de manzanilla común y otro de sólo flores de la misma planta. Ambos en presentación de bolsas filtrantes para infusión.

Existen tres niveles para ambos productos que determinan las necesidades que los compradores desean satisfacer al adquirirlos:

\section{- Producto básico:}

Ambos productos sirven para preparar una infusión que sirva como acompañante, bajativo o por sus propiedades.

\section{- Producto real:}

El producto de planta entera en caja de 20 bolsas filtrantes de un gramo cada una dentro de sobres de envoltura que contienen planta entera (partes verdes y flores) de manzanilla común deshidratada, molida y tamizada.

El producto de flores en caja de 15 bolsas filtrantes de un gramo cada una dentro de sobres de envoltura que contienen solamente flores de manzanilla común deshidratada, molida y tamizada. Según el artículo 117 del D.S. No 007-98-SA para ambos productos:

- Cada bolsa filtrante está sujeta a un cordel, ambos a su vez están empacados dentro de un sobre de envoltura.

- El sobre de envoltura incluye la marca (Alacev), el nombre de la infusión, ingredientes, contenido neto, nombre y dirección tanto del productor como del envasador, país de origen, instrucciones para su conservación, registro sanitario e instrucciones para su consumo. Las figuras 2.1 y 2.2 muestran estos datos para cada producto.

- La caja muestra el lote de producción, la fecha de vencimiento y vuelve a incluir la marca (Alacev) tal y como muestra el ejemplo del Anexo 1. 
Figura 2. 1

Modelo de sobre de envoltura y bolsa filtrante de planta entera de manzanilla común
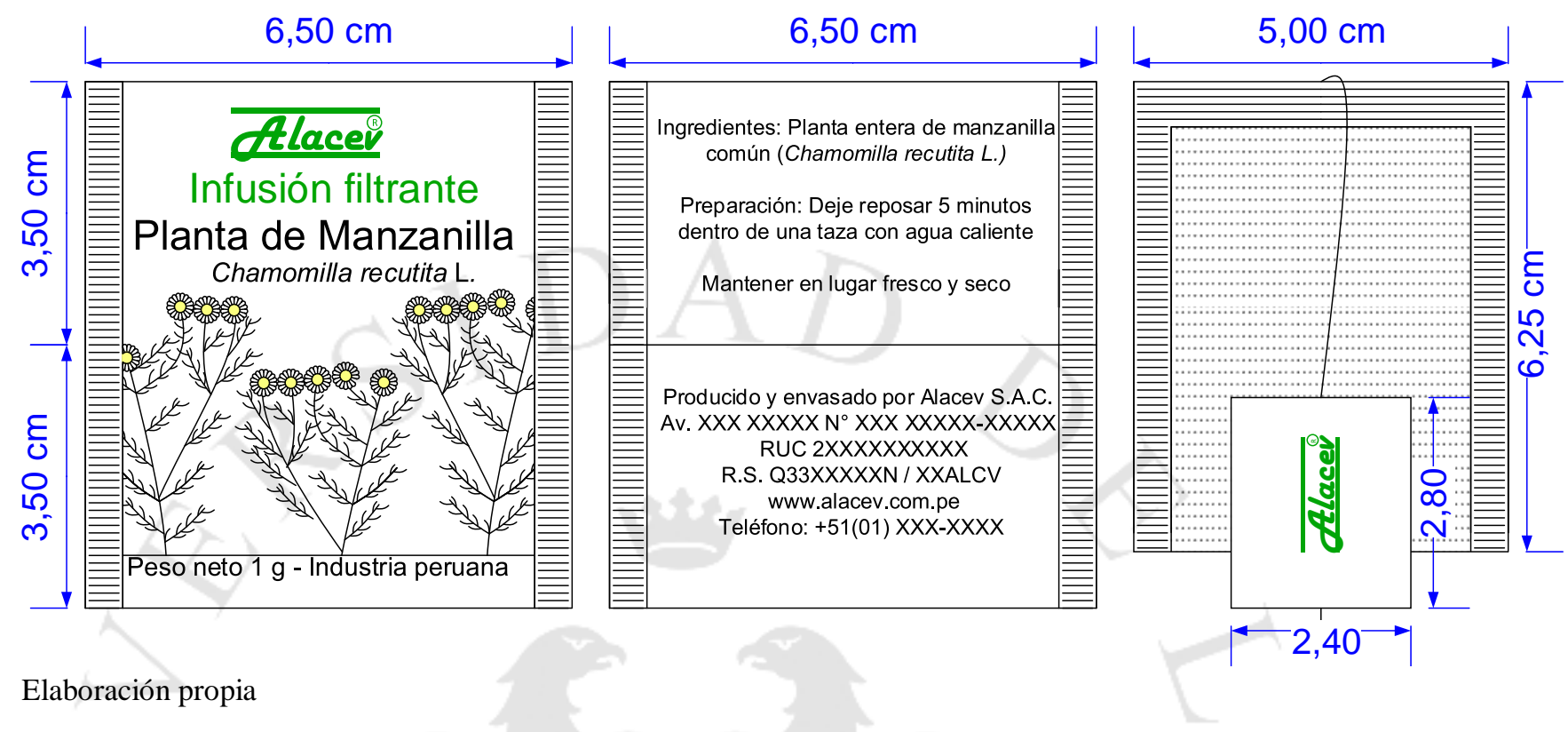

Elaboración propia

Figura 2. 2

Modelo de sobre de envoltura y bolsa filtrante de sólo flores de manzanilla común
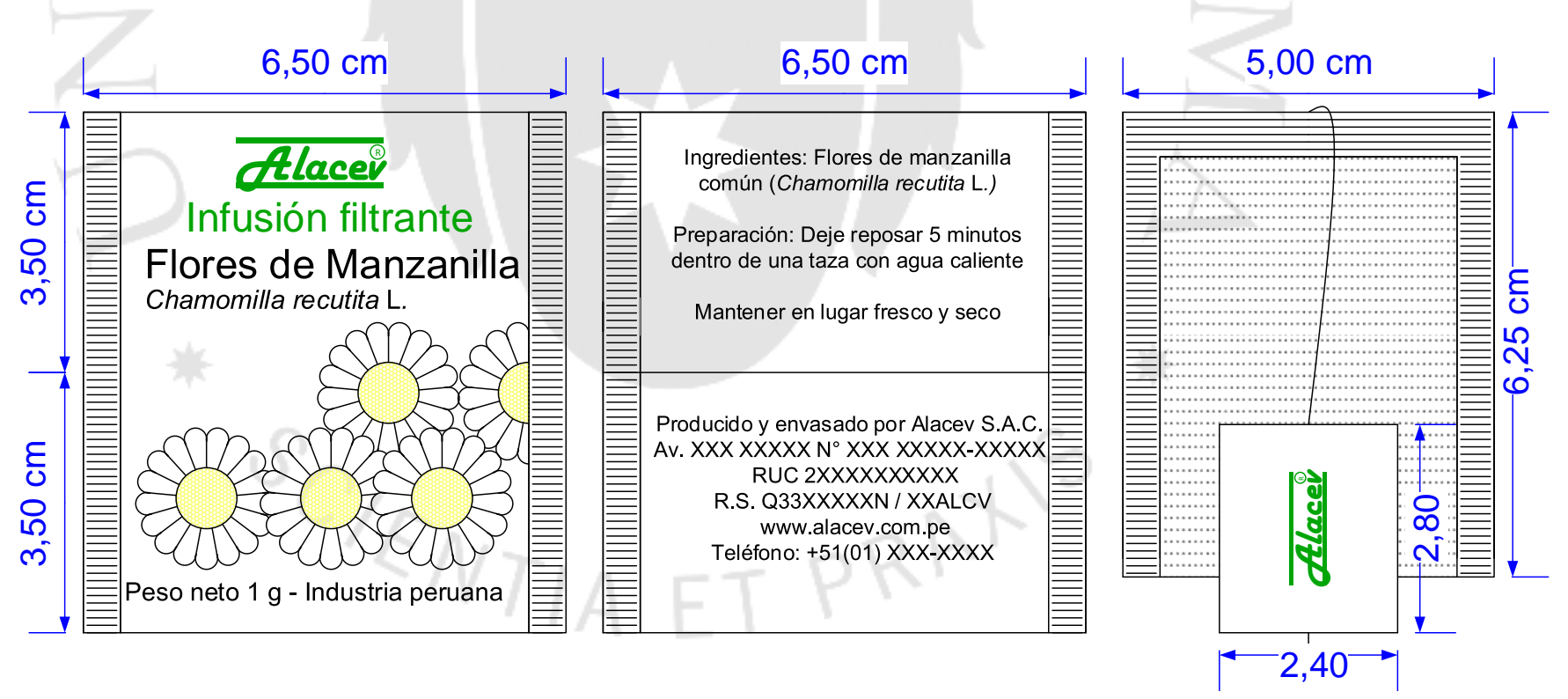

Elaboración propia

\section{- Producto aumentado:}

Se contará con una página web con datos de la empresa y con la descripción de los productos.

Asimismo, se brindará el servicio de postventa mediante la atención al cliente por vía 
telefónica, así este podrá absolver cualquier inquietud con referencia a los productos o servicios que ofrece la empresa.

\subsubsection{Principales características del producto}

La planta entera de manzanilla común o alguna de sus partes en forma fresca, seca, cortada o pulverizada se encuentra clasificada dentro del CIIU C1079 en la sección de industrias manufactureras, y en la clase de fabricación de otros productos alimenticios no clasificados previamente. Asimismo, la nomenclatura andina, también llamada NANDINA, en la que se basa la Superintendencia Nacional de Aduanas y de Administración Tributaria (Sunat), le asigna la partida arancelaria $\mathrm{N}^{\circ} 1211.90 .90 .99$, referida a las demás plantas o partes de estas no clasificadas anteriormente dentro de plantas industriales o medicinales, dentro de la sección de productos del reino vegetal.

\subsubsection{Usos y características del producto}

Ambos productos del presente estudio es usado para su consumo como infusión en presentación de bolsas filtrantes. La manera de usar estos productos en dicha presentación es: introducir la bolsa filtrante en una taza con agua, de preferencia caliente, dejar reposar por un lapso no menor a cinco minutos, se recomienda tapar la taza, finalmente, pasado ese lapso se puede beber.

Por otro lado, Mckay y Blumberg (2006) mediante pruebas en personas empleando bolsas filtrantes de flores de manzanilla común determinaron que el consumo de esta infusión tiene efectos beneficiosos tales como:

- Antiespasmódico.- Contra las contracciones de los músculos.

- Ansiolítico.- Contra los trastornos de angustia y ansiedad.

- Antiinflamatorio.- Contra las inflamaciones de los tejidos.

- Antimutagénico.- $\mathrm{Al}$ reducir la acción de agentes que provocan mutaciones en el $\mathrm{ADN}^{4}$.

\footnotetext{
${ }^{4}$ Sigla de ácido desoxirribonucleico, proteína del núcleo de las células que es el principal constituyente del material genético de los seres vivos.
} 
Del mismo modo según Franke y Schilcher (2005), la infusión a base de manzanilla común es requerida en la medicina tradicional, ya que al ser consumida como bebida actúa contra dolores gástricos, diarreas, flatulencias, y enfermedades gástricas e intestinales como gastritis y enteritis. Asimismo, en uso externo contra irritaciones, heridas mal curadas, hemorroides, furúnculos y enfermedades femeninas (p. 260).

Asimismo, según el artículo "Filtrantes para calentar tu negocio" (2012) de la revista Don Bodega, las bolsas filtrantes poseen características a tener en cuenta para su uso:

- Deben mantenerse y almacenarse en lugares secos para su conservación.

- Deben usarse de preferencia una sola vez, ya que si son más veces sus características organolépticas y efectos disminuirán. Una bolsa filtrante rinde en promedio para $300 \mathrm{ml}$ de agua.

- Se recomienda tapar el envase mientras el filtrante reposa, ya que las sustancias que contienen sus propiedades son volátiles. Si se deja reposar más de 5 minutos la bebida se torna amarga.

\subsubsection{Bienes sustitutos y complementarios}

Los bienes sustitutos de las bolsas filtrantes a base de manzanilla común son:

- Deshidratados de té o plantas aromáticas.

- Partes frescas de cualquier planta aromática.

- Cualquier otra infusión (café instantáneo, cocoa, etc.)

Los bienes complementarios, es decir los que acompañan al consumo de la infusión de manzanilla común son usualmente:

- Agua caliente, imprescindible.

- Azúcar u otro edulcorante, opcional. 


\subsubsection{Determinación del área geográfica que abarcará el estudio}

El presente estudio abarcó a todo el Perú, enfocándose en áreas que tienen mayor gasto en consumo de alimentos. Según el Consejo Nacional de Competitividad (CNC, 2014) estas áreas son, a la vez, las que presentan mayor desarrollo en infraestructura, desempeño económico e innovación, entre otros. Lima Metropolitana lidera esta lista, además según un estudio del Instituto Nacional de Estadística e Informática (INEI, 2015) tiene una población aproximada de 10.000 .000 de habitantes.

\subsubsection{Análisis del sector}

Para analizar la industria peruana de infusiones se debe conocer las fuerzas competitivas que la estructuran. En primer lugar los proveedores de materia prima, que son generalmente agricultores reflejan los mayores problemas de la agricultura peruana, como el minifundio, excesiva parcelación de las tierras de cultivo, y la poca organización de agricultores según el Ministerio de Agricultura y Riego (Minagri, 2006) lo que dificulta la disponibilidad de la materia prima. En cuanto a los proveedores de materiales, existen y se concentran en Lima.

También están los competidores, es decir, otras marcas de infusiones. La mayoría de estos se abastece de insumos procesados listos para envasar, algunos están consolidados en el mercado y manejan economías de escala, lo que representa barreras de entrada para los competidores potenbciales. Existen varios productos sustitutos. Los compradores se caracterizan por el habitual consumo del producto y baja fidelidad hacia una marca en especial. A continuación se detallan las cinco fuerzas competitivas:

\section{Poder de negociación de los compradores}

Se refiere a la fuerza de los compradores de infusiones filtrantes en Perú, estos son muchos, consumen infusiones habitualmente y además poseen:

- Alta variedad de productos a escoger.

- Mediana sensibilidad a la variación del precio.

- Poca fidelidad a una marca específica. 
Según los aspectos señalados se puede afirmar que los compradores tienen un poder de negociación alto.

\section{Poder de negociación de proveedores}

Tienen un poder de negociación bajo según el siguiente análisis:

- Hay proveedores de la materia prima, por lo general fuera de Lima. También hay varios proveedores de materiales, la mayoria se encuentra en Lima.

- En el caso de la manzanilla común no existe un comité u organización de productores que pueda negociar los precios de su materia prima.

- La forma de pago a los proveedores de manzanilla común es al crédito en la mayoría de casos. Los proveedores de materiales venden $50 \%$ por adelantado y $50 \%$ a contra entrega.

\section{Amenazas de nuevos entrantes}

La amenaza de nuevos entrantes es baja ya que las barreras de entrada son altas, ya que:

- El mercado está dominado por un grupo de empresas nacionales con marcas reconocidas y canales de distribución sólidos según un informe de Euromonitor International sobre la industria de las infusiones en Perú (2015).

- Es más difícil para las pequeñas empresas ingresar al sector de las infusiones debido a: economías de escala, acceso a canales de distribución y acceso a materias primas. Las barrerar por costos cambiantes y acceso a capital no son significativas en este sector.

\section{Amenaza de productos sustitutos}

La amenaza de productos sustitutos es alta ya que existen muchos productos similares que satisfacen la misma necesidad (bebida caliente, acompañante digestivo o relajante). 


\section{Rivalidad entre competidores}

Existen al menos 18 competidores cuya rivalidad es baja, por la poca publicidad, poca diferenciación de productos y poca inversión en investigación y desarrollo en este sector.

\subsubsection{Determinación de la metodología que se empleará en la investigación de mercado}

Para el presente estudio se recabó datos históricos de infusiones. Asimismo, se realizaron degustaciones, encuestas y estudios de campo (Anexo 2), con lo cual se pudo estimar la demanda del proyecto.

\subsection{Análisis de la demanda}

\subsubsection{Demanda histórica}

Se obtuvo las ventas históricas del mercado peruano de infusiones envasadas a base de té, de plantas aromáticas y de frutas de los 10 últimos años.

\subsubsection{Importaciones/exportaciones}

La entidad peruana encargada de registrar las importaciones y exportaciones del Perú (Sunat) no asigna un único código de transacción a las infusiones filtrantes, motivo por el cual es posible encontrar dentro de esta categoría otros productos, lo que dificulta hacer estimaciones sobre el consumo aparente. La Tabla 2.1. presenta tales transacciones.

Tabla 2. 1 Importaciones y exportaciones de infusiones del 2009 al 2013 hechas por Perú (toneladas)

\begin{tabular}{|c|c|c|}
\hline $\begin{array}{c}\text { Año/ } \\
\text { Transacción }\end{array}$ & $\begin{array}{c}\text { Importación } \\
\text { (toneladas) }\end{array}$ & $\begin{array}{c}\text { Exportación } \\
\text { (toneladas) }\end{array}$ \\
\hline 2009 & 278,90 & 2,90 \\
\hline 2010 & 444,60 & 88,40 \\
\hline 2011 & 646,60 & 2,20 \\
\hline 2012 & 647,20 & 5,20 \\
\hline 2013 & 693,20 & 12,20 \\
\hline
\end{tabular}

Fuente: Superintendencia Nacional de Aduanas y de Administración Tributaria-Sunat, (2015). 


\subsubsection{Producción nacional}

Existe poca información estadística sobre la producción peruana de infusiones filtrantes según tipo de producto. Igualmente, se presentan estos datos como referencia tal y como muestra la Tabla 2.2.

Tabla 2. 2

Producción de infusiones filtrantes del 2009 al 2013 (toneladas)

\begin{tabular}{|c|c|}
\hline $\begin{array}{c}\text { Año/ } \\
\text { Transacción }\end{array}$ & $\begin{array}{c}\text { Producción } \\
\text { (toneladas) }\end{array}$ \\
\hline 2009 & 459,30 \\
\hline 2010 & 548,00 \\
\hline 2011 & 538,80 \\
\hline 2012 & 390,60 \\
\hline 2013 & 606,80 \\
\hline
\end{tabular}

Fuente: Ministerio de la Producción del Perú-Produce, (2015).

\subsubsection{Ventas históricas}

Euromonitor International (2015) corrobora la dificultad para establecer la demanda interna aparente peruana de infusiones (p. 10), por tal motivo se usó las ventas históricas de infusiones envasadas a base de té, de plantas aromáticas y de frutas en el Perú, tanto en los canales on-trade como off-trade ${ }^{5}$. La Tabla 2.3 muestra dichas ventas.

Tabla 2. 3

Ventas históricas de infusiones en el Perú del 2005 al 2014 (toneladas)

\begin{tabular}{|c|c|c|c|}
\hline $\mathbf{A n \tilde { n }}$ & $\begin{array}{c}\text { Off-trade } \\
\text { (toneladas) }\end{array}$ & $\begin{array}{c}\text { On-trade } \\
\text { (toneladas) }\end{array}$ & $\begin{array}{c}\text { Total ventas } \\
\text { (toneladas) }\end{array}$ \\
\hline 2005 & 963,90 & 7,90 & 971,80 \\
\hline 2006 & 991,50 & 8,10 & 999,60 \\
\hline 2007 & $1.057,30$ & 8,40 & $1.065,70$ \\
\hline 2008 & $1.529,60$ & 12,30 & $1.541,90$ \\
\hline 2009 & $1.663,40$ & 13,20 & $1.676,60$ \\
\hline 2010 & $2.020,70$ & 15,60 & $2.036,30$ \\
\hline 2011 & $2.003,20$ & 15,20 & $2.018,40$ \\
\hline 2012 & $1.993,30$ & 15,50 & $2.008,80$ \\
\hline 2013 & $2.042,50$ & 16,00 & $2.058,50$ \\
\hline 2014 & $2.120,40$ & 16,40 & $2.136,80$ \\
\hline
\end{tabular}

Fuente: Euromonitor International, (2015).

\footnotetext{
${ }^{5}$ Clasificación según el canal de venta. On-trade, productos consumidos en el mismo lugar de compra y Off-
} trade, productos consumidos en otro lugar al de la compra. 


\subsubsection{Demanda potencial}

Es la cantidad máxima de infusiones filtrantes de manzanilla común, sea planta entera o sólo flores, que podría demandar el Perú. Se tomará como referencia el consumo de Chile.

\subsubsection{Patrones de consumo: incremento poblacional, consumo per cápita, estacionalidad}

Chile consume infusiones filtrantes de té y de plantas aromáticas entre 600 y 650 g por habitante al año según el Departamento de Agricultura de los Estados Unidos USDA (2011) y la revista Don Bodega (2012), respectivamente. Además, en Perú el INEI (2010) proyecta una población de 31.488.625 al 2016 y no hay estacionalidad en la demanda de filtrantes, aunque hay bajas no significativas en verano, ya que son productos de primera necesidad.

\subsubsection{Determinación de la demanda potencial}

La Tabla 2.4 muestra la demanda potencial de infusiones filtrantes aplicando la siguiente fórmula:

$$
Q=P \times C . P . C
$$

Tabla 2.4

Demanda potencial de infusiones filtrantes a base de manzanilla común en Perú (toneladas)

\begin{tabular}{|c|c|c|c|}
\hline Fórmula & P & C.P.C. & Q \\
\hline Año & Habitantes & $\begin{array}{c}\text { Consumo per cápita chileno } \\
\mathbf{2 0 1 2} \text { (toneladas/habitante) }\end{array}$ & $\begin{array}{c}\text { Demanda potencial } \\
\text { (toneladas) }\end{array}$ \\
\hline 2016 & 31.488 .625 & 0,00065 & $20.467,61$ \\
\hline
\end{tabular}

Fuente: Instituto Nacional de Estadística e Informática-INEI, (2016) y Uniliever Chile, (2012).

\subsubsection{Demanda mediante fuentes primarias}

\subsubsection{Diseño y aplicación de encuestas u otras técnicas}

Una prueba sensorial de tipo triangular a través de degustaciones estimó que casi el $80 \%$ de los evaluados sí percibió una diferencia significativa entre los productos en estudio como se ve Anexo 2. 
Asimismo, a través de encuestas (Anexo 2) en Lima Metropolitana, se estimó la demanda susceptible de ser captada para ambos productos. Se logró conocer los hábitos y la intensión de consumo de infusiones filtrantes de los productos en estudio, tal como muestra el Anexo 2 con los respectivos resultados. Las tablas 2.5 y 2.6 muestran la intención de compra de ambos productos.

Tabla 2. 5

Intención e intensidad de compra de bolsas filtrantes de manzanilla común entera

\begin{tabular}{|l|c|c|}
\hline Descripción & Cálculos & Cantidad \\
\hline Personas encuestadas que consumen infusiones filtrantes & $\mathrm{a}$ & 50,00 \\
\hline Personas que consumen infusiones filtrantes de manzanilla común & $\mathrm{b}$ & 40,00 \\
\hline Personas con intención de compra de producto de planta entera & $\mathrm{c}$ & 40,00 \\
\hline Intención de compra & $\mathrm{d}=(\mathrm{c} / \mathrm{a}) \%$ & $80,00 \%$ \\
\hline Promedio del nivel de intención de compra & $\Sigma(\mathrm{IxC}$ i $) / \Sigma\left(\mathrm{C}_{\mathrm{i}}\right)$ & 7,6750 \\
\hline Promedio porcentual del nivel de intención de compra & $\mathrm{e}=(\mathrm{IC} / \mathrm{c}) \%$ & $76,75 \%$ \\
\hline Intención de compra porcentual del producto & $\mathrm{f}=(\mathrm{d} \mathrm{x}$ e) $\%$ & $61,40 \%$ \\
\hline
\end{tabular}

Elaboración propia

Tabla 2.6

Intención e intensidad de compra de bolsas filtrantes de sólo flores de manzanilla común

\begin{tabular}{|l|c|c|}
\hline Descripción & Cálculos & Cantidad \\
\hline Personas encuestadas que consumen infusiones filtrantes & $\mathrm{a}$ & 50,00 \\
\hline Personas que consumen infusiones filtrantes de manzanilla común & $\mathrm{b}$ & 40,00 \\
\hline Personas con intención de compra de producto de sólo flores & $\mathrm{c}$ & 35,00 \\
\hline Intención de compra & $\mathrm{d}=(\mathrm{c} / \mathrm{a}) \%$ & $70,00 \%$ \\
\hline Promedio del nivel de intención de compra & $\Sigma\left(\mathrm{IxC}\right.$ ) $/ \Sigma\left(\mathrm{C}_{\mathrm{i}}\right)$ & 8,3270 \\
\hline Promedio porcentual del nivel de intención de compra & $\mathrm{e}=(\mathrm{IC} / \mathrm{c}) \%$ & $83,27 \%$ \\
\hline Intención de compra porcentual del producto & $\mathrm{f}=(\mathrm{d} \mathrm{x}$ e $) \%$ & $58,29 \%$ \\
\hline
\end{tabular}

Elaboración propia

\subsubsection{Determinación de la demanda}

Para hallar esta demanda se relacionó las ventas históricas totales de infusiones envasadas a base de té, de plantas aromáticas y de frutas en Perú de los 10 últimos años con la población histórica peruana en ese mismo periodo, tal y como muestra la Tabla 2.7.

Posteriormente, se evaluó las funciones de correlación y se escogió la que tiene mayor coeficiente, ver Tabla 2.8, misma que muestra tales regresiones con sus respectivas ecuaciones y coeficientes. Finalmente, la ecuación de la función logarítmica fue seleccionada y es con esta que se proyecta la demanda. 
Tabla 2.7

Población y venta de infusiones en el Perú del 2005 al 2014 (toneladas)

\begin{tabular}{|c|c|c|}
\hline Año & $\begin{array}{c}\text { Población } \\
\text { peruana }\end{array}$ & $\begin{array}{c}\text { Ventas históricas } \\
\text { (toneladas) }\end{array}$ \\
\hline 2005 & 27.810 .540 & 971,80 \\
\hline 2006 & 28.151 .443 & 999,60 \\
\hline 2007 & 28.481 .901 & $1.065,70$ \\
\hline 2008 & 28.807 .034 & $1.541,90$ \\
\hline 2009 & 29.132 .013 & $1.676,60$ \\
\hline 2010 & 29.461 .933 & $2.036,30$ \\
\hline 2011 & 29.797 .694 & $2.018,40$ \\
\hline 2012 & 30.135 .875 & $2.008,80$ \\
\hline 2013 & 30.475 .144 & $2.058,50$ \\
\hline 2014 & 30.814 .175 & $2.136,80$ \\
\hline
\end{tabular}

Fuente: INEI, (2015).

Tabla 2.8

Correlación entre la población histórica y las ventas históricas de infusiones en Perú

\begin{tabular}{|c|c|c|}
\hline Función & Ecuación & (Coeficiente de correlación) $^{\mathbf{2}}$ \\
\hline Exponencial & $\mathrm{y}=0,2658 \mathrm{e}^{3 \mathrm{E}-07 \mathrm{x}}$ & 0,8462 \\
\hline Lineal & $\mathrm{y}=0,0004 \mathrm{x}-11347$ & 0,8738 \\
\hline Potencial & $\mathrm{y}=1 \mathrm{E}-62 \mathrm{x}^{8,7253}$ & 0,8538 \\
\hline Logarítmica & $\mathrm{y}=13038 \ln (\mathrm{x})-222512$ & 0,8799 \\
\hline
\end{tabular}

Elaboración propia

\subsubsection{Proyección de la demanda}

Se proyectó las ventas históricas de infusiones usando la ecuación logarítmica. Siendo la variable independiente $(\mathrm{X})$, la población peruana proyectada según un estudio de proyecciones y estimaciones del INEI (2015) como muestra la Tabla 2.9.

Tabla 2.9

Proyección de la demanda de infusiones en el Perú del 2016 al 2025 (toneladas)

\begin{tabular}{|c|c|c|}
\hline \multicolumn{3}{|c|}{ Y = 13.038* $\ln (\mathbf{X})-\mathbf{2 2 2 . 5 1 2}$} \\
\hline Año & X=Población proyectada & Y=Demanda Proyectada (toneladas) \\
\hline 2016 & 31.488 .625 & $2.590,86$ \\
\hline 2017 & 31.826 .018 & $2.729,81$ \\
\hline 2018 & 32.162 .184 & $2.866,80$ \\
\hline 2019 & 32.495 .510 & $3.001,23$ \\
\hline 2020 & 32.824 .358 & $3.132,51$ \\
\hline 2021 & 33.149 .016 & $3.260,83$ \\
\hline 2022 & 33.470 .569 & $3.386,70$ \\
\hline 2023 & 33.788 .589 & $3.509,99$ \\
\hline 2024 & 34.102 .668 & $3.630,63$ \\
\hline 2025 & 34.412 .393 & $3.748,50$ \\
\hline
\end{tabular}

Fuente: INEI, (2015). 


\subsubsection{Consideraciones sobre la vida útil del proyecto}

El proyecto tendrá una vida útil de 10 años, proyectados a partir del año 2016.

\subsection{Análisis de la oferta}

\subsubsection{Empresas productoras, importadoras y comercializadoras}

\section{Empresas productoras}

Según Pindyck y Rubinfeld (2009), una empresa productora es aquella que aplica cierta tecnología, propia o rentada, para transformar materias primas en productos con mayor valor agregado (p. 219). La Tabla 2.10 muestra las empresas productoras de infusiones en Perú.

Tabla 2.10

Ventas off-trade porcentuales de empresas de infusiones del 2005 al 2014 en Perú (\%)

\begin{tabular}{|c|c|c|c|c|c|c|c|c|c|c|c|}
\hline Empresa & Marca & $\mathbf{2 0 0 5}$ & $\mathbf{2 0 0 6}$ & $\mathbf{2 0 0 7}$ & $\mathbf{2 0 0 8}$ & $\mathbf{2 0 0 9}$ & $\mathbf{2 0 1 0}$ & $\mathbf{2 0 1 1}$ & $\mathbf{2 0 1 2}$ & $\mathbf{2 0 1 3}$ & $\mathbf{2 0 1 4}$ \\
\hline $\begin{array}{c}\text { Corporación Oro } \\
\text { Verde SAC }\end{array}$ & Herbi & 45,50 & 43,67 & 39,47 & 40,32 & 39,90 & 35,83 & 34,25 & 31,77 & 29,83 & 28,22 \\
\hline $\begin{array}{c}\text { Unilever Andina } \\
\text { Perú SA }\end{array}$ & McColin's & 24,69 & 23,49 & 22,76 & 23,55 & 22,99 & 20,54 & 19,34 & 17,74 & 16,38 & 15,52 \\
\cline { 2 - 11 } & Lipton & 0,21 & 1,20 & 1,87 & 2,13 & 3,06 & 4,47 & 5,72 & 7,20 & 7,52 & 7,22 \\
\hline \multirow{2}{*}{ Axur SA } & Hornimans & 5,96 & 7,13 & 6,58 & 6,49 & 6,07 & 5,58 & 5,45 & 5,31 & 5,10 & 4,87 \\
\cline { 2 - 10 } & $\begin{array}{c}\text { Hornimans } \\
\text { Manzanilla }\end{array}$ & 0,52 & 0,50 & 0,36 & 0,35 & 0,32 & 0,29 & 0,28 & 0,30 & 0,27 & 0,27 \\
\hline Herbalife Perú SRL & Herbalife & - & - & 4,89 & 5,79 & 6,93 & 14,80 & 16,57 & 19,78 & 23,76 & 27,23 \\
\hline Alicorp SAA & Zurit & 3,77 & 3,92 & 4,09 & 4,19 & 3,92 & 3,65 & 3,51 & 3,38 & 3,22 & 3,07 \\
\hline $\begin{array}{c}\text { Fujian Tea Import } \\
\text { Export Co Ltd }\end{array}$ & Fujian & 5,23 & 5,32 & 4,71 & 3,42 & 3,54 & 2,95 & 2,88 & 2,71 & 2,35 & 2,29 \\
\hline $\begin{array}{c}\text { Dinamika Business } \\
\text { SAC }\end{array}$ & Sunka & 0,10 & 0,70 & 1,42 & 1,53 & 1,56 & 1,35 & 1,54 & 1,60 & 1,81 & 1,87 \\
\hline Aurandina SAC & Wawasana & 0,63 & 0,70 & 1,33 & 1,48 & 1,50 & 1,60 & 1,70 & 2,04 & 2,05 & 2,02 \\
\hline Otros & Otros & 12,55 & 12,35 & 11,64 & 9,68 & 8,97 & 7,71 & 7,50 & 6,94 & 6,58 & 6,32 \\
\hline E Wong SA & Wong & 0,10 & 0,10 & 0,09 & 0,12 & 0,11 & 0,12 & 0,12 & 0,11 & 0,10 & 0,12 \\
\hline $\begin{array}{c}\text { Cencosud Retail } \\
\text { Perú SA }\end{array}$ & Metro & 0,00 & 0,10 & 0,09 & 0,12 & 0,11 & 0,12 & 0,12 & 0,15 & 0,13 & 0,12 \\
\hline Otras marcas & Otros & 0,73 & 0,80 & 0,89 & 0,89 & 0,97 & 1,03 & 0,99 & 0,93 & 0,87 & 0,84 \\
\hline Total (\%) & Total (\%) & 100 & 100 & 100 & 100 & 100 & 100 & 100 & 100 & 100 & 100 \\
\hline
\end{tabular}

Fuente: Euromonitor International, (2015).

Existen otras marcas cuya participación en conjunto bordea el 6,30\%. Asimismo, existen marcas blancas ${ }^{6}$ cuya participación alcanza el $1.14 \%$. La Tabla 2.11 muestra los volúmenes comercializados por las marcas descritas en la Tabla 2.10.

\footnotetext{
${ }^{6}$ También llamada marca propia, de distribuidor o genérica, es la marca perteneciente a una cadena de distribución (generalmente un establecimiento comercial) donde se venden productos fabricados por terceros.
} 
Tabla 2. 11

Ventas off-trade de principales empresas de infusiones al 2014 en Perú (toneladas)

\begin{tabular}{|c|c|c|c|c|c|c|c|c|c|c|c|}
\hline Empresa & Marca & 2005 & 2006 & 2007 & 2008 & 2009 & 2010 & 2011 & 2012 & 2013 & 2014 \\
\hline $\begin{array}{c}\text { Corporación Oro } \\
\text { Verde SAC }\end{array}$ & Herbi & 438,59 & 433,03 & 417,28 & 616,72 & 663,75 & 724,10 & 686,18 & 633,36 & 609,32 & 598,36 \\
\hline \multirow{2}{*}{$\begin{array}{c}\text { Unilever Andina } \\
\text { Perú SA }\end{array}$} & McColin's & 237,95 & 232,94 & 240,59 & 360,28 & 382,35 & 415,08 & 387,36 & 353,67 & 334,48 & 329,16 \\
\hline & Lipton & 2,02 & 11,95 & 19,74 & 32,51 & 50,92 & 90,31 & 114,63 & 143,54 & 153,53 & 153,10 \\
\hline \multirow[b]{2}{*}{ Axur SA } & Hornimans & 57,47 & 70,68 & 69,55 & 99,32 & 100,95 & 112,68 & 109,09 & 105,81 & 104,18 & 103,34 \\
\hline & $\begin{array}{l}\text { Hornimans } \\
\text { Manzanilla }\end{array}$ & 5,04 & 4,98 & 3,76 & 5,42 & 5,36 & 5,80 & 5,53 & 5,92 & 5,48 & 5,74 \\
\hline Herbalife Perú SRL & Herbalife & - & - & 51,69 & 88,49 & 115,24 & 299,09 & 332,02 & 394,37 & 485,27 & 577,31 \\
\hline Alicorp SAA & Zurit & 36,30 & 38,82 & 43,23 & 64,11 & 65,21 & 73,74 & 70,36 & 67,33 & 65,80 & 65,07 \\
\hline $\begin{array}{c}\text { Fujian Tea Import } \\
\text { Export Co Ltd }\end{array}$ & Fujian & 50,41 & 52,76 & 49,81 & 52,37 & 58,96 & 59,65 & 57,71 & 54,01 & 47,98 & 48,48 \\
\hline $\begin{array}{c}\text { Dinamika Business } \\
\text { SAC } \\
\end{array}$ & Sunka & 1,01 & 6,97 & 15,04 & 23,48 & 25,91 & 27,34 & 30,83 & 31,82 & 37,01 & 39,55 \\
\hline Aurandina SAC & Wawasana & 6,05 & 6,97 & 14,10 & 22,57 & 25,01 & 32,31 & 33,99 & 40,69 & 41,81 & 42,74 \\
\hline Otros & Otros & 120,99 & 122,44 & 123,12 & 148,08 & 149,19 & 155,76 & 150,20 & 138,36 & 134,34 & 133,96 \\
\hline E Wong SA & Wong & 1,01 & 1,00 & 0,94 & 1,81 & 1,79 & 2,49 & 2,37 & 2,22 & 2,06 & 2,55 \\
\hline $\begin{array}{c}\text { Cencosud Retail } \\
\text { Perú SA }\end{array}$ & Metro & 0,00 & 1,00 & 0,94 & 1,81 & 1,79 & 2,49 & 2,37 & 2,96 & 2,74 & 2,55 \\
\hline $\begin{array}{l}\text { Otras Marcas } \\
\text { Blancas }\end{array}$ & Otros & 7,06 & 7,96 & 9,40 & 13,54 & 16,08 & 20,71 & 19,76 & 18,50 & 17,82 & 17,86 \\
\hline \multicolumn{2}{|c|}{ Total (Toneladas) } & 963,90 & 991,50 & $1.057,30$ & $1.529,60$ & $1.663,40$ & $2.020,70$ & $2.003,20$ & $1.993,30$ & $2.042,50$ & $2.120,40$ \\
\hline
\end{tabular}

Fuente: Euromonitor International, (2015). 


\section{Empresas importadoras}

La Tabla 2.12 muestra la participación porcentual histórica de las principales empresas que importan infusiones, ya sean envasadas o como materia prima. Se aprecia que algunas empresas productoras son también empresas que importan como Unilever Andina Perú S.A.C., Corporación Oro Verde S.A.C. y Alicorp S.A.A. entre las principales.

Tabla 2. 12

Participación de las empresas que importan infusiones del 2005 al 2014 en Perú (\%)

\begin{tabular}{|l|c|c|c|c|c|c|c|c|c|c|}
\hline \multicolumn{1}{|c|}{ Importador } & $\mathbf{2 0 0 5}$ & $\mathbf{2 0 0 6}$ & $\mathbf{2 0 0 7}$ & $\mathbf{2 0 0 8}$ & $\mathbf{2 0 0 9}$ & $\mathbf{2 0 1 0}$ & $\mathbf{2 0 1 1}$ & $\mathbf{2 0 1 2}$ & $\mathbf{2 0 1 3}$ & $\mathbf{2 0 1 4}$ \\
\hline Unilever Andina Perú SA & 37,32 & 66,42 & 55,97 & 58,36 & 48,41 & 33,00 & 32,20 & 37,68 & 34,00 & 29,90 \\
\hline Corporación Oro Verde SAC & 32,05 & 5,97 & 2,12 & 2,33 & 1,23 & 15,28 & 28,65 & 22,58 & 32,12 & 33,69 \\
\hline América Sam SAC & - & 1,57 & 1,84 & 6,92 & 5,00 & 11,32 & 7,76 & 8,49 & 6,50 & 8,18 \\
\hline Frutos y Especias SAC & 2,72 & 9,05 & 2,57 & 4,79 & 6,24 & 4,94 & 4,92 & 5,16 & 6,83 & 3,70 \\
\hline Industria He SAC & - & - & - & - & 10,35 & 9,57 & 3,39 & 7,41 & 5,33 & 5,36 \\
\hline Xin Xing SA & 1,85 & 0,84 & 3,44 & 3,80 & 5,86 & 4,86 & 4,50 & 2,37 & 1,06 & 0,71 \\
\hline S B Trading SRL & 0,78 & 1,82 & 1,73 & 3,62 & 2,62 & 1,96 & 2,30 & 1,87 & 1,32 & 1,34 \\
\hline Tai Feng SAC & - & - & - & 0,87 & 5,04 & 8,13 & 2,30 & 1,92 & 0,02 & - \\
\hline Frutos Huanchi SAC & 5,15 & 6,58 & 5,03 & 2,40 & - & - & - & - & - & - \\
\hline Importación \& exportación Tay SAC & - & - & - & - & 0,44 & & 0,88 & - & 2,47 & 5,08 \\
\hline Frutas Industrias SAC & - & - & - & 1,21 & 1,14 & 2,58 & 1,27 & 1,81 & 1,82 & 1,29 \\
\hline Alicorp SAA & - & - & 13,70 & - & - & - & - & - & - & - \\
\hline Asa Alimentos SA & 9,95 & - & - & - & - & - & - & - & - & - \\
\hline Lpun SA & 0,93 & 0,81 & 0,71 & 1,35 & 1,13 & - & 0,70 & 0,93 & 0,61 & 0,62 \\
\hline Fitomedica SRLTDA & 0,81 & 1,30 & 1,02 & 1,06 & - & 0,76 & 0,71 & 0,69 & 0,59 & 0,54 \\
\hline Jia He SA & - & - & - & - & - & 0,64 & 1,88 & 1,96 & 0,63 & 0,60 \\
\hline Aurandina SAC & - & - & 0,35 & 0,41 & 1,12 & 0,30 & 0,63 & 0,93 & 0,47 & 1,09 \\
\hline Chan Sen Tak Luen & 0,39 & 0,65 & 0,34 & 1,03 & 0,43 & 0,34 & 0,28 & 0,72 & 0,51 & - \\
\hline Industrias Del Packing SAC & - & - & - & - & - & - & - & - & - & 2,34 \\
\hline Los demás & 8,06 & 4,98 & 11,19 & 11,85 & 10,98 & 6,33 & 7,63 & 5,49 & 5,71 & 5,59 \\
\hline Total & 100 & 100 & 100 & 100 & 100 & 100 & 100 & 100 & 100 & 100 \\
\hline
\end{tabular}

Fuente: Datatrade, (2015).

\section{Empresas comercializadoras}

Finalmente, las empresas comercializadoras se dividen en dos grupos: mayoristas y minoristas. No se encontró datos exactos sobre los volúmenes comercializados por los primeros. Sin embargo, al abastecer los mayoristas a los minoristas ${ }^{7}$, para que estos a su vez lo vendan a los consumidores finales, bastará con conocer la participación de los minoristas. La Tabla 2.13 muestra la clasificación del mercado minorista de infusiones. Igualmente, la Figura 2.3 grafica dicha participación de acuerdo al canal de venta off-trade.

\footnotetext{
${ }^{7}$ La forma de abastecimiento varía por categoría; siendo las principales: a través de un distribuidor directo, indirecto o trasladándose personalmente a comprar el producto en grandes volúmenes a un mayorista.
} 
Tabla 2. 13

Ventas de infusiones en canal off-trade del 2005 al 2014 en Perú (toneladas)

\begin{tabular}{|c|c|c|c|c|c|c|c|c|c|c|}
\hline Minoristas & 2005 & 2006 & 2007 & 2008 & 2009 & 2010 & 2011 & 2012 & 2013 & 2014 \\
\hline Hipermercados & 58,60 & 67,70 & 75,70 & 118,40 & 138,20 & 168,00 & 166,70 & 166,90 & 172,00 & 180,80 \\
\hline Supermercados & 77,70 & 74,10 & 76,30 & 103,30 & 104,00 & 127,40 & 127,60 & 128,80 & 135,70 & 144,90 \\
\hline I.-Subtotal & 136,30 & 141,80 & 152,00 & 221,60 & 242,20 & 295,40 & 294,30 & 295,70 & 307,70 & 325,60 \\
\hline Bodegas & 533,10 & 545,30 & 580,00 & 836,70 & 904,90 & $1.097,20$ & $1.085,50$ & $1.073,20$ & $1.095,20$ & $1.132,70$ \\
\hline Otros $^{8}$ & 294,60 & 304,40 & 325,20 & 471,30 & 516,30 & 628,00 & 623,40 & 624,30 & 639,60 & 662,00 \\
\hline II.-Subtotal & 827,60 & 849,70 & 905,30 & $1.308,00$ & $1.421,20$ & $1.725,20$ & $1.708,90$ & $1.697,50$ & $1.734,80$ & $1.794,70$ \\
\hline Subtotales ( I+II ) & 963,90 & 991,50 & $1.057,30$ & $1.529,60$ & $1.663,40$ & $2.020,70$ & $2.003,20$ & $1.993,30$ & $2.042,50$ & $2.120,40$ \\
\hline On-trade $^{9}$ & 7,90 & 8,10 & 8,40 & 12,30 & 13,20 & 15,60 & 15,20 & 15,50 & 16,00 & 16,40 \\
\hline Total & 971,80 & 999,60 & $1.065,70$ & $1.541,90$ & $1.676,60$ & $2.036,30$ & $2.018,40$ & $2.008,80$ & $2.058,50$ & $2.136,80$ \\
\hline
\end{tabular}

Fuente: Euromonitor International, (2015).

Figura 2. 3

Ventas de infusiones en canal off-trade del 2014 en Perú (\%)

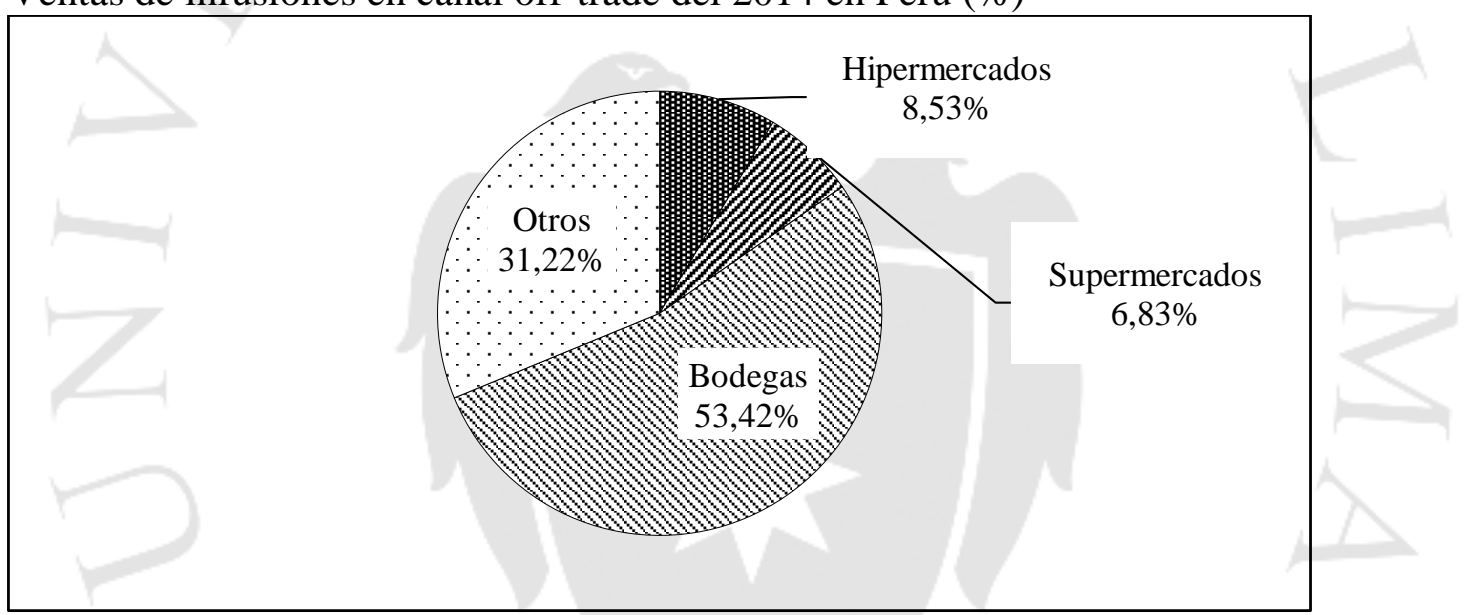

Fuente: Euromonitor International, (2015).

\subsubsection{Competidores actuales y potenciales}

\section{Competidores actuales}

Los competidores actuales pueden ser directos o indirectos. En base al punto 2.3.1 los competidores directos actuales son las marcas cuyos productos tienen presentación de bolsas filtrantes. Sin embargo, el presente estudio se centra en las marcas que tengan productos de manzanilla común, sea de planta entera o solo flores, sin mezclarse con otro producto. La Tabla 2.14 muestra tales marcas especificando detalles de sus productos.

\footnotetext{
${ }^{8}$ Se refiere a puestos de mercados, tiendas especializadas, tiendas de estaciones de servicio y otros.

${ }^{9}$ Se refiere a ventas en restaurantes, hoteles y demás lugares donde el producto es comprado y es consumido en el mismo lugar.
} 
Tabla 2. 14

Competidores directos de infusiones filtrantes a base de manzanilla común al 2015 en Perú

\begin{tabular}{|c|c|c|c|c|c|c|}
\hline Marca & Línea & Filtrante & $\begin{array}{c}\text { Peso neto } \\
\text { filtrante }(\mathbf{g})\end{array}$ & $\begin{array}{c}\text { Filtrantes } \\
\text { /Empaque }\end{array}$ & Parte usada & $\begin{array}{c}\text { País de } \\
\text { envasado }\end{array}$ \\
\hline Herbi & Clásica & Estándar ${ }^{10}$ & 1,00 & $25,00 / 100,00$ & Planta entera & Perú \\
\hline McCollin's & Clásica & Estándar & 1,00 & $25,00 / 100,00$ & Planta entera & Perú \\
\hline Lipton & Clásica & Estándar & 1,00 & 20,00 & Planta entera & Chile \\
\hline Hornimans & Clásica & Estándar & 1,00 & $25,00 / 100,00$ & Planta entera & Perú \\
\hline Wawasana & Aromática & Estándar & 1,00 & 20,00 & Planta entera & Perú \\
\hline Wong & - & Estándar & 1,00 & 25,00 & Planta entera & Perú \\
\hline Metro & - & Estándar & 1,00 & 25,00 & Planta entera & Perú \\
\hline Tottus & - & Estándar & 1,00 & $25,00 / 100,00$ & Planta entera & Perú \\
\hline Aro & - & Estándar & 1,00 & 100,00 & Planta entera & Perú \\
\hline Del Valle & Aromática & Estándar & 1,00 & $25,00 / 100,00$ & Planta entera & Perú \\
\hline Del Valle & Gold & Estándar & 1,00 & $25,00 / 100,00$ & Planta entera & Perú \\
\hline Ecoinca & Clásica & Estándar & 1,20 & 15,00 & Planta entera & Perú \\
\hline Alma & Ecológica & Piramidal & 1,40 & 15,00 & Flores & España \\
\hline Terrafertil & Té orgánico & Estándar & 1,00 & 20,00 & Planta entera & Ecuador \\
\hline Saint Gottard & Aromática & Estándar & 1,00 & 15,00 & Flores & Argentina \\
\hline Bells & - & Estándar & 1,00 & $20,00 / 100,00$ & Planta entera & Perú \\
\hline A1 & - & Estándar & 1,00 & $25,00 / 100,00$ & Planta entera & Perú \\
\hline Té mar & - & Estándar & 1,00 & 25,00 & Planta entera & Perú \\
\hline Huerto del edén & Aromática & Estándar & 1,00 & 25,00 & Planta entera & Perú \\
\hline Elaboración propia & & & & &
\end{tabular}

Elaboración propia

Como se puede apreciar en la tabla anterior, consecuencia de un estudio de campo ${ }^{11}$, se halló 17 marcas de infusiones filtrantes a base de manzanilla común, sea de planta entera o sólo flores, sin mezclarse con otro producto.

Respecto a los competidores indirectos, estos se refieren a las demás marcas cuyos productos no son bolsas filtrantes, pero sirven para infusiones, y se comercializan en otras presentaciones, principalmente como partes de plantas (frescas o secas) y solubles.

La Tabla 2.15 muestra las principales marcas que vienen en otras presentaciones de partes frescas o secas. Asimismo, la Tabla 2.16 muestra los competidores indirectos con productos instantáneos como Nescafé a base de café listo para mezclar con agua caliente o productos solubles como la marca Herbalife ${ }^{12}$.

\footnotetext{
${ }^{10}$ Estándar se refiere a la bolsa filtrante de forma rectangular y de uso más extendido, de ahí tal denominación.

${ }^{11}$ En supermercados, hipermercados, bodegas, mercados tradicionales y demás. Realizadas el mes de Julio del 2015.

${ }^{12}$ En cuanto a infusiones, Herbalife posee productos a base de té, de plantas aromáticas o de frutas tanto en presentación de instantáneos o concentrados como también de productos solubles. Los primeros son consumidos de preferencia agregando solamente agua caliente y los segundos son consumidos agregando otras bebidas frías o tibias.
} 
Tabla 2. 15

Competidores indirectos a base de partes de plantas para infusiones

\begin{tabular}{|c|c|c|c|}
\hline Estado & Insumo & Presentació & Marcas \\
\hline Frescas & \multicolumn{3}{|c|}{$\begin{array}{l}\text { Cualquier tipo de planta, su presentación es por lo general entera. No } \\
\text { tienen marca ya que se venden por atados en los mercados tradicionales. }\end{array}$} \\
\hline \multirow{4}{*}{ Secas } & Aromática & Hojas & \begin{tabular}{ll}
\multicolumn{2}{l}{ Ejemplos: } \\
- & Naturandes \\
- & Renacer \\
- & Schagreen
\end{tabular} \\
\hline & Yerbamate & Molido & $\begin{array}{ll}\text { Ejemplos: } \\
\text { - } \quad \text { Taragüi } \\
\text { - } \quad \text { Rosamonte }\end{array}$ \\
\hline & \multirow[b]{2}{*}{ Café } & Granos & \begin{tabular}{ll}
\multicolumn{2}{l}{ Ejemplos: } \\
- $\quad$ Britt \\
- $\quad$ Chasqui \\
- $\quad$ Mountain Villa Rica
\end{tabular} \\
\hline & & Molido & $\begin{array}{ll}\text { Ejemplos: } \\
\text { - } & \text { Cafetal } \\
\text { - } & \text { Britt } \\
\text { - } & \text { Altomayo } \\
\text { - } & \text { Illy }\end{array}$ \\
\hline
\end{tabular}

Elaboración propia

Tabla 2. 16

Competidores indirectos a base de solubles para infusiones

\begin{tabular}{|c|c|c|}
\hline Insumo & Presentación & Marcas \\
\hline \multirow{2}{*}{ Café } & & Ejemplos: \\
& Instantáneo & $\bullet \quad$ Colcafé \\
& & $\bullet \quad$ Nescafé \\
\hline \multirow{2}{*}{ Mezcla } & Polvo & Kruger \\
\hline
\end{tabular}

Elaboración propia

\section{Competidores potenciales}

Son aquellos que pueden ingresar a competir en el rubro de infusiones, como son empresas del rubro de alimentos, bebidas y afines.

\subsection{Determinación de la demanda para el proyecto}

\subsubsection{Segmentación del mercado}

Permitirá identificar al público objetivo para cada tipo de producto. Para ello se analizará las principales variables de segmentación de los mercados de consumo propuesta por Kotler y Armstrong (2013), estas variables son: 


\section{Segmentación geográfica}

Lima Metropolitana es el mercado escogido para los dos productos en estudio. Las ventas de infusiones filtrantes en este mercado abarcan aproximadamente el 70\% de todo el Perú según la Compañia de Investigación de Mercado CCR (2003) como muestra el Anexo 3.

\section{Segmentación demográfica y psicográfica}

Ambos productos se dirigirán a personas de ambos sexos, a partir de los ocho años, antes de esta edad se consume más leche, INEI (2015). En cuanto al nivel socioeconómico, combinación de clase social (psicográfico) e ingreso (demográfico), el producto de planta entera se dirigirá a todos los niveles socioeconómicos, y el de sólo flores a los niveles socioeconómicos A y B.

\section{Segmentación conductual}

Mediante encuestas se estimó la intención de compra porcentual de cada producto. Los resultados son de $61,40 \%$ y 58,29\% para los productos de planta entera y de solo flores, respectivamente. Asimismo, según Euromonitor International (2015), del total de infusiones el 72,77\% se venden en presentación de filtrantes. Por último, las ventas en supermercados de manzanilla en filtrantes alcanzan el 23,83\% según un reporte mensual de supermercados Tottus (Anexo 3).

\subsubsection{Selección de mercado meta}

Para ambos productos: personas de Lima Metropolitana de ambos sexos a partir de los ocho años de edad. Para el producto de planta entera los NSE: A, B, C, D y E; para el producto de sólo flores los NSE: A y B.

La Tabla 2.17 muestra los perfiles socioeconómicos de Lima Metropolitana según un estudio de Ipsos Perú (2014), que establece cinco niveles socioeconómicos (NSE) en dicha zona (p. 12). 
Tabla 2. 17

Estratificación de Lima Metropolitana por NSE al 2015

\begin{tabular}{|c|c|c|c|c|c|c|}
\hline Nivel socioeconómico & Nivel A & Nivel B & Nivel C & Nivel D & Nivel E & Total \\
\hline Porcentaje (\%) & 4,90 & 18,80 & 40,70 & 26,20 & 9,40 & 100 \\
\hline
\end{tabular}

Fuente: Ipsos Apoyo, (2015).

Asimismo, la Tabla 2.18, según un estudio de liderazgo en productos comestibles de Ipsos Perú (2012) muestra los lugares más frecuentes de compra de infusiones filtrantes de té, manzanilla y anís por nivel socioeconómico (NSE) en Lima Metropolitana (p. 66).

Tabla 2. 18

Lugares más frecuentes de compra de infusiones filtrantes en Lima Metropolitana por NSE

\begin{tabular}{|c|c|c|c|c|c|}
\hline Lugar de compra & $\mathbf{A}(\boldsymbol{\%})$ & $\mathbf{B}(\boldsymbol{\%})$ & $\mathbf{C}(\boldsymbol{\%})$ & $\mathbf{D}(\boldsymbol{\%})$ & $\mathbf{E}(\boldsymbol{\%})$ \\
\hline Mercado & 11,00 & 31,00 & 48,00 & 47,00 & 58,00 \\
\hline Bodega & 18,00 & 19,00 & 35,00 & 42,00 & 31,00 \\
\hline Supermercado & 70,00 & 45,00 & 13,00 & 9,00 & 4,00 \\
\hline Mayorista & 1,00 & 5,00 & 2,00 & 1,00 & 0,00 \\
\hline
\end{tabular}

Fuente: Ipsos Apoyo, (2015).

La Tabla 2.19 presenta los porcentajes de edad en Lima Metropolitana por intervalos.

Tabla 2. 19

Proporción por intervalos de edad de la población en Lima Metropolitana al 2014

\begin{tabular}{|c|c|c|c|c|c|c|c|c|c|}
\hline Intervalo de edad & $\mathbf{0 - 7}$ & $\mathbf{8 - 1 7}$ & $\mathbf{1 8 - 2 9}$ & $\mathbf{3 0 - 3 9}$ & $\mathbf{4 0 - 4 9}$ & $\mathbf{5 0 - 5 9}$ & $\mathbf{6 0 - 6 5}$ & $\mathbf{6 5}-$ más & Total \\
\hline Porcentaje (\%) & 11,00 & 16,00 & 20,00 & 14,00 & 13,00 & 11,00 & 5,00 & 10,00 & 100,00 \\
\hline
\end{tabular}

Fuente: Ipsos Apoyo, (2015).

\section{Porcentaje de participación}

En supermercados Tottus la manzanilla común en filtrantes representa un 23,83\% respecto a otros filtrantes, y este establecimiento cuenta con un $37 \%$ de las marcas de todo el mercado, así como la mayor cantidad de marcas de filtrantes de manzanilla según muestra la Tabla 2.22. En tal sentido se eligió una participación de mercado de $15,16 \%$ y de 7,58\% para los productos de planta entera y sólo flores, respectivamente, puesto que la participación del segundo producto es aproximadamente la mitad, en base a un conteo en góndolas.

\subsubsection{Demanda específica para el proyecto}

Las Tablas 2.20 y 2.21 muestran la demanda del proyecto para ambos productos, teniendo en cuenta las variables de segmentación, así como la participación de ambos productos. 
Tabla 2. 20

Demanda específica del proyecto para producto de planta entera de manzanilla común del 2016 al 2025 (toneladas)

\begin{tabular}{|c|c|c|c|c|c|c|c|c|c|}
\hline Año & $\begin{array}{c}\text { Demanda } \\
\text { proyectada } \\
\text { toneladas) }\end{array}$ & $\begin{array}{c}\text { \% Ventas en } \\
\text { Lima } \\
\text { Metropolitana }\end{array}$ & $\begin{array}{c}\text { \% } \\
\text { Población } \\
\mathbf{8} \text { años }\end{array}$ & $\begin{array}{c}\text { \% Ventas } \\
\text { presentación } \\
\text { en filtrante }\end{array}$ & $\begin{array}{c}\text { \% Ventas en } \\
\text { supermercados } \\
\text { por NSE }\end{array}$ & $\begin{array}{c}\text { \% Ventas } \\
\text { Manzanilla } \\
\text { común }\end{array}$ & $\begin{array}{c}\text { \% } \\
\text { Intención } \\
\text { compra }\end{array}$ & $\begin{array}{c}\text { \% } \\
\text { Participación }\end{array}$ & $\begin{array}{c}\text { Demanda } \\
\text { (toneladas) }\end{array}$ \\
\hline 2016 & $2.590,86$ & 70,00 & 89,00 & 72,77 & 19,92 & 23,83 & 61,40 & 15,16 & 5,19 \\
\hline 2017 & $2.729,81$ & 70,00 & 89,00 & 72,77 & 19,92 & 23,83 & 61,40 & 15,16 & 5,47 \\
\hline 2018 & $2.866,80$ & 70,00 & 89,00 & 72,77 & 19,92 & 23,83 & 61,40 & 15,16 & 5,74 \\
\hline 2019 & $3.001,23$ & 70,00 & 89,00 & 72,77 & 19,92 & 23,83 & 61,40 & 15,16 \\
\hline 2020 & $3.132,51$ & 70,00 & 89,00 & 72,77 & 19,92 & 23,83 & 61,40 & 15,16 \\
\hline 2021 & $3.260,83$ & 70,00 & 89,00 & 72,77 & 19,92 & 23,83 & 61,40 & 15,16 \\
\hline 2022 & $3.386,70$ & 70,00 & 89,00 & 72,77 & 19,92 & 23,83 & 61,40 & 15,16 \\
\hline 2023 & $3.509,99$ & 70,00 & 89,00 & 72,77 & 19,92 & 23,83 & 61,40 & 15,16 \\
\hline 2024 & $3.630,63$ & 70,00 & 89,00 & 72,77 & 19,92 & 23,83 & 61,40 & 15,16 \\
\hline 2025 & $3.748,50$ & 70,00 & 89,00 & 72,77 & 19,92 & 23,83 & 61,40 & 15,16 & 7,03 \\
\hline
\end{tabular}

Elaboración propia

Tabla 2.21

Demanda específica del proyecto para producto de sólo flores de manzanilla común del 2016 al 2025 (toneladas)

\begin{tabular}{|c|c|c|c|c|c|c|c|c|c|}
\hline Año & $\begin{array}{c}\text { Demanda } \\
\text { proyectada } \\
\text { (toneladas) }\end{array}$ & $\begin{array}{c}\text { \% Ventas en } \\
\text { Lima } \\
\text { Metropolitana }\end{array}$ & $\begin{array}{c}\text { \% } \\
\text { Población } \\
\mathbf{8} \text { años }\end{array}$ & $\begin{array}{c}\text { \% Ventas } \\
\text { presentación } \\
\text { en filtrante }\end{array}$ & $\begin{array}{c}\text { \% Ventas en } \\
\text { supermercados } \\
\text { por NSE }\end{array}$ & $\begin{array}{c}\text { \% Ventas } \\
\text { Manzanilla } \\
\text { común }\end{array}$ & $\begin{array}{c}\% \\
\text { Intención } \\
\text { compra }\end{array}$ & $\begin{array}{c}\text { \% } \\
\text { Participación }\end{array}$ & $\begin{array}{c}\text { Demanda } \\
\text { toneladas) }\end{array}$ \\
\hline 2016 & $2.590,86$ & 70,00 & 89,00 & 72,77 & 11,30 & 23,83 & 58,29 & 7,58 \\
\hline 2017 & $2.729,81$ & 70,00 & 89,00 & 72,77 & 11,30 & 23,83 & 58,29 & 7,58 \\
\hline 2018 & $2.866,80$ & 70,00 & 89,00 & 72,77 & 11,30 & 23,83 & 58,29 & 7,58 \\
\hline 2019 & $3.001,23$ & 70,00 & 89,00 & 72,77 & 11,30 & 23,83 & 58,29 & 7,58 \\
\hline 2020 & $3.132,51$ & 70,00 & 89,00 & 72,77 & 11,30 & 23,83 & 58,29 & 7,58 & 1,62 \\
\hline 2021 & $3.260,83$ & 70,00 & 89,00 & 72,77 & 11,30 & 23,83 & 58,29 & 7,58 & 1,76 \\
\hline 2022 & $3.386,70$ & 70,00 & 89,00 & 72,77 & 11,30 & 23,83 & 58,29 & 7,58 \\
\hline 2023 & $3.509,99$ & 70,00 & 89,00 & 72,77 & 11,30 & 23,83 & 58,29 & 7,53 \\
\hline 2024 & $3.630,63$ & 70,00 & 89,00 & 72,77 & 11,30 & 23,83 & 58,29 & 7,58 & 1,89 \\
\hline 2025 & $3.748,50$ & 70,00 & 89,00 & 72,77 & 11,30 & 23,83 & 58,29 & 7,58 & 2,02 \\
\hline
\end{tabular}

Elaboración propia 


\subsection{Definición de la estrategia de comercialización}

La estrategia de comercialización para ambos productos será por un canal indirecto de un intermediario minorista puesto que ambos productos serán vendidos en supermercados solamente. Intentar venderlos en bodegas, mercados tradicionales, puestos de mercados o demás no sería factible, ya que sería difícil competir con otras marcas de infusiones filtrantes de menor precio. Se precisa que los productos en estudio proyectan tener atributos superiores ${ }^{13}$ al del promedio en el mercado peruano. La Figura 2.4 muestra el esquema de distribución para ambos productos.

Figura 2. 4

Canal de distribución de productos para el presente estudio

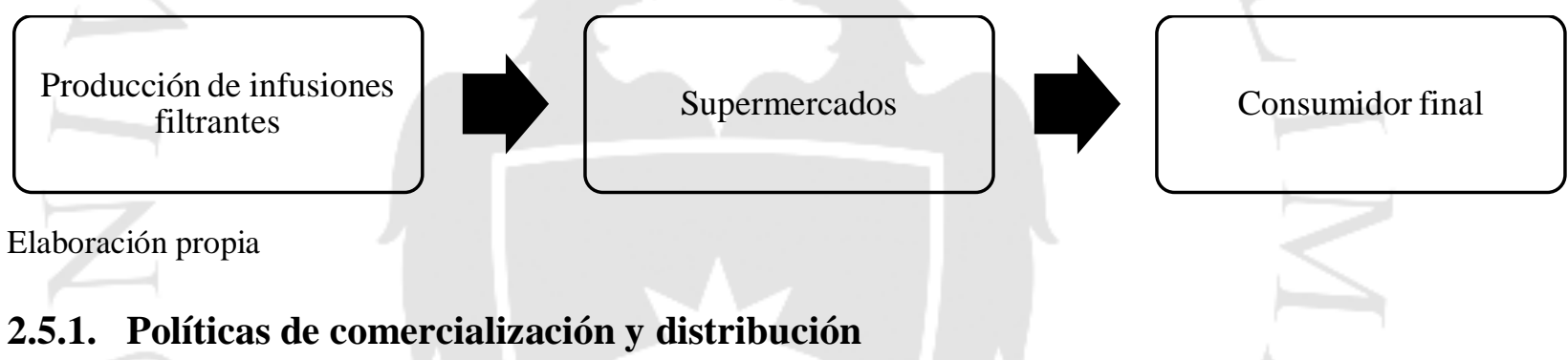

Los productos serán distribuidos asumiendo los costos de transporte y flete. El producto de planta entera prevé llegar a todos los supermercados posibles, mientras que el producto de sólo flores será distribuido a los supermercados de nivel socioeconómico A y B. Teniendo en cuenta que las marcas con mayor participación pueden llegar al consumidor final por diferentes canales, en razón de su economía de escala lo que les permite abarcar varios tipos de establecimientos minoristas.

La Tabla 2.22 muestra las marcas de infusiones filtrantes de manzanilla común sin mezclarse con otro producto, sea de planta entera o sólo flores y los supermercados donde suelen venderse. Asimismo, la Tabla 2.23 muestra la leyenda de los establecimientos donde se hizo el estudio de campo, el cual se llevó a cabo en el mes de julio del año 2015.

\footnotetext{
${ }^{13}$ Ambos productos sobresalen por su aroma y sabor debido a la materia prima y a los métodos para su elaboración. En consecuencia los beneficios de su consumo serán superiores a los de otros productos, sumado a que el producto de flores cumple la Norma Técnica Peruana (NTP) 209.228.
} 
Por otro lado, se debe tener en cuenta que los productos de planta entera y de sólo flores, debido a sus características y precios, se asemejan a las marcas de infusiones filtrantes de manzanilla común de Litpon y Saint Gottard respectivamente.

Tabla 2. 22

Lugares usuales de ubicación de infusiones filtrantes de manzanilla común el 2015 en Perú

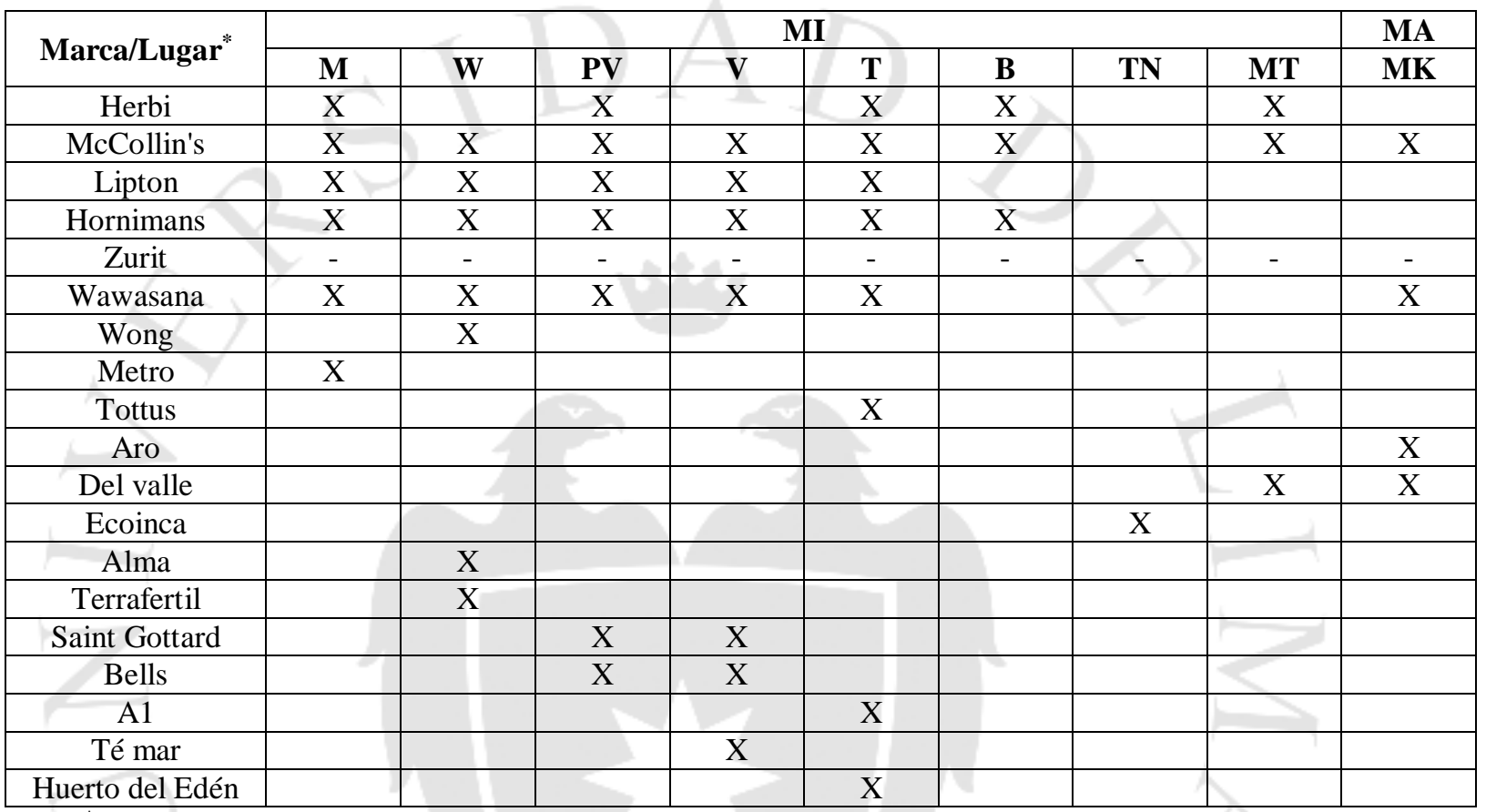

Nota: *Ver la siguiente Tabla de leyenda de lugares.

Elaboración propia

Tabla 2. 23

Leyenda de la Tabla 2.22

\begin{tabular}{|c|c|c|}
\hline M & Metro & \multirow{2}{*}{} \\
\hline W & Wong & \multirow{2}{*}{ Minorista } \\
(MI) \\
\hline PV & Plaza Vea & \\
\hline V & Vivanda & \\
\hline T & Tottus & \\
\hline B & Bodegas en general & \\
\hline TN & Tiendas naturistas & \\
\hline MT & Mercados tradicionales & \\
\hline MK & Makro & Mayorista (MA) \\
\hline
\end{tabular}

Elaboración propia 


\subsubsection{Publicidad y promoción}

Según un informe de liderazgo en productos comestibles, las infusiones filtrantes a base de té, de manzanilla y de anís son consumidos habitualmente ${ }^{14}$ en Lima Metropolitana en un porcentaje de los hogares del "94\%" (Ipsos Perú, 2014, p. 12). Por tal motivo se puede aprovechar internet, redes sociales y medios de comunicación masiva para dar a conocer los productos, resaltando la calidad de los mismos en comparación a otras marcas. La publicidad en televisión y radio se puede evaluar en el largo plazo. En el corto plazo el objetivo debe ser que los clientes conozcan los productos. Para eso se prevé entregar folletos y publicidad en los supermercados.

\subsubsection{Análisis de los precios}

\subsubsection{Tendencia histórica de los precios}

Los precios promedio al por menor de las infusiones filtrantes en Perú han venido en ascenso en los últimos diez años, tal y como lo muestra la Figura 2.5.

Figura 2. 5

Tendencia histórica de precios minoristas de infusiones del 2005 al 2014 en Perú (S/. / kg.)

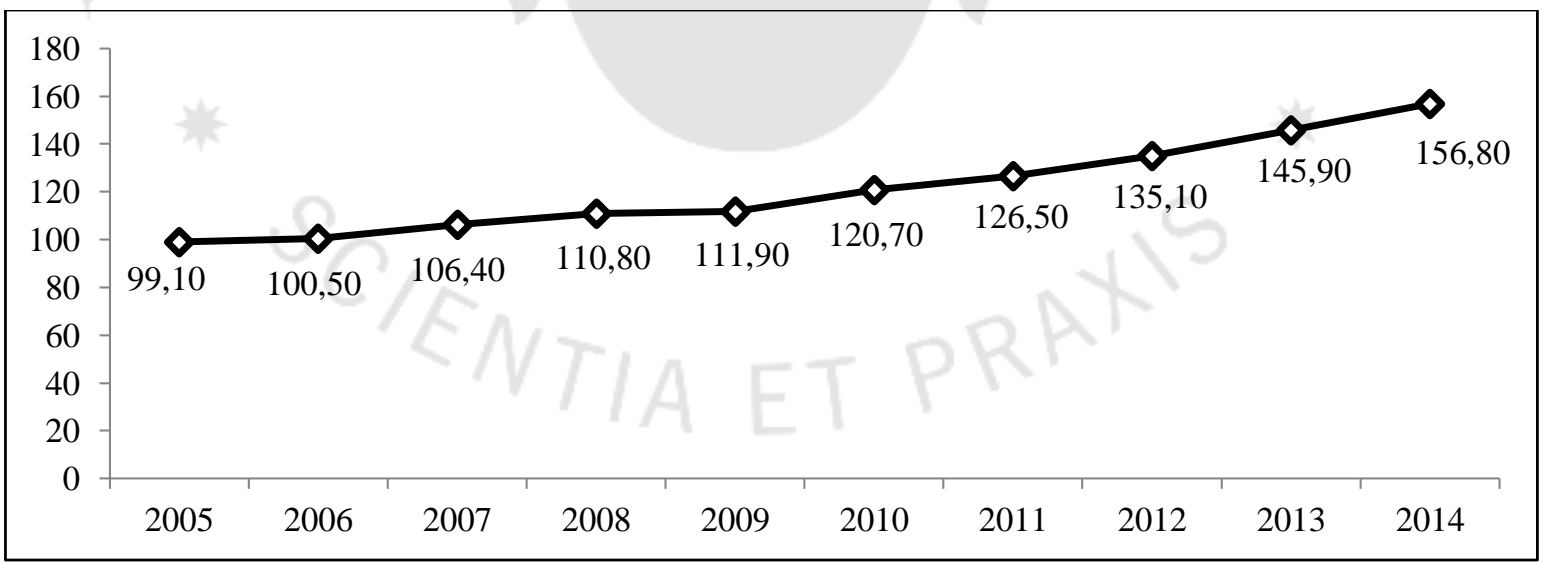

Fuente: Euromonitor International, (2015).

\footnotetext{
${ }^{14}$ Ipsos Perú considera consumo habitual de un producto si este es consumido al menos una vez al mes.
} 


\subsubsection{Precios actuales}

Se debe establecer los precios para cada tipo de producto comparándolos con productos de similares características mediante un estudio de campo en supermercados. En base a dicho estudio se establecieron precios al consumidor final (incluyendo IGV ${ }^{15}$ ) de S/. 3,50 y S/. 5,99 soles, para los productos de planta entera y de sólo flores de manzanilla común, respectivamente. Considerando un margen mínimo de ganancia en supermercados de 37\% (Anexo 3), los precios de fábrica de planta entera y sólo flores serán de S/. 2,21 y S/. 3,78 soles, respectivamente.

La Tabla 2.24 muestra los precios de marcas de infusiones filtrantes que cuentan con productos que tienen como ingrediente a la manzanilla común sin mezclarse con otro producto.

Tabla 2. 24

Precios de infusiones filtrantes a base de manzanilla común el 2015 en Perú

\begin{tabular}{|c|c|c|c|c|c|l|}
\hline Marca & Línea & Filtrante & $\begin{array}{c}\text { Peso Neto } \\
\text { Filtrante }(\mathbf{g})\end{array}$ & $\begin{array}{c}\text { Filtrantes } \\
\text { /Caja }\end{array}$ & $\begin{array}{c}\text { Precio*(S/.) } \\
/ \text { Caja }\end{array}$ & Parte usada \\
\hline Herbi & Clásica & Estándar & 1,00 & $25,00 / 100,00$ & $1,90 / 6,19$ & Planta entera \\
\hline McCollin's & Clásica & Estándar & 1,00 & $25,00 / 100,00$ & $2,45 / 8,20$ & Planta entera \\
\hline Lipton & Clásica & Estándar & 1,00 & 20,00 & 3,59 & Planta entera \\
\hline Hornimans & Clásica & Estándar & 1,00 & $25,00 / 100,00$ & $2,30 / 7,70$ & Planta entera \\
\hline Wawasana & Aromática & Estándar & 1,00 & 20,00 & 3,20 & Planta entera \\
\hline Wong & - & Estándar & 1,00 & 25,00 & 2,35 & Planta entera \\
\hline Metro & - & Estándar & 1,00 & 25,00 & 2,24 & Planta entera \\
\hline Tottus & - & Estándar & 1,00 & $25,00 / 100,00$ & $1,95 / 6,80$ & Planta entera \\
\hline Aro & - & Estándar & 1,00 & 100,00 & 4,50 & Planta entera \\
\hline Del valle & Aromática & Estándar & 1,00 & $25,00 / 100,00$ & $2,00 / 8,00$ & Planta entera \\
\hline Del valle & Gold & Estándar & 1,00 & $25,00 / 100,00$ & $3,00 / 9,40$ & Planta entera \\
\hline Ecoinca & Clásica & Estándar & 1,20 & 15,00 & 8,00 & Planta entera \\
\hline Alma & Ecológica & Piramidal & 1,40 & 15,00 & 22,99 & Flores \\
\hline Terrafertil & Té orgánico & Estándar & 1,00 & 20,00 & 5,99 & Planta entera \\
\hline Saint Gottard & Aromática & Estándar & 1,00 & 15,00 & 5,99 & Flores \\
\hline Bells & - & Estándar & 1,00 & 20,00 & 1,49 & Planta entera \\
\hline A1 & - & Estándar & 1,00 & 25,00 & 2,45 & Planta entera \\
\hline Té mar & - & Estándar & 1,00 & 25,00 & 2,79 & Planta entera \\
\hline Huerto del Edén & Aromática & Estándar & 1,00 & 25,00 & 2,30 & Planta entera \\
\hline
\end{tabular}

Nota: *Los precios incluyen IGV.

Elaboración propia

\footnotetext{
${ }^{15}$ Impuesto general a las ventas, se incluye en los precios de los bienes que se adquiere. Su tasa es del $18 \%$.
} 
Finalmente, según Keat y Young (2004) los productos de primera necesidad presentan una demanda inelástica con respecto al precio (p. 120). Esto significa que si aumentan su precio no habrá cambios significativos en la cantidad demandada.

\subsection{Análisis de disponibilidad de los insumos principales}

\subsubsection{Características principales de la materia prima}

\section{Generalidades}

Con el nombre de la manzanilla se designan a varias especies, todas pertenecientes a la familia de las asteráceas o también llamadas compuestas. Resaltando la manzanilla común o alemana (Chamomilla recutita (L.) Rauschert) y la manzanilla romana (Anthemis nobilis, L.).

De acuerdo con Franke y Schilcher (2005), en la mayoría de los libros Matricaria chamomilla L. es considerado como el nombre correcto de la manzanilla común. Sin embargo, los mismos autores señalan que según el Código Internacional de Nomenclatura Botánica el nombre correcto de esta especie es Chamomilla recutita (L.) Rauschert (p. 29).

Según Páez (1943) la planta surge de manera silvestre en regiones de clima templado de Europa, el norte de Asia, Medio Oriente y en Asia Menor. Al Perú fue traído por los conquistadores españoles. Antes de mitad del siglo XVII ya existía referencia a esta planta en el Perú (p. 3).

\section{Descripción}

La Figura 2.6 muestra las partes de la manzanilla común. Las cabezuelas contienen flores de dos tipos, ambas insertas en el receptáculo de forma cónica que en su parte inferior está rodeado por brácteas verdosas. Las flores del primer tipo son tubulares, insertas sobre el receptáculo y son de color amarillo. Las del segundo tipo son liguladas, de mayor tamaño, insertas radialmente al final del receptáculo y son de color blanco. 
Figura 2. 6

Descripción de la manzanilla común y sus partes

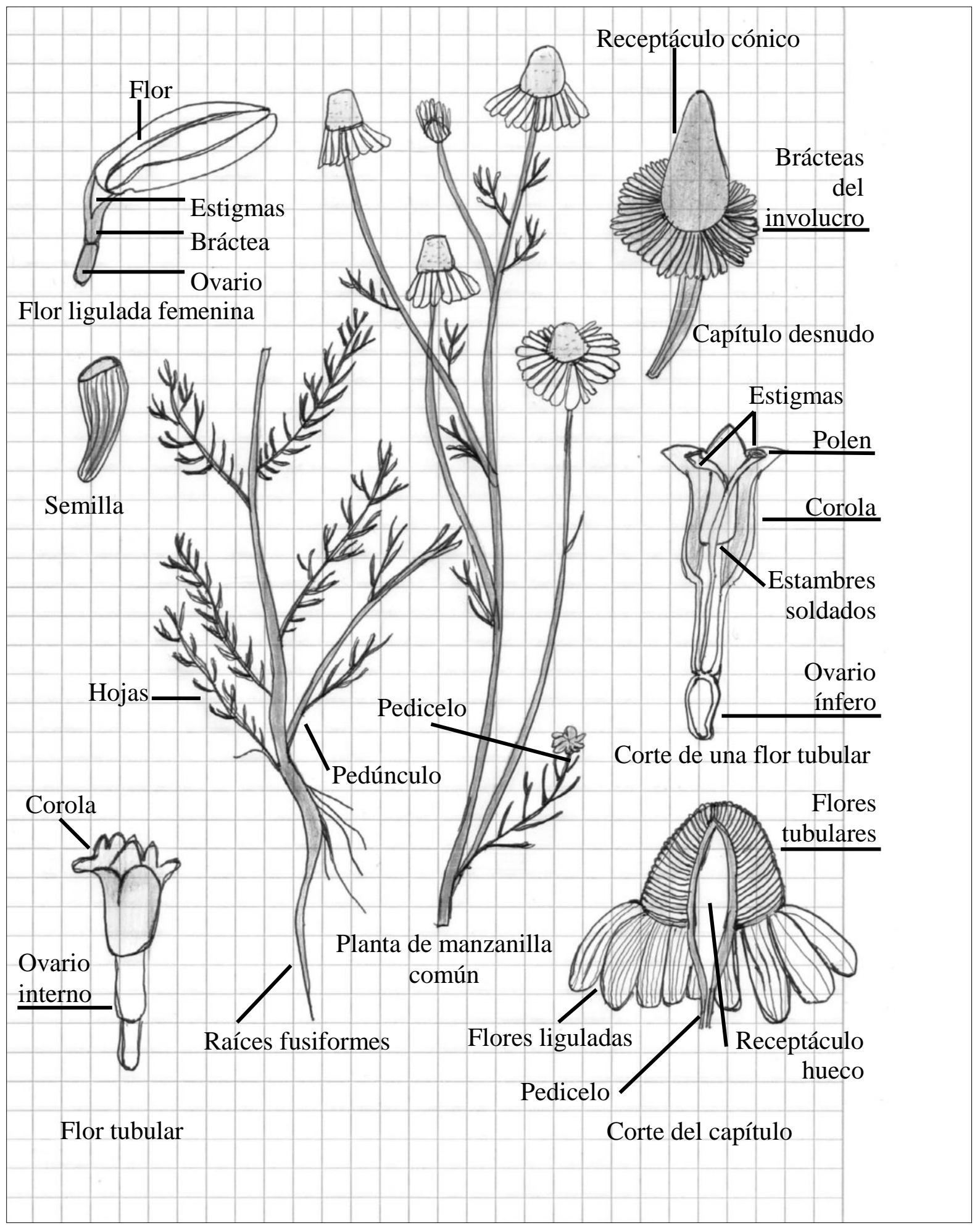

Elaboración propia 
Asimismo, en base a una visita de dos días a fines de enero del 2015 a la ciudad de Tarma se pudo establecer que en esta provincia la planta entera de manzanilla común cortada al ras llega a los 0,60 $\mathrm{cm}$ de altura en promedio. La misma tiene una densidad aproximada de $64 \mathrm{~kg} / \mathrm{m}^{3}$ (Anexo 4).

\section{Clima y suelo}

La manzanilla común se puede adecuar a climas fríos, templados o medianamente cálidos. Sin embargo, su mejor desarrollo se observa en climas templados y cálidos según Amadeo y Campodónico (como se citó en Silva, 1985, p. 12). En ese sentido Páez (1943) corrobora:

En el país sea zona muy aparente para su cultivo, la cabecera de la sierra peruana y los valles abrigados de la misma, por su clima seco y sobre todo por su alta luminosidad, factor que siempre motiva en la manzanilla común alto rendimiento en flores grandes, pesadas y de aroma intenso (p. 5).

Asimismo, de acuerdo con el Cender (2013) la altitud óptima para sembrar es a partir de los 3.000 m.s.n.m. Respecto al suelo, Franke y Schilcher (2005) sostienen que esta planta prefiere los suelos arenosos a los arcillosos además de no tener gran demanda de agua ni de nutrientes (p. 48).

\section{Semillas}

De acuerdo con Páez (1943) la manzanilla común que es especie anual, a diferencia de la manzanilla romana, se propaga solamente por semillas. Estas son de tamaño muy pequeño y se sacan de las cabezuelas una vez que estas hayan madurado (p. 6).

\section{Siembra mediante método directo}

Este método de cultivo es el más utilizado en el Perú. Consiste básicamente en echar las semillas directamente en los terrenos de siembra, es decir no usa almácigos. Esto se logra esparciendo las semillas en el área a sembrar. Existen desde vehículos agrícolas hasta equipos manuales para lograr un racionamiento uniforme en todo el área a sembrar, sin embargo en el Perú, por lo general, se hace manualmente, por el método llamado boleo, que depende del cálculo y destreza de la persona que lo realiza. 
Se debe tener en cuenta que si la cantidad de semillas por área es muy densa se obstaculiza el desarrollo adecuado de la planta. Según el Cender (2012) se debe usar entre 4 y $5 \mathrm{~kg}$ de semillas por hectárea. Se puede sembrar usando surcos o prescindiendo de ellos, siempre y cuando se respete la proporción mencionada. Se debe tener en cuenta que las semillas se encuentran en las flores tubulares amarillas de la planta, y siempre, sea por el viento o las lluvias, se desprenden al terreno. Motivo por el cual después de la rotación del campo y ya con la siembra de otro producto vuelven a retoñar algunas plantas de manzanilla común.

\section{Cosecha}

De acuerdo con Páez (1943) el principio de la floración de la manzanilla común para siembra indirecta es en promedio 80 días después del trasplante, continuando entre 110 a 120 días más (p. 9). Para la siembra directa, a los 120 días en promedio se puede cosechar según el Cender (2012). Se investigó, además, en los mismos agricultores de Tarma que las plantas pueden estar hasta 30 días sin cosechar, luego de esto empiezan a caer las semillas de los capítulos y la planta entera se seca.

La apertura de las flores es continua. Todos los días una "cantidad variable de flores se abren en el campo" (Páez, 1943, p. 9). Así, para obtener una mejor calidad, el recojo debe hacerse apenas la cabezuela haya terminado de abrir y muestre las flores liguladas, de color blanco, "perfectamente horizontales" (Franke y Schilcher, 2005, p. 160). Si se demora más tiempo se inicia el desarrollo de los frutos o polinización, disminuyendo notablemente el aroma de las cabezuelas. La Figura 2.7 muestra la posición de las flores liguladas como indicativo de cosecha.

Figura 2. 7

Posición de las flores liguladas (blancas) como indicativo para su cosecha

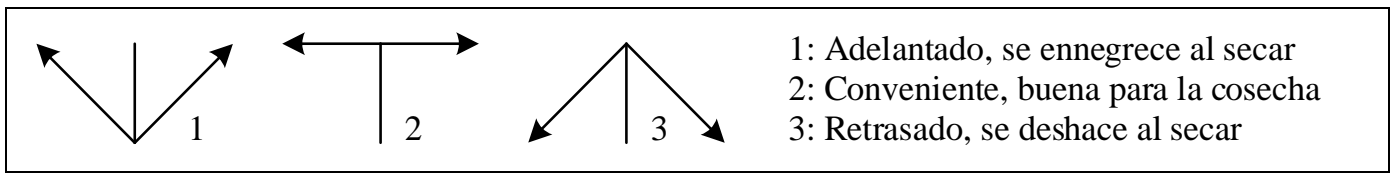

Fuente: Chamomile Industrial Profiles, (2005). 
Finalmente, se prefiere que la cosecha de la manzanilla común no coincida con precipitaciones pluviales ya que no pueden ser oreadas al sol. La Figura 2.8 muestra el porcentaje de producción promedio mensual en Tarma provincia el 2007.

Figura 2. 8

Producción promedio mensual de manzanilla común en Tarma provincia el 2007 (\%)

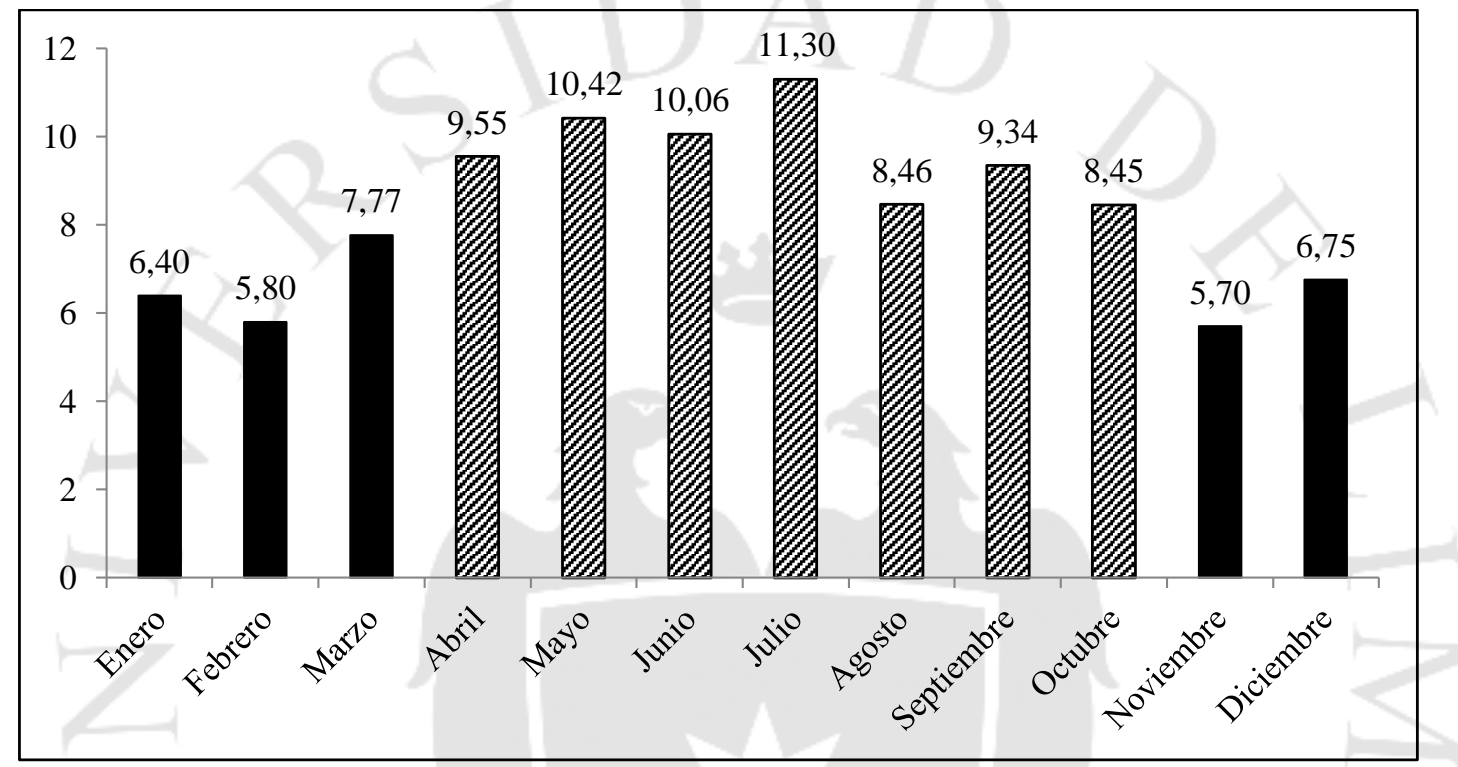

Fuente: Agencia Agraria de Tarma, (2008).

Como se puede apreciar, los meses cuya producción de manzanilla común es mayor al 8\%, coinciden con los periodos donde las precipitaciones pluviales disminuyen. Por tal motivo su estacionalidad es entre abril y noviembre. Se precisa que la producción se basó en el informe de la Agencia Agraria de Tarma (2008), adjunto en el Anexo 1, y no teniendo por que cambiar sustancialmente a la fecha se consideró válido.

\section{Rendimientos}

Según Páez (1943), estos son muy variables de acuerdo a diversos factores, especialmente, las condiciones de clima y suelo de cultivo; a la madurez de la cosecha, a la humedad de las plantas cosechadas, a que si el corte es al ras o mitad de la planta; y en menor medida a la manipulación después de la cosecha y la tecnología usada en esta operación (p. 12). 
Cuantitativamente, existen diferencias en lo que respecta al rendimiento de cosecha de planta entera en verde: Según la Agencia Agraria de Tarma (2008), en promedio, se obtiene $40.000 \mathrm{~kg} / \mathrm{ha}$ al año en dicha provincia. En cuanto al rendimiento de secado de planta entera, según Franke y Schilcher (2005), la relación entre planta entera seca y planta entera fresca es alrededor de 1:5 (p. 146). Respecto a las flores, Páez (1943) establece que la relación de secado es de 1:5,555 (p. 12).

Por otro lado, según Silva (1985) la manzanilla común de Tarma es reconocida por sus grandes y coloridas cabezuelas a comparación de las de otros lugares en el Perú (p. 113114). El mismo autor sostiene que, de la planta entera, el $30 \%$ son cabezuelas y el $70 \%$ son partes verdes blandas aproximadamente (p. 114).

\subsubsection{Disponibilidad de la materia prima}

No existe información pública de alguna entidad gubernamental respecto a las hectáreas sembradas, la producción o rendimiento de la manzanilla común en Perú. Sin embargo, sí hay algunos datos en las agencias agrarias en provincias, empresas privadas, $\mathrm{u}$ otros relacionados a las infusiones filtrantes.

Según un estudio de inversión productiva de Sierra Exportadora (2014), los distritos de Incahuasi y Cañari, en la sierra de Lambayeque, ya producen manzanilla común para exportar, también se menciona que cuenta con un proyecto aprobado para su ejecución con el fin de fortalecer y aumentar la exportación.

Asimismo, un estudio de campo de enero del 2015 en el Gran Mercado Mayorista de Lima (EMMSA) reveló que las ciudades de donde proceden las mayores cantidades de manzanilla común en verde son Tarma y Andahuaylas. Con supremacía de la primera, debido a que tienen mejor tamaño y aroma.

En tal sentido, se estimó la producción actual en las regiones de Junín, Apurímac y Lambayeque, cuyos datos se muestran en la Tabla 2.25. Es más, se recabó información en la misma Agencia Agraria de Tarma (2008) a fines de enero del año 2015. Se decidió viajar a dicha provincia ya que la bibliografía revisada y los estudios de campo indicaban que la planta en estudio de dicha provincia posee los mejores atributos. 
Tabla 2. 25

Producción de manzanilla común en el Perú según zonas de mayor producción al 2014 (toneladas)

\begin{tabular}{|c|c|c|c|c|}
\hline Provincia & Región & $\begin{array}{c}\text { Superficie cosechada } \\
\text { (hectáreas) }\end{array}$ & $\begin{array}{c}\text { Rendimiento } \\
\text { (toneladas /hectáreas) }\end{array}$ & $\begin{array}{c}\text { Producción Total } \\
\text { (toneladas) }\end{array}$ \\
\hline Tarma & Junín & $97,84^{*}$ & $39,84^{*}$ & $3.897,95$ \\
\hline Andahuaylas & Apurímac & 60,00 & 30,00 & $1.800,00$ \\
\hline Ferreñafe & Lambayeque & 80,00 & 30,00 & $2.400,00$ \\
\hline
\end{tabular}

Nota: "Para el caso de Tarma son promedios desde los años 2001 al 2007 en base al Anexo 1.

Fuentes: Agencia Agraria de Tarma, (2008) y Sierra Exportadora, (2014).

En la provincia de Tarma se pudo recabar información sobre la oferta y demanda de las cosechas. De todo lo producido el $55,00 \%$ se destina a dicha provincia, de este porcentaje el 93,90\% lo demandan Acobamba y Palcamayo. Finalmente, el 5,17\% en esta sciudades está disponible en sus mercados mayoristas. La Tabla 2.26 muestra la disponibilidad de materia prima, asumiendo los mismos rendimientos y extensiones de siembra.

Tabla 2.26

Disponibilidad de manzanilla común en Tarma del 2016 al 2025 (toneladas)

\begin{tabular}{|c|c|c|c|c|}
\hline Año & $\begin{array}{c}\text { Rendimiento } \\
\text { (toneladas/ hectárea) }\end{array}$ & $\begin{array}{c}\text { Siembra manzanilla } \\
\text { (hectáreas) }\end{array}$ & $\begin{array}{c}\text { Porcentaje de } \\
\text { disponibilidad (\%) }\end{array}$ & $\begin{array}{c}\text { Materia prima } \\
\text { disponible (toneladas) }\end{array}$ \\
\hline $2016-2025$ & 39,84 & 97,84 & 2,67 & 104,08 \\
\hline
\end{tabular}

Elaboración propia

\subsubsection{Costos de la materia prima}

En la visita a la provincia de Tarma se pudo conocer el valor de venta de la manzanilla común en dicha zona. En primer lugar se indagó con los mismos agricultores que siembran dicha planta, ya que el presente estudio prevé adquirirla en el mismo lugar de la siembra. El valor de venta a fines de enero del 2015 fue de $0,70 \mathrm{~S} / . / \mathrm{kg}$ de manzanilla común en verde.

En segundo lugar se indagó en los mercados mayoristas de la ciudad de Tarma. El valor en estos establecimientos varía entre 1,30 y 1,50 S/./kg de manzanilla común entera en verde. También se pudo encontrar atados de flores, cuyo valor de venta es de 1,00 S/./kg.

Como dato adicional se debe indicar que, Tarma es un valle estrecho, por lo que los sembríos se hacen en pequeñas parcelas denominadas tongos ${ }^{16}$. Un tongo tiene la treceava parte de una hectárea, es decir 769,23 $\mathrm{m}^{2}$.

\footnotetext{
${ }^{16}$ Es una unidad de área. Por ejemplo el feddan en Egipto equivale a $4.200,00 \mathrm{~m}^{2}$.
} 


\section{CAPÍTULO III: LOCALIZACIÓN DE PLANTA}

\subsection{Identificación y análisis detallado de los factores de localización}

\section{Disponibilidad de materia prima}

Se refiere a la mayor cantidad de manzanilla común sembrada disponible, teniendo en cuenta su rendimiento. Este factor está muy ligado a la ubicación de la instalación industrial ya que el procesamiento de la materia prima después de su cosecha debe iniciarse lo más antes posible.

\section{Cercanía al mercado meta}

Al ser Lima Metropolitana el mercado meta escogido para el presente proyecto, sería favorable un traslado rápido de los productos terminados desde la instalación industrial hasta dicho mercado.

\section{Costo de terreno}

Para la ubicación de la instalación industrial se deberá seleccionar un terreno adecuado para tal fin. Por tanto, se evaluó el valor por metro cuadrado promedio en cada región, tomando como referencia las zonas donde ya existen plantas industriales o similares.

\section{Costo de mano de obra}

Para la producción de bolsas filtrantes a base de manzanilla común no se requiere de mano de obra especializada. Una persona común, mediante capacitaciones, puede encargarse de cualquier operación del proceso. Por consiguiente, se deberá evaluar por el nivel de salario que se percibe en cada región.

\section{Costo de energía}

La energía es de suma importancia para el funcionamiento de la maquinaria y de otros equipos, tanto en la parte operativa como en la administrativa. Se evalúan la energía eléctrica 
y la térmica, ya que se prevé usar un deshidratador a GLP. El costo de energía varía según cada región para ambos tipos de energía.

\section{Costo de transporte terrestre}

La comunicación terrestre por carreteras se debe tener en cuenta tanto para atender el mercado meta (Lima Metropolitana) como para el suministro de materiales a la instalación industrial. Este factor evaluó el valor del flete.

\section{Costo de agua potable}

El agua es un insumo importante para la operación unitaria de lavado y para otros servicios básicos. Por tanto, el costo del agua es un factor a evaluar ya que no es igual para todo el Perú.

\section{Vías de acceso}

Se refieren a las carreteras, pistas, rieles u otros medios de transporte que hagan posible la comunicación entre el mercado meta y la instalación industrial. Se considera el estado, restricciones y disponibilidad de las mismas. Este factor es más representativo a nivel de micro localización.

\section{Disponibilidad de GLP}

Se prevé usar un tanque estacionario para asegurar la disponibilidad de este combustible líquido. Este factor también se evalúa a nivel de micro localización debido a que el suministro llega a todas las regiones que se evalúan, mas no a todas las provincias de las mismas.

\subsection{Identificación y descripción de las alternativas de localización}

Para las alternativas de localización se evaluó, principalmente, a las regiones con disponibilidad de la materia prima y aquella región más cercana a Lima, que es el mercado meta, es decir a la región del mismo nombre. En tal sentido, las regiones evaluadas fueron: Lima, Lambayeque, Apurímac y Junín. 


\section{Disponibilidad de materia prima}

La Tabla 3.1 muestra la producción de manzanilla común en las regiones a evaluar, al año 2015. Se especifica la producción de cada una. Asimismo, la Tabla 3.2 muestra el rango de valores de producción y su puntaje según la escala.

Tabla 3. 1

Disponibilidad de manzanilla común en verde al 2015 en regiones productoras (toneladas)

\begin{tabular}{|c|c|c|}
\hline Región & Producción 2015 (toneladas) & Escala \\
\hline Lima & 779,59 & 2,00 \\
\hline Lambayeque & $2.400,00$ & 6,00 \\
\hline Apurímac & $1.800,00$ & 6,00 \\
\hline Junín & $3.897,95$ & 10,00 \\
\hline
\end{tabular}

Fuente: Agencia Agraria de Tarma, (2008), Sierra Exportadora, (2014) y EMMSA, (2015).

Tabla 3.2

Escala de calificación de disponibilidad de materia prima

\begin{tabular}{|c|c|c|}
\hline Calificación & Rango & Escala \\
\hline Excelente & {$[3.401-$ más $]$} & 10,00 \\
\hline Muy bueno & {$[2.551-3.400]$} & 8,00 \\
\hline Bueno & {$[1.701-2.500]$} & 6,00 \\
\hline Regular & {$[851-1.700]$} & 4,00 \\
\hline Malo & {$[0-850]$} & 2,00 \\
\hline
\end{tabular}

Elaboración propia

\section{Cercanía al mercado meta}

La Tabla 3.3 muestra las distancias entre los lugares con disponibilidad de materia prima y Lima Metropolitana (mercado meta). Asimismo, la misma tabla muestra el tiempo de transporte por carretera en dichas rutas. Se evaluó la distancia que se debe recorrer en cada una de las rutas. La Tabla 3.4 muestra su escala de calificación.

Tabla 3.3

Distancia y tiempo hacia Lima Metropolitana desde regiones a evaluar (kilómetros y horas)

\begin{tabular}{|c|c|c|c|c|}
\hline Región & $\begin{array}{c}\text { Distancia } \\
(\mathbf{k m})\end{array}$ & $\begin{array}{l}\text { Tiempo } \\
\text { (horas) }\end{array}$ & Ruta & Escala \\
\hline Lima (Huarochirí) & 100,00 & 3,90 & Carretera central-Cocachacra-Huarochiri & 10,00 \\
\hline Lambayeque (Ferreñafe) & 817,00 & 12,62 & Panamericana norte-Chiclayo-Ferreñafe & 2,00 \\
\hline Apurímac (Andahuaylas) & 820,00 & 14,32 & Panamericana sur-Pisco-Andahuaylas & 2,00 \\
\hline Junín (Tarma) & 253,00 & 6,60 & Carretera central-Oroya-Tarma & 6,00 \\
\hline
\end{tabular}

Fuente: Google Maps, (2015). 
Tabla 3.4

Escala de calificación de cercanía al mercado meta

\begin{tabular}{|c|c|c|}
\hline Calificación & Rango & Escala \\
\hline Excelente & {$[0-100]$} & 10,00 \\
\hline Muy bueno & {$[101-200]$} & 8,00 \\
\hline Bueno & {$[201-300]$} & 6,00 \\
\hline Regular & {$[301-400]$} & 4,00 \\
\hline Malo & {$[401-$ más $]$} & 2,00 \\
\hline
\end{tabular}

Elaboración propia

\section{Costo de terreno}

En el Perú a la fecha existen como máximo cinco parques industriales, todos ellos en Lima. Estos se definen como lugares dotados de infraestructura, equipamiento y servicios comunes para la manufactura o logística de bienes. Actualmente, existen mayor cantidad de zonas industriales que operan según los requerimientos exigidos por las municipalidades. La Tabla 3.5 muestra el costo medio de terreno en zonas industriales de cada región. La Tabla 3.6 muestra su escala de calificación.

Tabla 3.5

Costo promedio de terrenos en zonas industriales en regiones a evaluar al 2015 (soles)

\begin{tabular}{|c|c|c|c|c|}
\hline \multirow{2}{*}{ Región } & Sector & $\begin{array}{c}\text { Costo } \\
\left(\mathbf{S} / . / \mathbf{~ m}^{\mathbf{2}}\right)\end{array}$ & $\begin{array}{c}\text { Costo máximo } \\
\left(\mathbf{S} / . / \mathbf{m}^{\mathbf{2}}\right)\end{array}$ & Escala \\
\hline \multirow{3}{*}{ Lima } & Lima Este & $2.800,00$ & \\
& Lima Norte & $1.050,00$ & \multirow{2}{*}{$2.800,00$} & 2,00 \\
\cline { 2 - 3 } & Lima Centro & $1.575,00$ & \\
\cline { 2 - 3 } & Callao (Lima Oeste) & $1.050,00$ & & 6,00 \\
\cline { 2 - 3 } & Lima Sur & 630,00 & 650,00 & 8,00 \\
\hline Lambayeque & Zona industrial & 650,00 & 390,00 & 4,00 \\
\hline Apurímac & Zona industrial & 390,00 & 950,00 & \\
\hline Junín & Zona industrial & 950,00 & & \\
\hline
\end{tabular}

Fuente: CBRE Group Inc., (2015) y Colliers International Peru, (2015).

Tabla 3.6

Escala de calificación de costo de terreno

\begin{tabular}{|c|c|c|}
\hline Calificación & Rango & Escala \\
\hline Excelente & {$[0-300]$} & 10,00 \\
\hline Muy bueno & {$[301-600]$} & 8,00 \\
\hline Bueno & {$[601-900]$} & 6,00 \\
\hline Regular & {$[901-1.200]$} & 4,00 \\
\hline Malo & {$[1.201-$ más $]$} & 2,00 \\
\hline
\end{tabular}

Elaboración propia 


\section{Costo de mano de obra}

Se evaluó el costo laboral promedio en cada una de las regiones a evaluar. La Tabla 3.7 muestra los niveles. La Tabla 3.8 muestra su escala de calificación.

Tabla 3.7

Nivel de remuneración a pagar en las regiones a evaluar al 2015 (soles)

\begin{tabular}{|c|c|c|}
\hline Región & Nivel de ingresos (S/.) & Escala \\
\hline Lima & $1.526,00$ & 6,00 \\
\hline Lambayeque & 836,00 & 10,00 \\
\hline Apurímac & 779,00 & 10,00 \\
\hline Junín & $1.005,00$ & 8,00 \\
\hline
\end{tabular}

Fuente: Instituto Peruano de Economía, (2015) y Ministerio de Trabajo, (2015).

Tabla 3.8

Escala de calificación de costo de mano de obra

\begin{tabular}{|c|c|c|}
\hline Calificación & Rango & Escala \\
\hline Excelente & {$[0-850]$} & 10,00 \\
\hline Muy bueno & {$[851-1.500]$} & 8,00 \\
\hline Bueno & {$[1.501-2.000]$} & 6,00 \\
\hline Regular & {$[2.001-2.500]$} & 4,00 \\
\hline Malo & {$[2.501-$ más $]$} & 2,00 \\
\hline
\end{tabular}

Elaboración propia

\section{Costo de energía}

La Tabla 3.9 muestra el costo mensual de energía eléctrica y de energía térmica (GLP) para actividades manufactureras en las cuatro regiones a evaluar teniendo en cuenta que el máximo consumo de energía eléctrica anual para la producción es de 22.763,59kWh y 428 balones de GLP. La Tabla 3.10 muestra su escala.

Tabla 3.9

Costo medio de energía eléctrica para manufacturas en regiones a evaluar al 2015 (soles)

\begin{tabular}{|c|c|c|c|c|c|c|c|c|c|}
\hline & \multicolumn{4}{|c|}{ Energía eléctrica } & \multicolumn{3}{c|}{ Energía térmica (GLP) } & Total & \\
\hline Región & $\begin{array}{c}\text { Cent.US\$ } \\
\text { /kWh }\end{array}$ & $\begin{array}{c}\text { S/. } \\
\text { /kWh }\end{array}$ & $\begin{array}{c}\mathbf{k W . h} \\
\text { /mes }\end{array}$ & $\begin{array}{c}\text { S/. } \\
\text { /mes }\end{array}$ & $\begin{array}{c}\text { S/. } \\
\text { /litro }\end{array}$ & $\begin{array}{c}\text { Litros } \\
\text { /mes }\end{array}$ & $\begin{array}{c}\text { S/. } \\
\text { /mes }\end{array}$ & S/./mes & Escala \\
\hline Lima & 7,53 & 0,25 & $1.896,97$ & 471,38 & 1,48 & 661,84 & 979,53 & $1.450,90$ & 10,00 \\
\hline Lambayeque & 10,01 & 0,33 & $1.896,97$ & 626,62 & 1,34 & 661,84 & 886,87 & $1.513,49$ & 10,00 \\
\hline Apurímac & 23,76 & 0,78 & $1.896,97$ & $1.487,37$ & 2,29 & 661,84 & $1.515,62$ & $3.002,99$ & 4,00 \\
\hline Junín & 7,15 & 0,24 & $1.896,97$ & 447,59 & 1,53 & 661,84 & $1.012,62$ & $1.460,21$ & 10,00 \\
\hline
\end{tabular}

Nota: *Se usó un tipo de cambio de S/. 3,30 a diciembre del 2015 y 1 balón equivale a 18,75 litros de GLP. Fuente: Ministerio de Energía y Minas de Perú-MINEM, (2015) y Organismo Supervisor de la Inversión en Energía y Minería-OSINERGMIN, (2015). 
Tabla 3. 10

Escala de calificación de costo de energía

\begin{tabular}{|c|c|c|}
\hline Calificación & Rango & Escala \\
\hline Excelente & {$[0-1.550]$} & 10,00 \\
\hline Muy bueno & {$[1.551-2.050]$} & 8,00 \\
\hline Bueno & {$[2.051-2.550]$} & 6,00 \\
\hline Regular & {$[2.551-3.050]$} & 4,00 \\
\hline Malo & {$[3.051-$ más $]$} & 2,00 \\
\hline
\end{tabular}

Elaboración propia

\section{Costo de transporte terrestre}

El flete de transporte, vía terrestre, por carretera entre las posibles ubicaciones y Lima Metropolitana es mostrado en la Tabla 3.11, asimismo, la Tabla 3.12 muestra su escala de calificación.

Tabla 3. 11

Costo de flete entre Lima Metropolitana y regiones a evaluar (soles)

\begin{tabular}{|c|c|c|c|}
\hline Región & Destino & S/. (incluido IGV) & Escala \\
\hline Lima (Huarochirí) & & $1.100,00$ & 8,00 \\
\hline Lambayeque (Ferreñafe) & \multirow{3}{*}{ Lima } & 2.800 .00 & 4,00 \\
\cline { 1 - 1 } Apurímac (Andahuaylas) & Metropolitana & $3.500,00$ & 2,00 \\
\cline { 4 - 4 } Junín (Tarma) & & $2.100,00$ & 6,00 \\
\hline
\end{tabular}

Fuente: Transhuamali EIRL, (2015).

Tabla 3. 12

Escala de calificación de costo de transporte terrestre

\begin{tabular}{|c|c|c|}
\hline Calificación & Rango & Escala \\
\hline Excelente & {$[0-700]$} & 10,00 \\
\hline Muy bueno & {$[701-1.400]$} & 8,00 \\
\hline Bueno & {$[1.401-2.100]$} & 6,00 \\
\hline Regular & {$[2.101-2.800]$} & 4,00 \\
\hline Malo & {$[2.801-$ más $]$} & 2,00 \\
\hline
\end{tabular}

Elaboración propia

\section{Costo de agua potable}

A continuación la Tabla 3.13 muestra las Empresas Prestadoras del Servicio de Agua Potable y Saneamiento (EPS) en las posibles regiones donde se ubicaría la planta. Asimismo, se muestra la facturación de agua potable y alcantarillado del año 2015. Para cuantificar mejor la evaluación se asumió un consumo de un metro cúbico al mes, para instalación clase no 
residencial, categoría comercial y se evaluó el costo medio según las EPS en cada región. La Tabla 3.14 muestra su escala de calificación.

Tabla 3.13

Costo medio de agua potable al 2015 en regiones a evaluar (soles)

\begin{tabular}{|c|c|c|c|c|c|c|}
\hline Región & Nombre de la EPS ${ }^{17}$ & $\begin{array}{l}\text { Tarifa* } \\
\left(\mathbf{S} / . / \mathbf{m}^{3}\right)\end{array}$ & $\begin{array}{l}\text { Cargo fijo } \\
\text { (S/./mes) }\end{array}$ & $\begin{array}{c}\text { Tarifas } \\
\text { consumo: } 1 \\
\text { m }^{3} / \mathbf{m e s}\end{array}$ & $\begin{array}{c}\text { Tarifa } \\
\text { máxima } \\
\text { S/. }\end{array}$ & Escala \\
\hline \multirow{5}{*}{ Lima } & SEMAPA Barranca S.A. & 2,794 & 1,500 & 4,29 & \multirow{5}{*}{11,94} & \multirow{5}{*}{2,00} \\
\hline & EMAPA Huacho S.A. & 2,831 & 2,650 & 5,48 & & \\
\hline & EMAPA Huaral S.A. & 2,160 & 1,700 & 3,86 & & \\
\hline & EMAPA Cañete S.A. & 0,991 & 1,450 & 2,44 & & \\
\hline & Sedapal S.A. & 7,051 & 4,886 & 11,94 & & \\
\hline Lambayeque & Epsel S.A. & 2,828 & 1,370 & 4,20 & 4,20 & 4,00 \\
\hline \multirow{2}{*}{ Apurímac } & EMUSAP Abancay S.A.C. & 1,439 & 1,480 & 2,92 & \multirow{2}{*}{2,92} & \multirow{2}{*}{6,00} \\
\hline & EMSAP Chanka S.A. & 1,301 & 1,290 & 2,59 & & \\
\hline \multirow{5}{*}{ Junín } & Sedam Huancayo S.A. & 1,153 & 1,400 & 2,55 & \multirow{5}{*}{3,01} & \multirow{5}{*}{6,00} \\
\hline & EPS Mantaro S.A. & 0,883 & 1,376 & 2,26 & & \\
\hline & EPS Sierra Central S.A. & 1,413 & 1,600 & 3,01 & & \\
\hline & EPS Selva Central S.A. & 0,602 & 1,400 & 2,00 & & \\
\hline & EMSAPA Yauli S.R.LTDA & 1,381 & 1,500 & 2,88 & & \\
\hline
\end{tabular}

Nota: "La tarifa incluye la facturación por los servicios de agua potable y de alcantarillado Fuente: Superintendencia Nacional de Servicios de Saneamiento-SUNASS, (2015).

Tabla 3.14

Escala de calificación de costo de agua potable

\begin{tabular}{|c|c|c|}
\hline Calificación & Rango & Escala \\
\hline Excelente & {$[0-1,20]$} & 10,00 \\
\hline Muy bueno & {$[1,21-2,40]$} & 8,00 \\
\hline Bueno & {$[2,41-3,60]$} & 6,00 \\
\hline Regular & {$[3,61-4,80]$} & 4,00 \\
\hline Malo & {$[4,81-$ más $]$} & 2,00 \\
\hline
\end{tabular}

Elaboración propia

\subsection{Evaluación y selección de localización}

\subsubsection{Evaluación y selección de la macro localización}

Para facilidad de la evaluación de la macro localización de la planta se abrevió el nombre de los factores de localización según la Tabla 3.15.

\footnotetext{
${ }^{17}$ Las Empresas Prestadoras de Servicio de Saneamiento son 50 en todo el Perú, brindan el servicio de agua potable y alcantarillado.
} 
Tabla 3. 15

Abreviación de los factores de localización para evaluación de macro localización

\begin{tabular}{|c|c|}
\hline Factor & Nominación \\
\hline Disponibilidad de materia prima & DMP \\
\hline Cercanía al mercado meta & CMM \\
\hline Costo de terreno & CT \\
\hline Costo de mano de obra & CMO \\
\hline Costo de energía & CE \\
\hline Costo de transporte terrestre & CTT \\
\hline Costo de agua potable & CAP \\
\hline
\end{tabular}

Asimismo, la Tabla 3.16 determina la importancia de cada uno de los factores de localización en la selección de la región.

Tabla 3.16

Ponderado de factores de evaluación para macro localización

\begin{tabular}{|c|c|c|c|c|c|c|c|c|c|}
\hline Factor & DMP & CMM & CT & CMO & CE & CTT & CAP & Sumatoria & Ponderado \% \\
\hline DMP & - & 1,00 & 1,00 & 1,00 & 1,00 & 1,00 & 1,00 & 6,00 & 27,27 \\
\hline CMM & 0,00 & - & 1,00 & 1,00 & 1,00 & 1,00 & 1,00 & 5,00 & 22,72 \\
\hline CT & 0,00 & 0,00 & - & 1,00 & 1,00 & 1,00 & 1,00 & 4,00 & 18,18 \\
\hline CMO & 0,00 & 0,00 & 0,00 & - & 1,00 & 1,00 & 1,00 & 3,00 & 13,64 \\
\hline CE & 0,00 & 0,00 & 0,00 & 0,00 & - & 1,00 & 1,00 & 2,00 & 9,09 \\
\hline CTT & 0,00 & 0,00 & 0,00 & 0,00 & 0,00 & - & 1,00 & 1,00 & 4,55 \\
\hline CAP & 0,00 & 0,00 & 0,00 & 0,00 & 0,00 & 1,00 & - & 1,00 & 4,55 \\
\hline & & & & & & & & 22,00 & 100,00 \\
\hline
\end{tabular}

Elaboración propia

A continuación, la Tabla 3.17 presenta la escala de calificación para comparar los factores de localización en cada región. Esta escala comienza desde dos y tiene un puntaje máximo de diez, con intervalos pares.

Tabla 3.17

Escala de calificación

\begin{tabular}{|c|c|c|c|c|c|}
\hline Estado & Excelente & Muy bueno & Bueno & Regular & Malo \\
\hline Calificación & 10,00 & 8,00 & 6,00 & 4,00 & 2,00 \\
\hline
\end{tabular}

Elaboración propia

Finalmente, para cada región, se multiplicó el ponderado de cada factor de localización con la escala de calificación de los mismos factores. Luego se suman estos puntajes y se totaliza para cada región tal y como muestra la Tabla 3.18. 
Tabla 3.18

Resultados de la evaluación a nivel de macro localización

\begin{tabular}{|c|c|c|c|c|c|c|c|c|c|}
\hline \multirow{2}{*}{ Factor } & Ponderado & \multicolumn{2}{|c|}{ Lima-Callao } & \multicolumn{2}{c|}{ Lambayeque } & \multicolumn{2}{c|}{ Apurímac } & \multicolumn{2}{c|}{ Junín } \\
\cline { 3 - 10 } & $\%$ & Escala & Puntaje & Escala & Puntaje & Escala & Puntaje & Escala & Puntaje \\
\hline DMP & 27,27 & 2,00 & 0,55 & 6,00 & 1,64 & 6,00 & 1,64 & 10,00 & 2,73 \\
\hline CMM & 22,72 & 10,00 & 2,27 & 2,00 & 0,45 & 2,00 & 0,45 & 6,00 & 1,36 \\
\hline CT & 18,18 & 2,00 & 0,36 & 6,00 & 1,09 & 8,00 & 1,45 & 4,00 & 0,73 \\
\hline CMO & 13,64 & 6,00 & 0,82 & 10,00 & 1,36 & 10,00 & 1,36 & 8,00 & 1,09 \\
\hline CE & 9,09 & 10,00 & 0,91 & 10,00 & 0,91 & 4,00 & 0,36 & 10,00 & 0,91 \\
\hline CTT & 4,55 & 8,00 & 0,36 & 4,00 & 0,18 & 2,00 & 0,09 & 6,00 & 0,27 \\
\hline CAP & 4,55 & 2,00 & 0,09 & 4,00 & 0,18 & 6,00 & 0,27 & 6,00 & 0,27 \\
\hline Total & 100,00 & & 5,36 & & 5,82 & & 5,64 & & $\mathbf{7 , 3 6}$ \\
\hline
\end{tabular}

Elaboración propia

\subsubsection{Evaluación y selección de micro localización}

Al ser seleccionada la región Junín a nivel de macro localización, y sabiendo que la provincia de Tarma sobresale por su producción de manzanilla común, la micro localización se define entre tres distritos de esta provincia: Acobamba, Palcamayo y Tarma. Los dos primeros son los principales productores de manzanilla común en dicha provincia, y el tercero es la capital de la provincia, por tanto, el centro de la actividad económica de la misma. En tal sentido, los factores a evaluar son la disponibilidad de materia prima, el costo de la energía eléctrica, el costo de terreno, las vías de acceso a los distritos y el suministro de GLP. Las tabla 3.19 y 3.20 muestran los porcentajes de producción en distritos y su escala, respectivamente.

Tabla 3. 19

Porcentaje de producción de manzanilla común en los distritos a evaluar

\begin{tabular}{|c|c|c|}
\hline Distrito & Porcentaje (\%) & Escala \\
\hline Acobamba & 86,38 & 10,00 \\
\hline Palcamayo & 7,52 & 2,00 \\
\hline Tarma & 1,47 & 2,00 \\
\hline Otros (6 distritos) & 4,63 & No se evalúan \\
\hline
\end{tabular}

Fuente: Agencia Agraria de Tarma, (2008).

Tabla 3.20

Escala de calificación de porcentaje de producción de manzanilla común

\begin{tabular}{|c|c|c|}
\hline Calificación & Rango (\%) & Escala \\
\hline Excelente & {$[81-100]$} & 10,00 \\
\hline Muy bueno & {$[61-80]$} & 8,00 \\
\hline Bueno & {$[41-60]$} & 6,00 \\
\hline Regular & {$[21-40]$} & 4,00 \\
\hline Malo & {$[0-20]$} & 2,00 \\
\hline
\end{tabular}

Elaboración propia 
La Tabla 3.21 muestra las tarifas de energía eléctrica de tipo BT5B no residencial para los distritos a evaluar según su pliego tarifario. Se eligió esta tarifa ya que la potencia contratada es menos de $20 \mathrm{~kW}$, y porque no diferencia el consumo de energía activa en horas punta o fuera de estas. Para facilidad de comparación se asume la energía reactiva como despreciable.

Tabla 3.21

Tarifas de energía eléctrica de tipo BT5B no residencial de distritos a evaluar al 2015 (soles por kilowatt hora)

\begin{tabular}{|c|c|c|c|c|c|c|}
\hline Distrito & Pliego tarifario & $\begin{array}{c}\text { Energía } \\
\text { activa } \\
\text { S///kWh }\end{array}$ & $\begin{array}{c}\text { Fijo } \\
\text { mensual } \\
\text { S/./mes }\end{array}$ & $\begin{array}{c}\text { Consumo } \\
(\mathbf{k W h} / \mathbf{m e s})\end{array}$ & $\begin{array}{c}\text { Consumo } \\
(\mathbf{S} / .)\end{array}$ & Escala \\
\hline Acobamba & Tarma rural & 0,8759 & 4,02 & $1.896,97$ & $1.665,57$ & 2,00 \\
\hline Palcamayo & Tarma rural & 0,8759 & 4,02 & $1.896,97$ & $1.665,57$ & 2,00 \\
\hline Tarma & Tarma-Chamchamayo & 0,7102 & 3,18 & $1.896,97$ & $1.350,41$ & 4,00 \\
\hline
\end{tabular}

Fuente: OSINERGMIN, (2015).

Tabla 3.22

Escala de calificación de energía eléctrica de tipo BT5B

\begin{tabular}{|c|c|c|}
\hline Calificación & Rango & Escala \\
\hline Excelente & {$[0-100]$} & 10,00 \\
\hline Muy bueno & {$[101-500]$} & 8,00 \\
\hline Bueno & {$[501-1.000]$} & 6,00 \\
\hline Regular & {$[1.001-1.500]$} & 4,00 \\
\hline Malo & {$[1.501-$ más $]$} & 2,00 \\
\hline
\end{tabular}

Elaboración propia

Asimismo, la Tabla 3.23 muestra el costo promedio de terrenos en los distritos evaluados. La Tabla 3.24 muestra su escala de calificación.

Tabla 3.23

Costo de terreno en los distritos a evaluar (soles por metro cuadrado)

\begin{tabular}{|c|c|c|}
\hline Distrito & Costo $\left(\mathbf{S} / . / \mathbf{m}^{\mathbf{2}}\right)$ & Escala \\
\hline Acobamba & 35,00 & 6,00 \\
\hline Palcamayo & 20,00 & 8,00 \\
\hline Tarma & 70,00 & 2,00 \\
\hline
\end{tabular}

Elaboración propia 
Tabla 3.24

Escala de calificación de costo de terreno

\begin{tabular}{|c|c|c|}
\hline Calificación & Rango & Escala \\
\hline Excelente & {$[0-15]$} & 10,00 \\
\hline Muy bueno & {$[16-30]$} & 8,00 \\
\hline Bueno & {$[31-45]$} & 6,00 \\
\hline Regular & {$[46-60]$} & 4,00 \\
\hline Malo & {$[60-75]$} & 2,00 \\
\hline
\end{tabular}

Elaboración propia

Por otro lado, la Tabla 3.25 evalúa el suministro de GLP para consumidores directos, es decir a aquellos que cuentan con tanques estacionarios de GLP. Esta evaluación se basa en la cantidad de consumidores directos de GLP y en la capacidad total de GLP en los distritos a evaluar. Se asume que hay mayor posibilidad de suministro en aquellos distritos que ya cuentan con tanques estacionarios. La Tabla 3.26 muestra su escala de calificación.

Tabla 3. 25

Disponibilidad de GLP para consumidores directos en los distritos a evaluar al 2015

\begin{tabular}{|c|c|c|c|c|}
\hline Distrito & $\begin{array}{c}\text { Cantidad } \\
\text { consumidores } \\
\text { directos }\end{array}$ & $\begin{array}{c}\text { Capacidad total } \\
\text { (galones) }\end{array}$ & $\begin{array}{c}\text { Ratio } \\
\text { Galón/consumidor }\end{array}$ & Escala \\
\hline Acobamba & - & - & - & 2,00 \\
\hline Palcamayo & - & - & - & 2,00 \\
\hline Tarma & 7,00 & 4.500 & 642,86 & 8,00 \\
\hline Otros (La Unión) & 3,00 & 3.000 & $1.000,00$ & No se evalúa \\
\hline
\end{tabular}

Fuente: MEM, (2015)

Tabla 3. 26

Escala de calificación de disponibilidad de GLP

\begin{tabular}{|c|c|c|}
\hline Calificación & Rango & Escala \\
\hline Excelente & {$[801-$ más $]$} & 10,00 \\
\hline Muy bueno & {$[601-800]$} & 8,00 \\
\hline Bueno & {$[401-600]$} & 6,00 \\
\hline Regular & {$[201-400]$} & 4,00 \\
\hline Malo & {$[0-200]$} & 2,00 \\
\hline
\end{tabular}

Elaboración propia

Además, la Tabla 3.27 muestra las vías de acceso a los distritos a evaluar. Considerándose la distancia y tiempo hacia un punto, se escogió la Oroya, ya que desde esta ciudad se llega a Lima por una vía asfaltada. La Tabla 3.28 muestra su escala de calificación. 
Tabla 3.27

Vías de acceso a evaluar desde la Oroya hacia los distritos a evaluar

\begin{tabular}{|c|c|c|c|c|c|c|}
\hline Hacia & Tramo 1 & Tramo 2 & $\begin{array}{c}\text { Tramo 1 } \\
(\mathbf{k m})\end{array}$ & $\begin{array}{c}\text { Tramo 2 } \\
(\mathbf{k m})\end{array}$ & $\begin{array}{c}\text { Tramos } \\
\mathbf{1 - 2}(\mathbf{k m})\end{array}$ & Escala \\
\hline Acobamba & Oroya-Tarma & Tarma-Acobamba & 56,70 & 9,30 & 66,00 & 4,00 \\
\hline Palcamayo & Oroya-Condorin & Condorin-Palcamayo & 42,00 & 25,40 & 67,40 & 4,00 \\
\hline Tarma & Oroya-Tarma & - & 56,70 & - & 56,70 & 6,00 \\
\hline
\end{tabular}

Nota: "El tramo Condorin-Palcamayo es el único que no está asfaltado.

Elaboración propia

Tabla 3.28

Escala de calificación de vías de acceso desde la Oroya

\begin{tabular}{|c|c|c|}
\hline Calificación & Rango & Escala \\
\hline Excelente & {$[0-20]$} & 10,00 \\
\hline Muy bueno & {$[21-40]$} & 8,00 \\
\hline Bueno & {$[41-60]$} & 6,00 \\
\hline Regular & {$[61-80]$} & 4,00 \\
\hline Malo & {$[81-$ más $]$} & 2,00 \\
\hline
\end{tabular}

Elaboración propia

La abreviación de los factores de micro localización se resumen en la Tabla 3.29.

Tabla 3.29

Abreviación de factores de evaluación a nivel de micro localización

\begin{tabular}{|c|c|}
\hline Factor & Nominación \\
\hline Disponibilidad materia prima & DMP \\
\hline Costo de energía eléctrica & CEE \\
\hline Costo de terreno & CT \\
\hline Vías de acceso & VA \\
\hline Disponibilidad de GLP & DGLP \\
\hline
\end{tabular}

Elaboración propia

A continuación se presenta la tabla de enfrentamiento para determinar el peso de cada uno de los factores de micro localización antes analizados según la Tabla 3.30.

Tabla 3.30

Ponderado de factores de evaluación a nivel de micro localización

\begin{tabular}{|c|c|c|c|c|c|c|c|}
\hline Factor & DMP & CEE & CT & VA & DGLP & Puntaje & Ponderado \% \\
\hline DMP & - & 1,00 & 1,00 & 1,00 & 1,00 & 4,00 & 36,36 \\
\hline CEE & 0,00 & - & 1,00 & 1,00 & 1,00 & 3,00 & 27,27 \\
\hline CT & 0,00 & 0,00 & - & 0,00 & 1,00 & 1,00 & 9,09 \\
\hline VA & 0,00 & 0,00 & 1,00 & - & 1,00 & 2,00 & 18,18 \\
\hline DGLP & 0,00 & 1,00 & 0,00 & 0,00 & - & 1,00 & 9,09 \\
\hline \multicolumn{7}{|r|}{}
\end{tabular}

Elaboración propia 
Finalmente, la Tabla 3.31 evalúa los factores de micro localización.

Tabla 3.31

Resultados de la evaluación a nivel de micro localización

\begin{tabular}{|c|c|c|c|c|c|c|c|}
\hline Distrito & \multirow{2}{*}{ Ponderado \% } & \multicolumn{2}{|c|}{ Acobamba } & \multicolumn{2}{c|}{ Palcamayo } & \multicolumn{2}{c|}{ Tarma } \\
\cline { 3 - 8 } Factor & & Escala & Puntaje & Escala & Puntaje & Escala & Puntaje \\
\hline DMP & 36,36 & 10,00 & 3,64 & 2,00 & 0,73 & 2,00 & 0,73 \\
\hline CEE & 27,27 & 2,00 & 0,55 & 2,00 & 0,55 & 4,00 & 1,09 \\
\hline CT & 9,09 & 6,00 & 0,55 & 8,00 & 0,73 & 2,00 & 0,18 \\
\hline VA & 18,18 & 4,00 & 0,73 & 4,00 & 0,73 & 6,00 & 1,09 \\
\hline DGLP & 9,09 & 2,00 & 0,18 & 2,00 & 0,18 & 8,00 & 0,73 \\
\hline Total & 100,00 & & $\mathbf{5 , 6 4}$ & & 2,91 & & 3,82 \\
\hline
\end{tabular}

Elaboración propia

El distrito seleccionado fue Acobamba. La Figura 3.1 muestra la división política y las vías de acceso de la Provincia de Tarma.

Figura 3. 1

División política de Tarma provincia

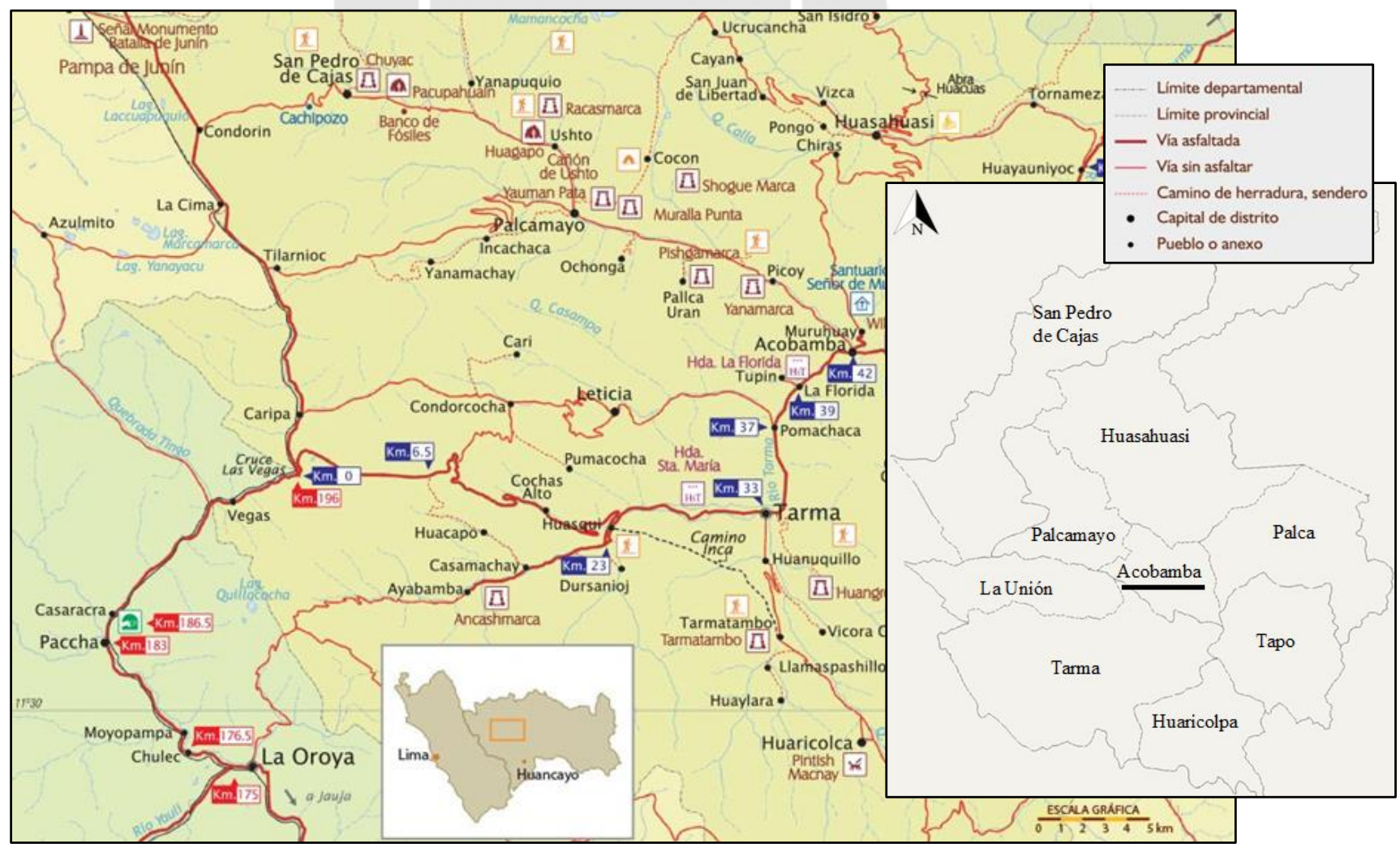

Fuente: Google Maps, (2015). 


\section{CAPÍTULO IV: TAMAÑO DE PLANTA}

\subsection{Relación tamaño-mercado}

Para esta relación se usó la demanda del proyecto para ambos productos. Al 2025, trabajando 24 horas al día, seis días a la semana y 52 semanas al año. Descontando 12 días feriados, que por lo regular se dan en un año.

Horas al año $=24 \frac{\text { horas }}{\text { día }} \times\left[\left(6 \frac{\text { dias }}{\text { semana }} \times 52 \frac{\text { semanas }}{a \tilde{n} o}\right)-12 \frac{\text { días feriados }}{a \tilde{n} o}\right]$

El cálculo resulta en 7.200 horas al año. La Tabla 4.1 resume dicha relación.

Tabla 4. 1

Relación tamaño-mercado

\begin{tabular}{|c|c|c|c|}
\hline \multirow{2}{*}{ Año } & Producto & $\begin{array}{c}\text { Producto terminado } \\
\text { (kg) }\end{array}$ & $\begin{array}{c}\text { Producto terminado } \\
\text { por hora (kg/hora) }\end{array}$ \\
\hline \multirow{3}{*}{2025} & Planta entera & $7.510,00$ & 1,04 \\
\cline { 2 - 4 } & Flores & $2.020,00$ & 0,28 \\
\cline { 2 - 4 } & Total & $9.530,00$ & 1,32 \\
\hline
\end{tabular}

Nota: *Según muestra la Figura 5.5 para obtener $1 \mathrm{~kg}$ de producto terminado se requieren de $5,20 \mathrm{~kg}$, aproximadamente, de materia prima de planta entera.

Elaboración propia

\subsection{Relación tamaño-recursos productivos}

Esta relación se basa en la materia prima disponible el 2025, según la Tabla 2.26. La cantidad de horas al año es la misma. Asimismo, se usa las cantidades de materia prima para cada producto a elaborar. La Tabla 4.2 muestra esta relación.

Tabla 4. 2

Relación tamaño-recursos productivos

\begin{tabular}{|c|c|c|c|c|}
\hline Año & Producto & Materia prima (kg) & $\begin{array}{c}\text { Materia prima por } \\
\text { hora (kg/hora) }\end{array}$ & $\begin{array}{c}\text { Producto terminado } \\
\text { por hora* }\end{array}$ (kg/hora) \\
\hline 2025 & Total & $104.080,00$ & 14,46 & 2,78 \\
\hline
\end{tabular}

Elaboración propia 


\subsection{Relación tamaño-tecnología}

Tabla 4.3

Relación tamaño-tecnología

\begin{tabular}{|c|c|c|c|}
\hline Año & Producto & $\begin{array}{c}\text { Materia prima por } \\
\text { hora }(\mathbf{k g} / \mathbf{h o r a})\end{array}$ & $\begin{array}{c}\text { Producto terminado } \\
\text { por hora* }\end{array}$ \\
\hline 2025 & Total & 7.07 & 1,36 \\
\hline
\end{tabular}

Elaboración propia

\subsection{Relación tamaño-punto de equilibrio}

Para determinar el punto de equilibrio, se calculó, en el último año, los costos fijos de ambos productos, sus valores de venta unitarios y sus costos variables unitarios tal como lo muestra la Tabla 4.4 .

Tabla 4.4

Relación tamaño-punto de equilibrio

\begin{tabular}{|c|c|c|}
\hline Año 2025 & Cf = & Q x (Vvu - Cvu) \\
\hline Ítem & Flores & Planta entera \\
\hline Cf: Costo fijo & $146.089,89$ & $407.354,14$ \\
\hline Vvu: Valor de venta unitario & 3,20 & 1,87 \\
\hline Cvu: Costo variable unitario & 0,44 & 0,47 \\
\hline Q: Cantidad (Cajas) & $52.978,00$ & $291.683,00$ \\
\hline Q: Cantidad (kg) & 794,67 & $5.833,66$ \\
\hline Qt: Cantidad total (kg) & \multicolumn{2}{|c|}{$6.628,33$} \\
\hline Horas/año & \multicolumn{2}{|c|}{$0,9200,00$} \\
\hline Qt (kg/hora) & \multicolumn{2}{|c|}{} \\
\hline
\end{tabular}

Elaboración propia

\subsection{Selección del tamaño de planta}

En base a lo desarrollado se seleccionó el tamaño de planta de acuerdo a la tecnología como muestra la Tabla 4.5. Teniendo en cuenta que el tamaño de tecnología supera ligeramente al de tamaño mercado se eligió el primero porque la tecnología no tendrá una eficiencia y utilización del 100\% lo que hará que se aproxime a la segunda. El tamaño recursos productivos no es limitante, no se toma en cuenta ya que no se requiere de tanta cantidad de producto terminado. El de punto de equilibrio señala lo mínimo que se debe producir para no ganar ni perder. 
Tabla 4.5

Selección del tamaño de planta

\begin{tabular}{|c|c|c|}
\hline Relación & kg M.P. / hora & kg P.T. / hora \\
\hline Tamaño - mercado & 6,86 & 1,32 \\
\hline Tamaño - recursos productivos & 14,46 & 2,78 \\
\hline Tamaño - tecnología & 7,07 & 1,36 \\
\hline Punto de equilibrio & 4,78 & 0,92 \\
\hline Tamaño de planta escogido & $\mathbf{7 , 0 7}$ & $\mathbf{1 , 3 6}$ \\
\hline
\end{tabular}

Elaboración propia

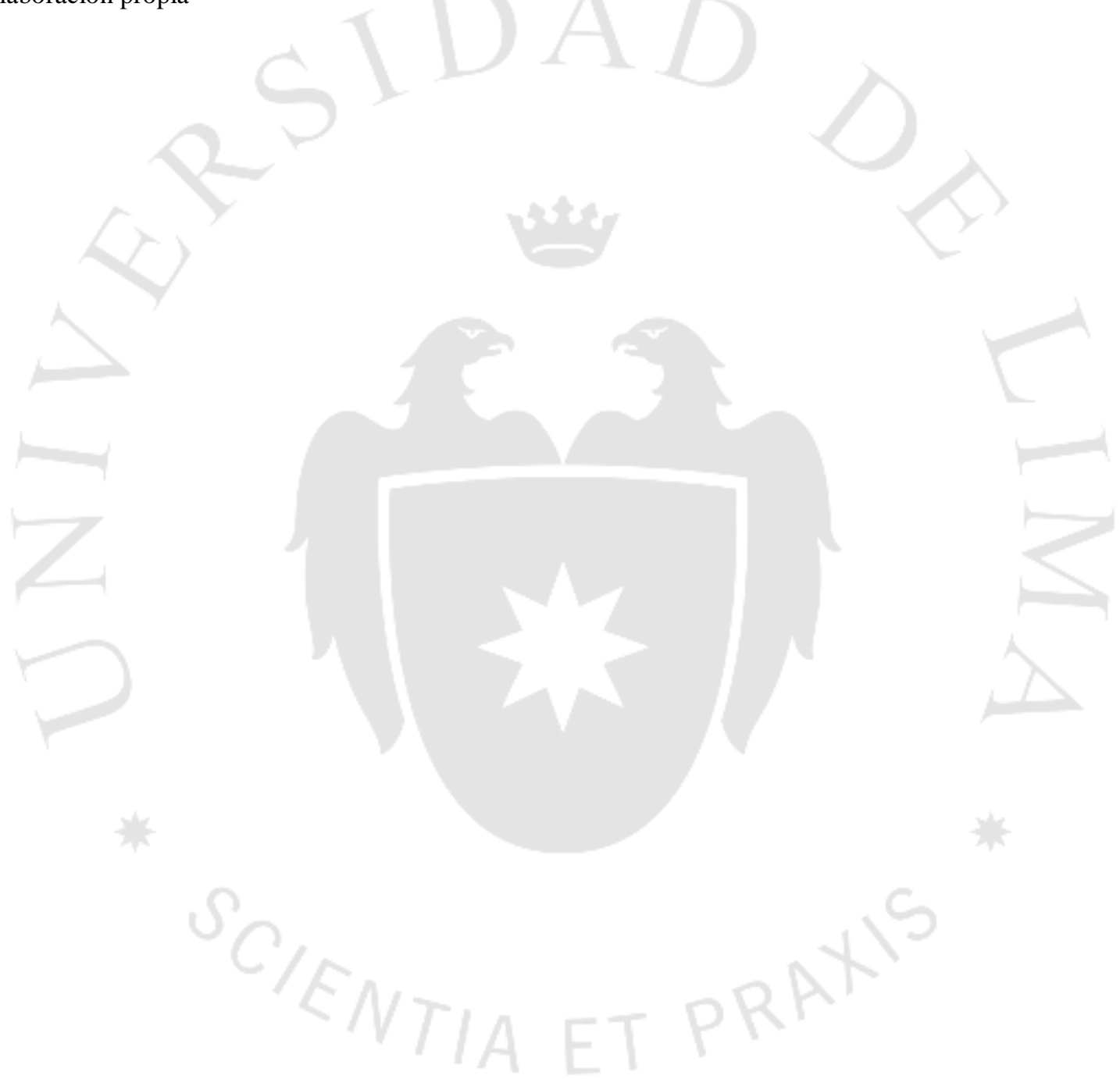




\section{CAPÍTULO V: INGENIERÍA DEL PROYECTO}

\subsection{Definición técnica del producto}

\subsubsection{Especificaciones técnicas del producto}

Las tablas 5.1 y 5.2 muestran las especificaciones técnicas de los dos productos en estudio.

Tabla 5. 1

Especificaciones técnicas del producto de planta entera de manzanilla común

\begin{tabular}{|c|c|c|c|c|}
\hline Nombre del producto: & \multicolumn{4}{|c|}{ Bolsa filtrante de manzanilla común entera } \\
\hline Función: & \multicolumn{4}{|c|}{ Bebida } \\
\hline Tamaño y apariencia: & \multicolumn{4}{|c|}{20 bolsas filtrantes en cajas de $6,80 \times 7,30 \times 11,00 \mathrm{~cm}$} \\
\hline Composición: & \multicolumn{4}{|c|}{ Planta entera (partes verdes y flores*) de manzanilla común } \\
\hline Características: & Clase & Valor Neto +- total & Medio de control & Técnica \\
\hline -Organolépticas & & & & \\
\hline Color & Crítico & Amarillo verdoso & Sensorial & Muestreo \\
\hline Olor & Crítico & Manzanilla común & Sensorial & Muestreo \\
\hline Sabor & Crítico & Amargo & Sensorial & Muestreo \\
\hline Aroma & Crítico & Manzanilla común & Sensorial & Muestreo \\
\hline \multicolumn{5}{|l|}{-Fisicoquímicas } \\
\hline Humedad & Crítico & Máximo 6,50 \% & Análisis & Muestreo \\
\hline Cenizas totales & Menor & Máximo $10 \%$ & Análisis & Muestreo \\
\hline Granulometría & Crítico & Mínimo $75 \%$ Malla N³0** & Análisis & Muestreo \\
\hline -Microbiológicas ${ }^{* * * *}$ & $V^{2}$ & P & & \\
\hline Entero bacterias & Crítico & Máximo $10^{2} \mathrm{ufc} / \mathrm{g}^{* * * * *}$ & Análisis & Muestreo \\
\hline Mohos & Crítico & Máximo $10^{2} \mathrm{ufc} / \mathrm{g}$ & Análisis & Muestreo \\
\hline
\end{tabular}

Nota: ${ }^{*}$ Las flores tubulares (amarillas) contienen a su vez subproductos como polen y semillas; ${ }^{* *}$ Se debe retener como mínimo un $75 \%$ del material a través de una mala $\mathrm{N}^{\circ} 30$ ASTM (equivalente a 0,6 mm). Asimismo, para no dificultar el envasado se recomienda no superar los 2,00 mm; ${ }^{* * *}$ Según la NTS $\mathrm{N}^{\mathrm{o}} 071$ MINSA/DIGESA-V.01; ${ }^{* * * *}$ Unidades formadoras de colonias por gramo.

Fuente: Ministerio de Salud-MINSA, (2015). 
Tabla 5.2

Especificaciones técnicas del producto de flores de manzanilla común

\begin{tabular}{|c|c|c|c|c|}
\hline Nombre del producto: & \multicolumn{4}{|c|}{ Bolsa filtrante de flores de manzanilla común } \\
\hline Función: & \multicolumn{4}{|c|}{ Bebida } \\
\hline Tamaño y apariencia: & \multicolumn{4}{|c|}{15 bolsas filtrantes en cajas de $6,80 \times 7,30 \times 9,00 \mathrm{~cm}$} \\
\hline Composición: & \multicolumn{4}{|c|}{ Flores tubulares y liguladas de manzanilla común } \\
\hline Características: & Clase & Valor Neto +- total & Medio de control & Técnica \\
\hline \multicolumn{5}{|l|}{-Organolépticas } \\
\hline Color & Crítico & Amarillo pardusco & Sensorial & Muestreo \\
\hline Olor & Crítico & Manzanilla común & Sensorial & Muestreo \\
\hline Sabor & Crítico & Amargo & Sensorial & Muestreo \\
\hline Aroma & Crítico & Manzanilla común & Sensorial & Muestreo \\
\hline \multicolumn{5}{|l|}{-Fisicoquímicas } \\
\hline Humedad & Crítico & Máximo $6,50 \%$ & Análisis & Muestreo \\
\hline Cenizas totales & Menor & Máximo $10 \%$ & Análisis & Muestreo \\
\hline Granulometría & Crítico & Mínimo $75 \%$ Malla $\mathrm{N}^{\circ} 30$ & Análisis & Muestreo \\
\hline -Microbiológicas & & + & 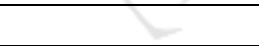 & \\
\hline Entero bacterias & Crítico & Máximo $10^{2} \mathrm{ufc} / \mathrm{g}$ & Análisis & Muestreo \\
\hline Mohos & Crítico & Máximo $10^{2} \mathrm{ufc} / \mathrm{g}$ & Análisis & Muestreo \\
\hline
\end{tabular}

Fuente: MINSA, (2015).

\subsubsection{Composición del producto}

Las tablas 5.3 y 5.4 muestran las composiciones de los dos productos según Franke y

Schilcher (2005, p. 56) y cálculos mostrados en el Anexo 4.

Tabla 5.3

Composición del producto de planta entera de manzanilla común

\begin{tabular}{|c|c|c|c|}
\hline Insumo & Descripción & Composición & Principales compuestos \\
\hline Flores de manzanilla común & Flores tubulares y liguladas & $10,67 \%$ & $\begin{array}{c}\text { Óxido de bisabolol A } \\
\text { Óxido de bisabolol B } \\
\text { Camazuleno }\end{array}$ \\
\hline Partes verdes de manzanilla común & Hojas, pedicelos y pedúnculos & $82,83 \%$ & $\begin{array}{c}\text { Espatulenol, nerol y } \\
\text { farneseno }\end{array}$ \\
\hline Agua & Humedad & $6,50 \%$ & Hidrógeno y oxigeno \\
\hline
\end{tabular}

Fuente: Franke y Schilcher, (2005).

Tabla 5.4

Composición del producto de flores de manzanilla común

\begin{tabular}{|c|c|c|c|}
\hline Insumo & Descripción & Composición & Principales compuestos \\
\hline Flores de manzanilla común & Flores tubulares y liguladas & $93,50 \%$ & $\begin{array}{c}\text { Óxido de bisabolol A } \\
\text { Óxido de bisabolol B } \\
\text { Camazuleno }\end{array}$ \\
\hline Agua & Humedad & $6,50 \%$ & Hidrógeno y oxigeno \\
\hline
\end{tabular}

Fuente: Franke y Schilcher, (2005). 


\subsubsection{Diseño gráfico del producto}

Las figuras 5.1 y 5.2 muestran las vistas frontales y laterales de las cajas.

Figura 5. 1

Diseño frontal y lateral de caja de 20 bolsas filtrantes de planta entera de manzanilla común
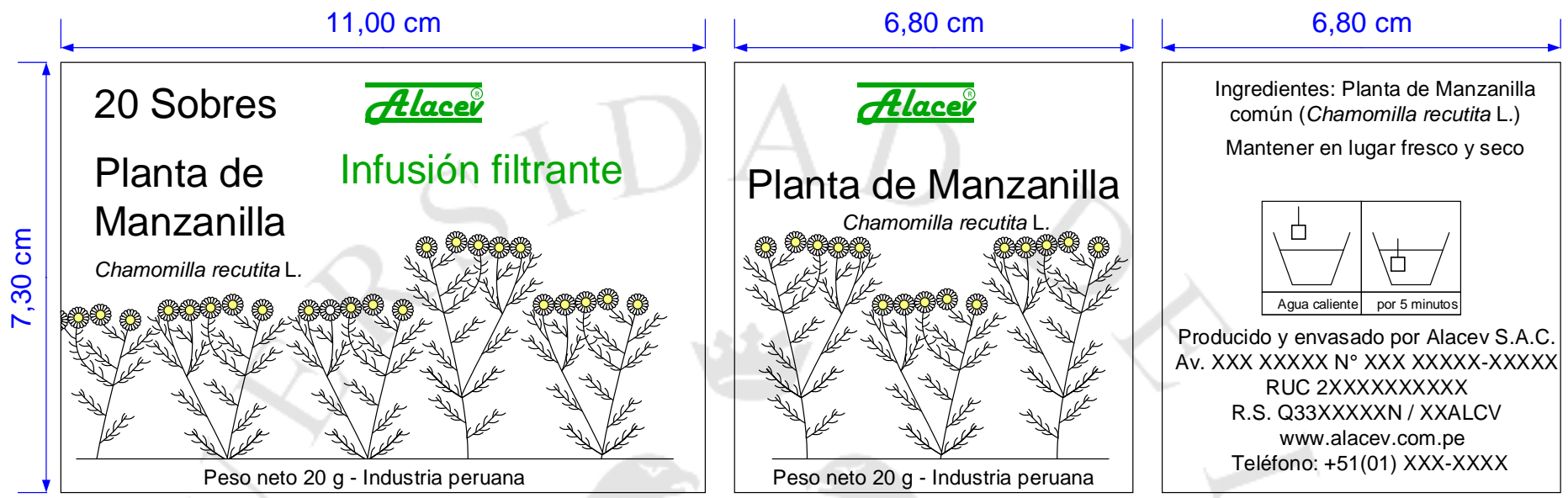

Elaboración propia

Figura 5.2

Diseño frontal y lateral de caja de 15 bolsas filtrantes de flores de manzanilla común
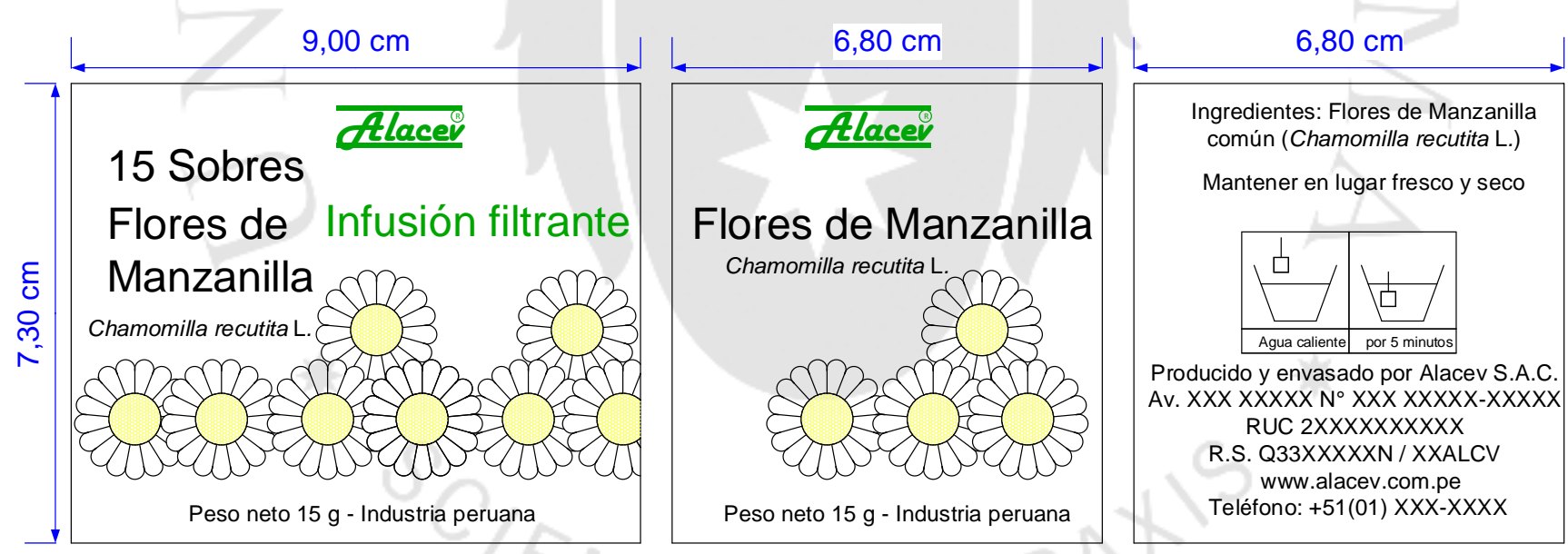

Elaboración propia

\subsubsection{Regulaciones técnicas del producto}

Según el artículo 91 de la Ley $\mathrm{N}^{\circ} 26842$, todo alimento o bebida industrializada que se comercializa en el Perú debe contar con Registro Sanitario. No obstante, el 25 de septiembre del 2015 se publicó el D.L. N ${ }^{\circ}$ 1222, el cual modificó, entre otros, el mencionado artículo disponiendo que para fabricarse, importarse, fraccionarse, almacenarse o comercializarse cualquier producto alimenticio industrial se debe contar con un certificado de Principios 
Generales de Higiene (PGH) o con la validación técnica oficial del plan HACCP. Es decir la inocuidad ya no se enfocaría en el producto, sino en las instalaciones y procesos para su elaboración. Así, se ahorraría dinero y trámites burocráticos, además de salvaguardar mejor la inocuidad. A la fecha aún no se publica el reglamento de dicho Decreto Legislativo, por tanto está en vigencia el reglamento de la primera ley (D.S. $\left.N^{\circ} 007-98-S A\right)$.

Por otro lado, acogiendo la Ley No 29482 (vigente hasta el 2019), ley de promoción para el desarrollo de actividades productivas en zonas altoandinas que exonera de impuesto a la renta de tercera categoría, tasas arancelarias e IGV a la importación de bienes de capital para micro y pequeñas empresas que se instalen a partir de los 2.500 m.s.n.m. Asimismo, para las empresas que se acojan a dicha ley, existen topes máximos de ventas por trabajador según se indica en el D.S. N 011-2016-EF.

\subsection{Tecnologías existentes y procesos de la producción}

\subsubsection{Naturaleza de la tecnología requerida}

\subsubsection{Descripción de las tecnologías existentes}

A continuación se describen las tecnologías existentes:

La selección de la manzanilla común por lo general es llevada a cabo de manera manual usando una herramienta en forma de peine que arranque sólo las cabezuelas, sin embargo, también se puede realizar esta operación de manera automática.

El picado, operación exclusiva para las partes verdes, puede ser hecho manualmente con un cuchillo o cortadora. Asimismo, existen picadoras automáticas para plantas.

Para el lavado se evalúa entre el método de inmersión, que consiste en sumergir las partes a lavar dentro de una solución para quitarle las cargas bacteriológicas y el método de aspersión que consiste en lavar mediante chorros de agua desde aspersores hacia el producto a lavar.

El centrifugado se realiza de manera automática y es necesario para sacar el agua ganada en el lavado. Si no se separa el líquido ganado se requerirá más energía para secar las partes. 
El secado, es la operación más crítica para el presente estudio. Se clasifica en dos grupos, los que se realizan dependiendo de la energía del sol, ya sea al aire libre o dentro de alguna estructura, y los que dependen de otras fuentes de energía, generalmente no renovables. Los últimos tienen la ventaja de un mejor control de los parámetros de secado sumado a un menor tiempo de operación por esto la denominación deshidratado, se clasifica a su vez en:

- Deshidratado por aire caliente

- Deshidratado por contacto con una superficie caliente

- Deshidratado por fuente radiante de microondas o dieléctrica

- Liofilización

El primer método es un secado por convección, ya que el fluido, generalmente aire caliente, retira directamente la humedad del producto a deshidratar. Es ampliamente usado en frutas, vegetales y comidas. El segundo método es un secado por conducción ya que primero calienta un cuerpo el cual entra en contacto con el producto para luego retirar la humedad. Es ideal para materiales finos y en polvo. El tercer método es un secado por radiación, es decir mediante ondas electromagnéticas, las cuales son absorbidas por las moléculas de agua originando fricción, y por ende calentamiento y evaporación. El deshidratado es uniforme y rápido pero la energía requerida es mayor a los otros métodos; se usa para volúmenes no tan grandes. Finalmente, la liofilización es un método por el cual se congela el producto, para después pasar a estado gaseoso el agua congelada (sublimación) y obtener un producto deshidratado. De acuerdo con Silva (1985), para plantas aromáticas esta operación debe ser exenta de rayos solares (p. 44).

Respecto a las tecnológicas de molienda, el molino de cuchillas produce un material completamente homogéneo, es ideal para materiales no tan finos ni abrasivos de tamaño intermedio a grueso y de resistencia blanda a semidura. Muele por corte y cizallamiento y es usado para productos agrícolas, en la industria de alimentos, biológica (productos que contienen celulosa) y farmaceutica, entre los principales. El molido de rodillo es ideal para materiales de tamaño grueso pero no tan duros, muele por compresión, impacto y cizalla. Es ampliamente usado para la industria del carbón y materiales similares. El molino de martillo 
es de alta eficiencia, ideal para productos sólidos y secos de resistencia blanda a semidura y de tamaño pequeño a intermedio, muele por el impacto entre los martillos en rotación. Según Celiz (1991) mediante el molido de martillos se pierde menos aceite esencial al moler la manzanilla común. Finalmente, el molido de bolas, las cuales muelen por fricción y percusión, y es ampliamente usado en la minería.

Respecto al tamizado, este posee tres variantes representativas. Las tamizadoras por nutación son ideales para obtener un tamizados muy finos y están dirigidos especialmente para productos en polvo. Las tamizadoras por vibración son ideales para tamizar productos a granel sean finos o gruesos con poca viscosidad. Finalmente, las placas de tamiz, sean fijas o movibles se insertan dentro de un molino u otro. Según Silva (1985) se debe usar un tamiz № 30 (ASTM), ya que un tamiz mayor genera más sustancias volátiles perdidas (p. 172).

El mezclado de las partes verdes y las flores para el producto de planta entera al ser estos dos sólidos livianos, se evaluó entre dos variantes. Primero, el mezclado por agitación, el cual consiste en un recipiente o tanque que contiene paletas o cualquier otro mecanismo que por medio de energía remueve y mezcla la carga. El segundo tipo es el mezclado por volteo, que consiste en un recipiente el cual rota sobre un eje mezclando la carga.

El envasado consiste en colocar el producto molido y tamizado en una bolsa filtrante estandar, esta a su vez se debe sujetar al extremo de un hilo, al otro extremo se sujeta una etiqueta. Así, bolsa filtrante con producto, hilo y etiqueta se introducen en un sobre de envoltura, ver figuras 2.1 y 2.2. En el empacado se colocan 20 y 15 sobres en cajas de productos de planta entera y flores, respectivamente, ver figuras 5.1 y 5.2. El empacado es manual. El envasado podría ser manual, aunque el dosificado, tiempo y uso de los materiales no serían tan eficientes.

Finalmente, el sellado y embolsado pueden ser automáticos o manuales. Para escoger la tecnología en esta operación bastará con conocer la cantidad de cajas a sellar y embolsar al día.

\subsubsection{Selección de la tecnología}

La Tabla 5.5 muestra la selección de la tecnología a lo largo de todo el proceso en base a la descripción del punto anterior. 
Tabla 5.5

Selección de tecnología de las operaciones o procesos

\begin{tabular}{|c|c|c|}
\hline Operación & Descripción de tecnología escogida & Equipo/Maquinaria \\
\hline Recepción y pesado & $\begin{array}{l}\text { La recepción, pesaje, registro y traslado de } \\
\text { carga es manual }\end{array}$ & $\begin{array}{l}\text { Balanza de plataforma y } \\
\text { coche de traslado }\end{array}$ \\
\hline Selección & La selección de partes es manual & Peine de selección y cestos \\
\hline Picado & $\begin{array}{l}\text { El picado de partes verdes es automático con } \\
\text { avance manual }\end{array}$ & Picadora \\
\hline Lavado & $\begin{array}{l}\text { Las partes, por separado, se lavan } \\
\text { manualmente por inmersión }\end{array}$ & Lavadero \\
\hline Centrifugado & $\begin{array}{l}\text { Las partes, por separado, se centrifugan de } \\
\text { manera automática con carga manual }\end{array}$ & ga \\
\hline Deshidratado & $\begin{array}{l}\text { Las partes juntas, sin mezclarse, se } \\
\text { deshidratan de manera automática }\end{array}$ & Deshidratador \\
\hline Molido y tamizado & $\begin{array}{l}\text { Las partes, por separado, se muelen y } \\
\text { tamizan de manera automática con avance } \\
\text { manual }\end{array}$ & Molino-tamiz \\
\hline Separado & $\begin{array}{l}\text { Un porcentaje de flores molidas se separan } \\
\text { manualmente para mezclarse }\end{array}$ & Jarra graduada y balanza \\
\hline Mezclado & $\begin{array}{l}\text { El molido de flores y partes verdes se } \\
\text { mezclan de manera automática con carga } \\
\text { manual }\end{array}$ & Mezcladora \\
\hline Envasado y empacado & $\begin{array}{l}\text { El envasado es de manera automática. El } \\
\text { Empacado es manual. }\end{array}$ & Envasadora \\
\hline Sellado y embolsado & $\begin{array}{l}\text { Las cajas de ambos productos se sellan } \\
\text { manualmente. Estas a su vez se llenan en } \\
\text { bolsas de manera manual. }\end{array}$ & Sellador \\
\hline
\end{tabular}

Elaboración propia

\subsubsection{Proceso de producción}

\subsubsection{Descripción del proceso}

\section{Recepción y pesado}

Se recibe la manzanilla común entera fresca en mantas atadas ${ }^{18}$, estas pueden envolver como máximo $25 \mathrm{~kg}$ de materia prima. Ver Anexo 4. Las mantas son muy utilizadas ya que favorecen la ventilación a diferencia de los costales cerrados. Se desata la carga, se hace un control visual de la misma, se vuelve a atar, se pesa, registra y verifica el total. Después se traslada mediante un coche que pueda contener hasta dos mantas atadas.

\footnotetext{
18 Telas de polipropileno $\left(75 \mathrm{gr} / \mathrm{m}^{2}\right)$ de 2,00 x 1,20 m., muy usadas en Tarma. Atadas cubren un volumen de
} $0,384 \mathrm{~m}^{3}(0,6 \times 0,8 \times \mathrm{h} 0,8 \mathrm{~m})$ de planta entera fresca de manzanilla común cuya densidad es $63,77 \mathrm{~kg} / \mathrm{m}^{3}$. 


\section{Selección}

Se separan las flores de las partes verdes usando un peine de selección. Las partes dañadas y elementos extraños son separados manualmente al ser encontrados. De acuerdo con Celiz (1991) hay una merma de 6\% entre partes dañadas y elementos extraños. El Anexo 4 muestra cuatro tiempos observados. Las flores seleccionadas se van llenando en cestos ${ }^{19}$ hasta un 93\% de su capacidad para facilitar las operaciones posteriores de lavado y centrifugado. Las partes verdes seleccionadas son puestas en mantas y trasladadas en un coche a la picadora.

\section{Picado}

Solamente se pican las partes verdes seleccionadas. La picadora debe cortar las partes con un tamaño aproximado de 1,00 cm. Según Silva (1985), es importante picar estas partes para que el secado posterior de las mismas sea más rápido y mejor (p. 121). El producto picado es recibido en cestos hasta en un $95 \%$ de su capacidad, también para facilitar las operaciones posteriores de lavado y centrifugado. Según Celiz (1991) se pierde el $1 \%$.

\section{Lavado}

Flores y partes verdes picadas, por separado, dentro de cestos, se sumergen en agua, se dejan reposar como máximo 10 minutos en una solución de agua potable y desinfectante NeoClor Dx Plus de $5 \mathrm{ml}$ cada $10 \mathrm{~L}$ de agua. Al final se lavan, enjuagan y escurren.

\section{Centrifugado}

Según el Anexo 4 después del lavado y reposo de las partes estas ganan en promedio 38\% de peso, siendo necesario centrifugarlas por separado. Para ello, se usan cestos con superficie lateral de malla $\mathrm{N}^{\circ} 14$ (ASTM). Esto impide que las partes se caigan, y también que haya pérdidas al centrifugar, puesto que las partes miden entre 1,0 y $1,5 \mathrm{~cm}$. Asimismo, estos cestos no se llenan al 100\% de su capacidad, tal y como muestran los cálculos del Anexo 4, en base a las densidades de partes verdes y flores, los cestos se cargan en aproximadamente un $95 \%$ y $93 \%$, respectivamente. Se decidió un tiempo de centrifugado de 4 min por carga.

19 Cestos de malla $\mathrm{N}^{\circ} 14$ (ASTM). Se precisa que los cestos no se llenan al $100 \%$ de su capacidad. 


\section{Deshidratado}

Centrifugadas partes verdes y flores se colocan dentro de un deshidratador en bandejas diferentes. Franke y Schilcher (2005) indican que las bandejas son de baja inversión, de simple operación y flexibles para pequeñas y medianas escalas de producción (p. 194), además, sugieren deshidratar a una temperatura controlada de " $45{ }^{\circ} \mathrm{C}$ " (Franke y Schilcher, 2005 , p. 153) y también indican que las capas de las bandejas no deben superar los " $2 \mathrm{~cm}$ " (Franke y Schilcher, 2005, p. 161). La humedad al ingreso de ambas partes bordea el "80\%" (Franke y Schilcher, 2005, p. 172) con lo que coincide Celiz (1991). Por último, en base a Silva (1985), ambas partes se deshidratan hasta una humedad de 6,5\%, con velocidad de 4,7 $\mathrm{m} / \mathrm{s}$ y una carga de flores de $4,5 \mathrm{~kg} / \mathrm{m}^{2}$.

\section{Molido y tamizado}

Luego del deshidratado las partes verdes y flores se muelen por separado. Según Silva (1985) la operación de tamizado está asociada a la molienda, por tanto se llevan a cabo en una sola operación (p. 470). Se usa un tamiz N 30 (ASTM). Al final se vacían las bolsas de molido en una tina. La merma es $2 \%$.

\section{Separado}

El 29,84 \% de flores molidas es separado mediante una jarra de medida para ser mezclado con el molido de partes verdes.

\section{Mezclado}

Los molidos de un porcentaje de flores y el total de partes verdes son mezclados para el producto de planta entera. La proporción de las mismas es de 88,56 y 11,44\% respectivamente.

\section{Envasado y empacado}

El envasado es automático. Deben ser cargados manualmente el molido a envasar, bobinas de: etiquetas, papel filtro termosellable y sobres de envoltura, además de hilo y adhesivo. El 
Anexo 4 calcula la carga de molido teniendo en cuenta las especificaciones de cada producto. El empacado es manual, consiste en colocar los sobres que va suministrando la envasadora dentro de cajas, en las que previamente se puso las etiquetas adhesivas y luego se armaron.

\section{Sellado y embolsado}

Las cajas se envuelven con la ayuda de una selladora. Estas a su vez se llenan manualmente en bolsas en cantidad de 24 cajas. Asimismo, las figura 5.3, 5.4, 5.5 y 5.6 muestran los diagramas de flujo, diagrama de operaciones (DOP) y balances de materia y energía, respectivamente.

Figura 5. 3

Diagrama de flujo del proceso productivo

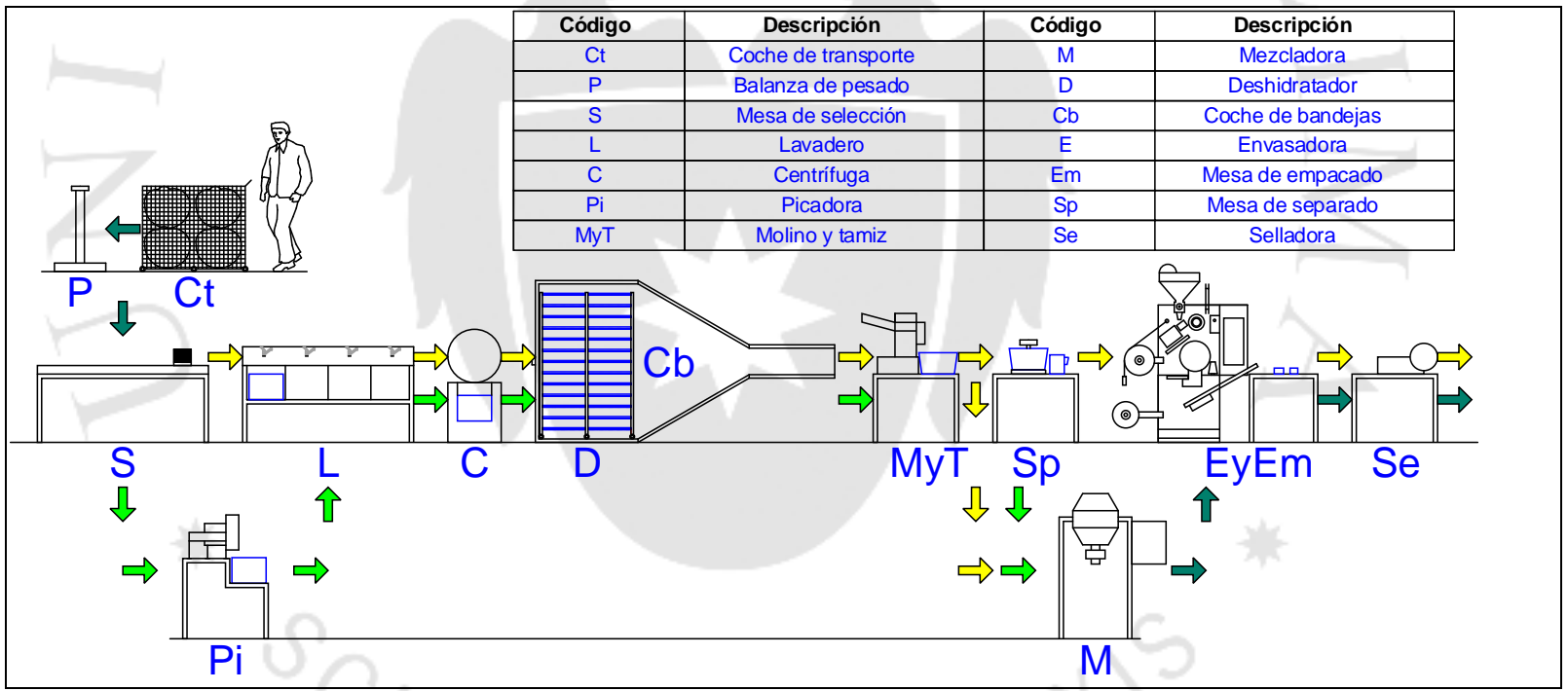

Elaboración propia 


\subsubsection{Diagrama de proceso: DOP}

Figura 5. 4

Diagrama de operaciones del proceso de bolsas filtrantes de manzanilla común

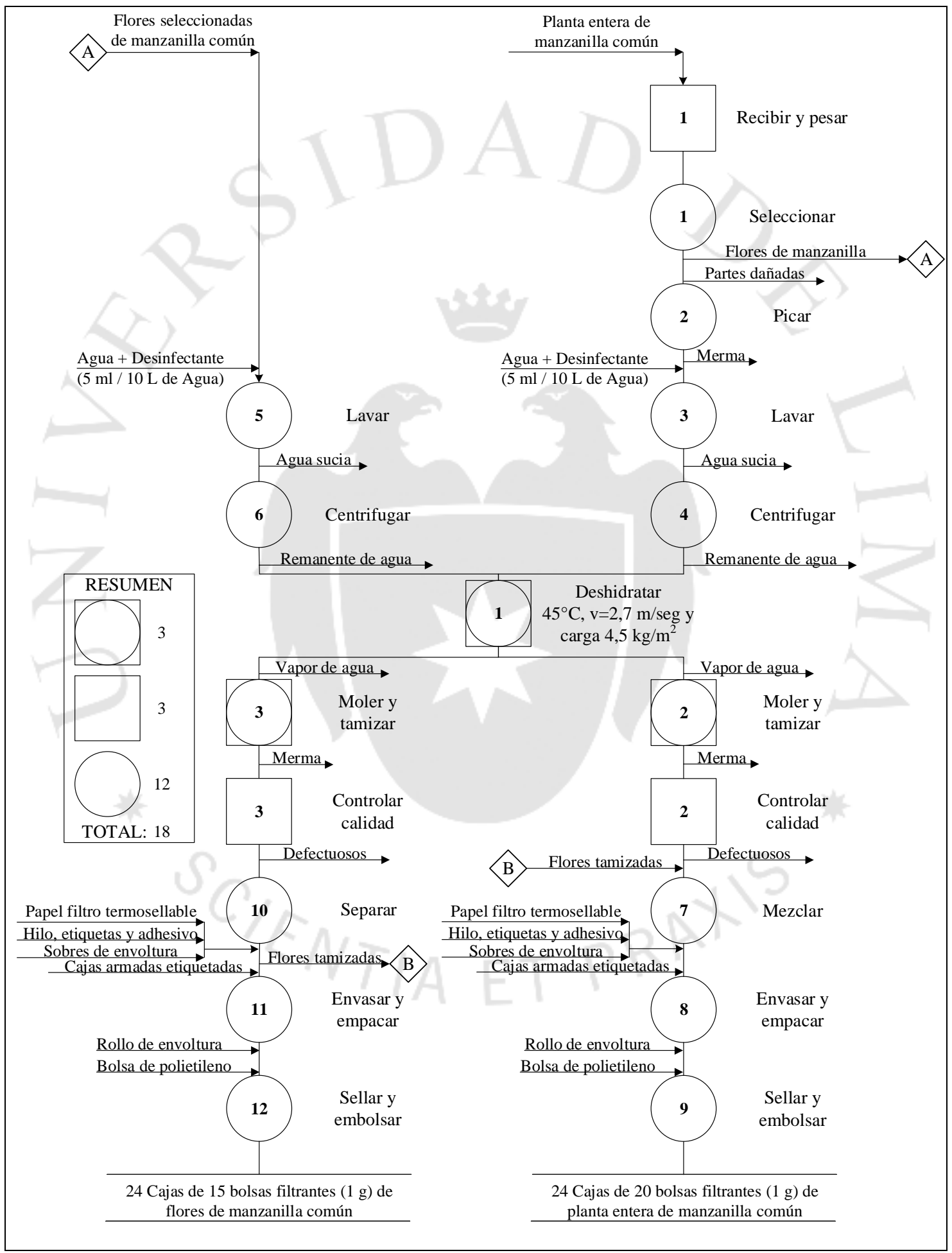

Elaboración propia 


\subsubsection{Balance de materia y energía}

Figura 5. 5

Balance de materia del proceso de fabricación de bolsas filtrantes de manzanilla común

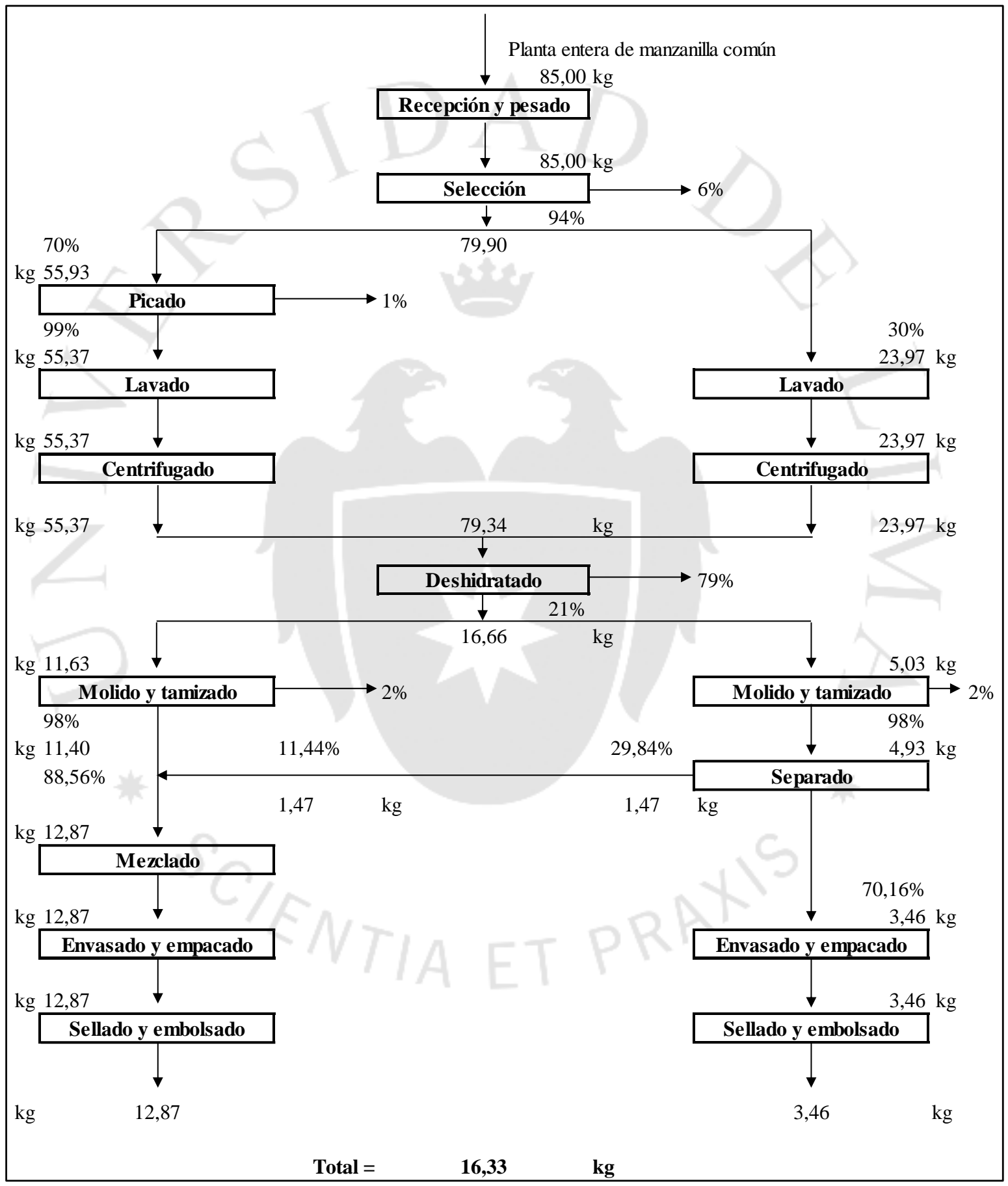

Elaboración propia 
Figura 5. 6

Balance de energía de la operación de deshidratado de manzanilla común

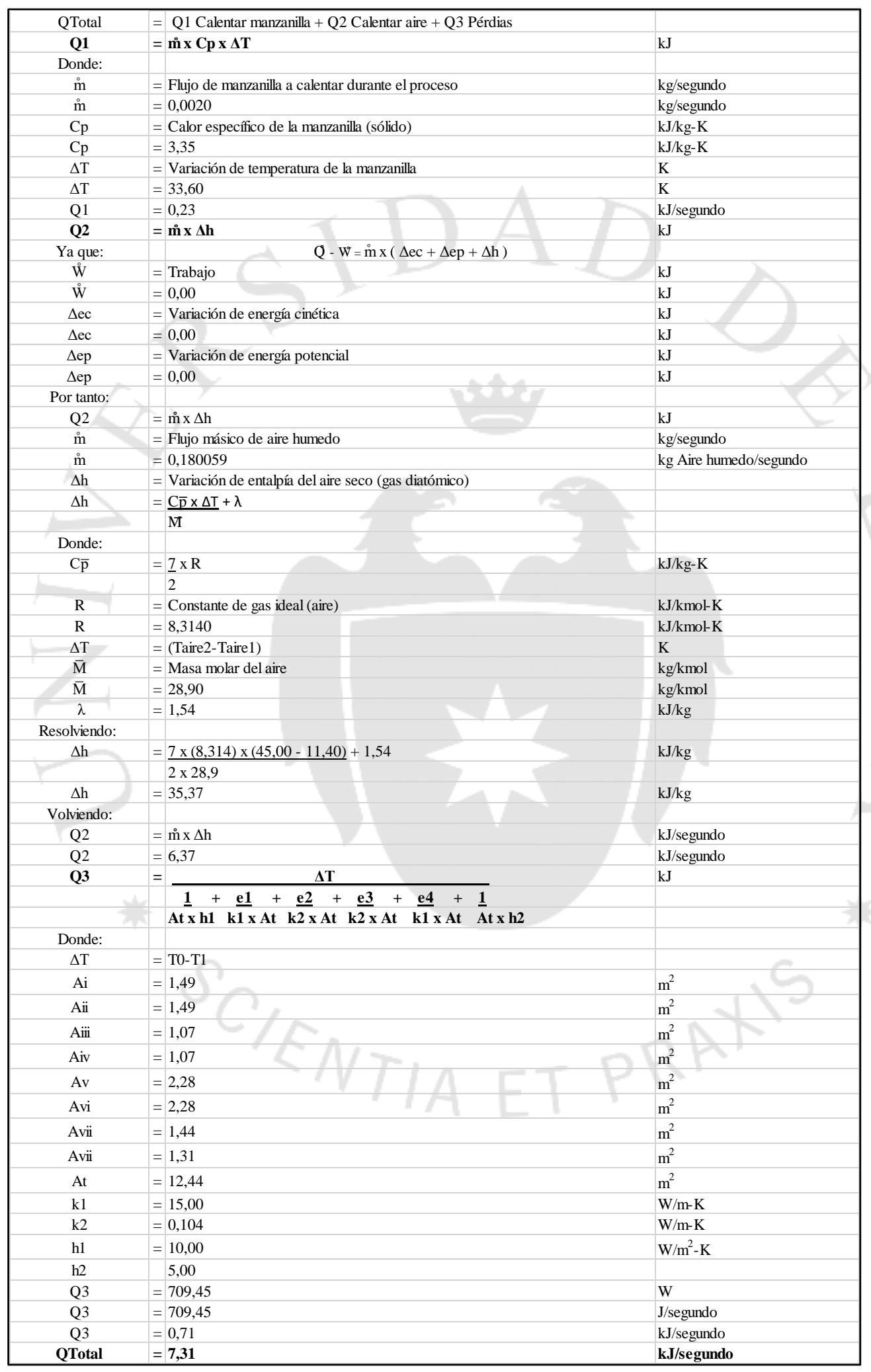

Elaboración propia 


\subsection{Características de las instalaciones y equipos}

\subsubsection{Selección de la maquinaria y equipos}

Según la naturaleza de la tecnología y el DOP de la Figura 5.4, la Tabla 5.6 resume la cantidad y tipo de maquinaria necesaria para el proceso productivo. Desde la Tabla 5.7 hasta la 5.26 se especifica cada una.

Tabla 5.6

Resumen de cantidad y tipo de maquinaria para el proceso productivo

\begin{tabular}{|c|c|}
\hline Operación/Control & Resumen de maquinaria, equipos y herramientas \\
\hline Recepción y pesado & (01)balanza de plataforma y (01)coche de traslado cerrado \\
\hline Selección & (01)mesa de selección, (01)peine de selección y (04)cestos \\
\hline Picado & (01)picadora de hierbas o plantas frescas y (01) mesa \\
\hline Lavado & (01)lavadero de acero inoxidable de 04 pozas \\
\hline Centrifugado & (01)centrifuga de vegetales \\
\hline Deshidratado & (01)deshidratador por flujo de aire calentado, (01)quemador de GLP \\
\hline & (01)extractor, (01)Coche con (52)bandejas de acero inoxidable \\
\hline Molido y tamizado & (01)molino de martillos con Tamiz, (02)tinas y (01) mesa \\
\hline Separado & (01)jarra de medida, (01)balanza de sobremesa y (01) mesa \\
\hline Mezclado & (01)mezcladora por volteo tipo rombo \\
\hline Envasado y empacado & (01)envasadora de bolsas filtrantes, $(01)$ removedor y (01) mesa \\
\hline Sellado y embolsado & (01)selladora semiautomática de cajas pequeñas y (01) mesa \\
\hline Calidad & (01)balanza de humedad y (01) horno de mufla \\
\hline
\end{tabular}

Elaboración propia

\subsubsection{Especificaciones de la maquinaria}

Tabla 5.7

Especificaciones técnicas de balanza de plataforma

\begin{tabular}{|l|l|}
\hline Balanza de plataforma & \multicolumn{1}{|c|}{ Especificaciones técnicas } \\
\hline & Tipo: Balanza de plataforma \\
Material: Hierro fundido & Pantalla LCD \\
Indicador electrónico en metal \\
Capacidad: $250 \mathrm{~kg}$ \\
Graduación: De 50 en $50 \mathrm{~g}$ \\
Dimensiones plataforma: $800 \mathrm{x} 600 \mathrm{xh} 1.000 \mathrm{~mm}$ \\
Fuente de Poder: Batería (200 horas) o adaptador \\
C.A. \\
Marca: SORES \\
Modelo: GSW \\
Precio: S/. 2.397,67 soles (Inc. IGV)
\end{tabular}

Fuente: Balanzas Sores, (2016). 
Tabla 5.8

Especificaciones técnicas de coche de traslado

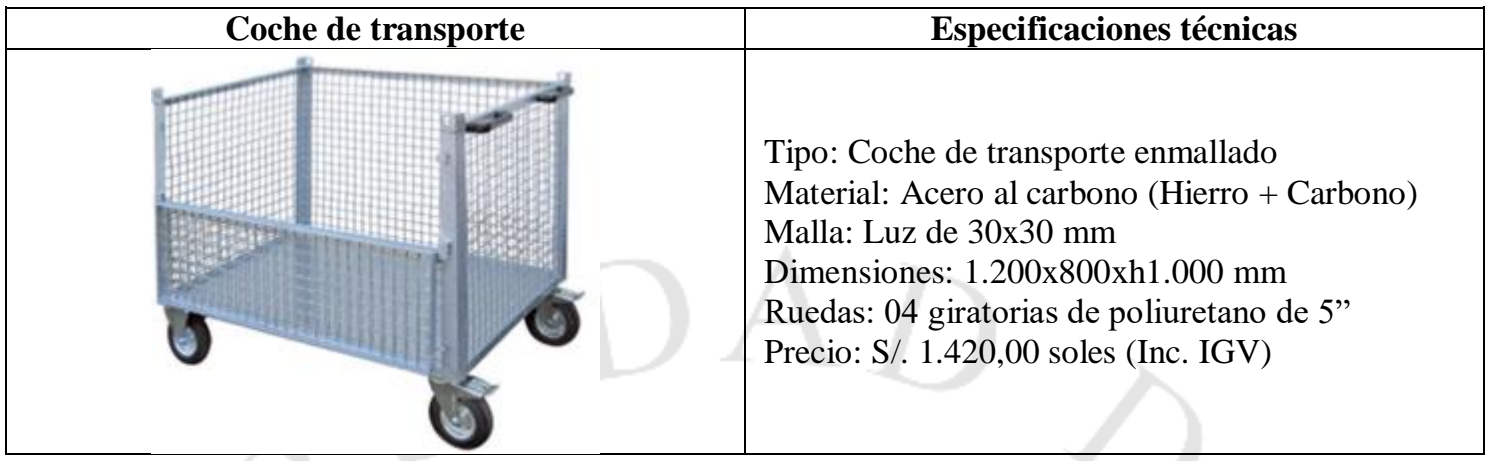

Fuente: EJV EIRL, (2016).

Tabla 5.9

Especificaciones técnicas de mesa de selección

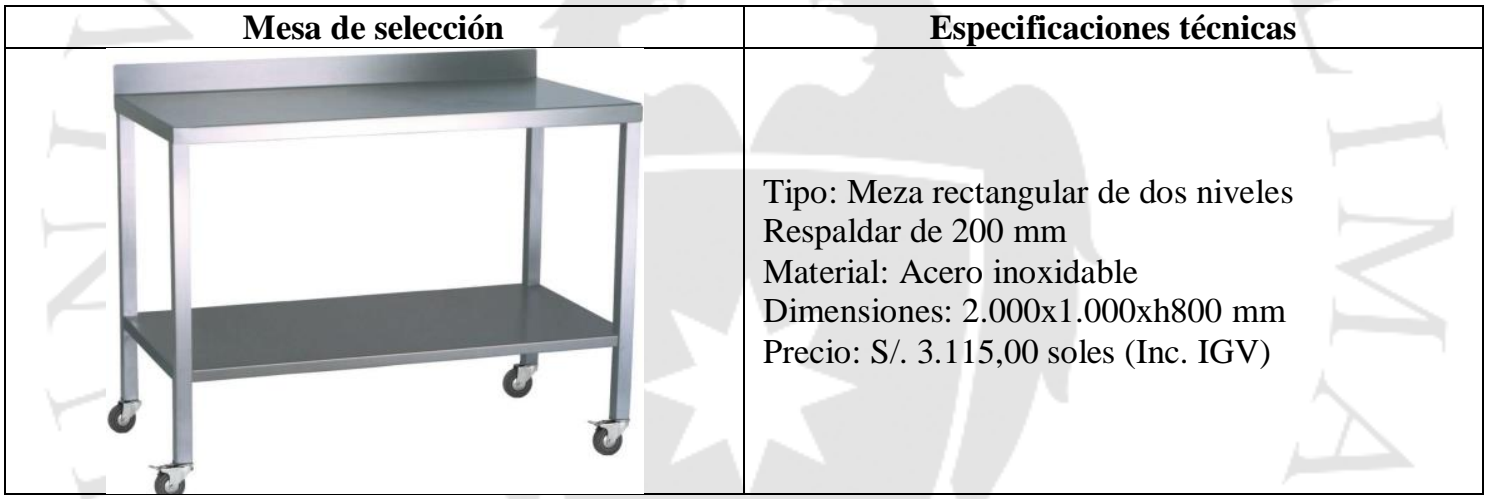

Fuente: Arturo Ravello Soto, (2016).

Tabla 5. 10

Especificaciones técnicas de peine de selección

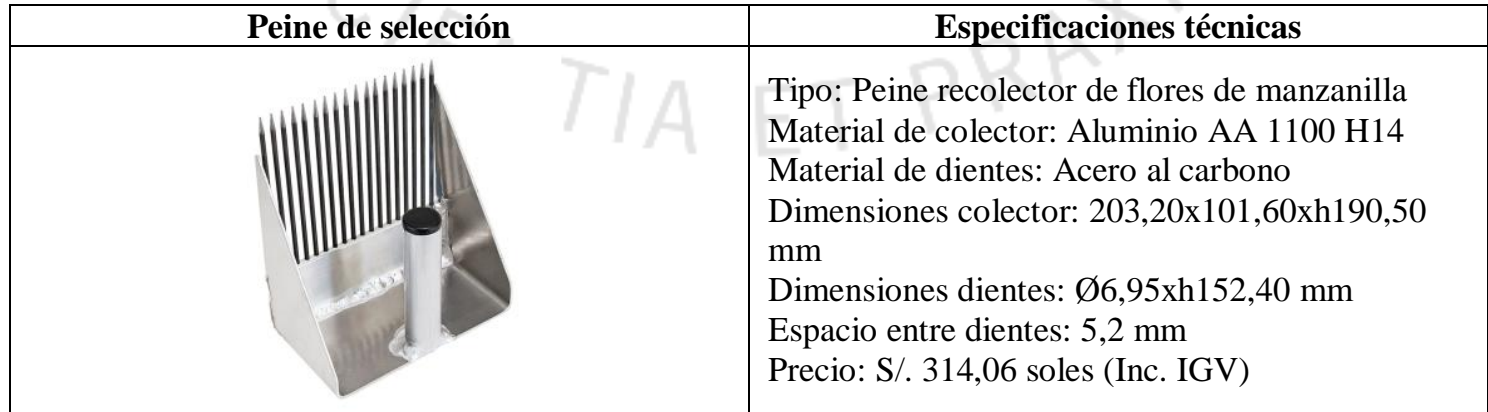

Fuente: Acsegral, (2016). 
Tabla 5. 11

Especificaciones técnicas de cestos

\begin{tabular}{|l|l|}
\hline \multicolumn{1}{|c|}{ Cestos } & \multicolumn{1}{|c|}{ Especificaciones técnicas } \\
\hline & Tipo: Cesto circular con dos asas \\
Material: Acero inoxidable AISI 304 \\
Dimensiones: Ø400xh300 mm \\
Volumen: 37,70 L \\
Peso: 0,925 kg \\
Malla $\mathrm{N}^{\circ} 14$ (ASTM) \\
Precio: S/. 250,00 soles (Inc. IGV) \\
\hline
\end{tabular}

Fuente: Arvisac, (2016).

Tabla 5. 12

Especificaciones técnicas de picadora

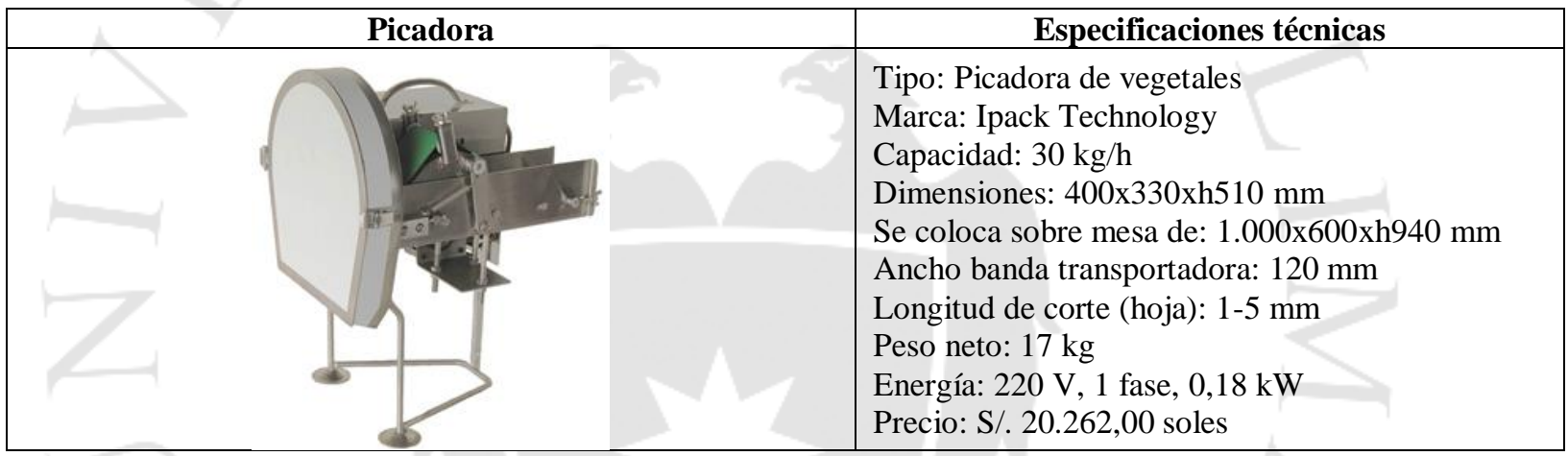

Fuente: Ipack Technology, (2016).

Tabla 5. 13

Especificaciones técnicas del lavadero

\begin{tabular}{|l|l|}
\hline & \multicolumn{1}{|c|}{ Especificaciones técnicas } \\
\hline
\end{tabular}

Fuente: Acsegral, (2016). 
Tabla 5.14

Especificaciones técnicas de la centrífuga

\begin{tabular}{|l|l|}
\hline \multicolumn{1}{|c|}{ Centrífuga } & \multicolumn{1}{|c|}{ Especificaciones técnicas } \\
\hline & $\begin{array}{l}\text { Tipo: Centrífuga de vegetales de hojas y } \\
\text { hortalizas enteras o cortadas. } \\
\text { Material estructura: Acero al carbono } \\
\text { Material de cesto: Acero inoxidable AISI 305 } \\
\text { Dimensiones: } \varnothing 550 x h 700 \text { mm } \\
\text { Dimensiones de cesto: } \varnothing \text { 400xh300 mm } \\
\text { Malla de cesto: } \mathrm{N}^{\circ} 14 \text { (ASTM) } \\
\text { Potencia: } 1 \text { HP } \\
\text { Peso: 125 kg } \\
\text { Marca: Incalfer } \\
\text { Modelo: CE400 } \\
\text { Precio: S/. 31.135,94 soles (Inc. IGV) }\end{array}$ \\
\\
\end{tabular}

Fuente: Incalfer, (2016).

Tabla 5. 15

Especificaciones técnicas del deshidratador

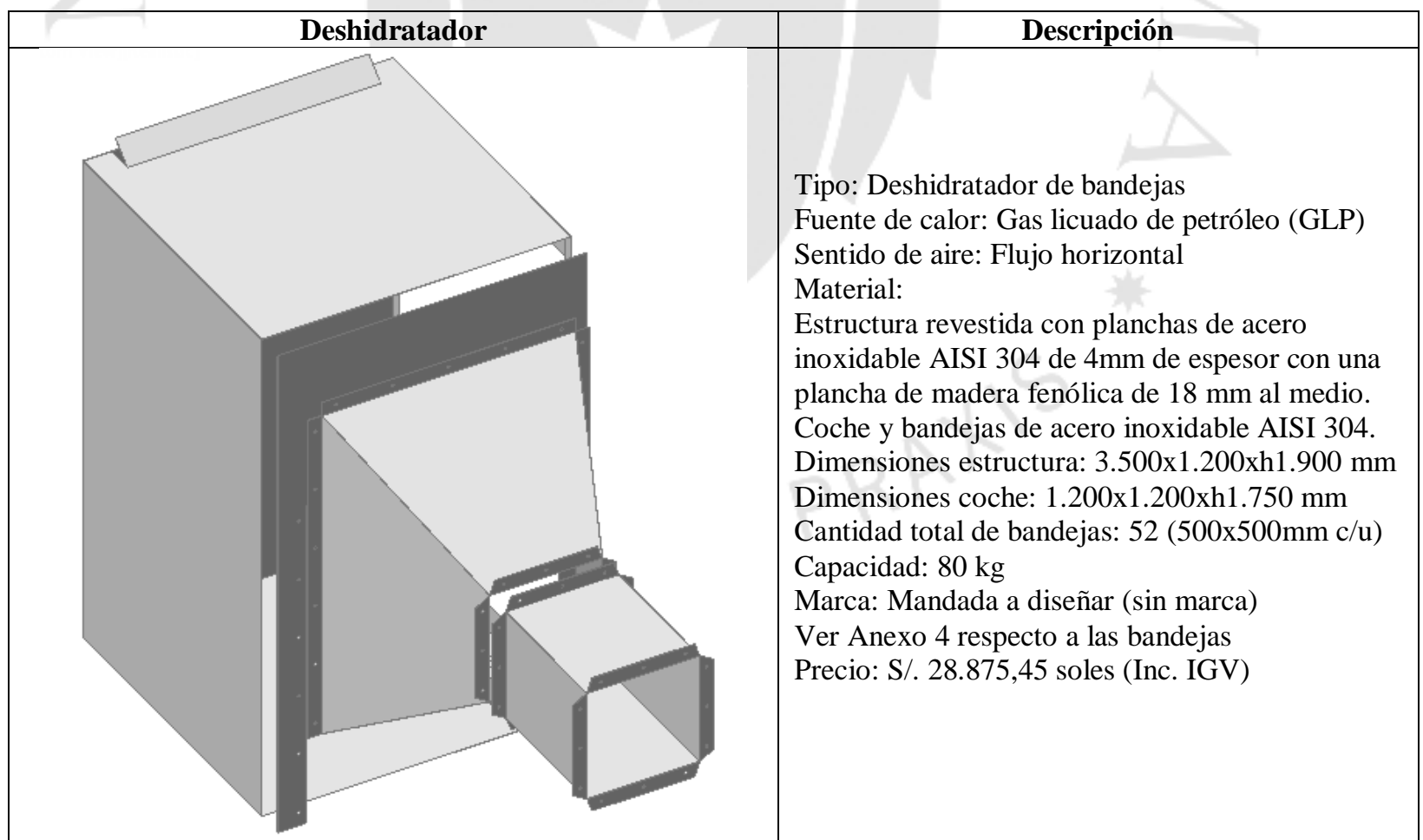

Fuente: Consorcio Alanper, (2016); Wayler S.A., (2016); JCC Industriales, (2016) y Acsegral, (2016). 
Tabla 5. 16

Especificaciones técnicas del molino de martillos

\begin{tabular}{|l|l|}
\hline Molino de martillos & \multicolumn{1}{|c|}{ Descripción } \\
\hline Tipo: Molino continuo de martillos \\
Material: Acero inoxidable y acero al carbono \\
Dimensiones:250x240xh490 mm \\
Se coloca sobre mesa de: $1.000 \times 600 \times 4800 \mathrm{~mm}$ \\
Voltaje: $110 / 220 \mathrm{~V}$ \\
Potencia: $1.200 \mathrm{~W}$ \\
Velocidad de rotación de motor: $20.000 \mathrm{rpm}$ \\
Capacidad: $15 \mathrm{~kg} / \mathrm{h}$ \\
Peso: $12 \mathrm{~kg}$ \\
Marca: DC House \\
Modelo: DF-15 \\
Accesorios: Tamices (60-180 mesh) \\
Precio: S/. $1.497,97$ soles (Inc. IGV)
\end{tabular}

Fuente: DC House, (2016).

Tabla 5.17

Especificaciones técnicas de tina

\begin{tabular}{|c|l|}
\hline Tina & \multicolumn{1}{|c|}{ Especificaciones técnicas } \\
\hline & Tipo: Tina circular con doble asa \\
& Material: Acero inoxidable AISI 304 \\
& Dimensiones: \\
& -Diámetro mayor $\varnothing 450 \mathrm{~mm}$ \\
& -Diámetro menor $\varnothing 380 \mathrm{~mm}$ \\
& -Altura: $\mathrm{h} 250 \mathrm{~mm}$ \\
& Volumen: $33,90 \mathrm{~L}$ \\
& Espesor: $2,5 \mathrm{~mm}$ \\
& Precio: $\mathrm{S} / .120,00$ soles (Inc. IGV) \\
\hline
\end{tabular}

Fuente: Arvisac, (2016).

Tabla 5. 18

Especificaciones técnicas de jarra de medida

\begin{tabular}{|c|c|c|}
\hline & Jarra de medida & Especificaciones técnicas \\
\hline & & $\begin{array}{l}\text { Tipo: Jarra de medida } \\
\text { Material: Acero inoxidable AISI } 304 \\
\text { Dimensiones: } \varnothing 170 \times 225 \mathrm{~mm} \\
\text { Se coloca sobre mesa de: } 1.600 \times 600 \times 400 \mathrm{~mm} \\
\text { Volumen: } 5,11 \mathrm{~L} \\
\text { Precio: S/. } 161,45 \text { soles (Inc. IGV) }\end{array}$ \\
\hline
\end{tabular}

Fuente: Acsegral, (2016). 
Tabla 5. 19

Especificaciones técnicas de balanza de sobremesa

\begin{tabular}{|l|l|}
\hline Balanza de sobremesa & \multicolumn{1}{|c|}{ Especificaciones técnicas } \\
\hline & $\begin{array}{l}\text { Tipo: Balanza de sobremesa } \\
\text { Material: Cédula de carga de aluminio } \\
\text { Plataforma de acero inoxidable AISI 304 } \\
\text { Pantalla de LCD de 7 dígitos, 60 mm de alto } \\
\text { Dimensiones de plataforma: 400x500 mm } \\
\text { Fuente de Poder: 85-240V C.A o pilas AA(80h) } \\
\text { Capacidad: 60 kg } \\
\text { Marca: Mettler Toledo } \\
\text { Modelo: BBA231-3B60 } \\
\text { Precio: S/. 2.483,61 soles (Inc. IGV) }\end{array}$ \\
\hline
\end{tabular}

Fuente: Precisión Perú, (2016).

Tabla 5. 20

Especificaciones técnicas de la mezcladora

\begin{tabular}{|l|l|}
\hline \multicolumn{1}{|c|}{ Mezcladora } & \multicolumn{1}{c|}{ Descripción } \\
\hline & $\begin{array}{l}\text { Tipo: Mezcladora romboidal } \\
\text { Material: Acero inoxidable AISI (316) } \\
\text { Dimensiones: 1.250x1.000xh1.700 mm } \\
\text { Capacidad: 70 L } \\
\text { Marca: PULVEX } \\
\text { Modelo: MR70 } \\
\text { Motor: Reductor de 0,33 HP } \\
\text { Precio: S/. 16.203,66 soles (Inc. IGV) }\end{array}$ \\
\hline
\end{tabular}

Fuente: Pulvex, (2016).

Tabla 5. 21

Especificaciones técnicas de selladora

\begin{tabular}{|c|c|}
\hline Selladora & Descripción \\
\hline & $\begin{array}{l}\text { Tipo: Selladora manual } \\
\text { Dimensión de selladora: } 540 \times 300 \times 200 \mathrm{~mm} \\
\text { Se coloca sobre mesa de: } 1.000 \times 600 \times 400 \mathrm{~mm} \\
\text { Envoltura: Polipropileno Biorientado (BOPP) } \\
\text { Producción máxima: } 20 \text { cajas/min } \\
\text { Ancho máxima a sellar: } 240 \mathrm{~mm} \\
\text { Peso de selladora: } 9,00 \mathrm{~kg} \\
\text { Tensión de alimentación: 200/220 V-50/60 Hz } \\
\text { Potencia: } 0,15 \mathrm{~kW} \\
\text { Marca: Rozagrapisa } \\
\text { Modelo: } 18 \text { SWSS1240 } \\
\text { Precio: S/. 4.917,22 soles (Inc. IGV) }\end{array}$ \\
\hline
\end{tabular}

Fuente: Rozagrapisa, (2016). 
Tabla 5. 22

Especificaciones técnicas de la envasadora

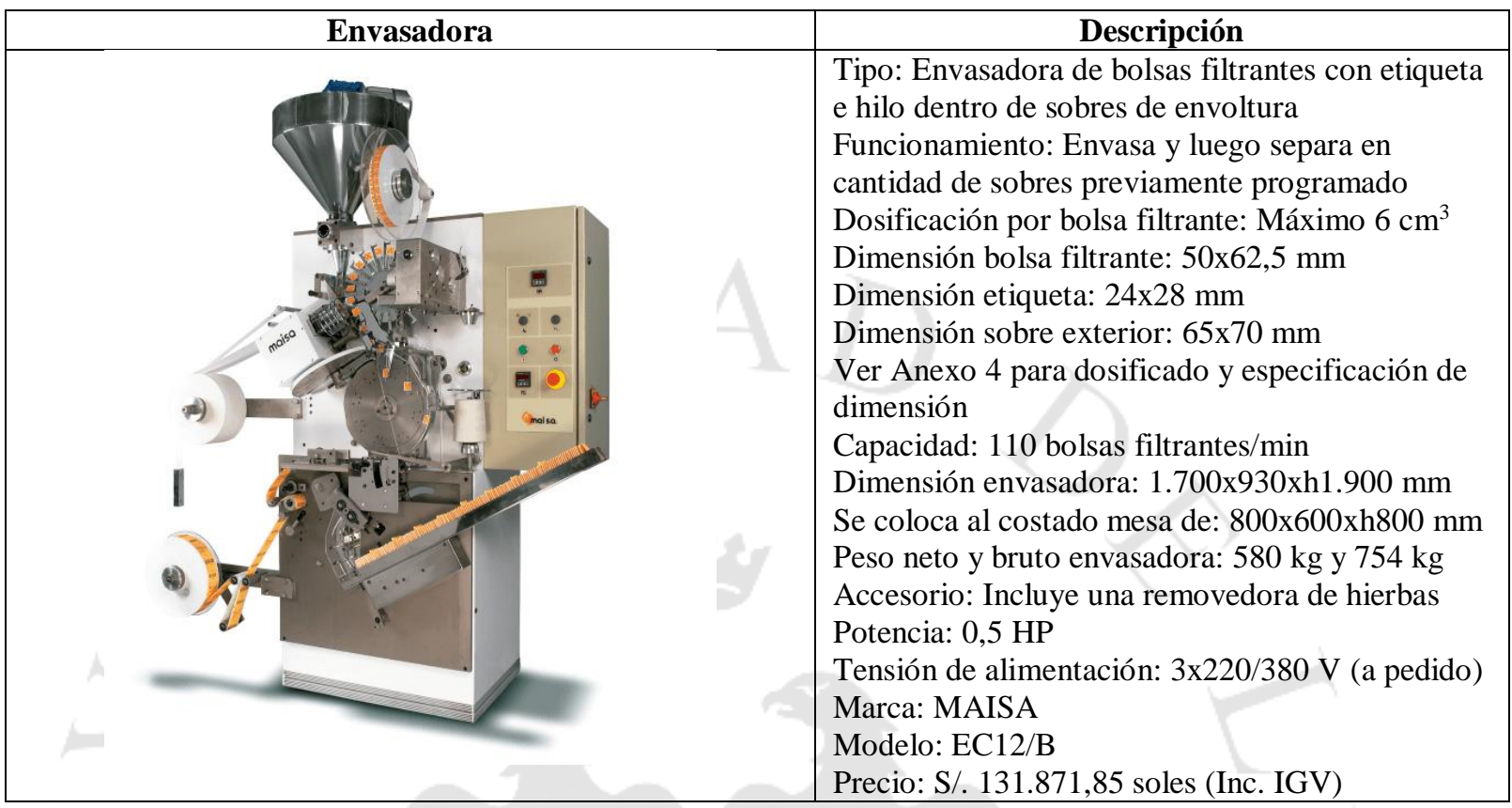

Fuente: Maisa S.A., (2016).

Tabla 5. 23

Especificaciones técnicas de tanque de GLP

\begin{tabular}{|c|c|}
\hline Tanque de GLP e instalación interna & Descripción \\
\hline$x_{x-2}$ & $\begin{array}{l}\text { Tipo: Tanque estacionario cilíndrico horizontal de } \\
\text { cabezales semiesféricos } \\
\text { Capacidad: } 1.000 \text { galones } \\
\text { Diámetro interior: } 1.040,4 \mathrm{~mm} \\
\text { Longitud total: } 4.846,6 \mathrm{~mm} \\
\text { Material: Cuerpo fabricado con plancha de acero } \\
\text { importado SA- } 455 \text { de } 6,0 \mathrm{~mm} \text { de espesor y acero } \\
\text { importado SA-285C de } 5,2 \mathrm{~mm} \text { de espesor para la } \\
\text { tapa según NFPA58. } \\
\text { Fabricación: De acuerdo con normas ASME, } \\
\text { sección VIII División } 1 \\
\text { Presión de diseño: } 250 \text { psi } \\
\text { Presión de prueba: } 325 \text { psi } \\
\text { Precios (Inc. IGV): } \\
\text { Tanque, traslado y accesorios: S/. 23.112,19 soles } \\
\text { Instalación interna: S/. 5.977,29 soles } \\
\text { Documentación: S/. } 3.586,37 \text { soles } \\
\text { Precio total: S/. } 32.675,85 \text { (Inc. IGV) }\end{array}$ \\
\hline
\end{tabular}

Fuente: Grupo Itsa, (2016). 
Tabla 5. 24

Especificaciones técnicas de horno de mufla

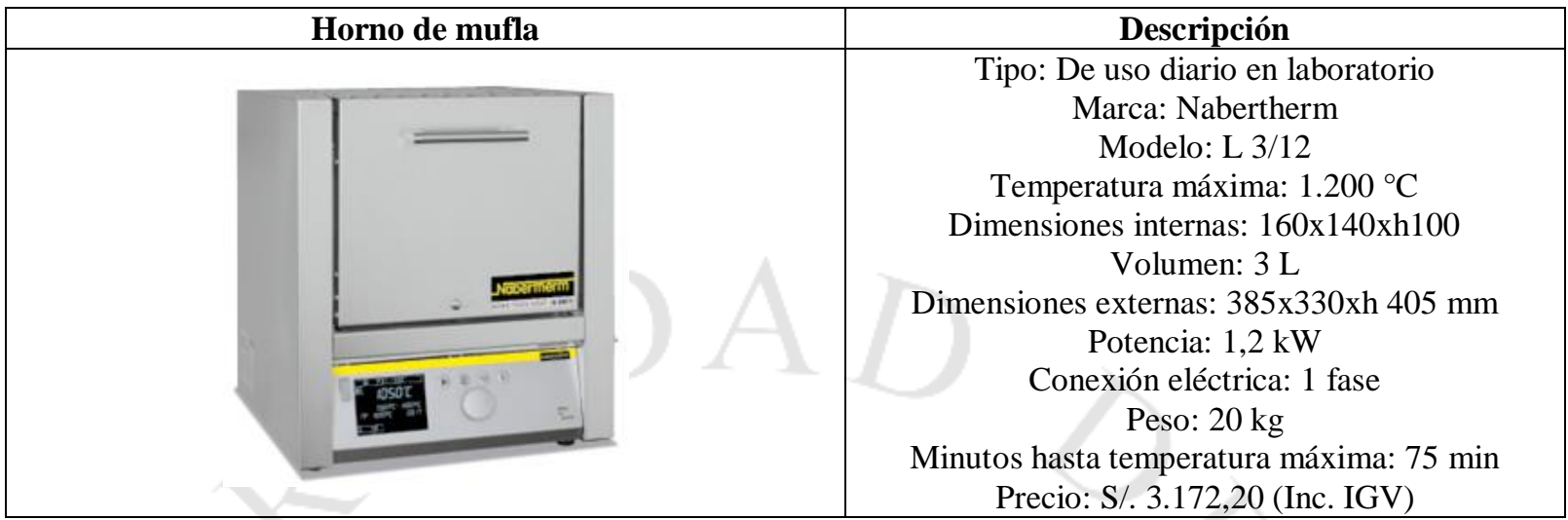

Fuente: Nabertherm, (2016).

Tabla 5. 25

Especificaciones técnicas de balanza de humedad

\begin{tabular}{|c|c|}
\hline Balanza de humedad & Descripción \\
\hline & $\begin{array}{c}\text { Tipo: Balanza de humedad } \\
\text { Marca: Ohaus } \\
\text { Capacidad: } 35 \mathrm{~g}\end{array}$ \\
$\begin{array}{c}\text { Dimensiones: } 355 \mathrm{x} 190 \mathrm{xh} 152 \mathrm{~mm} \\
\text { Diámetro de plato: } 90 \mathrm{~mm} \\
\text { Precisión: } 0,002 \mathrm{~g} \\
\text { Pjuste de temperatura: } 50-165^{\circ} \mathrm{C}\left(5^{\circ} \text { incremento) }\right. \\
\text { Fuente de calor: Halógeno } \\
\text { Peso: } 4,50 \mathrm{~kg}\end{array}$ \\
$\begin{array}{c}\text { Potencia máxima: } 4,50 \mathrm{~kW} \\
\text { Precio: S/. } 11.914,73 \text { (Inc. IGV) }\end{array}$ \\
\hline
\end{tabular}

Fuente: Ohaus, (2016).

Tabla 5. 26

Especificaciones técnicas de mesas

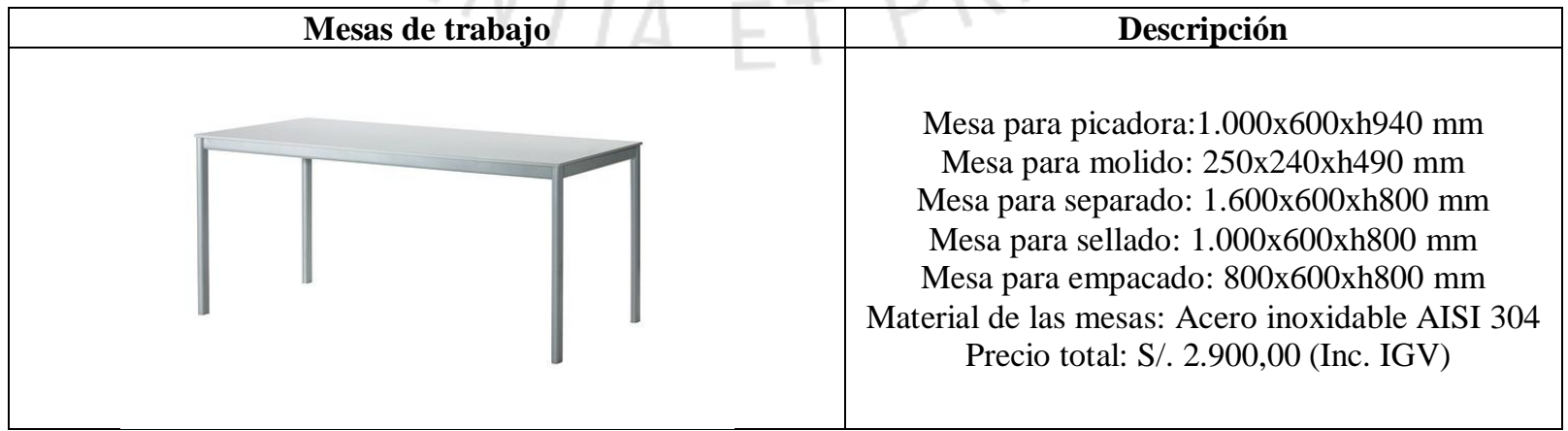

Fuente: Acsegral, (2016). 


\subsection{Capacidad instalada}

La capacidad instalada está determinada por la operación "cuello de botella", es decir por aquella operación que restringe todo el proceso. En el presente caso la operación unitaria de deshidratado es el cuello de botella puesto que demora 11 horas, esto restringe a todas las demás operaciones.

\subsubsection{Cálculo de la capacidad instalada}

Para este cálculo se inicia dando las valoraciones y suplementos (Anexo 4) a cada una de las operaciones. Se debe precisar si son manuales, semiautomáticos o automáticos. Una vez consolidados se halla el tiempo estándar de cada operación tal y como muestra el mismo Anexo 4, lo que permite a su vez hallar el factor de eficiencia de los mismos. Al final con los tiempos estándar se logra hallar el tiempo de ciclo de todo el proceso, que a su vez permite hallar el factor de utilización.

Asimismo, se debe tener en cuenta que al ser dos los productos en estudio, la capacidad instalada se puede calcular mediante el método de balance de materia o el de unidades equivalentes, el primer método se basa en uno de los productos, el segundo halla las capacidades de cada una de las operaciones, tanto para el proceso de partes verdes como el de flores. Por cualquier método los resultados deben coincidir. La Tabla 5.27 muestra las capacidades de las operaciones en producto terminado por hora mediante el primer método.

Como se puede comprobar la menor capacidad en cuanto a producto terminado corresponde a la operación unitaria de deshidratado, misma que representa la capacidad instalada. 
Tabla 5.27

Capacidades en producto terminado de las operaciones por el método de balance de materia

\begin{tabular}{|c|c|c|c|c|c|c|c|c|c|}
\hline & QE & $\mathbf{P}$ & $\mathbf{M}$ & $\mathbf{H}$ & $\mathbf{U}$ & $\mathbf{E}$ & $\begin{array}{c}\mathrm{CO} \\
(\mathrm{PxMxHxUxE)}) \\
\end{array}$ & QF/QE & $\begin{array}{c}\text { COPT: } \\
\text { COxQF/QE }\end{array}$ \\
\hline Operación & $\begin{array}{c}\text { Cantidad } \\
\text { Entrante } \\
(\mathrm{kg}) \\
\end{array}$ & $\begin{array}{c}\text { Producción } \\
\text { kg/h }\end{array}$ & $\begin{array}{l}\text { Máquina/ } \\
\text { Operario }\end{array}$ & $\begin{array}{c}\text { Horas* } \\
\text { /año }\end{array}$ & $\begin{array}{c}\text { Factor } \\
\text { Utilización }\end{array}$ & $\begin{array}{c}\text { Factor } \\
\text { Eficiencia }\end{array}$ & $\begin{array}{l}\text { Capacidad } \\
\text { Producción }\end{array}$ & $\begin{array}{c}\text { Factor } \\
\text { de } \\
\text { conversión } \\
\end{array}$ & $\begin{array}{c}\text { Capacidad } \\
\text { Producción } \\
\text { kg PT/año } \\
\end{array}$ \\
\hline Recepción y pesado (P.E.) & $49.610,14$ & $1.157,93$ & 1 & 7.200 & 1,0000 & 0,8470 & $7.061 .538,46$ & 0,1921 & $1.356 .506,26$ \\
\hline Selección (P.E.) & $49.610,14$ & 35,31 & 1 & 7.200 & 1,0000 & 0,8540 & $217.132,39$ & 0,1921 & $41.710,66$ \\
\hline Picado (Sólo P.V.) & $32.643,47$ & 37,18 & 1 & 7.200 & 0,9986 & 0,7998 & $213.784,47$ & 0,2301 & $49.183,44$ \\
\hline Lavado (P.V.) & $32.317,04$ & 202,77 & 1 & 7.200 & 1,0000 & 0,9102 & $1.328 .896,80$ & 0,2324 & $308.815,32$ \\
\hline Lavado (F.) & $13.990,06$ & 112,07 & $1=$ & 7.200 & 1,0000 & 0,9471 & $764.209,59$ & 0,1444 & $110.343,67$ \\
\hline Centrifugado (P.V.) & $32.317,04$ & 135,20 & 1 & 7.200 & 0,9986 & 0,9941 & $966.410,18$ & 0,2324 & $224.578,97$ \\
\hline Centrifugado (F.) & $13.990,06$ & 116,52 & 1 & 7.200 & 0,9986 & 0,9930 & $831.894,57$ & 0,1444 & $120.116,66$ \\
\hline Deshidratado (P.V. y F.) & $46.307,09$ & 6,62 & 1 & 7.200 & 0,9986 & 0,9890 & $47.099,29$ & 0,2058 & $9.693,03$ \\
\hline Molido y tamizado (P.V.) & $6.786,58$ & 18,36 & 1 & 7.200 & 0,9986 & 0,7998 & $105.577,89$ & 1,1066 & $116.831,85$ \\
\hline Molido y tamizado (F.) & $2.937,91$ & 18,35 & 1 & 7.200 & 0,9986 & 0,7998 & $105.541,46$ & 0,6876 & $72.566,93$ \\
\hline Separado (Sólo F.) & $2.879,15$ & 346,30 & 1 & 7.200 & 1,0000 & 0,7770 & $1.937 .333,85$ & 0,7016 & $1.359 .233,43$ \\
\hline Mezclado (F. + \%P.V.) & $7.509,99$ & 47,60 & 1 & 7.200 & 0,9986 & 0,9829 & $336.414,76$ & 1,0000 & $336.414,76$ \\
\hline Envasado y empacado (P.E.) & $7.509,99$ & 7,17 & 1 & 7.200 & 0,9986 & 0,9993 & $51.521,91$ & 1,0000 & $51.521,91$ \\
\hline Envasado y empacado (F.) & $2.020,01$ & 7,16 & 1 & 7.200 & 0,9986 & 0,9991 & $51.463,62$ & 1,0000 & $51.463,62$ \\
\hline Sellado y embolsado (P.E.) & $7.509,99$ & 29,69 & 1 & 7.200 & 0,9986 & 0,7999 & $170.768,65$ & 1,0000 & $170.768,65$ \\
\hline Sellado y embolsado (F.) & $2.020,01$ & 22,10 & 1 & 7.200 & 0,9986 & 0,7997 & $127.097,53$ & 1,0000 & $127.097,53$ \\
\hline
\end{tabular}

Nota:"6 días/semana, 8 horas/ turno, 3 turnos/día y 50 semanas/año; QF: Cantidad de producto terminado del último año (9.530,00); P.E.: Planta Entera; P.V.: Partes

Verdes; F.: Flores.

Elaboración propia

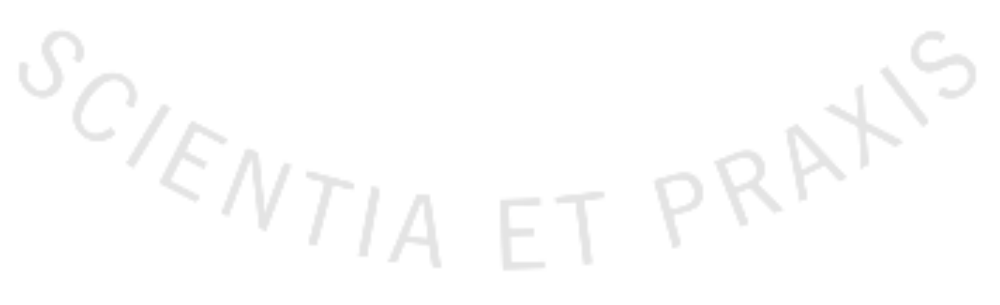




\subsubsection{Cálculo detallado del número de maquinaria requerida}

La Tabla 5.28 muestra el requerimiento de maquinaria u operarios según cada operación. Se precisa que esta tabla muestra todas las operaciones tanto para partes verdes como para flores.

Tabla 5. 28

Requerimiento de maquinaria u operarios

\begin{tabular}{|c|c|c|c|c|c|c|c|}
\hline Operación & $\begin{array}{c}\text { Cantidad a } \\
\text { ingresar } \\
\text { (kg/año) }\end{array}$ & $\begin{array}{l}\text { Tiempo } \\
\text { Estándar } \\
\text { (hora } / \mathrm{kg})\end{array}$ & $\begin{array}{c}\text { Horas/ } \\
\text { año }\end{array}$ & $\mathrm{U}(\%)$ & $\mathrm{E}(\%)$ & $\begin{array}{l}\text { Número de } \\
\text { maquinaria u } \\
\text { operarios }\end{array}$ & $\begin{array}{l}\text { Número de } \\
\text { maquinaria u } \\
\text { operarios }\end{array}$ \\
\hline Recepción y pesado (Planta Entera) & $49.610,14$ & 0,0009 & 7.200 & 1,0000 & 0,8470 & 0,0070 & 1,00 \\
\hline Selección (Planta Entera) & $49.610,14$ & 0,0283 & 7.200 & 1,0000 & 0,8540 & 0,2285 & 1,00 \\
\hline Picado (Sólo Partes Verdes) & $32.643,47$ & 0,0269 & 7.200 & 0,9986 & 0,7998 & 0,1527 & 1,00 \\
\hline Lavado (Partes Verdes) & $32.317,04$ & 0,0049 & 7.200 & 1,0000 & 0,9102 & 0,0243 & 1,00 \\
\hline Lavado (Flores) & $13.990,06$ & 0,0089 & 7.200 & 1,0000 & 0,9471 & 0,0183 & 1,00 \\
\hline Centrifugado (Partes Verdes) & $32.317,04$ & 0,0074 & 7.200 & 0,9986 & 0,9941 & 0,0334 & 1,00 \\
\hline Centrifugado (Flores) & $13.990,06$ & 0,0086 & 7.200 & 0,9986 & 0,9930 & 0,0168 & 1,00 \\
\hline Deshidratado (Partes Verdes y Flores) & $46.307,09$ & 0,1478 & 7.200 & 0,9986 & 0,9890 & 0,9623 & 1,00 \\
\hline Molido y tamizado (Partes Verdes) & $6.786,58$ & 0,0545 & 7.200 & 0,9986 & 0,7998 & 0,0643 & 1,00 \\
\hline Molido y tamizado (Flores) & $2.937,91$ & 0,0545 & 7.200 & 0,9986 & 0,7998 & 0,0278 & 1,00 \\
\hline Separado (Sólo Flores) & $2.879,15$ & 0,0029 & 7.200 & 1,0000 & 0,7770 & 0,0015 & 1,00 \\
\hline Mezclado (Flores + \%Partes Verdes) & $7.509,99$ & 0,0210 & 7.200 & 0,9986 & 0,9829 & 0,0223 & 1,00 \\
\hline Envasado y empacado (Planta Entera) & $7.509,99$ & 0,1395 & 7.200 & 0,9986 & 0,9993 & 0,1458 & 1,00 \\
\hline Envasado y empacado (Flores) & $2.020,01$ & 0,1396 & 7.200 & 0,9986 & 0,9991 & 0,0393 & 1,00 \\
\hline Sellado y embolsado (Planta Entera) & $7.509,99$ & 0,0337 & 7.200 & 0,9986 & 0,7999 & 0,0440 & 1,00 \\
\hline Sellado y embolsado (Flores) & 2020,01 & 0,0452 & 7.200 & 0,9986 & 0,7997 & 0,0159 & 1,00 \\
\hline
\end{tabular}

Elaboración propia

\subsection{Resguardo de la calidad e inocuidad del producto}

\subsubsection{Calidad de la materia prima, de materiales, del proceso y del producto}

\section{Materia prima}

La única materia prima que utiliza el proyecto es la planta entera de manzanilla común. Para el suministro se contará con dos proveedores a lo largo de un año. Así, se resguarda la disponibilidad y el control de calidad de dicha materia prima. Sumado a esto, un ingeniero agrónomo hará un seguimiento de los sembrios.

De igual modo, al momento de recibir la materia prima se realizará una inspección de atributos. El color del tallo y las hojas deben ser verde claro; las flores liguladas y 
tubulares de color blanco y amarillo, respectivamente. El tamaño promedio de la planta entera debe ser de $60 \mathrm{~cm}$. Tanto flores como partes verdes deben estar desarrolladas y sin marchitar.

Para asegurar la inocuidad se tomará una muestra para análizar una semana antes de cada cosecha en el mismo lugar. Se debe cumplir con la Norma Sanitaria $\mathrm{N}^{\circ} 071$ MINSA/DIGESA-V.01 que establece los criterios microbiológicos de inocuidad para alimentos y bebidas de consumo humano. Asimismo, se deberá verificar los límites máximos de residuos de plaguicidas (LMR's) y límites máximos permisibles de metales pesados (LMP's). La Tabla 5.29 resume estos límites.

Tabla 5. 29

Límites máximos para aceptar materia prima

\begin{tabular}{|c|c|c|c|c|}
\hline Tipo de análisis & Norma & Agente & Límites & Unidades \\
\hline \multirow{2}{*}{ Microbiológico } & \multirow{2}{*}{ NTS N071-MINSA/DIGESA-V.01 } & Escherichia coli & 100 & $\mathrm{ufc} / \mathrm{g}$ \\
\hline & & Salmonella sp. & Ausencia/25,00 & $\mathrm{g}$ \\
\hline \multirow{4}{*}{$\begin{array}{l}\text { Residuos de } \\
\text { plaguicidas }\end{array}$} & \multirow{4}{*}{$\begin{array}{c}\text { LMR de Plaguicidas-Codex } \\
\text { Alimentarius }\end{array}$} & Azoxistrobin & 70,00 & $\mathrm{mg} / \mathrm{kg}$ \\
\hline & & Bentazona & 0,10 & $\mathrm{mg} / \mathrm{kg}$ \\
\hline & & Ciprodinil & 40,00 & $\mathrm{mg} / \mathrm{kg}$ \\
\hline & & Fludioxonil & 9,00 & $\mathrm{mg} / \mathrm{kg}$ \\
\hline \multirow{2}{*}{ Metales pesados } & \multirow{2}{*}{$\begin{array}{l}\text { LMP de Metales Pesados-Codex } \\
\text { Alimentarius }\end{array}$} & Plomo & 0,10 & $\mathrm{mg} / \mathrm{kg}$ \\
\hline & & Cadmio & 0,05 & $\mathrm{mg} / \mathrm{kg}$ \\
\hline
\end{tabular}

Fuente: MINSA, (2015) y Organización de las Naciones Unidas para la Alimentación y la Agricultura-FAO, (2015).

\section{Materiales}

Los materiales en contacto directo con el producto deben ser inocuos. El papel filtro termosellable contiene el producto. Asimismo, al momento de consumir una infusión, el hilo y la etiqueta también pueden entran en contacto con la bebida. Por tal motivo los proveedores de estos tres materiales deben contar con el certificado de análisis (COA por sus siglas en inglés). De otro lado, cada insumo debe cumplir con las especificaciones técnicas de la maquinaria que los requerirá, si fuese el caso.

\section{Proceso de producción}

Mediante el D.S. N007-98-SA, vigente a la fecha, se aprobó el reglamento sobre vigilancia y control sanitario de alimentos y bebidas industrializadas comercializadas en Perú. En su 
artículo 58 señala que dicho control se sustenta en la implementación de un sistema HACCP, el cual permitirá analizar; monitorear, controlar y determinar puntos críticos importantes en el proceso. Por cada lote procesado se toma cinco muestras de 0,5 g por producto después del deshidratado para evaluar el grado de humedad y otras cinco de 1,0 g para hallar el porcentaje de cenizas totales. Después del molido para el análisis organoléptico y de granulometría se requieren de cinco muestras de $10 \mathrm{~g}$ por producto, respectivamente. Asimismo, en el lavado se usa desinfectante líquido NeoClor Dx Plus (5 ml / 10 L agua ${ }^{20}$, y cada seis meses, después del molido, se toman cinco muestras de $400 \mathrm{~g}$ por producto para un análisis microbiológico.

\section{Producto}

Respecto a la característica organoléptica, esta debe tener el color, olor, sabor y aroma propios de cada producto. Respecto a la característica físico-química, se debe cumplir con el grado de humedad, el tamaño de los molidos (granulometría) y la cantidad máxima de impurezas inorgánicas (cenizas totales). Asimismo, en base a la Norma Sanitaria $\mathrm{N}^{\circ} 071$ MINSA/DIGESA-V.01, según el artículo 2 del D.S. N007-98-SA, las infusiones filtrantes deben cumplir con los límites máximos de agentes microbiológicos. Estas características están resumidas en el punto 5.1.1.

Finalmente, el D.S. N007-98-SA también reglamenta los procedimientos y permisos para comercializar alimentos y bebidas industriales, los contenidos de rotulado de los envases (artículo 117), la distribución de ambientes para evitar la contaminación cruzada (artículo 36), el uso de algunos materiales en el área de producción, como el vidrio, que se reemplaza usando planchas de acrílico, y otros aspectos como infracciones al reglamento.

La Tabla 5.30 muestra el sistema de Análisis de Peligros y Puntos Críticos de Control (APPCC, o HACCP por sus siglas en inglés).

\footnotetext{
${ }^{20}$ En base a ficha técnica de NeoClor Dx Plus sobre dosis recomendada. Además este producto cuenta con aprobación de fabricación y comercialización por R.D. 1338-2016/DSA/DIGESA/SA.
} 
Tabla 5. 30

Análisis de Peligros y Puntos Críticos de Control

\begin{tabular}{|c|c|c|c|c|c|}
\hline Etapa del proceso & $\begin{array}{l}\text { Tipo de } \\
\text { peligro }\end{array}$ & $\begin{array}{c}\text { ¿Peligro } \\
\text { significativo? }\end{array}$ & Justificación & $\begin{array}{c}\text { Medidas preventivas a ser } \\
\text { aplicadas }\end{array}$ & $\begin{array}{l}\text { ¿Es un } \\
\text { punto crítico } \\
\text { de control? }\end{array}$ \\
\hline \multirow[b]{3}{*}{ Recepción y pesado } & Físico & No & Piedras, polvo, tierra, raíces y otros & \multirow{3}{*}{$\begin{array}{c}\text { Evaluación organoléptica y } \\
\text { análisis microbiológico, de } \\
\text { plaguicidas y metales } \\
\text { pesados. }\end{array}$} & \multirow[b]{3}{*}{ Sí } \\
\hline & Químico & Sí & Plaguicidas, fertilizantes y metales & & \\
\hline & Biológico & Sí & $\begin{array}{l}\text { Presencia de bacterias como Escherichia } \\
\text { coli, Salmonella, Listeria } \\
\text { monocytogenes y parásitos. }\end{array}$ & & \\
\hline \multirow{3}{*}{ Selección } & Físico & No & $\begin{array}{c}\text { Plantas putrefactas, cristales, fragmentos } \\
\text { de metal u otros. }\end{array}$ & \multirow{3}{*}{$\begin{array}{l}\text { Evaluación visual. } \\
\text { Limpieza y desinfección de } \\
\text { mesa de selección. }\end{array}$} & \multirow{3}{*}{ No } \\
\hline & Químico & No & Restos de plaguicidas y fertilizantes. & & \\
\hline & Biológico & No & Presencia de microorganismos & & \\
\hline \multirow{3}{*}{ Picado } & Físico & $\mathrm{Si}$ & Óxidos y suciedad en las cuchillas & \multirow{3}{*}{$\begin{array}{l}\text { Evaluación visual. } \\
\text { Limpieza y mantenimiento } \\
\text { de cuchillas. }\end{array}$} & \multirow{3}{*}{ No } \\
\hline & Químico & No & - & & \\
\hline & Biológico & No & - & & \\
\hline \multirow{3}{*}{ Lavado } & Físico & No & $10200-$ & \multirow{3}{*}{$\begin{array}{c}\text { Aplicar dosis de } \\
\text { desinfectante correcta y } \\
\text { enjuagar bien. }\end{array}$} & \multirow{3}{*}{ No } \\
\hline & Químico & Sí & Restos de desinfectante & & \\
\hline & Biológico & No & - & & \\
\hline \multirow{3}{*}{ Centrifugado } & Físico & No & Restos de materia prima centrifugada & \multirow{3}{*}{$\begin{array}{l}\text { Limpieza y desinfección } \\
\text { adecuada de la } \\
\text { centrifugadora. }\end{array}$} & \multirow{3}{*}{ No } \\
\hline & Químico & No & 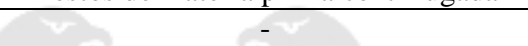 & & \\
\hline & Biológico & No & $-\quad+$ & & \\
\hline \multirow{3}{*}{ Deshidratado } & Físico & No & Suciedad y grasas en el deshidratador. & \multirow{3}{*}{$\begin{array}{l}\text { Limpieza y desinfección } \\
\text { del deshidratador. }\end{array}$} & \multirow{3}{*}{ No } \\
\hline & Químico & No & $\begin{array}{l}\text { Restos de productos de limpieza y } \\
\text { desinfección }\end{array}$ & & \\
\hline & Biológico & Sí & Sobrevivencia de microorganismos. & & \\
\hline \multirow{3}{*}{ Molido y tamizado } & Físico & No & $\begin{array}{c}\text { Grasa y suciedad en el molino y placas } \\
\text { de tamiz }\end{array}$ & \multirow{3}{*}{$\begin{array}{l}\text { Limpieza y desinfección } \\
\text { del Molino y placas de } \\
\text { tamiz. Análisis } \\
\text { microbiológico. }\end{array}$} & \multirow{3}{*}{ No } \\
\hline & Químico & No & - & & \\
\hline & Biológico & No & - & & \\
\hline \multirow{3}{*}{ Separado } & Físico & No & Suciedad por envase mal lavado & \multirow{3}{*}{$\begin{array}{l}\text { Limpieza y desinfección de } \\
\text { envase. }\end{array}$} & \multirow{3}{*}{ No } \\
\hline & Químico & No & 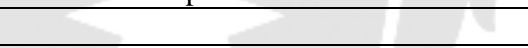 & & \\
\hline & Biológico & No & 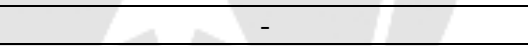 & & \\
\hline \multirow{3}{*}{ Mezclado } & Físico & No & Suciedad y grasas en la mezcladora & \multirow{3}{*}{$\begin{array}{l}\text { Limpieza y desinfección de } \\
\text { la mezcladora. }\end{array}$} & \multirow{3}{*}{ No } \\
\hline & Químico & No & $\begin{array}{c}\text { Restos de productos de limpieza y } \\
\text { desinfección }\end{array}$ & & \\
\hline & Biológico & No & - & & \\
\hline \multirow{3}{*}{$\begin{array}{l}\text { Envasado y } \\
\text { empacado }\end{array}$} & Físico & No & $\begin{array}{c}\text { Grasas y suciedad en envasadora. } \\
\text { Envases sucios o rotos permiten ingreso } \\
\text { de elementos extraños al envase }\end{array}$ & \multirow{3}{*}{$\begin{array}{l}\text { Limpieza y desinfección de } \\
\text { la envasadora. Verificar de } \\
\text { manera visual integridad y } \\
\text { contenido de envases } \\
\text { (bolsas filtrantes). }\end{array}$} & No \\
\hline & Químico & No & $\begin{array}{l}\text { Restos de productos de limpieza y } \\
\text { desinfección }\end{array}$ & & \\
\hline & Biológico & No & - & & \\
\hline & Físico & No & $\square$ & & \\
\hline Sellado y embolsado & Químico & No & 1 & - & No \\
\hline & Biológico & No & 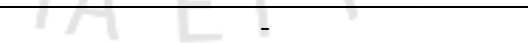 & & \\
\hline
\end{tabular}

Elaboración propia

Por consiguiente, se establece las acciones preventivas a ejecutar cuando el punto crítico se desvía de los límites establecidos. Por eso es necesario que todo el procedimiento sea documentado, ya que las incidencias ayudan a perfeccionar el proceso, y por ende a prevenir futuras desviaciones. La Tabla 5.31 muestra el punto crítico a controlar. 
Tabla 5. 31

Puntos críticos de control

\begin{tabular}{|c|c|c|c|c|c|c|c|c|c|}
\hline \multirow{2}{*}{$\begin{array}{c}\text { Puntos } \\
\text { críticos de } \\
\text { control }\end{array}$} & \multirow[b]{2}{*}{$\begin{array}{c}\text { Peligros } \\
\text { significativos }\end{array}$} & \multirow{2}{*}{$\begin{array}{l}\text { Límites } \\
\text { críticos }\end{array}$} & \multicolumn{4}{|c|}{ Monitoreo } & \multirow[b]{2}{*}{$\begin{array}{c}\text { Medidas } \\
\text { correctivas }\end{array}$} & \multirow[b]{2}{*}{ Registro } & \multirow[b]{2}{*}{ Verificación } \\
\hline & & & Qué & Cómo & $\begin{array}{c}\text { Frecuen } \\
\text { cia }\end{array}$ & Quién & & & \\
\hline \multirow{3}{*}{$\begin{array}{l}\text { Recepción } \\
\text { y pesado }\end{array}$} & $\begin{array}{l}\text { Presencia de } \\
\text { entero } \\
\text { bacterias como } \\
\text { Escherichia } \\
\text { coli, } \\
\text { Salmonella y } \\
\text { otros }\end{array}$ & $100 \mathrm{ufc} / \mathrm{g}$ & $\begin{array}{l}\text { Presencia } \\
\text { de } \\
\text { bacterias }\end{array}$ & $\begin{array}{l}\text { Análisis } \\
\text { bacterioló } \\
\text { gico }\end{array}$ & $\begin{array}{l}\text { Una vez } \\
\text { por } \\
\text { cosecha }\end{array}$ & $\begin{array}{l}\text { Ingeniero } \\
\text { Agrónomo }\end{array}$ & $\begin{array}{l}\text { Rechazar } \\
\text { materia } \\
\text { prima e } \\
\text { informar a } \\
\text { Jefe de } \\
\text { Planta }\end{array}$ & $\begin{array}{l}\text { Incidencia } \\
\text { en rastreo } \\
\text { de } \\
\text { terrenos }\end{array}$ & $\begin{array}{l}\text { Que no } \\
\text { supere el } \\
\text { límite crítico }\end{array}$ \\
\hline & $\begin{array}{l}\text { Residuos de } \\
\text { plaguicidas en } \\
\text { las plantas }\end{array}$ & $\begin{array}{l}\text { Azoxistrobin } \\
(70 \mathrm{mg} / \mathrm{kg}) \\
\text { Bentazona } \\
(0,1 \mathrm{mg} / \mathrm{kg}) \\
\text { Ciprodinil } \\
(40 \mathrm{mg} / \mathrm{kg}) \\
\text { Fludioxonil } \\
(9 \mathrm{mg} / \mathrm{kg})\end{array}$ & $\begin{array}{l}\text { Presencia } \\
\text { de residuos } \\
\text { de } \\
\text { plaguicidas }\end{array}$ & $\begin{array}{l}\text { Análisis } \\
\text { químico }\end{array}$ & $\begin{array}{l}\text { Una vez } \\
\text { por } \\
\text { cosecha }\end{array}$ & $\begin{array}{l}\text { Ingeniero } \\
\text { Agrónomo }\end{array}$ & $\begin{array}{l}\text { Rechazar } \\
\text { materia } \\
\text { prima e } \\
\text { informar a } \\
\text { Jefe de } \\
\text { Planta }\end{array}$ & $\begin{array}{l}\text { Incidencia } \\
\text { en rastreo } \\
\text { de } \\
\text { terrenos }\end{array}$ & $\begin{array}{l}\text { Que no } \\
\text { supere el } \\
\text { límite crítico }\end{array}$ \\
\hline & $\begin{array}{l}\text { Metales } \\
\text { pesados en las } \\
\text { plantas }\end{array}$ & $\begin{array}{l}\text { Plomo }(0,1 \\
\mathrm{mg} / \mathrm{kg}) \\
\text { Cadmio }(0,05 \\
\mathrm{mg} / \mathrm{kg})\end{array}$ & $\begin{array}{l}\text { Presencia } \\
\text { de metales } \\
\text { pesados }\end{array}$ & $\begin{array}{l}\text { Análisis } \\
\text { químico }\end{array}$ & $\begin{array}{l}\text { Una vez } \\
\text { por } \\
\text { cosecha }\end{array}$ & $\begin{array}{l}\text { Ingeniero } \\
\text { Agrónomo }\end{array}$ & $\begin{array}{l}\text { Rechazar } \\
\text { materia } \\
\text { prima e } \\
\text { informar a } \\
\text { Jefe de } \\
\text { Planta }\end{array}$ & $\begin{array}{l}\text { Incidencia } \\
\text { en rastreo } \\
\text { de } \\
\text { terrenos }\end{array}$ & $\begin{array}{l}\text { Que no } \\
\text { supere el } \\
\text { límite crítico }\end{array}$ \\
\hline
\end{tabular}

Elaboración propia

\subsubsection{Estrategias de mejora}

Al iniciar el proyecto se deben poner en práctica los Procedimientos Operativos Estandarizados para luego poder implementar el HACCP. Asimismo, sería conveniente que los proveedores implementen Buenas Prácticas de Agricultura (BPA) conforme avancen los años.

\subsection{Estudio de impacto ambiental}

En este punto se busca controlar los efectos positivos y negativos que la implementación del proyecto pueda ocasionar en el medio ambiente. Esto se realizó mediante el uso de una matriz de Leopold, la cual permitió analizar los impactos más significativos según el nivel de importancia que tengan.

La Tabla 5.32 muestra el criterio para la calificación de impactos, a partir de la cual se podrá hallar su significancia. 
Tabla 5. 32

Criterios de calificación de impactos

\begin{tabular}{|c|c|c|c|c|c|}
\hline Rangos & Magnitud (m) & Duración (d) & Extensión (e) & \multicolumn{2}{|c|}{ Sensibilidad (s) } \\
\hline \multirow{2}{*}{1} & Muy pequeña & Días & Puntual & \multirow{2}{*}{0,80} & \multirow{2}{*}{ Nula } \\
\hline & Casi imperceptible & 1 - 7 días & En un punto del proyecto & & \\
\hline \multirow{2}{*}{2} & Pequeña & Semanas & Local & \multirow{2}{*}{0,85} & \multirow{2}{*}{ Baja } \\
\hline & Leve alteración & 1 - 4 semanas & En una sección del proyecto & & \\
\hline \multirow{2}{*}{3} & Mediana & Meses & Área de proyecto & \multirow{2}{*}{0,90} & \multirow{2}{*}{ Media } \\
\hline & Moderada alteración & $1-12$ meses & En el área del proyecto & & \\
\hline \multirow{2}{*}{4} & Alta & Años & Más allá del proyecto & \multirow{2}{*}{0,95} & \multirow{2}{*}{ Alta } \\
\hline & Se produce modificación & $1-10$ años & Dentro del área de influencia & & \\
\hline \multirow{2}{*}{5} & Muy alta & Permanente & Distrital & \multirow{2}{*}{1,00} & \multirow{2}{*}{ Extrema } \\
\hline & Modificación sustancial & Más de 10 años & Fuera del área de influencia & & \\
\hline
\end{tabular}

Elaboración propia

$\mathrm{Al}$ obtener los valores de magnitud, duración, extensión y sensibilidad se usa la siguiente fórmula para calcular la intensidad de significancia:

$$
\text { Intensidad de significancia }(\text { IS })=\frac{(2 * \mathrm{~m}+\mathrm{d}+\mathrm{e}) * \mathrm{~s}}{20}
$$

Asimismo, la Tabla 5.33 muestra los rangos de significancia para cada impacto a evaluar. Lo que permite, finalmente, obtener la matriz de Leopold como se ve en la Tabla 5.34 .

Tabla 5.33

Rangos de significancia de impactos

\begin{tabular}{|c|c|}
\hline Rango & Magnitud (m) \\
\hline Muy poco significativo (1) & $0,10-0,39$ \\
\hline Poco significativo (2) & $0,40-0,49$ \\
\hline Moderadamente significativo (3) & $0,50-0,59$ \\
\hline Muy significativo (4) & $0,60-0,69$ \\
\hline Altamente significativo (5) & $0,70-1,00$ \\
\hline
\end{tabular}

Elaboración propia 
Tabla 5.34

Matriz de Leopold

\begin{tabular}{|c|c|c|c|c|c|c|c|c|c|c|c|c|}
\hline $\begin{array}{c}\text { Factores } \\
\text { Ambientales }\end{array}$ & Elementos ambientales / Impactos & $\mathbf{R}$ y $\mathbf{P}$ & $\mathbf{S}$ & $\mathbf{P i}$ & $\mathbf{L}$ & $\mathbf{C}$ & D & $\mathbf{M}$ y T & Sp & $\mathbf{M}$ & $\mathbf{E} \mathbf{y} \mathbf{E}$ & Se \\
\hline \multirow{8}{*}{$\begin{array}{l}\text { Medio } \\
\text { Físico }\end{array}$} & \multicolumn{12}{|l|}{ Aire } \\
\hline & Contaminación sonora & & & $-0,50$ & & $-0,36$ & $-0,28$ & $-0,50$ & & $-0,36$ & $-0,38$ & $-0,38$ \\
\hline & Emanación de vapor & & & & & & $-0,36$ & & & & & \\
\hline & Gases de combustión & & & & & & $-0,59$ & & & & & \\
\hline & \multicolumn{12}{|l|}{ Agua } \\
\hline & Vertimiento en acuíferos & & & & $-0,50$ & & & & & & & \\
\hline & \multicolumn{12}{|l|}{ Suelo } \\
\hline & Desecho de residuos sólidos & $-0,28$ & $-0,50$ & $-0,28$ & & & & $-0,28$ & & & & \\
\hline \multirow{5}{*}{$\begin{array}{l}\text { Medio } \\
\text { Ecológico }\end{array}$} & \multicolumn{12}{|l|}{ Flora } \\
\hline & Reducción de áreas de cultivo & $-0,43$ & 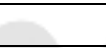 & +2 & & & & & & & & \\
\hline & Desgaste de suelo fértil & $-0,45$ & & & & & & + & +1 & & & \\
\hline & \multicolumn{12}{|l|}{ Fauna } \\
\hline & Reducción del hábitat silvestre & $-0,38$ & & & & & & ra & + & & & \\
\hline \multirow{5}{*}{$\begin{array}{c}\text { Medio } \\
\text { Socioeconómico }\end{array}$} & Seguridad y Salud & \multicolumn{11}{|c|}{ 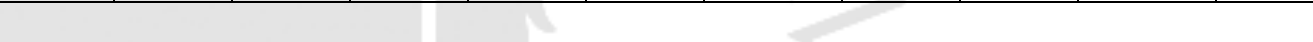 } \\
\hline & Exposición del personal a ruidos & $-0,51$ & $-0,51$ & $-0,51$ & $-0,51$ & $-0,51$ & $-0,51$ & $-0,51$ & $-0,51$ & $-0,51$ & $-0,51$ & $-0,51$ \\
\hline & Economía & \multicolumn{11}{|c|}{+2} \\
\hline & Generación de empleo & 0,68 & 0,68 & 0,68 & 0,68 & 0,68 & 0,68 & 0,68 & 0,68 & 0,68 & 0,68 & 0,68 \\
\hline & Mejora en la calidad de vida & 0,59 & 0,59 & 0,59 & 0,59 & 0,59 & 0,59 & 0,59 & 0,59 & 0,59 & 0,59 & 0,59 \\
\hline
\end{tabular}

Nota: Recepción y pesado (R y P); Selección (S); Picado (Pi); Lavado (L); Centrifugado (C); Deshidratado (D); Molido y Tamizado (M y T); Separado (Sp);

Mezclado (M); Envasado y empacado (E y E); Sellado y embolsado (Se).

Elaboración propia 
Según la matriz de Leopold, en el medio físico la mayor alteración al suelo es ocasionada por la operación de selección debido a los residuos que genera. Respecto al aire, resalta la emisión de gases de combustión en la operación de deshidratado. En el medio ecológico el desgaste de suelo fértil es poco significativo.

Referente al medio socioeconómico, habrá un aumento de empleo tanto para el personal que trabaja directamente en la planta, como para personal indirecto y proveedores, lo que conllevará a mejorar la calidad de vida de estas personas.

\subsection{Seguridad y salud ocupacional}

Se debe implementar el uso de los equipos de protección personal para los operarios que laboran en la industria de alimentos, como son:

- Tapones auditivos para protección contra ruidos.

- Lentes de seguridad para proteger los ojos de impactos de partículas.

- Guantes térmicos contra abrasamiento.

Asimismo, las tablas $5.35,5.36$ y 5.37 son necesarias para hallar la matriz de identificación de peligros y evaluación de riegos (IPER).

Tabla 5. 35

Índice de probabilidad de ocurrencia de un evento

\begin{tabular}{|c|c|c|c|c|c|}
\hline $\begin{array}{c}\text { Índice de } \\
\text { probabilidad }\end{array}$ & Índice & $\begin{array}{c}\text { Personas } \\
\text { expuestas } \\
\text { (PE) }\end{array}$ & $\begin{array}{c}\text { Procedimientos de } \\
\text { trabajo } \\
\text { (PT) }\end{array}$ & $\begin{array}{c}\text { Capacitación } \\
\text { (C) }\end{array}$ & $\begin{array}{c}\text { Exposición al riesgo } \\
\text { (ER) }\end{array}$ \\
\hline $\begin{array}{c}\text { Baja (El daño } \\
\text { ocurrirá raras } \\
\text { veces) }\end{array}$ & 1 & De 1-3 & $\begin{array}{c}\text { Existen, son } \\
\text { satisfactorios y } \\
\text { suficientes }\end{array}$ & $\begin{array}{c}\text { Personal entrenado, } \\
\text { conoce el peligro y lo } \\
\text { previene }\end{array}$ & $\begin{array}{c}\text { Al menos 1 vez por } \\
\text { año (S) } \\
\text { esporádicamente (SO) }\end{array}$ \\
\hline $\begin{array}{c}\text { Media (El daño } \\
\text { ocurrirá en algunas } \\
\text { ocasiones) }\end{array}$ & 2 & De 4-12 & $\begin{array}{c}\text { Existen parcialmente y } \\
\text { no son satisfactorios ni } \\
\text { suficientes }\end{array}$ & $\begin{array}{c}\text { Personal parcialmente } \\
\text { entrenado, conoce el } \\
\text { peligro pero no toma } \\
\text { acciones de control }\end{array}$ & $\begin{array}{c}\text { Al menos 1 vez al mes } \\
\text { (S) eventualmente } \\
\text { (SO) }\end{array}$ \\
\hline $\begin{array}{c}\text { Alta (El daño } \\
\text { ocurrirá siempre o } \\
\text { casi siempre) }\end{array}$ & 3 & De 12-más & No existen & $\begin{array}{c}\text { Personal no entrenado, } \\
\text { no conoce el peligro y } \\
\text { no toma acciones de } \\
\text { control }\end{array}$ & $\begin{array}{c}\text { Al menos 1 vez al día } \\
\text { (S) permanentemente } \\
\text { (SO) }\end{array}$ \\
\hline
\end{tabular}

Elaboración propia 
Tabla 5. 36

Índice de severidad al ocurrir un evento

\begin{tabular}{|c|c|c|}
\hline $\begin{array}{c}\text { Índice de severidad } \\
\text { (Consecuencias) }\end{array}$ & Índice & Severidad (Consecuencia) \\
\hline \multirow{2}{*}{ Ligeramente dañino } & \multirow{2}{*}{1} & Lesión sin incapacidad (S) \\
\hline & & Molestia o incomodidad (SO) \\
\hline \multirow{2}{*}{ Dañino } & \multirow{2}{*}{2} & Lesión con incapacidad temporal (S) \\
\hline & & Daño a la salud reversible (SO) \\
\hline \multirow{2}{*}{ Extremadamente dañino } & \multirow[t]{2}{*}{3} & Lesión con incapacidad permanente $(\mathrm{S})$ \\
\hline & & Daño a la salud irreversible (SO) \\
\hline
\end{tabular}

Elaboración propia

Tabla 5. 37

Nivel de riesgo de un evento y su significancia

\begin{tabular}{|c|c|c|}
\hline \multicolumn{3}{|c|}{ Estimación del nivel de riesgo y su significancia } \\
\hline $\begin{array}{c}\text { Probabilidad/ } \\
\text { severidad }\end{array}$ & Grado de riesgo & $\begin{array}{c}\text { Criterio de } \\
\text { significancia }\end{array}$ \\
\hline 4 & Trivial & $\mathbf{N}$ \\
\hline $5-8$ & Tolerable & \\
\hline $9-16$ & Moderado & No significativo \\
\hline $17-24$ & Importante & \\
\hline $25-36$ & Intolerable & si signiticativo \\
\hline
\end{tabular}

Elaboración propia

Finalmente, dentro del marco legal que lo regula, se debe asegurar un clima laboral adecuado en concordancia con el Reglamento de Seguridad y Salud en el Trabajo reglamentada por DS N 009-2005-TR, de la ley N²9783, Ley de Seguridad y Salud en el Trabajo. También existen normas internacionales en que basarse, entre ellas la OSHAS 18001, que ayuda a implementar un Sistema de Gestión de Seguridad y Salud en el Trabajo y la NFPA 10, norma para extintores portátiles contra incendios. En tal sentido la Tabla 5.38 muestra el diagrama de identificación de peligros y evaluación de riesgos o simplemente (IPER), diagrama que facilita la identificación, evaluación y control de riesgos de accidente y enfermedades en el trabajo. Las figuras 5.7 y 5.8 muestran la disposición de extintores en cada nivel en caso de incendios. 
Tabla 5. 38

Matriz de identificación de peligros y evaluación de riesgos (IPER)

\begin{tabular}{|c|c|c|c|c|c|c|c|c|c|c|c|c|}
\hline \multirow[b]{2}{*}{ Proceso } & \multirow[b]{2}{*}{ Peligro } & \multirow[b]{2}{*}{ Riesgo } & \multicolumn{4}{|c|}{ Probabilidad } & \multirow{2}{*}{$\begin{array}{c}\text { Índice de } \\
\text { probabilidad } \\
(\text { IP) } \\
(\mathbf{A}+\mathbf{B}+\mathbf{C}+\mathbf{D}) \\
\end{array}$} & \multirow{2}{*}{$\begin{array}{l}\text { Índice de } \\
\text { severidad } \\
\quad \text { (IS) }\end{array}$} & \multirow[b]{2}{*}{ IP x IS } & \multirow[b]{2}{*}{$\begin{array}{l}\text { Nivel de } \\
\text { riesgo }\end{array}$} & \multirow[b]{2}{*}{$\begin{array}{c}\text { Criterio de } \\
\text { significancia }\end{array}$} & \multirow[b]{2}{*}{$\begin{array}{l}\text { Medidas de control } \\
\text { propuestas }\end{array}$} \\
\hline & & & $\begin{array}{l}\text { PE } \\
(\mathbf{A})\end{array}$ & $\begin{array}{l}\text { PT } \\
\text { (B) }\end{array}$ & $\begin{array}{c}\mathrm{C} \\
(\mathrm{C})\end{array}$ & $\begin{array}{l}\text { ER } \\
\text { (D) }\end{array}$ & & & & & & \\
\hline $\begin{array}{l}\text { Pesado y } \\
\text { recepción }\end{array}$ & $\begin{array}{l}\text { Levantamiento de mantas con } \\
\text { un peso de } 25 \mathrm{~kg}\end{array}$ & $\begin{array}{l}\text { Daños y/o } \\
\text { luxación en la } \\
\text { espalda }\end{array}$ & 1 & 1 & 2 & 3 & 7 & 1 & 7 & Tolerable & No significativo & $\begin{array}{l}\text { Buenas posturas para levantar } \\
\text { cargas. Máximo } 50 \mathrm{~kg}\end{array}$ \\
\hline Selección & $\begin{array}{l}\text { Movimiento repetitivo y mala } \\
\text { postura }\end{array}$ & $\begin{array}{c}\text { Lesiones } \\
\text { musculares y/o } \\
\text { ergonómicas }\end{array}$ & 1 & 1 & 2 & 3 & 7 & 1 & 7 & Tolerable & No significativo & $\begin{array}{c}\text { Buena postura, uso de peine de } \\
\text { selección y de muñequeras } \\
\text { protectoras }\end{array}$ \\
\hline Picado & Hojas de corte en movimiento & $\begin{array}{c}\text { Mutilación de los } \\
\text { dedos }\end{array}$ & 1 & 1 & 1 & 3 & 6 & 2 & 12 & Moderado & No significativo & $\begin{array}{c}\text { Dispositivo de parada de } \\
\text { emergencia e instrucción de } \\
\text { uso }\end{array}$ \\
\hline Lavado & Mezcla de desinfectante y agua & $\begin{array}{c}\text { Intoxicación por } \\
\text { contacto con la } \\
\text { piel }\end{array}$ & 1 & 1 & 1 & 3 & 6 & 2 & 12 & Moderado & No significativo & $\begin{array}{l}\text { Uso de guantes durante el } \\
\text { lavado }\end{array}$ \\
\hline Centrifugado & Revoluciones del cesto & $\begin{array}{c}\text { Enganchamiento } \\
\text { y/o golpe con } \\
\text { cesto }\end{array}$ & 1 & 1 & 1 & 3 & 6 & 2 & 12 & Moderado & No significativo & $\begin{array}{c}\text { Dispositivo de parada } \\
\text { emergencia e instrucción de } \\
\text { uso }\end{array}$ \\
\hline Deshidratado & $\begin{array}{l}\text { Combustión de GLP para } \\
\text { calentar aire hasta } 45^{\circ} \mathrm{C}\end{array}$ & $\begin{array}{c}\text { Quemadura } \\
\text { térmica }\end{array}$ & 1 & 1 & 1 & 3 & 6 & 2 & 12 & Moderado & No significativo & $\begin{array}{l}\text { Tablero de control del } \\
\text { quemador, uso de guantes } \\
\text { térmicos y capacitación }\end{array}$ \\
\hline $\begin{array}{l}\text { Molido y } \\
\text { tamizado }\end{array}$ & $\begin{array}{l}\text { Martillos de molido en } \\
\text { movimiento }\end{array}$ & $\begin{array}{l}\text { Aplastamiento de } \\
\text { los dedos }\end{array}$ & 1 & 1 & 1 & 3 & 6 & 2 & 12 & Moderado & No significativo & $\begin{array}{l}\text { Dispositivo de parada de } \\
\text { emergencia e instrucción de } \\
\text { uso }\end{array}$ \\
\hline Separado & $\begin{array}{l}\text { No presenta peligro } \\
\text { significativo }\end{array}$ & No existe peligros & - & - & - & - & - & - & - & - & - & - \\
\hline Mezclado & Giro de mezcladora tipo rombo & Lesiones por golpe & 1 & 1 & 1 & 3 & 6 & 2 & 12 & Moderado & No significativo & $\begin{array}{l}\text { Barrera móvil de seguridad y } \\
\text { señalización }\end{array}$ \\
\hline $\begin{array}{l}\text { Envasado y } \\
\text { empacado }\end{array}$ & $\begin{array}{l}\text { Solución de atasco de } \\
\text { materiales cargados en } \\
\text { envasadora }\end{array}$ & $\begin{array}{c}\text { Lesiones por } \\
\text { aplastamiento y/o } \\
\text { corte }\end{array}$ & 1 & 1 & 1 & 3 & 6 & 2 & 12 & Moderado & No significativo & $\begin{array}{l}\text { Dispositivo de parada de } \\
\text { emergencia y capacitación }\end{array}$ \\
\hline $\begin{array}{l}\text { Sellado y } \\
\text { embolsado }\end{array}$ & $\begin{array}{l}\text { Calor de resistencias de la } \\
\text { selladora }\end{array}$ & $\begin{array}{l}\text { Quemadura } \\
\text { térmica }\end{array}$ & 1 & 1 & 1 & 3 & 6 & 2 & 12 & Moderado & No significativo & $\begin{array}{c}\text { Uso de guantes térmicos } \\
\text { ergonómicos e instrucción de } \\
\text { uso } \\
\end{array}$ \\
\hline
\end{tabular}

\section{Elaboración propia}


Figura 5.7

Distribución de extintores y señalización en primer piso

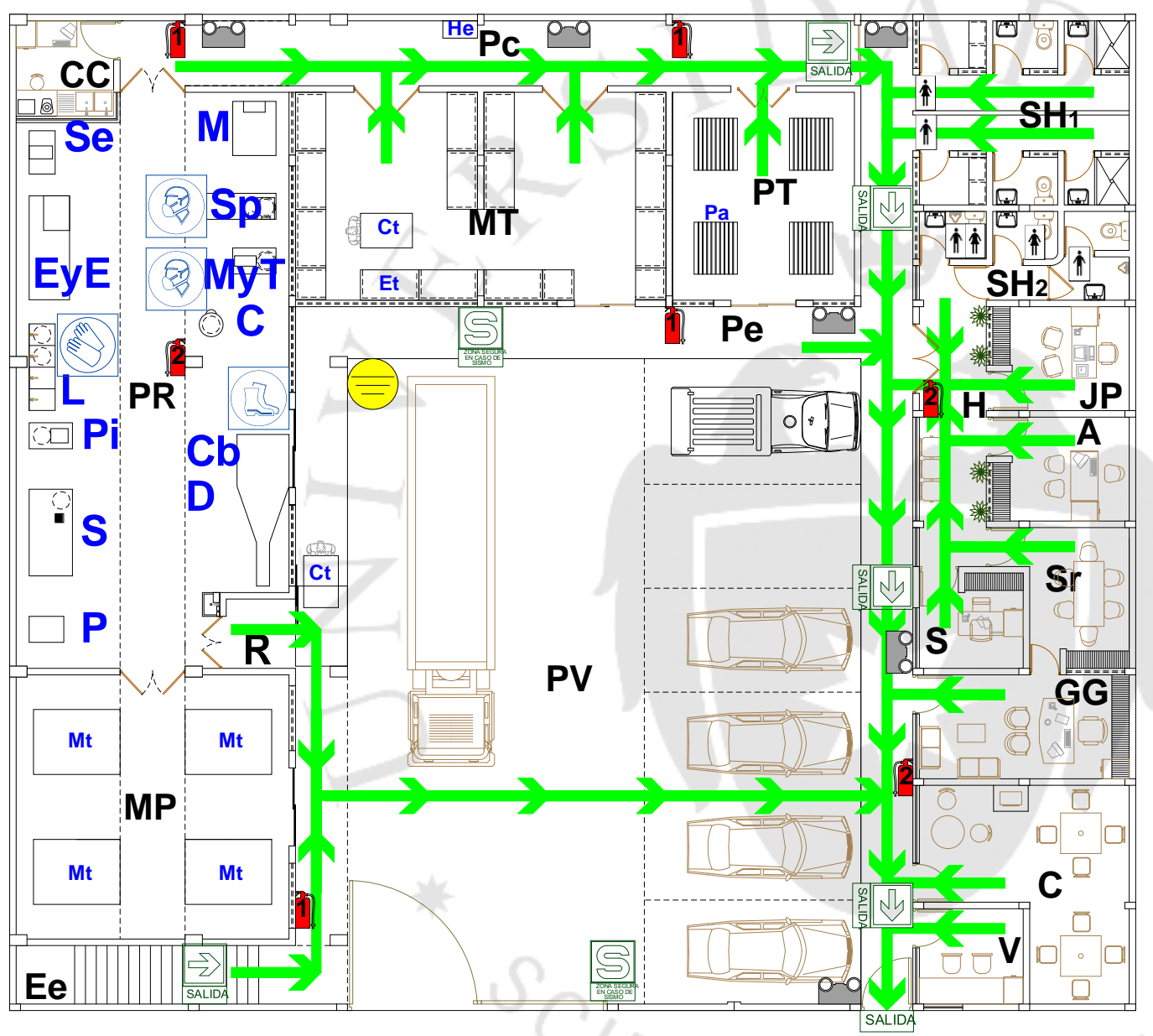

\begin{tabular}{|c|c|}
\hline Señal & Descripción \\
\hline & $\begin{array}{c}\text { Extintor de PQS } \\
\text { (Equipo contra incendio) }\end{array}$ \\
\hline ) & $\begin{array}{c}\text { Extintor de } \mathrm{CO}^{\wedge} 2 \\
\text { (Equipo contra incendio) } \\
\end{array}$ \\
\hline \begin{tabular}{|l|}
$\mathrm{D}$ \\
SALIDA
\end{tabular} & $\begin{array}{c}\text { Salida } \\
\text { (Señal de seguridad) }\end{array}$ \\
\hline S & $\begin{array}{l}\text { Zona segura en sismos } \\
\text { (Señal de seguridad) }\end{array}$ \\
\hline 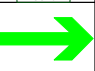 & Ruta de evacuación \\
\hline 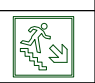 & $\begin{array}{l}\text { Salida por escalera } \\
\text { (Señal de seguridad) }\end{array}$ \\
\hline$\Longrightarrow$ & $\begin{array}{l}\text { Plesta a tierra } \\
\text { Señal de advertencia }\end{array}$ \\
\hline \begin{tabular}{l|l|}
$\boldsymbol{i}$ & $\dot{\boldsymbol{i}}$ \\
\end{tabular} & $\begin{array}{l}\text { Servicios higiénicos } \\
\text { (Señal de información) }\end{array}$ \\
\hline$a-q$ & $\begin{array}{l}\text { Luces de emergencia } \\
\text { (Equipo de seguridad) }\end{array}$ \\
\hline$\Leftrightarrow$ & $\begin{array}{l}\text { Uso botas de seguridad } \\
\text { (Señal de obligación) }\end{array}$ \\
\hline \multicolumn{2}{|c|}{ Ambientes de planta } \\
\hline Código & Descripción \\
\hline $\mathrm{MP}$ & Materia prima \\
\hline PR & Producción \\
\hline MT & Materiales \\
\hline PT & Producto terminado \\
\hline PV & Patio de vehiculos \\
\hline CC & Control de calidad \\
\hline $\mathrm{Pc}$ & Pasadizo de circulación \\
\hline $\mathrm{Pe}$ & Pasadizo externo \\
\hline $\mathrm{Ee}$ & Espacio de escalera \\
\hline $\mathrm{R}$ & Recepción \\
\hline
\end{tabular}

\begin{tabular}{|c|c|c|c|c|c|c|}
\hline \multirow{3}{*}{$*$} & \multirow{3}{*}{$\begin{array}{l}\text { Universidad de Lima } \\
\text { Facultad de Ingeniería y Arquitectura } \\
\text { Carrera de Ingeniería Industrial }\end{array}$} & \multicolumn{5}{|c|}{ Plano de evacuación y señalización - primer piso } \\
\hline & & Int & & Dibujo: & Fecha: & Escala: \\
\hline & & & & Elic & \begin{tabular}{|l|l}
$01 / 0$ \\
\end{tabular} & $1 / 500$ \\
\hline
\end{tabular}

Elaboración propia 
Figura 5.8

Distribución de extintores y señalización en segundo piso

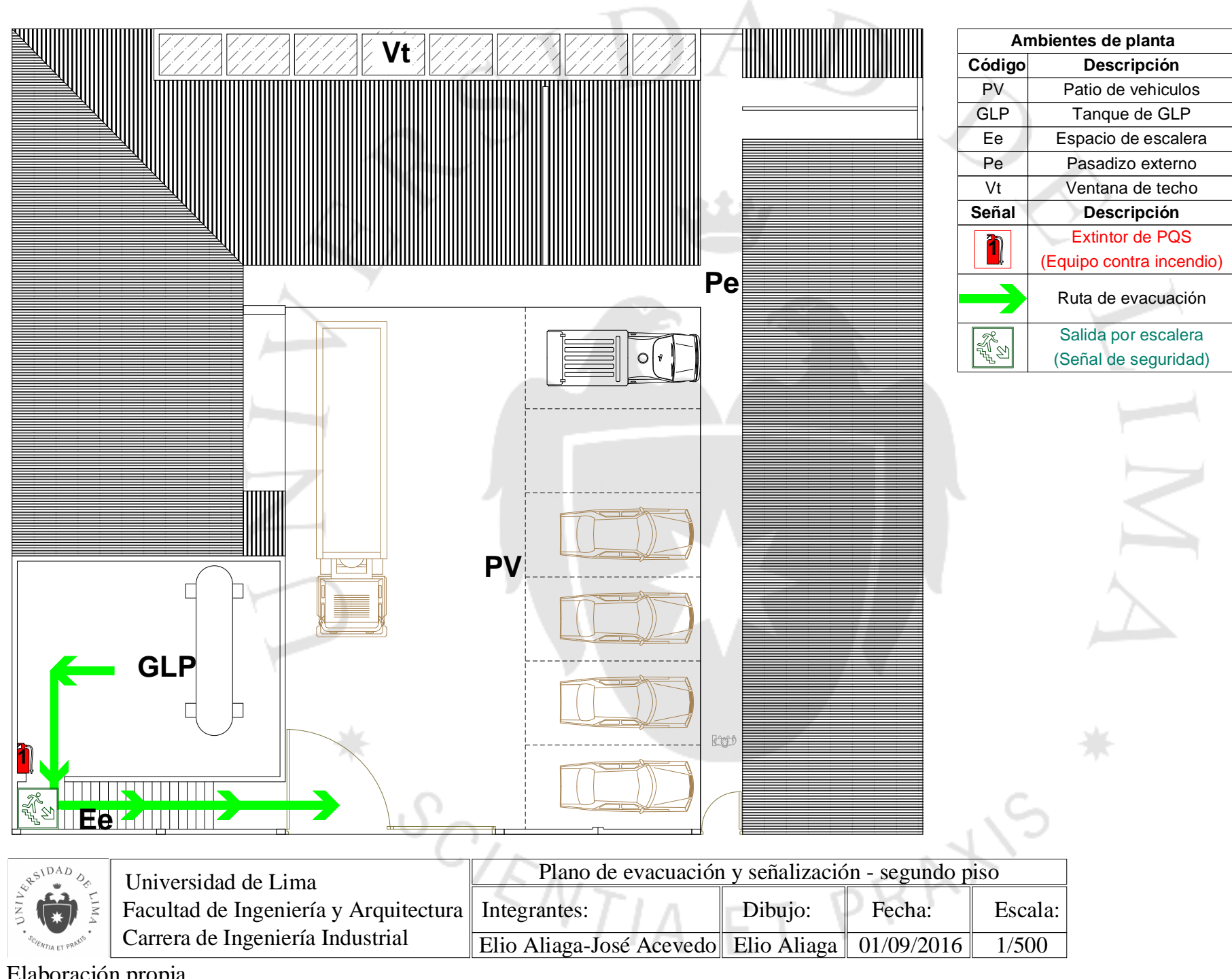

Elaboración propia 


\subsection{Sistema de mantenimiento}

La planta contará con un sistema de mantenimiento para asegurar la productividad y la disponibilidad de la maquinaria de producción, con lo cual se busca garantizar la rentabilidad del proyecto.

Se capacitará a los operarios sobre Normas de Buenas Prácticas de Manufactura y se implementará un plan de mantenimiento preventivo que se basará en programas de inspección, actividades de conservación y sustitución preventiva, de ser el caso, lo que garantiza el uso confiable de la maquinaria durante su toda su vida útil. La Tabla 5.39 muestra el plan de mantenimiento preventivo.

Tabla 5. 39

Plan de mantenimiento preventivo aplicada a la maquinaria y equipos

\begin{tabular}{|c|c|c|c|c|}
\hline Máquina & Actividad & Descripción & Frecuencia & Encargado \\
\hline \multirow[t]{2}{*}{$\begin{array}{l}\text { Balanza de } \\
\text { plataforma }\end{array}$} & $\begin{array}{l}\text { Limpieza de la plataforma } \\
\text { de pesaje. }\end{array}$ & $\begin{array}{l}\text { Para que este se encuentre libre de polvo o suciedad la } \\
\text { limpieza se efectúa con una pieza de tela limpia que } \\
\text { puede estar humedecida con agua destilada. Si es } \\
\text { necesario retirar alguna mancha, se puede aplicar un } \\
\text { detergente suave. También se puede usar un pincel de } \\
\text { pelo suave para remover las partículas o el polvo que se } \\
\text { hubiesen depositado sobre la plataforma de pesaje. }\end{array}$ & Diaria & Operario \\
\hline & $\begin{array}{l}\text { Verificar calibración a cero } \\
\text { de la balanza. }\end{array}$ & Para garantizar que la marcación de peso es correcta. & Anual & $\begin{array}{l}\text { Técnico } \\
\text { externo }\end{array}$ \\
\hline \multirow{3}{*}{ Picadora } & Limpieza del equipo. & $\begin{array}{c}\text { Se desmonta el equipo y se limpia las partes solo con } \\
\text { agua caliente y algún detergente espumoso } \\
\text { biodegradable. Se debe usar un paño suave y } \\
\text { esponjoso. }\end{array}$ & Semanal & Operario \\
\hline & $\begin{array}{l}\text { Lubricación de } \\
\text { rodamientos de banda } \\
\text { transportadora. }\end{array}$ & $\begin{array}{l}\text { Se usan lubricantes para rodamientos que estén } \\
\text { expuestos a velocidades medias. }\end{array}$ & Mensual & Operario \\
\hline & $\begin{array}{l}\text { Afilamiento de las hojas de } \\
\text { corte. }\end{array}$ & $\begin{array}{l}\text { Se afilan las hojas de corte de acero inoxidable con una } \\
\text { piedra de esmeril. }\end{array}$ & Mensual & Operario \\
\hline \multirow{5}{*}{ Centrífuga } & $\begin{array}{l}\text { Limpieza de cestos y } \\
\text { superficie externa }\end{array}$ & $\begin{array}{c}\text { Se usa una tela suave humedecida con un poco de } \\
\text { detergente. Los cestos además pueden lavarse con una } \\
\text { escobilla o cerda. }\end{array}$ & Diaria & Operario \\
\hline & \multirow{3}{*}{$\begin{array}{l}\text { Verificación del nivel y } \\
\text { existencia de vibración. }\end{array}$} & Si hubiese ruido nivelar las patas de la máquina. & Semanal & Operario \\
\hline & & $\begin{array}{l}\text { Si persiste el ruido revisar parte interna donde se coloca } \\
\text { el cesto. }\end{array}$ & Semanal & Operario \\
\hline & & $\begin{array}{l}\text { Verificar el correcto acoplado y balance entre del eje } \\
\text { del tambor y la estructura. }\end{array}$ & Trimestral & Operario \\
\hline & $\begin{array}{l}\text { Verificación de caja de } \\
\text { transmisión, de faja de } \\
\text { transmisión y sello de } \\
\text { agua. }\end{array}$ & $\begin{array}{l}\text { Balancear la caja de transmisión y el motor, así como el } \\
\text { estado de la faja y el sello de agua. }\end{array}$ & Anual & $\begin{array}{l}\text { Técnico } \\
\text { externo }\end{array}$ \\
\hline \multirow{2}{*}{ Deshidratador } & \multirow{2}{*}{$\begin{array}{l}\text { Limpieza y secado de la } \\
\text { cámara interna de } \\
\text { deshidratador. }\end{array}$} & $\begin{array}{c}\text { Verificar que no haya acumulación de agua en el } \\
\text { interior de la cámara antes y después de la operación. }\end{array}$ & Diaria & Operario \\
\hline & & $\begin{array}{c}\text { Verificar y localizar ruidos y vibraciones anormales } \\
\text { que se puedan presentar. }\end{array}$ & Diaria & Operario \\
\hline
\end{tabular}




\begin{tabular}{|c|c|c|c|c|}
\hline Máquina & Actividad & Descripción & Frecuencia & Encargado \\
\hline & \multirow{3}{*}{$\begin{array}{l}\text { Verificar que no haya } \\
\text { elementos corrosivos } \\
\text { dentro de la estructura. }\end{array}$} & $\begin{array}{l}\text { Inspección visual en todo el deshidratador y coche de } \\
\text { bandejas. }\end{array}$ & \multirow{3}{*}{ Tres meses } & \multirow{3}{*}{ Operario } \\
\hline & & Verificar que no exista corrosión. & & \\
\hline & & Verificar que no exista defectos en las soldaduras. & & \\
\hline & \multirow{3}{*}{$\begin{array}{l}\text { Mantenimiento al } \\
\text { quemador. }\end{array}$} & Limpieza del quemador. & \multirow{3}{*}{ Seis meses } & \multirow{3}{*}{$\begin{array}{l}\text { Técnico } \\
\text { externo }\end{array}$} \\
\hline & & Detección que fugas de GLP. & & \\
\hline & & $\begin{array}{l}\text { Limpieza de ductos de admisión y salida de aire del } \\
\text { quemador. }\end{array}$ & & \\
\hline & & $\begin{array}{c}\text { Verificar que no exista humedad en tablero de control } \\
\text { del deshidratador. }\end{array}$ & \multirow{4}{*}{ Tres meses } & \multirow{4}{*}{ Operario } \\
\hline & Verificar el sistema & $\begin{array}{c}\text { Verificar que los sensores de control estén bien } \\
\text { ubicados y que funcionen. }\end{array}$ & & \\
\hline & electrico. & Aislar correctamente las conexiones eléctricas. & & \\
\hline & & $\begin{array}{l}\text { Verificar el funcionamiento de los controladores de } \\
\text { temperatura. }\end{array}$ & & \\
\hline \multirow{4}{*}{$\begin{array}{l}\text { Molino de } \\
\text { martillos y } \\
\text { tamizadora }\end{array}$} & \multirow{2}{*}{ Verificar malla del equipo. } & $\begin{array}{c}\text { Verificar si el tamaño del producto está de acuerdo a } \\
\text { parámetros establecidos (granulometría). }\end{array}$ & Semanal & Operario \\
\hline & & Verificar el desgaste de martillos. & Tres meses & Operario \\
\hline & \multirow{2}{*}{$\begin{array}{l}\text { Verificación de vibración } \\
\text { excesiva. }\end{array}$} & Verificar vibraciones o sonidos extraños. & Semanal & Operario \\
\hline & & $\begin{array}{l}\text { Verificar si el equipo o algún componente no está } \\
\text { centrado. }\end{array}$ & Mensual & Operario \\
\hline \multirow{2}{*}{$\begin{array}{l}\text { Mezcladora } \\
\text { tipo rombo }\end{array}$} & Limpieza del envase. & $\begin{array}{c}\text { Verificar que no haya algún elemento extraño dentro de } \\
\text { la mezcladora. }\end{array}$ & Diaria & Operario \\
\hline & $\begin{array}{l}\text { Verificación del estado de } \\
\text { la catarina y la cadena de } \\
\text { rodillos. }\end{array}$ & $\begin{array}{l}\text { Lubricar la catarina, el eje de rotación y la cadena de } \\
\text { rodillos para que se produzca el correcto giro del } \\
\text { recipiente. }\end{array}$ & Semestral & Operario \\
\hline \multirow{9}{*}{ Envasadora } & \multirow{8}{*}{$\begin{array}{l}\text { Limpieza, lubricación y } \\
\text { ajuste de mecanismos.. }\end{array}$} & $\begin{array}{l}\text { Verificar el avance alineado del papel filtro } \\
\text { termosellable. }\end{array}$ & \multirow{8}{*}{ Diario } & \multirow{8}{*}{ Operario } \\
\hline & & $\begin{array}{l}\text { Verificar que se encuentre bien colocado el separador } \\
\text { de hilo, así como las horquillas y los pines de hilo. }\end{array}$ & & \\
\hline & & $\begin{array}{l}\text { Verificar que el dosificado de adhesivo para etiquetas } \\
\text { sea el correcto. }\end{array}$ & & \\
\hline & & $\begin{array}{l}\text { Verificar la sujeción y buen estado de las cuchillas de } \\
\text { corte. }\end{array}$ & & \\
\hline & & $\begin{array}{l}\text { Verificar que los rodillos termo selladores cierren } \\
\text { correctamente las bolsas y los sobres de envoltura. }\end{array}$ & & \\
\hline & & $\begin{array}{l}\text { Verificar que el sistema de fotocentrado funcione bien } \\
\text { y doble correctamente los sobres de envoltura. }\end{array}$ & & \\
\hline & & $\begin{array}{c}\text { Verificar que se encuentre lubricada la guía de la pinza } \\
\text { plegadora. }\end{array}$ & & \\
\hline & & $\begin{array}{l}\text { Verificar el correcto dosificado en la tolva de envasado. } \\
\text { Se usa un removedor de hierbas que cuenta con un } \\
\text { motor. }\end{array}$ & & \\
\hline & $\begin{array}{l}\text { Verificación del sistema de } \\
\text { lubricación. }\end{array}$ & $\begin{array}{l}\text { Verificar la cantidad de aceite de la envasadora, si es } \\
\text { necesario se debe cambiar o reponer. }\end{array}$ & Anual & $\begin{array}{l}\text { Técnico } \\
\text { externo }\end{array}$ \\
\hline \multirow[t]{2}{*}{ Selladora } & Limpieza de equipo. & $\begin{array}{l}\text { Limpiar la superficie del sellador, removiendo } \\
\text { cualquier residuo plástico que se encuentre adherido a } \\
\text { éste. }\end{array}$ & Semanal & Operario \\
\hline & $\begin{array}{l}\text { Verificación de correcto } \\
\text { calentamiento de sellado. }\end{array}$ & $\begin{array}{c}\text { Verificar que las resistencias lleguen a la temperatura } \\
\text { adecuada para sellar las cajas con envolturas. }\end{array}$ & Diario & Operario \\
\hline
\end{tabular}

Elaboración propia

\subsection{Programa de producción}

\subsubsection{Factores para la programación de la producción}


La producción se programa en base a la demanda de mercado para el proyecto durante su vida útil. La Tabla 5.40 muestra la producción anual.

\subsubsection{Programa de producción}

Tabla 5. 40

Programa de producción del proyecto

\begin{tabular}{|c|c|c|c|}
\hline Año & $\begin{array}{c}\text { Demanda } \\
\text { (toneladas) }\end{array}$ & $\begin{array}{c}\text { Capacidad } \\
\text { (toneladas) }\end{array}$ & $\begin{array}{c}\text { Utilización } \\
(\mathbf{\%})\end{array}$ \\
\hline 2016 & 6,59 & 9,69303 & 67,99 \\
\hline 2017 & 6,94 & 9,69303 & 71,60 \\
\hline 2018 & 7,29 & 9,69303 & 75,21 \\
\hline 2019 & 7,63 & 9,69303 & 78,72 \\
\hline 2020 & 7,96 & 9,69303 & 82,12 \\
\hline 2021 & 8,29 & 9,69303 & 85,53 \\
\hline 2022 & 8,61 & 9,69303 & 88,83 \\
\hline 2023 & 8,92 & 9,69303 & 92,02 \\
\hline 2024 & 9,23 & 9,69303 & 95,22 \\
\hline 2025 & 9,53 & 9,69303 & 98,32 \\
\hline
\end{tabular}

Elaboración propia

\subsection{Requerimiento de materiales, servicios y personal}

\subsubsection{Materia prima, materiales y otros}

El requerimiento de manzanilla común es de 5,20 kg de planta entera en verde para obtener $1 \mathrm{~kg}$ de planta entera deshidratada, molida y tamizada, es decir lista para envasar. La Tabla 5.41 muestra los requerimientos de materia prima para cada año del proyecto.

Tabla 5. 41

Requerimiento de materia prima

\begin{tabular}{|c|c|}
\hline Año & Materia prima $(\mathbf{k g})$ \\
\hline 2016 & $34.305,44$ \\
\hline 2017 & $36.127,42$ \\
\hline 2018 & $37.949,41$ \\
\hline 2019 & $39.719,34$ \\
\hline 2020 & $41.437,22$ \\
\hline 2021 & $43.155,09$ \\
\hline 2022 & $44.820,91$ \\
\hline 2023 & $46.434,67$ \\
\hline 2024 & $48.048,43$ \\
\hline 2025 & $49.610,14$ \\
\hline
\end{tabular}

Elaboración propia 
El papel filtro termosellable en bobinas de $125 \mathrm{~mm}$ de ancho, medida específica para la envasadora maisa EC12B, con un largo efectivo de $2.400 \mathrm{~m}$ por bobina, que será cortada cada $5,00 \mathrm{~cm}$ tendrá un rendimiento de 48.000 bolsas filtrantes por bobina. La Tabla 5.42 muestra el requerimiento para cada año de este material.

Tabla 5.42

Requerimiento de papel filtro termosellable

\begin{tabular}{|c|c|}
\hline Año & $\begin{array}{c}\text { Papel termosellable } \\
\text { (bobinas) }\end{array}$ \\
\hline 2016 & 138,00 \\
\hline 2017 & 145,00 \\
\hline 2018 & 152,00 \\
\hline 2019 & 159,00 \\
\hline 2020 & 166,00 \\
\hline 2021 & 173,00 \\
\hline 2022 & 180,00 \\
\hline 2023 & 186,00 \\
\hline 2024 & 193,00 \\
\hline 2025 & 199,00 \\
\hline
\end{tabular}

Fuente: Iprex Corporación S.A.C., (2016).

Se requiere una longitud aproximada de $21,00 \mathrm{~cm}$ de hilo por cada bolsa filtrante, debe ser de torsión nula, es decir que no se enreda. Asimismo, y aunque las especificaciones de la envasadora maisa EC12B recomiendan un hilo de título 14/2, en base a lo investigado, el hilo de título 16/2 rinde en promedio 20\% más. En Perú se usan conos de $1 \mathrm{~kg}$ de longitud efectiva de $13.560 \mathrm{~m}$ que rinde 64.571 bolsas filtrantes. La Tabla 5.43 muestra lo requerido.

Tabla 5. 43

Requerimiento de hilo

\begin{tabular}{|l|l|}
\hline Año & $\begin{array}{c}\text { Hilo } \\
\text { (conos) }\end{array}$ \\
\hline 2016 & 103,00 \\
\hline 2017 & 108,00 \\
\hline 2018 & 113,00 \\
\hline 2019 & 119,00 \\
\hline 2020 & 124,00 \\
\hline 2021 & 129,00 \\
\hline 2022 & 134,00 \\
\hline 2023 & 139,00 \\
\hline 2024 & 143,00 \\
\hline 2025 & 148,00 \\
\hline
\end{tabular}

Fuente: La Colonial fábrica de hilos S.A., (2016). 
Las etiquetas vienen en bobinas impresas ${ }^{21}$ de papel bond de $60 \mathrm{~g} / \mathrm{m}^{2}$, aunque la envasadora sugiere $70 \mathrm{~g} / \mathrm{m}^{2}$ en base a lo recabado en los mismos fabricantes de etiquetas y sobres de envoltura, quienes indican que incluso se puede usar papel bond de $50 \mathrm{~g} / \mathrm{m}^{2}$. Por lo general las etiquetas son de 2,8 x 2,4 cm. Los rollos deben ser impresos por un solo lado. La envasadora corta cada dos etiquetas, pone adhesivo entre las dos y pega. Las etiquetas pueden ser además troqueladas, sin embargo estas tienen un costo mayor. El Anexo 1 muestra el diseño y medidas de las etiquetas cuyo diseño es similar para ambos productos.

Una bobina de $2,8 \mathrm{~cm}$ de ancho pesa $1,50 \mathrm{~kg}$ aproximadamente, de 1,00 $\mathrm{kg}$ salen en promedio 10.000 etiquetas dobles de 2,8 x 4,8 cm. La Tabla 5.44 muestra el requerimiento de este material.

Tabla 5.44

Requerimiento de etiquetas

\begin{tabular}{|c|c|c|}
\hline Año & $\begin{array}{c}\text { Etiquetas dobles } \\
\text { (kg) }\end{array}$ & $\begin{array}{c}\text { Etiquetas dobles } \\
\text { (bobinas) }\end{array}$ \\
\hline 2016 & 659,00 & 440,00 \\
\hline 2017 & 694,00 & 463,00 \\
\hline 2018 & 729,00 & 486,00 \\
\hline 2019 & 763,00 & 509,00 \\
\hline 2020 & 796,00 & 531,00 \\
\hline 2021 & 829,00 & 553,00 \\
\hline 2022 & 861,00 & 574,00 \\
\hline 2023 & 892,00 & 595,00 \\
\hline 2024 & 923,00 & 616,00 \\
\hline 2025 & 953,00 & 636,00 \\
\hline
\end{tabular}

Fuente: Stickers S.A.C., (2016).

El adhesivo sirve para pegar las etiquetas dobles. El tipo de adhesivo usado es la cola sintética o cola blanca. Se seleccionó baldes de $20 \mathrm{~kg}$. Por lo general $1 \mathrm{~kg}$ de adhesivo sirve para pegar las etiquetas de 70.000 bolsas filtrantes. La Tabla 5.45 muestra los requerimientos de este material.

\footnotetext{
${ }^{21}$ El tipo de impresión característico para bobinas es la flexografía. Mediante esta técnica se imprimen las etiquetas, los sobres de envoltura y las etiquetas autoadhesivas. Usa fotopolímeros, llamados también clichés.
} 
Tabla 5. 45

Requerimiento de adhesivo

\begin{tabular}{|c|c|c|}
\hline Año & Adhesivo (kg) & $\begin{array}{c}\text { Adhesivo } \\
\text { (galón 20 kg) }\end{array}$ \\
\hline 2016 & 94,14 & 5,00 \\
\hline 2017 & 99,14 & 5,00 \\
\hline 2018 & 104,14 & 5,00 \\
\hline 2019 & 109,00 & 5,00 \\
\hline 2020 & 113,71 & 6,00 \\
\hline 2021 & 118,43 & 6,00 \\
\hline 2022 & 123,00 & 6,00 \\
\hline 2023 & 127,43 & 6,00 \\
\hline 2024 & 131,86 & 7,00 \\
\hline 2025 & 136,14 & 7,00 \\
\hline
\end{tabular}

Fuente: Corporación Peruana de Productos Químicos S.A. - Cppq S.A.-Qroma, (2016).

Los sobres de envoltura serán también de papel bond de $60 \mathrm{~g} / \mathrm{m}^{2}$, impresos en bobinas de ancho de $6,5 \mathrm{~cm}$. Cada sobre abierto cortado tiene una longitud de 15,50 $\mathrm{cm}$ para la envasadora maisa EC12B. EL Anexo 1 muestra su diseño para cada producto.

Una bobina pesa en promedio $6,50 \mathrm{~kg}$, y de $1 \mathrm{~kg}$ se obtienen aproximadamente 1.600 sobres de envoltura. La Tabla 5.46 muestra los requerimientos de este material.

Tabla 5. 46

Requerimiento de sobres de envoltura

\begin{tabular}{|c|c|c|}
\hline Año & $\begin{array}{c}\text { Sobres de } \\
\text { envoltura (kg) }\end{array}$ & $\begin{array}{c}\text { Sobres de } \\
\text { envoltura (bobinas) }\end{array}$ \\
\hline 2016 & $4.118,75$ & 634,00 \\
\hline 2017 & $4.337,50$ & 668,00 \\
\hline 2018 & $4.556,25$ & 701,00 \\
\hline 2019 & $4.768,75$ & 734,00 \\
\hline 2020 & $4.975,00$ & 766,00 \\
\hline 2021 & $5.181,25$ & 798,00 \\
\hline 2022 & $5.381,25$ & 828,00 \\
\hline 2023 & $5.575,00$ & 858,00 \\
\hline 2024 & $5.768,75$ & 888,00 \\
\hline 2025 & $5.956,25$ & 917,00 \\
\hline
\end{tabular}

Fuente: Stickers S.A.C., (2016).

Las cajas, dependiendo del producto, difieren en el largo, mas no en la altura y ancho. El largo es de 11 y $9 \mathrm{~cm}$ para cajas de planta entera y flores, respectivamente. El gramaje para ambos es de $225 \mathrm{~g} / \mathrm{m}^{2}$ (Calibre 14). Se optó por cartulina dúplex de color beige. El tipo depende del modo de cierre de la caja. Se optaron por cajas de dos solapas y un solo lado pegado. La Tabla 5.47 muestra lo requerido. 
Tabla 5.47

Requerimiento de cajas para ambos productos

\begin{tabular}{|c|c|c|c|}
\hline Año & Cajas tipo 1 (Unidades) & Cajas tipo 2 (Unidades) & Total cajas \\
\hline 2016 & $259.500,00$ & $93.334,00$ & $352.834,00$ \\
\hline 2017 & $273.500,00$ & $98.000,00$ & $371.500,00$ \\
\hline 2018 & $287.000,00$ & $103.334,00$ & $390.334,00$ \\
\hline 2019 & $300.500,00$ & $108.000,00$ & $408.500,00$ \\
\hline 2020 & $313.500,00$ & $112.667,00$ & $426.167,00$ \\
\hline 2021 & $326.500,00$ & $117.334,00$ & $443.834,00$ \\
\hline 2022 & $339.000,00$ & $122.000,00$ & $461.000,00$ \\
\hline 2023 & $351.500,00$ & $126.000,00$ & $477.500,00$ \\
\hline 2024 & $363.500,00$ & $130.667,00$ & $494.167,00$ \\
\hline 2025 & $375.500,00$ & $134.667,00$ & $510.167,00$ \\
\hline
\end{tabular}

Fuente: Stickers S.A.C., (2016).

Las etiquetas adhesivas son necesarias para la colocar la fecha de vencimiento del producto. Según el inciso f del artículo 117 del D.S. № 007-98-SA, así como la Ley Nº 28405 referida al rotulado de productos industriales manufacturados inciso c, artículo 3.indica que si el producto es perecible se debe rotular la fecha de vencimiento, las condiciones de conservación y algunas observaciones complementarias referidas al lote. Ambos productos tendrán una fecha de caducidad de 2 años.

Las etiquetas vienen en presentación de rollos de 1.000 unidades. La Tabla 5.48 muestra la cantidad de etiquetas adhesivas requeridas.

Tabla 5.48

Requerimiento de etiquetas adhesivas

\begin{tabular}{|c|c|}
\hline Año & $\begin{array}{c}\text { Etiquetas } \\
\text { adhesivas } \\
\text { (Unidades) }\end{array}$ \\
\hline 2016 & 353,00 \\
\hline 2017 & 372,00 \\
\hline 2018 & 391,00 \\
\hline 2019 & 409,00 \\
\hline 2020 & 427,00 \\
\hline 2021 & 444,00 \\
\hline 2022 & 461,00 \\
\hline 2023 & 478,00 \\
\hline 2024 & 495,00 \\
\hline 2025 & 511,00 \\
\hline
\end{tabular}

Fuente: Label Peru S.A.C., (2016). 
Finalmente, la envoltura de las cajas tiene la función de contener el aroma y aislar el producto de la humedad del medio ambiente. Las envolturas son de polipropileno en bobinas con espesor de 17 micras. El ancho de la bobina es de $21 \mathrm{~cm}$, asumiendo la envoltura de la caja más larga y teniendo en cuenta que se cortará cada $30 \mathrm{~cm}$ por caja. Luego se embalan 24 cajas en bolsas de polietileno de 1,5 micras de 11 x 9 pulgadas con fuelles laterales, para luego cerrarse con cinta de embalaje de 2 pulgadas de largo de $100 \mathrm{~m}$. La Tabla 5.49 muestra estos requerimientos.

Tabla 5. 49

Requerimiento de envolturas de cajas, bolsas de polietileno y cintas de embalaje

\begin{tabular}{|c|c|c|c|}
\hline Año & $\begin{array}{c}\text { Envolturas de } \\
\text { cajas (Bobinas) }\end{array}$ & $\begin{array}{c}\text { Bolsas de } \\
\text { polietileno } \\
\text { (Unidades) }\end{array}$ & $\begin{array}{c}\text { Cintas de embalaje } \\
\text { (Unidades) }\end{array}$ \\
\hline 2016 & 27,00 & $14.702,00$ & 45,00 \\
\hline 2017 & 28,00 & $15.480,00$ & 47,00 \\
\hline 2018 & 30,00 & $16.264,00$ & 49,00 \\
\hline 2019 & 31,00 & $17.021,00$ & 52,00 \\
\hline 2020 & 32,00 & $17.757,00$ & 54,00 \\
\hline 2021 & 34,00 & $18.494,00$ & 56,00 \\
\hline 2022 & 35,00 & $19.209,00$ & 58,00 \\
\hline 2023 & 36,00 & $19.896,00$ & 60,00 \\
\hline 2024 & 38,00 & $20.591,00$ & 62,00 \\
\hline 2025 & 39,00 & $21.257,00$ & 64,00 \\
\hline
\end{tabular}

Fuente: Opp film S.A., (2016).

\subsubsection{Servicios: energía eléctrica, agua, vapor, combustible, etc.}

La tabla 5.50 muestra el requerimiento de agua potable y desinfectante. El agua potable para producción considera una poza de lavado de $0,0621 \mathrm{~m}^{3}$, que se usan 7 pozas por ciclo, $6 \mathrm{y}$ 12 ciclos a la semana, los primeros y últimos cinco años, respectivamente, asumiendo 52 semanas al año. El agua potable para otros servicios considera que una persona promedio consume $0,25 \mathrm{~m}^{3}$ al día, 5 administrativos todos los años, 8 y 12 operarios los cinco primeros y últimos años, respectivamente, 3 personas de servicio todos los años, 300 días al año. El desinfectante requiere $5 \mathrm{ml}$ por cada $10 \mathrm{~L}$ de agua. 
Tabla 5.50

Requerimiento de agua potable y desinfectante para operación de lavado

\begin{tabular}{|l|c|c|c|c|}
\hline Año & $\begin{array}{c}\text { Agua potable para } \\
\text { producción }\left(\mathbf{m}^{\mathbf{3}}\right)\end{array}$ & $\begin{array}{c}\text { Requerimiento de } \\
\text { desinfectante }\left(\mathbf{m}^{\mathbf{3}}\right)\end{array}$ & $\begin{array}{c}\text { Agua potable para } \\
\text { otros servicios }\left(\mathbf{m}^{\mathbf{3}}\right)\end{array}$ & $\begin{array}{c}\text { Agua potable total } \\
\left(\mathbf{m}^{\mathbf{3}}\right)\end{array}$ \\
\hline 2016 & 135,63 & 0,0678 & $1.200,00$ & $1.335,63$ \\
\hline 2017 & 135,63 & 0,0678 & $1.200,00$ & $1.335,63$ \\
\hline 2018 & 135,63 & 0,0678 & $1.200,00$ & $1.335,63$ \\
\hline 2019 & 135,63 & 0,0678 & $1.200,00$ & $1.335,63$ \\
\hline 2020 & 135,63 & 0,0678 & $1.200,00$ & $1.335,63$ \\
\hline 2021 & 271,25 & 0,1356 & $1.500,00$ & $1.771,25$ \\
\hline 2022 & 271,25 & 0,1356 & $1.500,00$ & $1.771,25$ \\
\hline 2023 & 271,25 & 0,1356 & $1.500,00$ & $1.771,25$ \\
\hline 2024 & 271,25 & 0,1356 & $1.500,00$ & $1.771,25$ \\
\hline 2025 & 271,25 & 0,1356 & $1.500,00$ & $1.771,25$ \\
\hline
\end{tabular}

Elaboración propia

La Tabla 5.51 muestra la energía eléctrica necesaria según la maquinaria y equipos y sus respectivos tiempos de operación para cada año.

Tabla 5. 51

Requerimiento de energía eléctrica

\begin{tabular}{|c|c|}
\hline Año & $\begin{array}{c}\text { Consumo total de } \\
\text { energía eléctrica } \\
(\mathbf{k W})\end{array}$ \\
\hline 2016 & $46.741,61$ \\
\hline 2017 & $47.423,87$ \\
\hline 2018 & $48.106,13$ \\
\hline 2019 & $48.768,89$ \\
\hline 2020 & $49.412,16$ \\
\hline 2021 & $50.055,43$ \\
\hline 2022 & $50.679,20$ \\
\hline 2023 & $51.283,49$ \\
\hline 2024 & $51.887,77$ \\
\hline 2025 & $52.472,56$ \\
\hline
\end{tabular}

Elaboración propia

Para el consumo de gas licuado de petróleo se debe tener en cuenta el poder calorífico del GLP, así como la cantidad a consumir por ciclo de este combustible. El Anexo 5 muestra estos cálculos. La Tabla 5.52 muestra el requerimiento de este combustible para el último año. Asimismo, debido a la localización de la planta de producción se ha previsto contar con un tanque estacionario de GLP que será abastecida tres veces al año. 
Tabla 5. 52

Requerimiento de gas licuado de petróleo (GLP)

\begin{tabular}{|c|c|}
\hline Año & $\begin{array}{c}\text { Consumo de GLP } \\
\text { (balones) }\end{array}$ \\
\hline 2016 & 428,00 \\
\hline 2017 & 428,00 \\
\hline 2018 & 428,00 \\
\hline 2019 & 428,00 \\
\hline 2020 & 428,00 \\
\hline 2021 & 428,00 \\
\hline 2022 & 428,00 \\
\hline 2023 & 428,00 \\
\hline 2024 & 428,00 \\
\hline 2025 & 428,00 \\
\hline
\end{tabular}

Elaboración propia

\subsubsection{Determinación del número de operarios y trabajadores indirectos}

En base a los tiempos que demoran las operaciones del proceso se halló que la cantidad de operarios necesarios no excede de cuatro personas por turno como muestra la Figura 5.9.

Figura 5. 9

Diagrama Hombre- Máquina de las operaciones

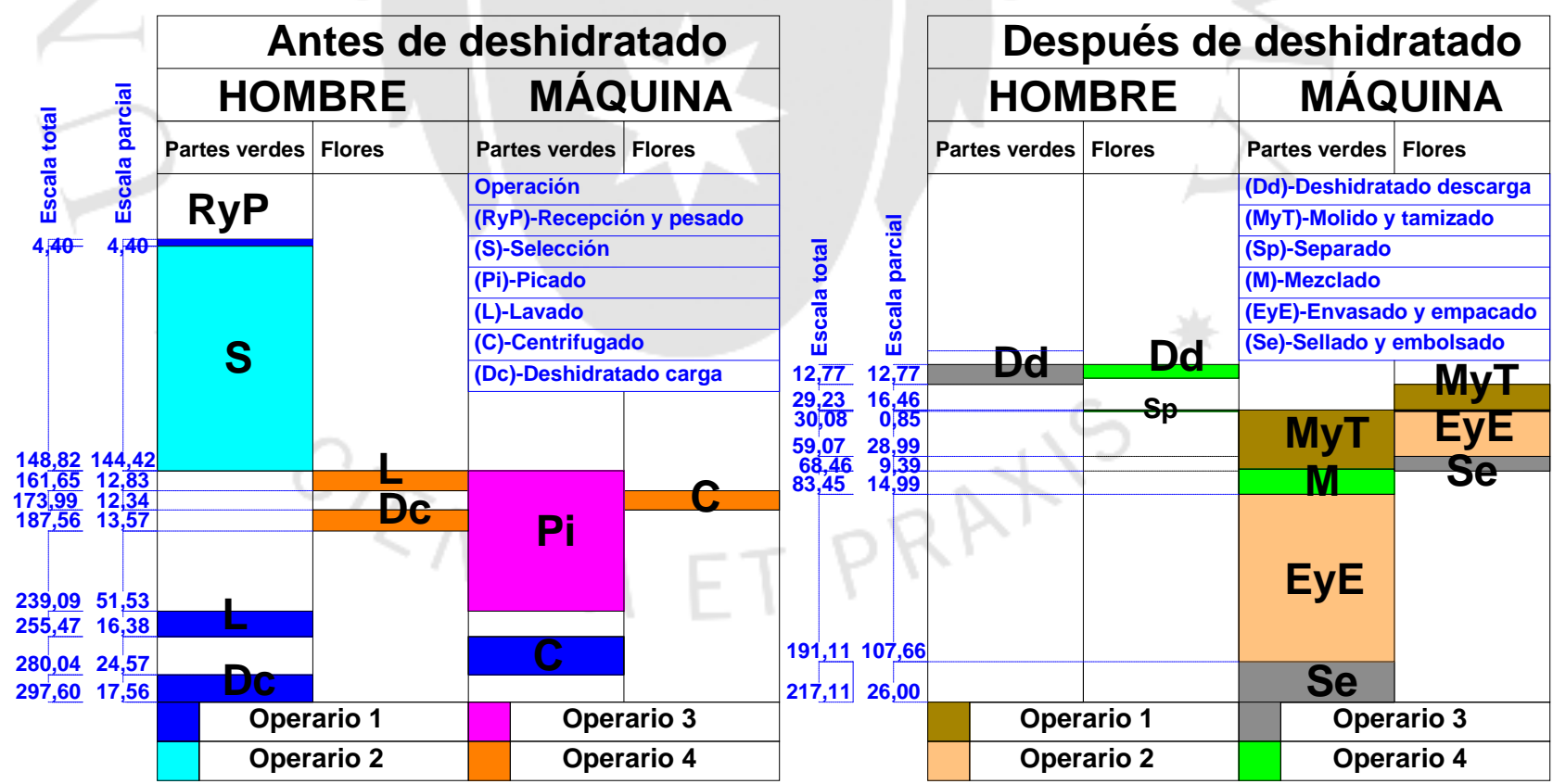

Nota: Las escalas de tiempo están en minutos.

Elaboración propia

Respecto a trabajadores indirectos, se tiene previsto contratar a un jefe de planta y a un encargado de calidad. 


\subsubsection{Servicios de terceros}

Los servicios a tercerizar serán el de transporte de productos terminados, análisis microbiológico, seguimiento de sembríos, calibración de balanzas, publicidad y mantenimientos preventivos.

\subsection{Disposición de planta}

\subsubsection{Características físicas del proyecto}

\section{Estudio de suelos}

El suelo sobre el cual se construirá la planta industrial debe ser capaz de soportar cargas muertas de la instalación como son cimientos, muros, columnas, vigas y demás; así como también la maquinaría, mobiliario y otros equipos necesarios para la actividad de producción; además de eso, también cargas vivas como el personal y elementos móviles; e inclusive la combinación de cualquiera de estas cargas con factores medio ambientales según el artículo 1 de la Norma de Cargas (E.020) del Título de Estructuras (III.2) del Reglamento Nacional de Edificaciones (RNE).

\section{Edificación}

Teniendo en cuenta que la edificación será de tipo industrial, el artículo 4 de la Norma Técnica de Habilitaciones para Uso Industrial (TH.030), contenida en el Numeral II.1 Tipos de Habitaciones, del Título II Habilitaciones Urbanas del RNE, en base a su uso permisible, señala que es industria de tipo elemental y complementario según muestra la Tabla 5.53.

Tabla 5.53

Tipo de industria en función de los usos permisibles

\begin{tabular}{|c|c|c|c|}
\hline Tipo & Área mínima de lote & Frente mínimo & Tipo de industria \\
\hline 1 & 300 & 10,00 & Elemental y complementaria \\
\hline 2 & 1.000 & 20,00 & Liviana \\
\hline 3 & 2.500 & 30,00 & Gran industria \\
\hline 4 & - & - & Industria pesada básica \\
\hline
\end{tabular}

Fuente: Ministerio de Viviendda, Construcción y Saneamiento-MVCS, (2016). 
Finalmente, se debe diseñar la construcción de planta industrial de modo que esta sea sismorresistente, es decir, que se construya conociendo de antemano el grado de sismicidad de la zona donde se ubica. El D.S. N$^{\circ}$ 003-2016-VIVIENDA que modifica y actualiza la Norma Técnica de Diseño Sismorresistente (E.030) contenida en el Numeral III.2 Estructuras, del Título III Edificaciones del Reglamento Nacional de Edificaciones (RNE). $\mathrm{Su}$ alcance es también para las edificaciones nuevas y establece condiciones mínimas para que estas sean construidas.

\subsubsection{Determinación de las zonas físicas requeridas}

Las áreas requeridas por el presente proyecto son las de: materia prima, producción, materiales, producto terminado, control de calidad, combustible (GLP), oficinas administrativas, vigilancia, comedor, patio de vehículos y servicios higiénicos.

\subsubsection{Cálculo de áreas para cada zona}

Las áreas de cada zona se hallarán en base a criterios y requisitos mínimos establecidos en el RNE y D.S. N007-98-SA. Sin embargo, para el área de producción además se deberá tener en cuenta las características y cantidad de la maquinaria requerida. Existen varios métodos para tal fin. El presente estudio usará el método de Guerchet. Asimismo, el área de materiales se dimensionará teniendo en cuenta que serán adquiridos cada seis meses. El área de productos terminados rotará cada dos semanas.

\section{Área de producción}

El método de Guerchet calcula la superficie de cada elemento realizando la suma de tres superficies parciales:

- Superficie estática: Ss = Largo x Ancho

- $\quad$ Superficie gravitacional: $\mathrm{Sg}=\mathrm{Ss} \times \mathrm{N}$

- $\quad$ Superficie de evolución: $\mathrm{Se}=(\mathrm{Ss}+\mathrm{Sg}) * \mathrm{~K}$ 
La superficie estática se refiere al área que ocupa la maquinaria, la superficie gravitacional se refiere al área alrededor de la maquinaría que se será utilizada considerando el número de lados que deben ser utilizados $(\mathrm{N})$. Por último, la superficie de evolución se refiere al área entre los puestos de trabajo para el desplazamiento del personal, de la maquinaria y del producto. Antes, se debe hallar el factor k, que es una media ponderada entre las alturas de los elementos móviles y los estáticos según la siguiente fórmula:

$$
\mathrm{k}=\frac{\text { Altura ponderada de elementos móviles }}{2 \times \text { Altura ponderada de elementos estáticos }}
$$

Reemplazando, y teniendo en cuenta que cada elemento estático requiere una sola máquina o equipo a diferencia de los móviles.

$$
\mathrm{k}=\frac{\left(\frac{1,65 \times 4+1,00 \times 2+1,75 \times 1}{7}\right)}{2 \times 1 \times\left(\frac{1,00+0,80+1,45+1,12+0,70+1,90+1,29+0,80+1,70+1,99+1,00}{11}\right)}
$$

La Tabla 5.54 muestra las áreas mínimas para cada elemento en el área de producción según el método de Guerchet.

Tabla 5.54

\begin{tabular}{|c|c|c|c|c|c|c|c|c|c|c|}
\hline $\begin{array}{l}\text { Elementos } \\
\text { estáticos }\end{array}$ & $\mathbf{n}$ & $\mathbf{N}$ & $\begin{array}{l}\text { Largo } \\
(\mathbf{L})\end{array}$ & $\begin{array}{c}\text { Ancho } \\
\text { (A) }\end{array}$ & $\begin{array}{c}\text { Altura } \\
\text { (h) }\end{array}$ & $\begin{array}{c}\mathbf{S s} \\
\left(\mathbf{L}^{*} \mathbf{A}\right)\end{array}$ & $\begin{array}{c}\mathbf{S g} \\
\left(\mathbf{S} \mathbf{s}^{*} \mathbf{N}\right)\end{array}$ & k & $\begin{array}{c}\mathbf{S e} \\
{[(\mathbf{S s}+\mathbf{S g}) * \mathbf{K}]}\end{array}$ & $\begin{array}{c}\mathbf{S t} \\
{[\mathbf{n} *(\mathbf{S s}+\mathbf{S g}+\mathbf{S e})]}\end{array}$ \\
\hline Balanza & 1 & 3 & 0,60 & 0,80 & 1,00 & 0,48 & 1,44 & 0,59 & 1,44 & 3,06 \\
\hline Mesa & 1 & 1 & 2,00 & 1,00 & 0,80 & 2,00 & 2,00 & 0,59 & 1,60 & 6,37 \\
\hline Picadora & 1 & 2 & 1,00 & 0,60 & 1,45 & 0,60 & 1,20 & 0,59 & 1,74 & 2,87 \\
\hline Lavadero & 1 & 1 & 2,00 & 0,60 & 1,12 & 1,20 & 1,20 & 0,59 & 1,34 & 3,82 \\
\hline Centrífuga & 1 & 2 & - & - & 0,70 & 0,24 & 0,48 & 0,59 & 0,33 & 1,13 \\
\hline Deshidratador & 1 & 1 & 3,50 & 1,20 & 1,90 & 4,20 & 4,20 & 0,59 & 7,96 & 13,37 \\
\hline Molino & 1 & 2 & 1,00 & 0,60 & 1,29 & 0,60 & 1,20 & 0,59 & 1,55 & 2,87 \\
\hline Mesa separado & 1 & 2 & 1,60 & 0,60 & 0,80 & 0,96 & 1,92 & 0,59 & 1,54 & 4,58 \\
\hline Mezcladora & 1 & 1 & 1,25 & 1,00 & 1,70 & 1,25 & 1,25 & 0,59 & 2,13 & 3,98 \\
\hline Envasadora & 1 & 1 & 2,40 & 0,93 & 1,99 & 2,24 & 2,24 & 0,59 & 4,44 & 7,13 \\
\hline Selladora & 1 & 1 & 1,00 & 0,60 & 1,00 & 0,60 & 0,60 & 0,59 & 0,60 & 1,91 \\
\hline $\begin{array}{l}\text { Elementos } \\
\text { móviles }\end{array}$ & $\mathbf{n}$ & $\mathbf{N}$ & $\begin{array}{l}\text { Largo } \\
\text { (L) }\end{array}$ & $\begin{array}{l}\text { Ancho } \\
\text { (A) }\end{array}$ & $\begin{array}{c}\text { Altura } \\
\text { (h) }\end{array}$ & $\begin{array}{c}\text { Ss } \\
\left(\mathbf{L}^{*} \mathbf{A}\right)\end{array}$ & $\begin{array}{c}\mathrm{Sg} \\
\left(\mathrm{Ss}^{*} \mathbf{N}\right)\end{array}$ & $\mathbf{k}$ & $\begin{array}{c}\mathbf{S e} \\
{[(\mathbf{S s}+\mathbf{S g}) * \mathbf{K}]}\end{array}$ & $\begin{array}{c}\mathbf{S t} \\
{[\mathrm{n} *(\mathrm{Ss}+\mathrm{Sg}+\mathrm{Se})]}\end{array}$ \\
\hline Operarios & 4 & - & - & - & 1,65 & 0,50 & - & 0,59 & 0,30 & 3,18 \\
\hline Coche $\mathrm{A}^{22}$ & 2 & 1 & 1,20 & 0,80 & 1,00 & - & - & 0,59 & - & - \\
\hline Coche B & 1 & 1 & 1,20 & 1,20 & 1,75 & 1,44 & 1,44 & 0,59 & 1,70 & 4,58 \\
\hline & & & & & & & & & Total & 58,85 \\
\hline
\end{tabular}

Área mínima del área de producción por el método de Guerchet

${ }^{22}$ Se refiere a los coches para el transporte de materia prima y materiales. Sólo se toma en cuenta sus alturas para el cálculo del factor $\mathrm{k}$ ya que, por lo regular, no permanecen estacionados dentro del área de producción. 
Entre otros aspectos importantes, de acuerdo con Diaz, Jarufe, y Noriega (2007), se debe tener en cuenta que si el elemento en la vista de planta tiene forma de círculo se le considera " $\mathrm{N}=2$ ", y su superficie estática se calcula como el área de un círculo. Asimismo, en caso de equipos que tengan puertas batientes que durante la operación permanecen cerradas, la superficie estática debe calcularse también en posición cerrada (p. 289).

\section{Área de materia prima}

Esta área sirve para que una carga de planta entera de manzanilla común aguarde mientras otra carga se procesa. Será requerida por razones de eficiencia cuando aumente la producción. Ya que al salir una carga del deshidratador se debe ingresar una nueva lo más rápido posible. La carga que aguarda no debe sufrir deterioros o pérdidas. Por este motivo se debe extender dicha planta y no se debe apilar. El tiempo de espera no debe ser mayor a siete horas. La Tabla 5.55 muestra la dimensión de dicha área.

Tabla 5. 55

Espacio mínimo de almacén de materia prima

\begin{tabular}{|c|c|c|}
\hline Espacio para materia prima (Altura: $\mathbf{3 0 0 , 0 0} \mathbf{~ c m}$ ) & Cantidad & Unidad \\
\hline Materia prima total a almacenar por día el 2025 & 85,00 & $\mathrm{~kg}$ \\
\hline Forma en que materia prima es recibida & & mantas atadas \\
\hline Peso máximo por manta & 25,00 & $\mathrm{~kg}$ \\
\hline Cantidad de mantas & 4,00 & mantas \\
\hline Forma de almacenamiento & & mantas abiertas \\
\hline Dimensiones de la mesa & 2,00 & $\mathrm{~m}$ \\
\hline Largo & 1,50 & $\mathrm{~m}$ \\
\hline Ancho & 1,00 & $\mathrm{~m}$ \\
\hline Altura & 4,00 & $\mathrm{mesas}$ \\
\hline Cantidad de mesas & 12,00 & $\mathrm{~m}^{2}$ \\
\hline Área que ocupan las mesas & 18,00 & $\mathrm{~m}^{2}$ \\
\hline Espacio para manipulación & 30,00 & $\mathrm{~m}^{2}$ \\
\hline Área mínima de almacén de materia prima &
\end{tabular}

Elaboración propia

\section{Área de materiales}

Los materiales requeridos por el presente proyecto serán adquiridos cada seis meses, es decir, dos veces al año. Se adoptó esta política de suministro debido a que es menos costoso comprar y transportar en gran volumen. 
Asimismo, se decidió escoger estantes de un solo tamaño para todos los materiales. Cada uno será de tres niveles, con medidas útiles en metros de 1,25 a lo largo, 0,65 a lo profundo y 0,75 a lo alto. El material de los estantes debe ser de preferencia madera ${ }^{23}$ de 2 pulgadas de espesor ya que deben soportar bobinas de regular peso.

Por tanto, y como lo muestra la Tabla 5.56 , en base a las dimensiones de los materiales, de los estantes y a los requerimientos para seis meses, se requieren 42 niveles como mínimo, es decir, 14 estantes de tres niveles cada uno. Asumiendo que serán de 2 pulgadas a cada lado $(0,05 \mathrm{~m})$ sumado a los $1,25 \mathrm{~m}$, se obtiene 1,35 $\mathrm{m}$ de lado; con 0,65 de profundidad se obtiene $0,88 \mathrm{~m}^{2}$ por estante. En 14 estantes hay 12,32 $\mathrm{m}^{2}$ solamente en área estática. Asumiendo N=1 habrá como mínimo 24,64 $\mathrm{m}^{2}$.

Tabla 5. 56

Espacio mínimo para materiales que cubran seis meses de producción el último año

\begin{tabular}{|c|c|}
\hline Espacio para materiales (Altura: 300,00 cm) & Cantidad de niveles \\
\hline Papel filtro termosellable en bobina & 8,33 \\
\hline Hilo enrollado en cono & 0,88 \\
\hline Etiquetas impresas en bobina & 1,53 \\
\hline Adhesivo en balde & 0,50 \\
\hline Sobres de envoltura impresos en bobina & 5,22 \\
\hline Cajas planas de producto 1 & 18,30 \\
\hline Cajas planas de producto 2 & 4,92 \\
\hline Etiquetas adhesivas en rollo & 0,04 \\
\hline Envolturas de cajas en bobina & 1,11 \\
\hline Desinfectante en galones & 0,67 \\
\hline Bolsas de polietileno en fardo & 0,13 \\
\hline Cintas de embalaje en caja & 0,10 \\
\hline Total de niveles & 41,73 \\
\hline Total de niveles enteros & 42,00 \\
\hline Total de estantes (1 estante tiene 3 niveles) & 14,00 \\
\hline
\end{tabular}

Elaboración propia

\section{Área de productos terminados}

Los productos tendrán una salida cada dos semanas. Se eligió este periodo en base a la rotación de infusiones filtrantes en supermercados. La Tabla 5.57 muestra la cantidad mínima de parihuelas de idénticas medidas.

\footnotetext{
${ }^{23}$ Se debe tener en cuenta que si una planta de producción de alimentos y bebidas utiliza madera cruda en la elaboración de anaqueles, estantes o parihuelas es preferible que hayan pasado por un tratamiento térmico según la R.D. N N $^{\circ}$ 05-2005-AG-SENASA-DGSV que se basa en la Norma Internacional de Medidas
} Fitosanitarias NINF $\mathrm{N}^{\circ} 15$. 
Tabla 5.57

Espacio mínimo de productos terminados para rotación cada dos semanas el último año

\begin{tabular}{|c|c|c|c|c|}
\hline $\begin{array}{c}\text { Espacio para productos terminados } \\
\text { (Altura: } 330 \mathrm{~cm} \text { ) }\end{array}$ & Producto 1 & Unidad & Producto 2 & Unidad \\
\hline Largo de caja & 11,00 & $\mathrm{~cm}$ & 9,00 & $\mathrm{~cm}$ \\
\hline Ancho de caja & 6,80 & $\mathrm{~cm}$ & 6,80 & $\mathrm{~cm}$ \\
\hline Altura de caja & 7,30 & $\mathrm{~cm}$ & 7,30 & $\mathrm{~cm}$ \\
\hline \multicolumn{5}{|l|}{ Requerimiento } \\
\hline Cajas producidas en 1 semana el 2025 & $7.722,00$ & cajas & $2.768,00$ & cajas \\
\hline Cajas producidas en 2 semanas el 2025 & $15.444,00$ & cajas & $5.536,00$ & cajas \\
\hline \multicolumn{5}{|l|}{ Requerimiento de parihuelas } \\
\hline Cajas a lo largo $(6,80 \mathrm{~cm})$ & 17,00 & cajas & 17,00 & cajas \\
\hline Cjas a lo ancho $(11,00 \mathrm{~cm}-9,00 \mathrm{~cm})$ & 9,00 & cajas & 11,00 & cajas \\
\hline Cajas apiladas a lo alto (altura apilada: $250,00 \mathrm{~cm}$ ) & 34,00 & cajas & 34,00 & cajas \\
\hline Cantidad de material por parihuela & $5.202,00$ & cajas & $6.358,00$ & cajas \\
\hline Total de parihuelas para 1 semana el 2025 & 2,00 & parihuelas & 1,00 & parihuelas \\
\hline Total de parihuelas para 2 semanas el 2025 & 3,00 & parihuelas & 1,00 & parihuelas \\
\hline
\end{tabular}

Elaboración propia

Según la Tabla 5.57, se requieren en total 4 parihuelas de 1,20 $\mathrm{m}^{2}$ de área $(1,00 \mathrm{~m} \mathrm{x}$ 1,20 m), es decir, ocupan un área de 4,80 $\mathrm{m}^{2}$, asumiendo un solo lado de maniobra $(\mathrm{N}=1)$, arroja $9,60 \mathrm{~m}^{2}$ de área mínima requerida.

Respecto a las demás áreas como son las administrativas y de servicios para el personal, u otras, no requieren de cálculos, sino más vienen normas de edificación o de seguridad tal y como lo resume el RNE.

\subsubsection{Dispositivos de seguridad industrial y señalización}

Las figuras 5.7 y 5.8 muestran los dispositivos de seguridad y señalización en el primer y segundo nivel de la planta industrial.

\subsubsection{Disposición general}

El análisis relacional de los ambientes de la planta debe ser hecho antes de proponer una disposición general. Consiste en determinar qué áreas deben estar necesariamente adyacentes, y que otros nunca deben estar juntas. En primer lugar, se deben establecer motivos por los cuales deben estar, o no, cerca. La tablas 5.58 y 5.59 muestran estos motivos y los codifica. 
Tabla 5. 58

Tabla de motivos para análisis relacional

\begin{tabular}{|c|c|}
\hline Código & Razón \\
\hline 1 & Flujo del materia prima e insumos \\
\hline 2 & Disponibilidad de un bien \\
\hline 3 & Control y seguridad \\
\hline 4 & Coordinación entre áreas \\
\hline 5 & Comodidad del personal \\
\hline 6 & Higiene, ruido y olores \\
\hline 7 & No hay relación \\
\hline
\end{tabular}

Elaboración propia

Tabla 5. 59

Códigos de análisis relacional

\begin{tabular}{|c|c|c|c|}
\hline Código & Proximidad & Color & Número de líneas \\
\hline $\mathbf{A}$ & Absolutamente necesario & Rojo & 4 líneas \\
\hline $\mathbf{E}$ & Especialmente necesario & Amarillo & 3 líneas \\
\hline $\mathbf{I}$ & Importante & Verde & 2 líneas \\
\hline $\mathbf{O}$ & Normal & Azul & 1 línea \\
\hline $\mathbf{U}$ & Sin importancia & --- & --- \\
\hline $\mathbf{X}$ & No deseable & Plomo & 1 zig-zag \\
\hline $\mathbf{X X}$ & Altamente no deseable & Negro & 2 zig-zag \\
\hline
\end{tabular}

Fuente: Diaz, B., Jarufe, B., y Noriega, M. (2007).

La Tabla 5.60 muestra las áreas entre las que se efectúa el análisis relacional.

Tabla 5. 60

Áreas de la planta industrial

\begin{tabular}{|c|c|c|c|}
\hline Numeración & Áreas & Identificación & Actividad \\
\hline 1 & Producción & $\mathbf{1}$ & Operación \\
\hline 2 & Materia prima & 3 & Almacenaje \\
\hline 3 & Productos terminados & 4 & Almacenaje \\
\hline 4 & Materiales & $\mathbf{5}$ & Almacenaje \\
\hline 5 & Oficinas administrativas & $\mathbf{6}$ & Oficina \\
\hline 6 & Servicios higiénicos & $\mathbf{7}$ & Servicio \\
\hline 7 & Comedor & $\mathbf{8}$ & Control \\
\hline 8 & Control de calidad & $\mathbf{9}$ & Transporte \\
\hline 9 & Patio de vehículos & $\mathbf{1 0}$ & Control \\
\hline 10 & Vigilancia & & \\
\hline
\end{tabular}

Elaboración propia

La Tabla 5.61 muestra los valores de proximidad entre dichas áreas. 
Tabla 5. 61

Valores de proximidad de las áreas de la instalación

\begin{tabular}{|c|c|c|c|c|c|c|}
\hline $\mathbf{A}$ & $\mathbf{E}$ & $\mathbf{I}$ & $\mathbf{O}$ & $\mathbf{U}$ & $\mathbf{X}$ & $\mathbf{X X}$ \\
\hline$(1,2)$ & $(2,8)$ & $(1,3)$ & $(2,3)$ & $(1,5)$ & $(1,7)$ & $(1,6)$ \\
\hline$(1,4)$ & $(2,9)$ & $(1,9)$ & $(2,4)$ & $(1,10)$ & $(3,6)$ & $(2,6)$ \\
\hline$(1,8)$ & $(3,9)$ & $(3,8)$ & $(3,5)$ & $(2,5)$ & $(3,7)$ & $(4,6)$ \\
\hline$(9,10)$ & $(4,9)$ & $(3,4)$ & $(4,5)$ & $(2,7)$ & $(6,7)$ & $(6,8)$ \\
\hline & & $(4,8)$ & $(5,8)$ & $(2,10)$ & $(7,8)$ & \\
\hline & & $(5,6)$ & $(5,10)$ & $(3,10)$ & & \\
\hline & & $(5,7)$ & $(6,10)$ & $(4,7)$ & & \\
\hline & & $(5,9)$ & $(7,9)$ & $(4,10)$ & & \\
\hline & & $(6,9)$ & & $(7,10)$ & & \\
\hline & & & & $(8,9)$ & & \\
\hline & & & & $(8,10)$ & & \\
\hline
\end{tabular}

Elaboración propia

Finalmente, las figuras 5.10 y 5.11 esquematizan y grafican, respectivamente, el análisis relacional entre las áreas de la planta industrial.

Figura 5. 10

Tabla relacional de áreas de la planta industrial

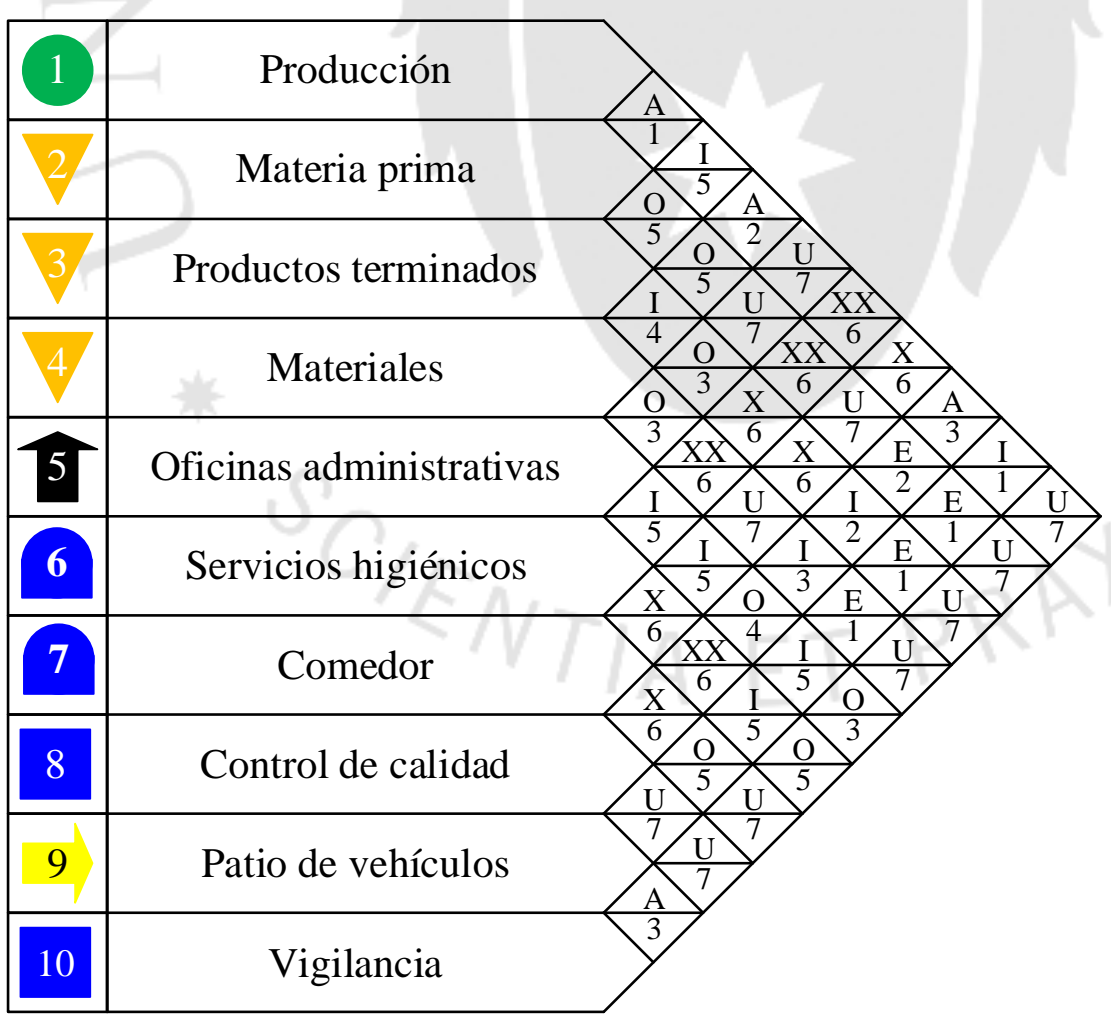

Elaboración propia 
Figura 5. 11

Diagrama de análisis relacional

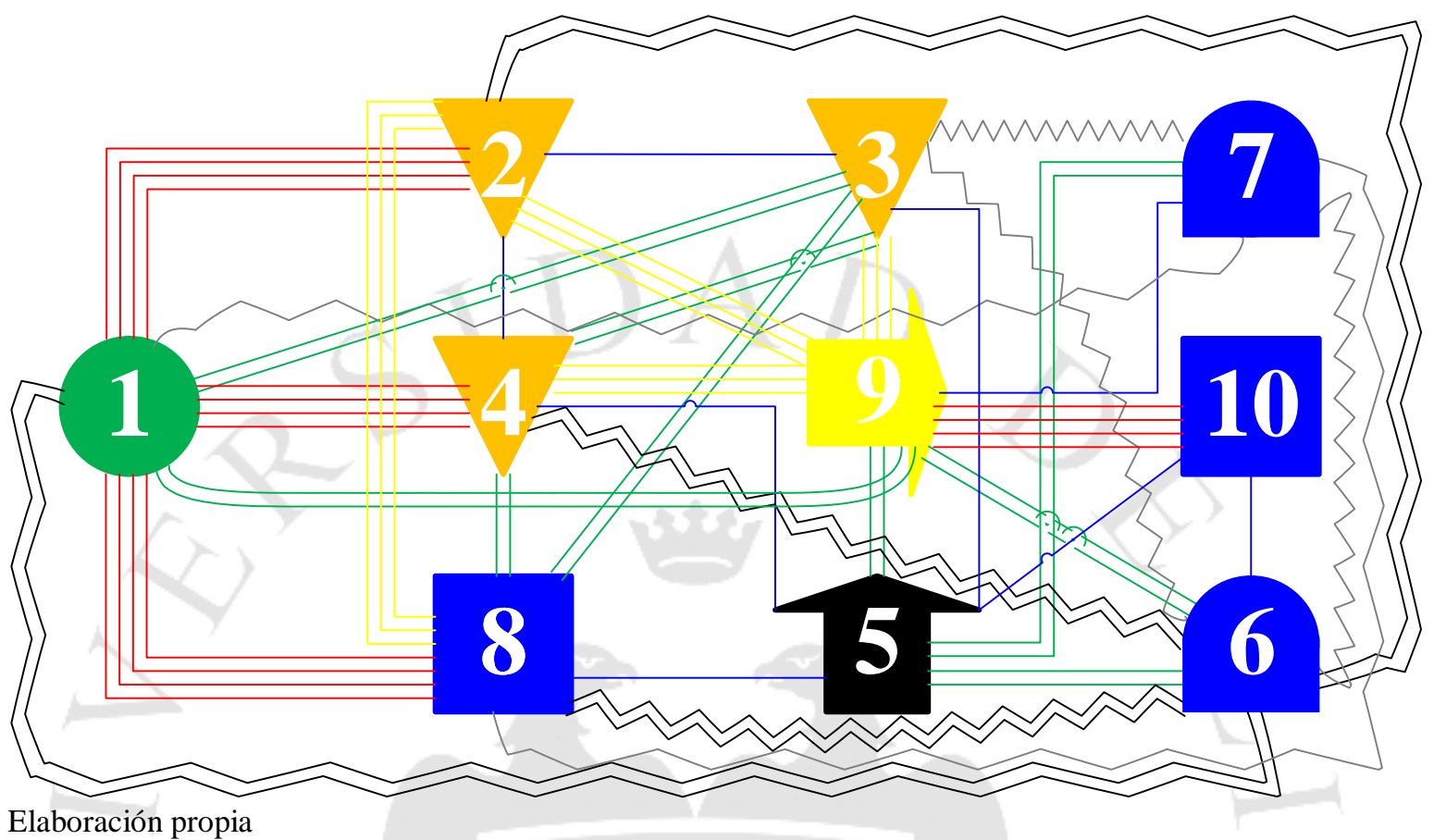

Una vez realizado el diagrama de análisis relacional es necesario esbozar los espacios y la distribución en base a este análisis. Con ese fin, se requiere emplear las superficies calculadas de las principales áreas de la planta industrial. Estas se resumen en la Tabla 5.62. Asimismo, la Figura 5.12 muestra el diagrama de los espacios de la instalación.

Tabla 5. 62

Superficies mínimas de las principales áreas de la planta industrial

\begin{tabular}{|c|c|c|}
\hline Áreas & Superficie $\mathbf{( m}^{\mathbf{2}}$ ) & $\begin{array}{c}\mathbf{N}^{\circ} \text { de unidades } \\
\text { superficiales } \\
\text { equivalentes }\end{array}$ \\
\hline Materia prima (2) & 15,00 & 3 \\
\hline Producción (1) & 60,00 & 12 \\
\hline Materiales (4) & 30,00 & 6 \\
\hline Producto terminado (3) & 15,00 & 3 \\
\hline Control de calidad (8) & 5,00 & 1 \\
\hline Patio de vehículos (9) & 120,00 & 24 \\
\hline Servicios higiénicos ${ }^{*}(6)$ & 20,00 & 4 \\
\hline Vigilancia (10) & 5,00 & 1 \\
\hline Comedor (7) & 20,00 & 4 \\
\hline
\end{tabular}

Nota: ${ }^{*}$ Se refiere a los servicios tanto para el personal administrativo, de servicio, de operaciones y de visitas. Elaboración propia 
Figura 5. 12

Diagrama relacional de espacios de la planta industrial

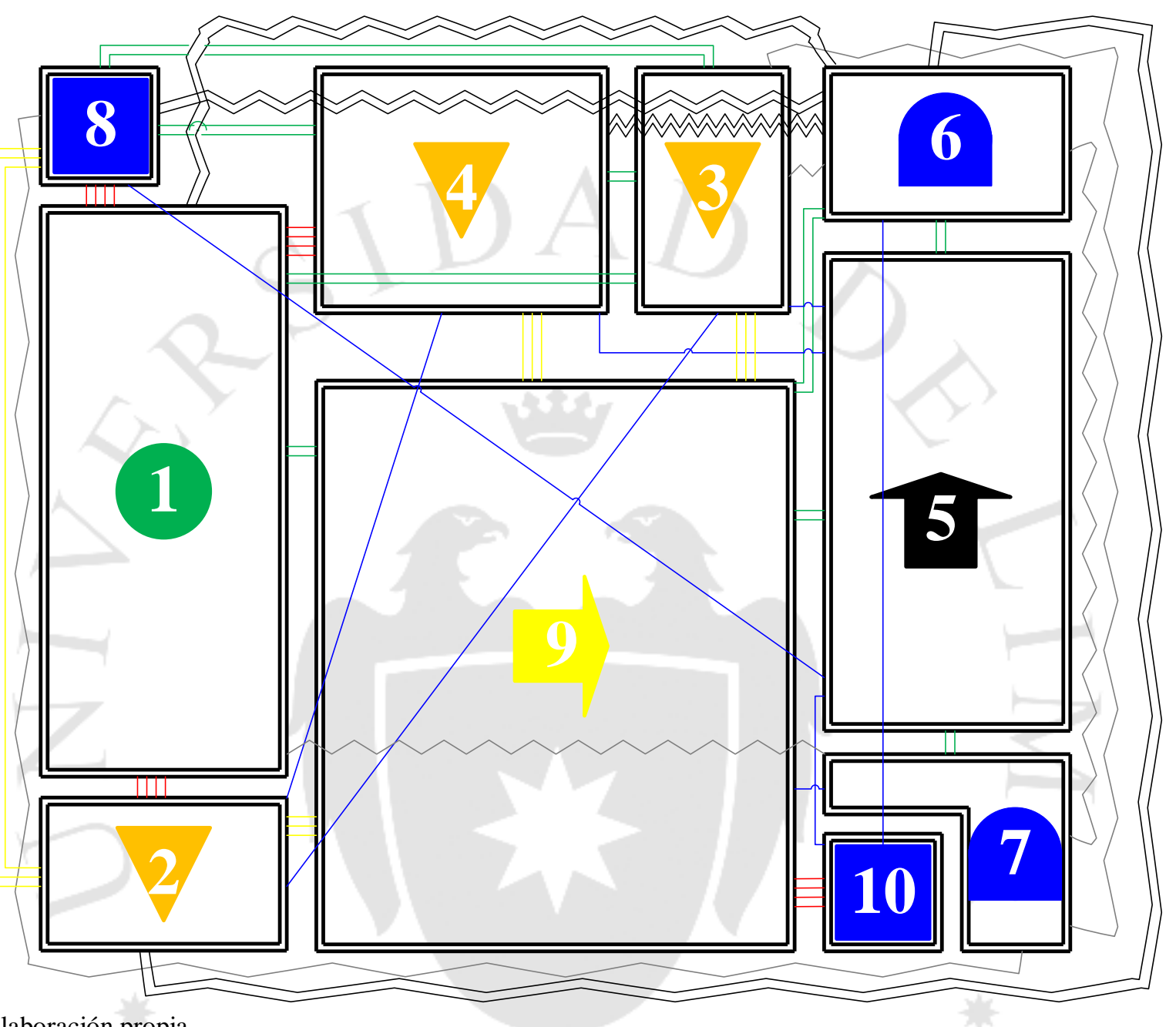

Elaboración propia

\subsubsection{Disposición de detalle}

De acuerdo con Díaz, B. et al. (2007) esta disposición se centra en un estudio detallado del ordenamiento interno de la planta de producción. En tal sentido depende de la naturaleza del producto. Si se trata de un solo producto, o más de uno, pero que sean estandarizados, se prefiere usar un diagrama de recorrido simple (p. 323). Las figura 5.13 y 5.14 muestran los planos de disposición de planta en cada piso, como los detalles de las áreas de producción, materia prima, materiales y producto terminados. 
Plano de disposición de planta del primer piso

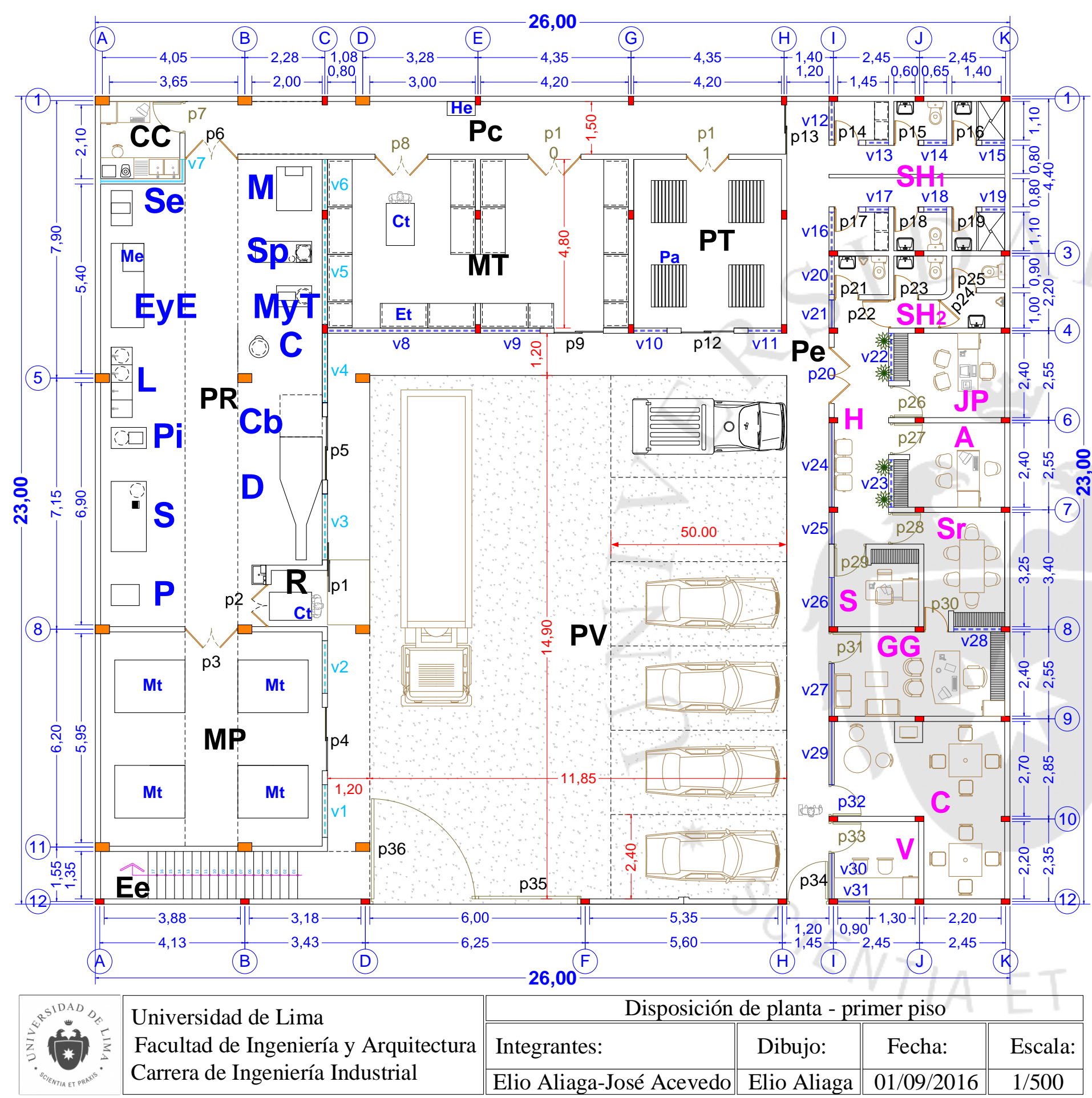

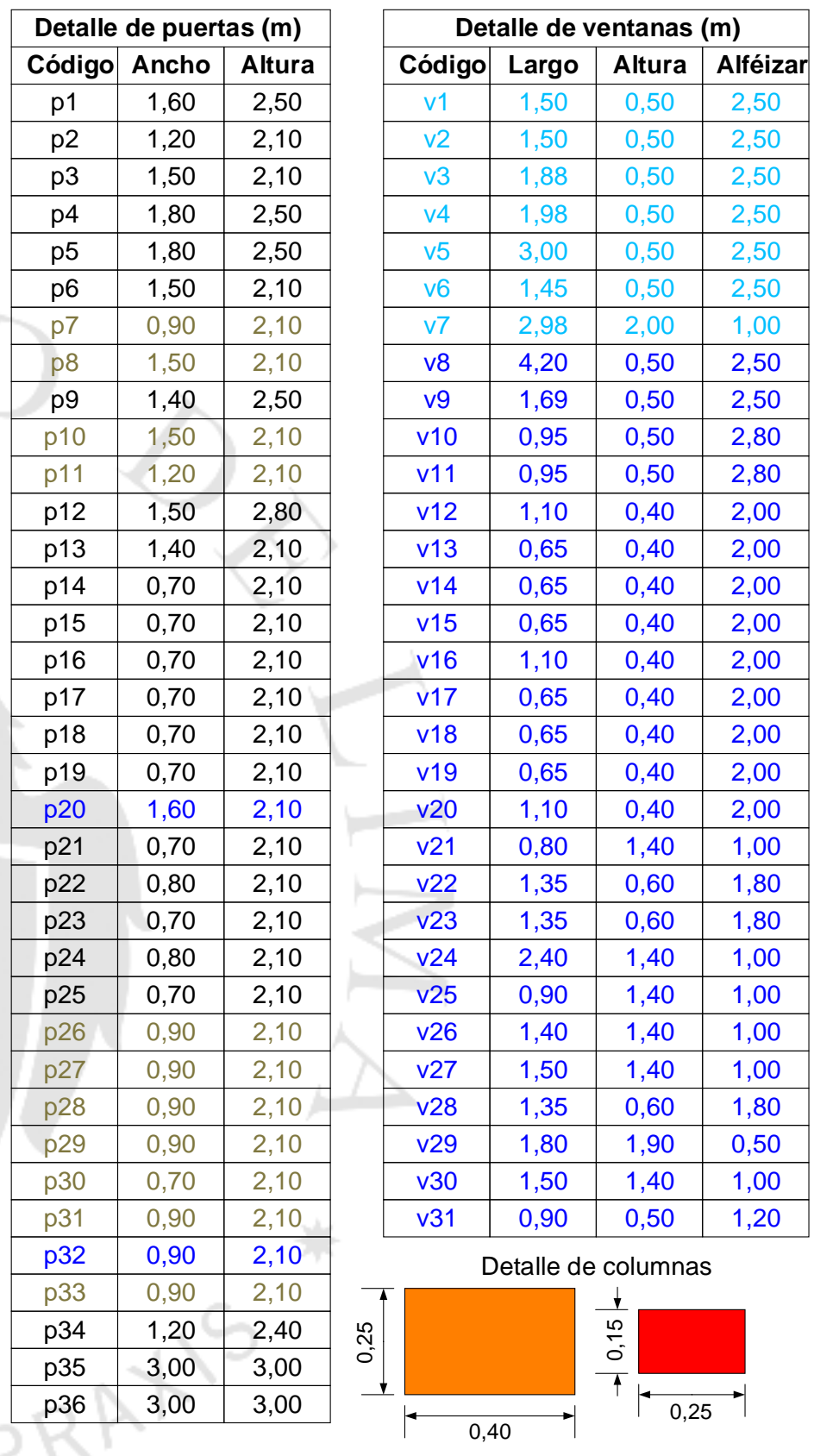

\begin{tabular}{|c|c|c|c|c|}
\hline \multicolumn{3}{|c|}{ Detalle de ambientes } & \multicolumn{2}{|c|}{ Áreas $\left(m^{2}\right)$} \\
\hline Código & \multicolumn{2}{|r|}{ Descripción } & & Pasad \\
\hline MP & \multirow{2}{*}{\multicolumn{2}{|c|}{$\begin{array}{l}\text { Materia prima } \\
\text { Producción }\end{array}$}} & 38,40 & 9,15 \\
\hline PR & & & 79,31 & 19,95 \\
\hline MT & \multicolumn{2}{|r|}{ Materiales } & 40,54 & 13,50 \\
\hline PT & \multicolumn{2}{|c|}{ Producto terminado } & 20,17 & 7,20 \\
\hline PV & \multirow{2}{*}{\multicolumn{2}{|c|}{ Patio de vehiculos }} & 117,52 & \\
\hline $\mathrm{CC}$ & & & 4,95 & \\
\hline$P c$ & \multicolumn{2}{|c|}{ Pasadizo de circulación } & 25,66 & - \\
\hline $\mathrm{Pe}$ & \multicolumn{2}{|c|}{ Pasadizo externo } & 61,81 & \\
\hline $\mathrm{Ee}$ & \multicolumn{2}{|c|}{ Espacio de escalera } & 56 & - \\
\hline $\mathrm{R}$ & \multicolumn{2}{|r|}{ Recepción } & 2,80 & \\
\hline $\mathrm{SH} 1$ & \multirow{2}{*}{\multicolumn{2}{|c|}{$\begin{array}{l}\text { Servicios higiénicos } 1 \\
\text { Servicios higiénicos } 2\end{array}$}} & 10,00 & 8,74 \\
\hline $\mathrm{SH} 2$ & & & 63 & 2,37 \\
\hline $\mathrm{H}$ & \multicolumn{2}{|r|}{ Hall } & 50 & \\
\hline JP & \multicolumn{2}{|c|}{ Jefatura de Planta } & 56 & \\
\hline A & \multirow{2}{*}{\multicolumn{2}{|c|}{$\frac{\text { Administración }}{\text { Secretaría }}$}} & 56 & \\
\hline $\mathrm{s}$ & & & 5,27 & - \\
\hline GG & \multicolumn{2}{|c|}{ Gerencia General } & 63 & - \\
\hline $\mathrm{Sr}$ & \multicolumn{2}{|c|}{ Sala de reunión } & 8,24 & - \\
\hline $\mathrm{C}$ & \multicolumn{2}{|r|}{ Comedor } & 18,48 & - \\
\hline $\begin{array}{c}\mathrm{V} \\
\mathrm{c}\end{array}$ & \multirow{2}{*}{\multicolumn{2}{|c|}{$\begin{array}{l}\text { Vigilancia y seguridad } \\
\text { de maquinaria/equipo }\end{array}$}} & 5,27 & \\
\hline Detalle de maquinaria/equipo & & & \multicolumn{2}{|c|}{ Superficie $\left(m^{2}\right)$} \\
\hline Código & \multirow{2}{*}{\multicolumn{2}{|c|}{$\begin{array}{l}\text { Operación } \\
\text { Balanza de plataforma }\end{array}$}} & Estática & Total \\
\hline$P$ & & & 0,48 & 3,08 \\
\hline$S$ & \multicolumn{2}{|c|}{ Mesa de selección } & & \\
\hline $\mathrm{Pi}$ & \multicolumn{2}{|r|}{ Picadora } & 60 & 2,88 \\
\hline L & \multicolumn{2}{|r|}{ Lavadero } & & \\
\hline C & \multirow{2}{*}{\multicolumn{2}{|c|}{$\begin{array}{l}\text { Centrífuga } \\
\text { Coche de bandeias }\end{array}$}} & 0,24 & 1,14 \\
\hline $\mathrm{Cb}$ & & & 1,44 & 4,70 \\
\hline $\mathrm{D}$ & \multicolumn{2}{|r|}{ Deshidratador } & 4,20 & 13,46 \\
\hline МуТ & & lido y tamizado & 0,60 & 2,88 \\
\hline $\mathrm{Sp}$ & & sa de separado & 0,96 & 4,62 \\
\hline M & & Mezcladora & 1,25 & 4,01 \\
\hline $\mathrm{E}$ & Enva: & asadora y mesa & 2,14 & 7,18 \\
\hline Se & & esa de sellado & 0,60 & 1,92 \\
\hline Mesa ten & iido (Mt) & t) $3,00 \mathrm{~m}^{2}$ & $(\mathrm{Me})$ & 0,48 \\
\hline Coc & & $0,96 \mathrm{~m}^{2}$ & te $(E t)$ & 0,95 \\
\hline & & & & \\
\hline
\end{tabular}
Elaboración propia

\begin{tabular}{|l||l||c||c||c|}
\hline $\begin{array}{l}\text { Facultad de Ingeniería y Arquitectura } \\
\text { Carrera de Ingeniería Industrial }\end{array}$ & Integrantes: & Dibujo: & Fecha: & Escala: \\
\cline { 2 - 5 } & Elio Aliaga-José Acevedo & Elio Aliaga & $01 / 09 / 2016$ & $1 / 500$ \\
\hline
\end{tabular} 
Figura 5. 14

Plano de disposición de planta del segundo piso

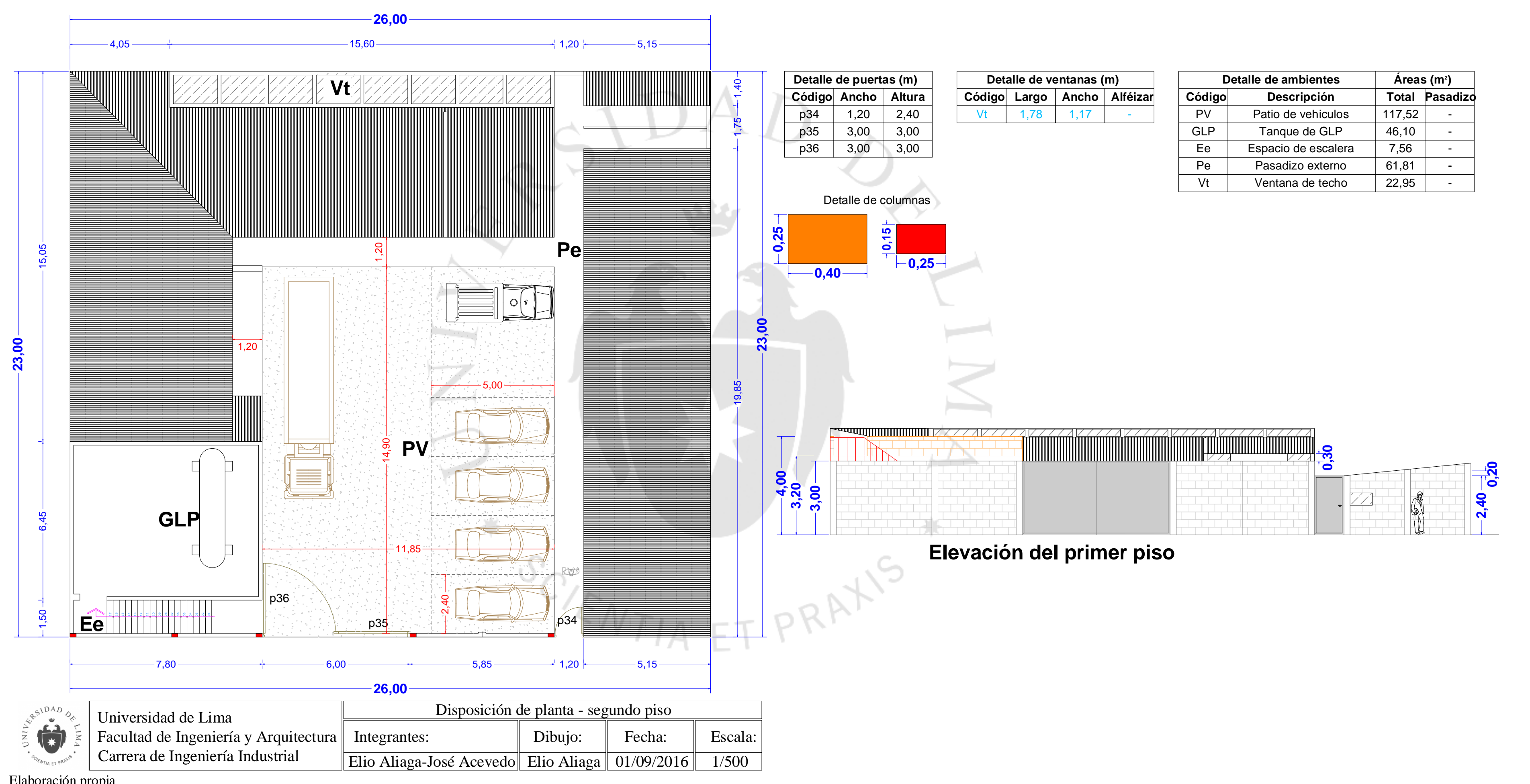




\subsection{Cronograma de implementación del proyecto}

Conforme muestran la Tabla 5.63 y la Figura 5.15 el proyecto se lograría implementar en aproximadamente un año, las actividades que más demoran son la construcción y el acondicionamiento de la planta industrial.

Tabla 5. 63

Cronograma de implementación del proyecto

\begin{tabular}{|c|c|c|c|}
\hline Código & Actividad & $\begin{array}{c}\text { Duración } \\
(\text { días })\end{array}$ & $\begin{array}{c}\text { Ruta crítica } \\
\text { (días) }\end{array}$ \\
\hline A & Estudios previos del proyecto & 60,00 & 60,00 \\
\hline B & Trámites y permisos legales para constitución de empresa & 7,00 & - \\
\hline C & Compra de terreno & 15,00 & 15,00 \\
\hline D & Obtención de permisos municipales & 20,00 & 20,00 \\
\hline E & Contrato con proveedores de materia prima, materiales y servicios & 14,00 & - \\
\hline F & Contrato con personal operativo y administrativo & 5,00 & - \\
\hline G & Construcción de planta industrial & 120,00 & 120,00 \\
\hline H & Acondicionamiento de ambientes de la planta industrial & 60,00 & 60,00 \\
\hline I & Solicitud y obtención de financiamiento & 30,00 & - \\
\hline J & Compra de maquinaria, equipos y mobiliario & 7,00 & - \\
\hline K & Traslado de maquinaria y equipos a la planta industrial & 30,00 & 30,00 \\
\hline L & Pruebas de funcionamiento de equipos y maquinaria & 5,00 & 5,00 \\
\hline M & Puesta en marcha y capacitación de personal & 3,00 & 3,00 \\
\hline & Total & 376,00 & 313,00 \\
\hline
\end{tabular}

Elaboración propia

Figura 5. 15

Diagrama de Gantt de implementación del proyecto

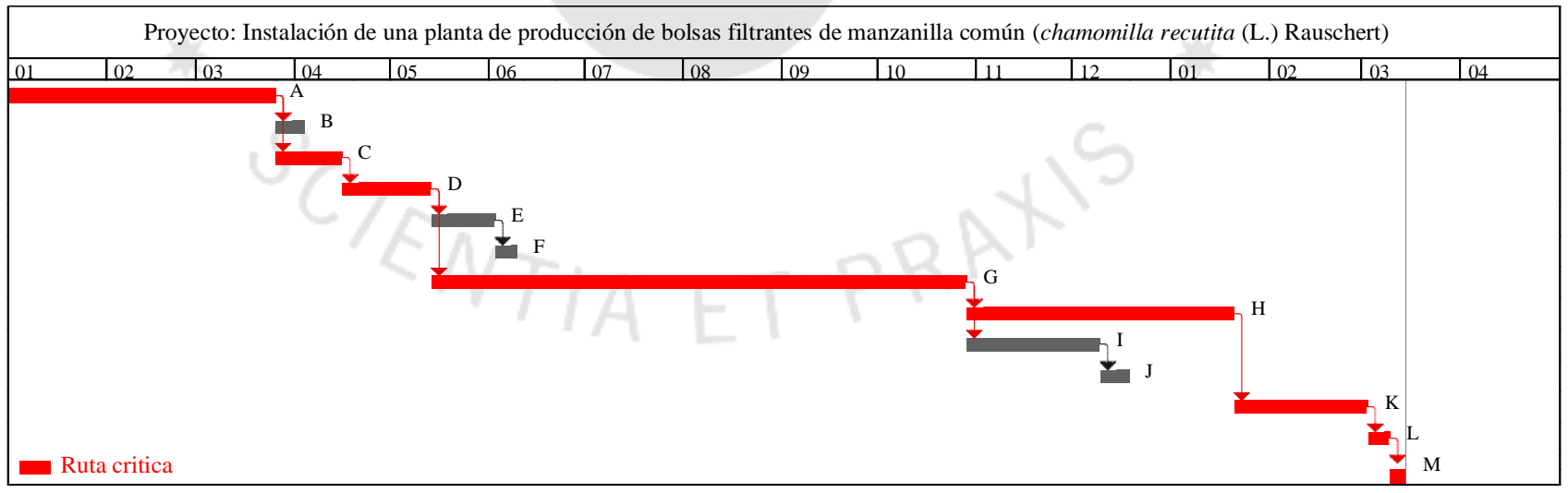

Elaboración propia 


\section{CAPÍTULO VI: ORGANIZACIÓN Y ADMINISTRACIÓN}

\subsection{Formación de la organización empresarial}

Se eligió una sociedad anomina cerrada (SAC) por el número reducido de socios y por ser una pequeña empresa. Asimismo, según la capacidad de planta , cantidad de trabajadores, entre los principales, la organización administrativa será como sigue:

\section{Gerente general}

Designará todas las posiciones en la planta y realizará evaluaciones periódicas del cumplimiento de las funciones de las demás áreas. A su vez realizará las funciones de jefe de ventas y marketing. Será él quien realice coodrinaciones con los clientes (supermercados).

\section{Administrador}

Elaborará la información financiera resultante de la gestión de la planta. Examinará y evaluará dichos resultados con la finalidad de controlar o corregir los objetivos de la empresa. Será el encargado de pagar las compras y de procurar el sueldo y beneficios sociales a todos los trabajadores de la planta. En consecuencia será él, quien también aplique los descuentos en caso de inasistencias no justificadas o tardanzas por parte del personal, ya que también está a cargo de recursos humanos.

\section{Jefe de planta}

Será el responsable de la operación y mantenimiento de la maquinaria y equipos necesarios para la producción de la planta. Él tiene la última decisión sobre el desarrollo y correcciones en el área de producción. Asimismo, él será el encargado de las coordinaciones o diligencias para el suministro de materia prima, materiales, GLP y cualquier otro necesario para la operación de la planta. Finalmente, también será el responsable del almacenamiento y buen estado de los insumos mencionados. 


\section{Encargado de calidad}

Se responsabiliza de los controles físico-químicos y organolépticos. Registra la evaluación de todos los lotes cosechados. El Ingeniero Agrónomo le reporta el seguimiento de los sembrios. Deberá dar conformidad a la materia prima que ingresa después de evaluar los atributos de la misma. Depende del Jefe de Planta.

\section{Operario}

Se encargarán de las operaciones del proceso productivo, verificando que todo esté funcionando, en caso contrario deben comunicárselo al Jefe de Planta. El grupo de operarios que termine la operación de un lote debe tomar datos para establecer registros de la producción y de trazabilidad. Asimismo, en las operaciones más simples, se encargarán de dar el mantenimiento preventivo a las maquinarias y equipos. Sólo para el caso de la centrífuga, deshidratador y envasadora lo realizará un técnico especializado. Los operarios dependen del Jefe de Planta.

\section{Secretaria}

Su principal función será la de asistir al Gerente General en las responsabilidades que este tiene, gestionando documentos y trámites entre los demás trabajadores y la gerencia general. Asímismo, será la encargada del servicio de postventa.

\section{Personal de seguridad}

Se encarga de la vigilancia de los bienes dentro de la planta, así como también del control de ingreso de personas. Depende del Administrador.

\section{Personal de limpieza}

Realizará la limpieza diaria de las oficinas, comedor, todos los servicios higiénicos y del área de vigilancia. Asimismo, cada dos días lo hará en las áreas de producción, materia prima, materiales y producto terminado. Para esto último, debe hacerlo de tal manera que cumpla ciertos protocolos que garanticen que no vulnere en ningún aspecto la inocuidad e higiene de los productos. 


\subsection{Requerimientos de la personal directivo, administrativo y de servicios}

La cantidad de personal está en concordancia con cálculos y criterios del último año del proyecto (tres turnos). La Tabla 6.1 resume estos requerimientos.

Tabla 6. 1

Cantidad total de personal de planta industrial al último año

\begin{tabular}{|c|c|c|}
\hline Tipo de trabajador & Cargo & Cantidad \\
\hline Personal administrativo & Gerente General (Jefe de ventas) & 1,00 \\
\hline Personal administrativo & Administrador (Recursos humanos) & 1,00 \\
\hline Personal administrativo & Secretaria & 1,00 \\
\hline Personal administrativo & Jefe de planta (Logística) & 1,00 \\
\hline Técnico de planta & Encargado de calidad & 1,00 \\
\hline Mano de obra no especializada & Operario de producción & 12,00 \\
\hline Personal de servicio & Seguridad de la planta & 2,00 \\
\hline Personal de servicio & Limpieza de la planta & 1,00 \\
\hline
\end{tabular}

Elaboración propia

\subsection{Estructura organizacional}

La Figura 6.1 esquematiza la organización de personal para el presente proyecto.

Figura 6. 1

Esquema de organización de personal del proyecto

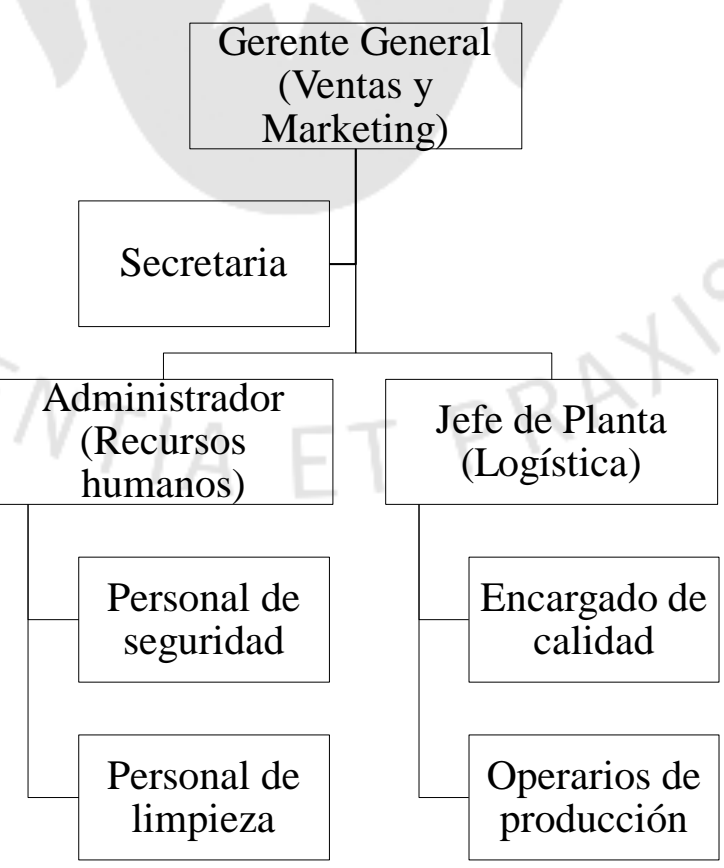

Elaboración propia 


\section{CAPÍTULO VII: ASPECTOS ECONÓMICOS Y FINANCIEROS}

\subsection{Inversiones}

Este capítulo desarrolla los aspectos concernientes al desembolso de dinero para la realización del presente proyecto, se estiman los costos y gastos asociados a la elaboración de los dos tipos de producto, sin incluir el IGV.

\subsubsection{Estimación de las inversiones de largo plazo (tangibles e intangibles)}

\section{Activos tangibles}

Para calcular el costo de adquisición de los activos tangibles se tuvo en cuenta los costos de transporte y los costos asociados a la instalación para que estos activos se encuentren en total disponibilidad para iniciar las operaciones en el lugar escogido. Estos activos son: maquinaria, equipos complementarios, mobiliario, terreno y obras civiles; mostradas desde la Tabla 7.1 hasta la 7.5 .

Tabla 7.1

Costos de maquinaria y equipos

\begin{tabular}{|c|c|c|c|}
\hline Maquinaria/Equipos & Cantidad (Unidad) & Costo (S/./Unidad) & Costo (S/.) \\
\hline Picadora & 1,00 & $17.171,19$ & $17.171,19$ \\
\hline Centrífuga & 1,00 & $26.386,39$ & $26.386,39$ \\
\hline Sistema de GLP e instalación & 1,00 & $27.691,40$ & $27.691,40$ \\
\hline Deshidratador & 1,00 & $24.470,72$ & $24.470,72$ \\
\hline Molino & 1,00 & $1.269,47$ & $1.269,47$ \\
\hline Mezcladora & 1,00 & $13.731,91$ & $13.731,91$ \\
\hline Envasadora & 1,00 & $120.341,40$ & $120.341,40$ \\
\hline Selladora & 1,00 & $4.167,13$ & $4.167,13$ \\
\hline \multicolumn{2}{|c|}{ Total } & $235.229,61$ \\
\hline
\end{tabular}

Elaboración propia 
Tabla 7.2

Costo de equipos complementarios asociados a la producción

\begin{tabular}{|c|c|c|c|}
\hline Equipos complementarios & Cantidad (Unidad) & Costo (S/./Unidad) & Costo (S/.) \\
\hline Balanza de plataforma & 1,00 & $2.031,92$ & $2.031,92$ \\
\hline Coche de traslado & 2,00 & $1.203,39$ & $2.406,78$ \\
\hline Mesa de selección & 1,00 & $2.639,83$ & $2.639,83$ \\
\hline Peine de selección & 1,00 & 266,15 & 266,15 \\
\hline Cestos metálicos & 7,00 & 211,86 & $1.483,05$ \\
\hline Lavadero & 1,00 & $4.280,40$ & $4.280,40$ \\
\hline Tinas & 3,00 & 101,69 & 305,08 \\
\hline Jarra de medida & 2,00 & 136,83 & 273,65 \\
\hline Balanza de precisión & 1,00 & $2.104,76$ & $2.104,76$ \\
\hline Balanza de humedad & 1,00 & $10.097,23$ & $10.097,23$ \\
\hline Estantes de almacenes & 15,00 & 85,13 & $1.276,96$ \\
\hline Mesas de acero inoxidable & 5,00 & 491,53 & $2.457,63$ \\
\hline Parihuelas & 4,00 & 85,13 & 340,52 \\
\hline Hormo de mufla & 1,00 & $2.432,58$ & $2.432,58$ \\
\hline \multicolumn{2}{|r|}{} & & $32.396,56$ \\
\hline
\end{tabular}

Elaboración propia

Tabla 7.3

Costo de mobiliario

\begin{tabular}{|c|c|c|c|}
\hline Mobiliario & Cantidad (Unidad) & Costo (S/./unidad) & Costo (S/.) \\
\hline Computadoras & 5,00 & $1.355,93$ & $6.779,66$ \\
\hline Escritorio & 6,00 & 355,93 & $2.135,59$ \\
\hline Cajonera & 6,00 & 152,54 & 915,25 \\
\hline Estantes aéreo & 5,00 & 237,29 & $1.186,44$ \\
\hline Sillas ergonómicas & 7,00 & 211,86 & $7.483,05$ \\
\hline Mesas de comedor & 2,00 & 381,36 & 338,98 \\
\hline Sillas de comedor & 8,00 & 42,37 & 169,49 \\
\hline Mesa de reunión & 1,00 & 169,49 & 762,71 \\
\hline Sillas simples & 18,00 & 42,37 & 84,75 \\
\hline Locker de herramientas & 1,00 & 84,75 & 288,14 \\
\hline Juego pequeño de sala & 1,00 & 288,14 & 194,92 \\
\hline Microondas & 1,00 & 194,92 & 847,46 \\
\hline Lockers & 2,00 & 423,73 & 720,34 \\
\hline Secador de manos eléctrico & 1,00 & 720,34 & $6.779,66$ \\
\hline Computadoras & 5,00 & $1.355,93$ & $16.669,49$ \\
\hline
\end{tabular}

Elaboración propia 
Tabla 7.4

Costos de implementos de seguridad y salubridad

\begin{tabular}{|c|c|c|}
\hline Implemento & $\mathbf{2 0 1 6} \mathbf{- 2 0 2 0}$ & $\mathbf{2 0 2 1}-\mathbf{2 0 2 5}$ \\
\hline Botas & 311,19 & 466,78 \\
\hline Tapones auditivos & 203,39 & 305,08 \\
\hline Guantes de látex & 366,10 & 549,15 \\
\hline Guantes térmicos & 114,58 & 171,86 \\
\hline Gorros de malla & 610,17 & 915,25 \\
\hline Lentes de seguridad & 46,78 & 70,17 \\
\hline Mascarillas & 610,17 & 915,25 \\
\hline Overoles & 107,80 & 161,69 \\
\hline Total & $2.370,17$ & $3.555,25$ \\
\hline
\end{tabular}

Elaboración propia

Tabla 7.5

Costo de terreno y edificación construida

\begin{tabular}{|c|c|c|c|}
\hline Descripción & Tamaño $\left.\mathbf{( m}^{\mathbf{2}}\right)$ & Costo de terreno $\left(\mathbf{S} / . / \mathbf{m}^{\mathbf{2}}\right)$ & Inversión $(\mathbf{S} /)$. \\
\hline Terreno & 598 & 35,00 & $20.930,00$ \\
\hline Edificio & 298,21 & 467,01 & $139.266,60$ \\
\hline \multicolumn{2}{|l|}{ Total } & & $160.196,60$ \\
\hline
\end{tabular}

Elaboración propia

\section{Activos intangibles}

Para calcular el costo de los activos intangibles se tomó en cuenta los servicios necesarios para la realización del proyecto según la Tabla 7.6.

Tabla 7.6

Costos de activos intangibles

\begin{tabular}{|c|c|}
\hline Descripción & Inversión (S/.) \\
\hline Estudios previos & $13.559,32$ \\
\hline Trámites y permisos legales & $3.389,83$ \\
\hline Capacitación de personal & $7.542,37$ \\
\hline Contingencias & $11.960,76$ \\
\hline Total & $36.452,29$ \\
\hline
\end{tabular}

Elaboración propia

\subsubsection{Estimación de las inversiones de corto plazo (capital de trabajo)}

Son los recursos necesarios para el funcionamiento operativo de la planta hasta que se logre el primer ingreso de ventas. Abarca la compra de materia prima, contratación de servicios básicos y mano de obra directa e indirecta por un lapso de 60 días, teniendo en cuenta que se comprará materiales e insumos cada 180 días, como muestra la Tabla 7.7. Asimismo, la Tabla 7.8 muestra el resumen de la inversión total del proyecto. 
Tabla 7.7

Capital de trabajo del proyecto

\begin{tabular}{|c|c|}
\hline Descripción & Costo $(\mathrm{S} /)$. \\
\hline Materia prima & $4.002,30$ \\
\hline Papel filtro termosellable & $12.279,66$ \\
\hline Hilo & 855,66 \\
\hline Etiquetas & $2.372,40$ \\
\hline Adhesivo & 310,00 \\
\hline Sobres de envoltura & $14.209,69$ \\
\hline Cajas & $35.283,40$ \\
\hline Etiquetas adhesivas & 953,66 \\
\hline Envoltura de cajas & $1.641,22$ \\
\hline Desinfectante & 459,00 \\
\hline Bolsas de polietileno & $1.619,54$ \\
\hline Cinta de embalaje & 85,81 \\
\hline Personal administrativo & $20.530,01$ \\
\hline Mano de obra indirecta & $10.911,05$ \\
\hline Mano de obra directa & $17.278,80$ \\
\hline Personal de limpieza & $1.866,36$ \\
\hline Personal de vigilancia & $4.881,26$ \\
\hline Agua potable total & 317,74 \\
\hline Energía electrica total & $4.874,65$ \\
\hline Teléfono & 169,49 \\
\hline Gas licuado de petróleo (GLP) & $2.418,08$ \\
\hline Calibración de balanza & 181,25 \\
\hline Análisis microbiológico & $2.460,67$ \\
\hline Servicio de seguimiento de sembríos & $4.200,00$ \\
\hline Mantenimiento de maquinaria & 395,48 \\
\hline Implementos de seguridad e higiene & 395,03 \\
\hline Gasto de publicidad & $3.509,03$ \\
\hline Gastos de distribución & $5.084,75$ \\
\hline Capital de trabajo & $153.545,99$ \\
\hline
\end{tabular}

Elaboración propia

Tabla 7.8

Inversión total del proyecto

\begin{tabular}{|c|c|}
\hline \multicolumn{1}{|c|}{ Descripción } & Costo (S/.) \\
\hline Capital fijo tangible & \\
\hline Maquinaria & $235.229,61$ \\
\hline Equipos complementarios & $32.396,56$ \\
\hline Mobiliario & $16.669,49$ \\
\hline Terreno & $20.930,00$ \\
\hline Edificio & $139.266,60$ \\
\hline Capital fijo intangible & $36.452,29$ \\
\hline Interés pre-operativo & $4.941,12$ \\
\hline Capital de trabajo & $153.545,99$ \\
\hline Inversión total & $639.431,66$ \\
\hline
\end{tabular}

Elaboración propia 


\subsection{Costos de producción}

\subsubsection{Costos de las materias primas}

La Tabla 7.9 muestra los costos de la materia prima. Se debe tener en cuenta que se utiliza toda la planta entera de manzanilla.

Tabla 7.9

Costo de materia prima

\begin{tabular}{|c|c|c|c|}
\hline Año & $\begin{array}{c}\text { Requerimiento de } \\
\text { materia prima (kg) }\end{array}$ & $\begin{array}{c}\text { Costo unitario de } \\
\text { materia prima }(\mathbf{S} / . / \mathbf{k g})\end{array}$ & $\begin{array}{c}\text { Costo de materia } \\
\text { prima }(\mathbf{S} / .)\end{array}$ \\
\hline 2016 & $34.305,44$ & 0,70 & $24.013,81$ \\
\hline 2017 & $36.127,42$ & 0,70 & $25.289,20$ \\
\hline 2018 & $37.949,41$ & 0,70 & $26.564,59$ \\
\hline 2019 & $39.719,34$ & 0,70 & $27.803,54$ \\
\hline 2020 & $41.437,22$ & 0,70 & $29.006,05$ \\
\hline 2021 & $43.155,09$ & 0,70 & $30.208,57$ \\
\hline 2022 & $44.820,91$ & 0,70 & $31.374,64$ \\
\hline 2023 & $46.434,67$ & 0,70 & $32.504,27$ \\
\hline 2024 & $48.048,43$ & 0,70 & $33.633,90$ \\
\hline 2025 & $49.610,14$ & 0,70 & $34.727,10$ \\
\hline
\end{tabular}

Elaboración propia

A continuación, desde la Tabla 7.10 hasta la 7.21 se muestran los materiales necesarios para la elaboración de los productos en estudio.

Tabla 7. 10

Costo de papel filtro termosellable

\begin{tabular}{|c|c|c|c|c|}
\hline Año & $\begin{array}{c}\text { Requerimiento de } \\
\text { bolsas filtrantes } \\
\text { (Unidad) }\end{array}$ & $\begin{array}{c}\text { Requerimiento de } \\
\text { papel termosellable } \\
\text { (Bobina) }\end{array}$ & $\begin{array}{c}\text { Costo unitario de papel } \\
\text { termosellable } \\
\text { (S/./Bobina) }\end{array}$ & $\begin{array}{c}\text { Costo papel filtro } \\
\text { termosellable (S/.) }\end{array}$ \\
\hline 2016 & $6.590 .000,00$ & 138,00 & 177,97 & $24.559,32$ \\
\hline 2017 & $6.940 .000,00$ & 145,00 & 177,97 & $25.805,08$ \\
\hline 2018 & $7.290 .000,00$ & 152,00 & 177,97 & $27.050,85$ \\
\hline 2019 & $7.630 .000,00$ & 159,00 & 177,97 & $28.296,61$ \\
\hline 2020 & $7.960 .000,00$ & 166,00 & 177,97 & $29.542,37$ \\
\hline 2021 & $8.290 .000,00$ & 173,00 & 177,97 & $30.788,14$ \\
\hline 2022 & $8.610 .000,00$ & 180,00 & 177,97 & $32.033,90$ \\
\hline 2023 & $8.920 .000,00$ & 186,00 & 177,97 & $33.101,69$ \\
\hline 2024 & $9.230 .000,00$ & 193,00 & 177,97 & $34.347,46$ \\
\hline 2025 & $9.530 .000,00$ & 199,00 & 177,97 & $35.415,25$ \\
\hline
\end{tabular}

Elaboración propia 
Tabla 7. 11

Costo de hilo

\begin{tabular}{|c|c|c|c|c|}
\hline Año & $\begin{array}{c}\text { Requerimiento de } \\
\text { bolsas filtrantes } \\
\text { (Unidad) }\end{array}$ & $\begin{array}{c}\text { Requerimiento de hilo } \\
\text { (Cono) }\end{array}$ & $\begin{array}{c}\text { Costo unitario de hilo } \\
\text { (S/./Cono) }\end{array}$ & Costo de hilo (S/.) \\
\hline 2016 & $6.590 .000,00$ & 103,00 & 16,615 & $1.711,33$ \\
\hline 2017 & $6.940 .000,00$ & 108,00 & 16,615 & $1.794,40$ \\
\hline 2018 & $7.290 .000,00$ & 113,00 & 16,615 & $1.877,48$ \\
\hline 2019 & $7.630 .000,00$ & 119,00 & 16,615 & $1.977,17$ \\
\hline 2020 & $7.960 .000,00$ & 124,00 & 16,615 & $2.060,24$ \\
\hline 2021 & $8.290 .000,00$ & 129,00 & 16,615 & $2.143,31$ \\
\hline 2022 & $8.610 .000,00$ & 134,00 & 16,615 & $2.226,39$ \\
\hline 2023 & $8.920 .000,00$ & 139,00 & 16,615 & $2.309,46$ \\
\hline 2024 & $9.230 .000,00$ & 143,00 & 16,615 & $2.375,92$ \\
\hline 2025 & $9.530 .000,00$ & 148,00 & 16,615 & $2.459,00$ \\
\hline
\end{tabular}

Elaboración propia

Tabla 7. 12

Costos de etiquetas

\begin{tabular}{|c|c|c|c|c|}
\hline Año & $\begin{array}{c}\text { Requerimiento de } \\
\text { bolsas filtrantes } \\
\text { (Unidad) }\end{array}$ & $\begin{array}{c}\text { Requerimiento de } \\
\text { etiquetas (Unidad) }\end{array}$ & $\begin{array}{c}\text { Costo unitario de } \\
\text { etiquetas (S/./Unidad) }\end{array}$ & Costo de etiquetas (S/.) \\
\hline 2016 & $6.590 .000,00$ & $13.180 .000,00$ & 0,00072 & $4.744,80$ \\
\hline 2017 & $6.940 .000,00$ & $13.880 .000,00$ & 0,00072 & $4.996,80$ \\
\hline 2018 & $7.290 .000,00$ & $14.580 .000,00$ & 0,00072 & $5.248,80$ \\
\hline 2019 & $7.630 .000,00$ & $15.260 .000,00$ & 0,00072 & $5.493,60$ \\
\hline 2020 & $7.960 .000,00$ & $15.920 .000,00$ & 0,00072 & $5.731,20$ \\
\hline 2021 & $8.290 .000,00$ & $16.580 .000,00$ & 0,00072 & $5.968,80$ \\
\hline 2022 & $8.610 .000,00$ & $17.220 .000,00$ & 0,00072 & $6.199,20$ \\
\hline 2023 & $8.920 .000,00$ & $17.840 .000,00$ & 0,00072 & $6.422,40$ \\
\hline 2024 & $9.230 .000,00$ & $18.460 .000,00$ & 0,00072 & $6.645,60$ \\
\hline 2025 & $9.530 .000,00$ & $19.060 .000,00$ & 0,00072 & $6.861,60$ \\
\hline
\end{tabular}

Elaboración propia

Tabla 7. 13

Costo de adhesivo

\begin{tabular}{|c|c|c|c|c|c|}
\hline Año & $\begin{array}{c}\text { Requerimiento de } \\
\text { bolsas filtrantes } \\
\text { (Unidad) }\end{array}$ & $\begin{array}{c}\text { Requerimiento de } \\
\text { adhesivo (kg) }\end{array}$ & $\begin{array}{c}\text { Requerimiento de } \\
\text { adhesivo (Galón) }\end{array}$ & $\begin{array}{c}\text { Costo unitario de } \\
\text { adhesivo } \\
\text { (S/./Galón) }\end{array}$ & $\begin{array}{c}\text { Costo de adhesivo } \\
\text { (S/.) }\end{array}$ \\
\hline 2016 & $6.590 .000,00$ & 94,14 & 5,00 & 124,00 & 620,00 \\
\hline 2017 & $6.940 .000,00$ & 99,14 & 5,00 & 124,00 & 620,00 \\
\hline 2018 & $7.290 .000,00$ & 104,14 & 5,00 & 124,00 & 620,00 \\
\hline 2019 & $7.630 .000,00$ & 109,00 & 5,00 & 124,00 & 620,00 \\
\hline 2020 & $7.960 .000,00$ & 113,71 & 6,00 & 124,00 & 744,00 \\
\hline 2021 & $8.290 .000,00$ & 118,43 & 6,00 & 124,00 & 744,00 \\
\hline 2022 & $8.610 .000,00$ & 123,00 & 6,00 & 124,00 & 744,00 \\
\hline 2023 & $8.920 .000,00$ & 127,43 & 6,00 & 124,00 & 744,00 \\
\hline 2024 & $9.230 .000,00$ & 131,86 & 7,00 & 124,00 & 868,00 \\
\hline 2025 & $9.530 .000,00$ & 136,14 & 7,00 & 124,00 & 868,00 \\
\hline
\end{tabular}

Elaboración propia 
Tabla 7. 14

Costo de sobres de envoltura para bolsas filtrantes

\begin{tabular}{|c|c|c|c|}
\hline Año & $\begin{array}{c}\text { Requerimiento de } \\
\text { sobres de } \\
\text { envoltura } \\
\text { (Unidad) }\end{array}$ & $\begin{array}{c}\text { Costo unitario de } \\
\text { sobres de } \\
\text { envoltura } \\
\text { (S/./Unidad) }\end{array}$ & $\begin{array}{c}\text { Costo de sobres } \\
\text { de envoltura (S/.) }\end{array}$ \\
\hline 2016 & $6.590 .000,00$ & 0,0043 & $28.419,38$ \\
\hline 2017 & $6.940 .000,00$ & 0,0043 & $29.928,75$ \\
\hline 2018 & $7.290 .000,00$ & 0,0043 & $31.438,13$ \\
\hline 2019 & $7.630 .000,00$ & 0,0043 & $32.904,38$ \\
\hline 2020 & $7.960 .000,00$ & 0,0043 & $34.327,50$ \\
\hline 2021 & $8.290 .000,00$ & 0,0043 & $35.750,63$ \\
\hline 2022 & $8.610 .000,00$ & 0,0043 & $37.130,63$ \\
\hline 2023 & $8.920 .000,00$ & 0,0043 & $38.467,50$ \\
\hline 2024 & $9.230 .000,00$ & 0,0043 & $39.804,38$ \\
\hline 2025 & $9.530 .000,00$ & 0,0043 & $41.098,13$ \\
\hline
\end{tabular}

Elaboración propia

Tabla 7. 15

Costos de cajas para producto de planta entera

\begin{tabular}{|c|c|c|c|c|c|}
\hline Año & $\begin{array}{c}\text { Producto } \\
\text { terminado de } \\
\text { planta entera (kg) }\end{array}$ & $\begin{array}{c}\text { Requerimiento de } \\
\text { bolsas filtrantes } \\
\text { (Caja) }\end{array}$ & $\begin{array}{c}\text { Requerimiento de } \\
\text { cajas (Unidad) }\end{array}$ & $\begin{array}{c}\text { Costo unitario de } \\
\text { cajas (S/./Caja) }\end{array}$ & $\begin{array}{c}\text { Costo de cajas } \\
\text { (S/.) }\end{array}$ \\
\hline 2016 & $5.190,00$ & $5.190 .000,00$ & $259.500,00$ & 0,200 & $51.900,00$ \\
\hline 2017 & $5.470,00$ & $5.470 .000,00$ & $273.500,00$ & 0,200 & $54.700,00$ \\
\hline 2018 & $5.740,00$ & $5.740 .000,00$ & $287.000,00$ & 0,200 & $57.400,00$ \\
\hline 2019 & $6.010,00$ & $6.010 .000,00$ & $300.500,00$ & 0,200 & $60.100,00$ \\
\hline 2020 & $6.270,00$ & $6.270 .000,00$ & $313.500,00$ & 0,200 & $62.700,00$ \\
\hline 2021 & $6.530,00$ & $6.530 .000,00$ & $326.500,00$ & 0,200 & $65.300,00$ \\
\hline 2022 & $6.780,00$ & $6.780 .000,00$ & $339.000,00$ & 0,200 & $67.800,00$ \\
\hline 2023 & $7.030,00$ & $7.030 .000,00$ & $351.500,00$ & 0,200 & $70.300,00$ \\
\hline 2024 & $7.270,00$ & $7.270 .000,00$ & $363.500,00$ & 0,200 & $72.700,00$ \\
\hline 2025 & $7.510,00$ & $7.510 .000,00$ & $375.500,00$ & 0,200 & $75.100,00$ \\
\hline
\end{tabular}

Elaboración propia

Tabla 7. 16

Costo de cajas para producto de flores

\begin{tabular}{|l|c|c|c|c|c|}
\hline Año & $\begin{array}{c}\text { Producto } \\
\text { terminado de } \\
\text { flores (kg) }\end{array}$ & $\begin{array}{c}\text { Requerimiento de } \\
\text { bolsas filtrantes } \\
\text { (Caja) }\end{array}$ & $\begin{array}{c}\text { Requerimiento de } \\
\text { cajas (Unidad) }\end{array}$ & $\begin{array}{c}\text { Costo unitario de } \\
\text { cajas (S/./Caja) }\end{array}$ & $\begin{array}{c}\text { Costo de cajas } \\
\text { (S/.) }\end{array}$ \\
\hline 2016 & $1.400,00$ & $1.400 .000,00$ & $93.334,00$ & 0,200 & $18.666,80$ \\
\hline 2017 & $1.470,00$ & $1.470 .000,00$ & $98.000,00$ & 0,200 & $19.600,00$ \\
\hline 2018 & $1.550,00$ & $1.550 .000,00$ & $103.334,00$ & 0,200 & $20.666,80$ \\
\hline 2019 & $1.620,00$ & $1.620 .000,00$ & $108.000,00$ & 0,200 & $21.600,00$ \\
\hline 2020 & $1.690,00$ & $1.690 .000,00$ & $112.667,00$ & 0,200 & $22.533,40$ \\
\hline 2021 & $1.760,00$ & $1.760 .000,00$ & $117.334,00$ & 0,200 & $23.466,80$ \\
\hline 2022 & $1.830,00$ & $1.830 .000,00$ & $122.000,00$ & 0,200 & $24.400,00$ \\
\hline 2023 & $1.890,00$ & $1.890 .000,00$ & $126.000,00$ & 0,200 & $25.200,00$ \\
\hline 2024 & $1.960,00$ & $1.960 .000,00$ & $130.667,00$ & 0,200 & $26.133,40$ \\
\hline 2025 & $2.020,00$ & $2.020 .000,00$ & $134.667,00$ & 0,200 & $26.933,40$ \\
\hline
\end{tabular}

Elaboración propia 
Tabla 7.17

Costo de etiquetas adhesivas

\begin{tabular}{|c|c|c|c|c|c|}
\hline Año & $\begin{array}{c}\text { Producto } \\
\text { terminado (Caja) }\end{array}$ & $\begin{array}{c}\text { Requerimiento de } \\
\text { etiquetas adhesivas } \\
\text { (Unidad) }\end{array}$ & $\begin{array}{c}\text { Requerimiento de } \\
\text { etiquetas } \\
\text { adhesivas (Rollo) }\end{array}$ & $\begin{array}{c}\text { Costo unitario } \\
\text { (S/./Rollo) }\end{array}$ & $\begin{array}{c}\text { Costo de etiquetas } \\
\text { adhesivas (S/.) }\end{array}$ \\
\hline 2016 & $352.834,00$ & $352.834,00$ & 353,00 & 0,0054 & $1.907,33$ \\
\hline 2017 & $371.500,00$ & $371.500,00$ & 372,00 & 0,0054 & $2.009,99$ \\
\hline 2018 & $390.334,00$ & $390.334,00$ & 391,00 & 0,0054 & $2.112,65$ \\
\hline 2019 & $408.500,00$ & $408.500,00$ & 409,00 & 0,0054 & $2.209,91$ \\
\hline 2020 & $426.167,00$ & $426.167,00$ & 427,00 & 0,0054 & $2.307,17$ \\
\hline 2021 & $443.834,00$ & $443.834,00$ & 444,00 & 0,0054 & $2.399,02$ \\
\hline 2022 & $461.000,00$ & $461.000,00$ & 461,00 & 0,0054 & $2.490,88$ \\
\hline 2023 & $477.500,00$ & $477.500,00$ & 478,00 & 0,0054 & $2.582,73$ \\
\hline 2024 & $494.167,00$ & $494.167,00$ & 495,00 & 0,0054 & $2.674,58$ \\
\hline 2025 & $510.167,00$ & $510.167,00$ & 511,00 & 0,0054 & $2.761,04$ \\
\hline
\end{tabular}

Elaboración propia

Tabla 7. 18

Costo de envoltura de cajas

\begin{tabular}{|c|c|c|c|c|}
\hline Año & $\begin{array}{c}\text { Requerimiento de } \\
\text { cajas totales } \\
\text { (Unidad) }\end{array}$ & $\begin{array}{c}\text { Requerimiento de } \\
\text { envolturas (Bobina) }\end{array}$ & $\begin{array}{c}\text { Costo de envolturas } \\
\text { (S/./Bobina) }\end{array}$ & $\begin{array}{c}\text { Costo de envolturas } \\
\text { (S/./Bobina) }\end{array}$ \\
\hline 2016 & $352.834,00$ & 27,00 & 121,57 & $3.282,44$ \\
\hline 2017 & $371.500,00$ & 28,00 & 121,57 & $3.404,02$ \\
\hline 2018 & $390.334,00$ & 30,00 & 121,57 & $3.647,16$ \\
\hline 2019 & $408.500,00$ & 31,00 & 121,57 & $3.768,73$ \\
\hline 2020 & $426.167,00$ & 32,00 & 121,57 & $3.890,30$ \\
\hline 2021 & $443.834,00$ & 34,00 & 121,57 & $4.133,45$ \\
\hline 2022 & $461.000,00$ & 35,00 & 121,57 & $4.255,02$ \\
\hline 2023 & $477.500,00$ & 36,00 & 121,57 & $4.376,59$ \\
\hline 2024 & $494.167,00$ & 38,00 & 121,57 & $4.619,74$ \\
\hline 2025 & $510.167,00$ & 39,00 & 121,57 & $4.741,31$ \\
\hline
\end{tabular}

Elaboración propia

Tabla 7. 19

Costo de desinfectante

\begin{tabular}{|c|c|c|c|c|c|}
\hline Año & $\begin{array}{c}\text { Requerimiento de } \\
\text { agua }\left(\mathbf{m}^{\mathbf{3}} \mathbf{)}\right.\end{array}$ & $\begin{array}{c}\text { Requerimiento de } \\
\text { desinfectante } \mathbf{( m}^{\mathbf{3}} \mathbf{)}\end{array}$ & $\begin{array}{c}\text { Requerimiento de } \\
\text { desinfectante }(\text { galón) }\end{array}$ & $\begin{array}{c}\text { Costo } \\
\text { unitario } \\
(\mathbf{S} / . / \text { galón) }\end{array}$ & $\begin{array}{c}\text { Costo Total } \\
(\mathbf{S} / .)\end{array}$ \\
\hline 2016 & 135,63 & 0,068 & 18,00 & 51,00 & 918,00 \\
\hline 2017 & 135,63 & 0,068 & 18,00 & 51,00 & 918,00 \\
\hline 2018 & 135,63 & 0,068 & 18,00 & 51,00 & 918,00 \\
\hline 2019 & 135,63 & 0,068 & 18,00 & 51,00 & 918,00 \\
\hline 2020 & 135,63 & 0,068 & 18,00 & 51,00 & 918,00 \\
\hline 2021 & 271,25 & 0,136 & 36,00 & 51,00 & $1.836,00$ \\
\hline 2022 & 271,25 & 0,136 & 36,00 & 51,00 & $1.836,00$ \\
\hline 2023 & 271,25 & 0,136 & 36,00 & 51,00 & $1.836,00$ \\
\hline 2024 & 271,25 & 0,136 & 36,00 & 51,00 & $1.836,00$ \\
\hline 2025 & 271,25 & 0,136 & 36,00 & 51,00 & $1.836,00$ \\
\hline
\end{tabular}

Elaboración propia 
Tabla 7. 20

Costo de bolsas para empaque de cajas

\begin{tabular}{|c|c|c|c|c|c|}
\hline Año & $\begin{array}{c}\text { Requerimiento } \\
\text { de cajas 1 y 2 } \\
\text { (Unidad) }\end{array}$ & $\begin{array}{c}\text { Cantidad de } \\
\text { cajas por bolsa } \\
\text { (Unidad) }\end{array}$ & $\begin{array}{c}\text { Cantidad de } \\
\text { bolsas (Unidad) }\end{array}$ & $\begin{array}{c}\text { Costo unitario } \\
\text { (S/./millar de bolsa) }\end{array}$ & Costo Total (S/.) \\
\hline 2016 & $352.834,00$ & 24,00 & 14.702 & 220,32 & $3.239,08$ \\
\hline 2017 & $371.500,00$ & 24,00 & 15.480 & 220,32 & $3.410,48$ \\
\hline 2018 & $390.334,00$ & 24,00 & 16.264 & 220,32 & $3.583,21$ \\
\hline 2019 & $408.500,00$ & 24,00 & 17.021 & 220,32 & $3.749,99$ \\
\hline 2020 & $426.167,00$ & 24,00 & 17.757 & 220,32 & $3.912,14$ \\
\hline 2021 & $443.834,00$ & 24,00 & 18.494 & 220,32 & $4.074,51$ \\
\hline 2022 & $461.000,00$ & 24,00 & 19.209 & 220,32 & $4.232,04$ \\
\hline 2023 & $477.500,00$ & 24,00 & 19.896 & 220,32 & $4.383,40$ \\
\hline 2024 & $494.167,00$ & 24,00 & 20.591 & 220,32 & $4.536,52$ \\
\hline 2025 & $510.167,00$ & 24,00 & 21.257 & 220,32 & $4.683,25$ \\
\hline
\end{tabular}

Elaboración propia

Tabla 7. 21

Costo de cinta de embalaje

\begin{tabular}{|c|c|c|c|}
\hline Año & $\begin{array}{c}\text { Cinta de } \\
\text { embalaje } \\
\text { (Unidad) }\end{array}$ & $\begin{array}{c}\text { Costo unitario de cinta } \\
\text { de embalaje (s/./ Unidad) }\end{array}$ & $\begin{array}{c}\text { Costo Total } \\
\text { (S/.) }\end{array}$ \\
\hline 2016 & 45,00 & 3,8 & 171,61 \\
\hline 2017 & 47,00 & 3,8 & 179,24 \\
\hline 2018 & 49,00 & 3,8 & 186,86 \\
\hline 2019 & 52,00 & 3,8 & 198,31 \\
\hline 2020 & 54,00 & 3,8 & 205,93 \\
\hline 2021 & 56,00 & 3,8 & 213,56 \\
\hline 2022 & 58,00 & 3,8 & 221,19 \\
\hline 2023 & 60,00 & 3,8 & 228,81 \\
\hline 2024 & 62,00 & 3,8 & 236,44 \\
\hline 2025 & 64,00 & 3,8 & 244,07 \\
\hline
\end{tabular}

Elaboración propia

\subsubsection{Costos de la mano de obra directa}

Se refiere al costo de todo el personal que interviene directamente en la transformación de la materia prima, la Tabla 7.22 resume este costo.

Tabla 7. 22

Costo de mano de obra directa

\begin{tabular}{|c|c|c|c|c|c|c|c|c|c|c|}
\hline Año & $\begin{array}{c}\text { Operario } \\
/ \\
\text { turno }\end{array}$ & $\begin{array}{c}\text { Turno } \\
/ \\
\text { día }\end{array}$ & $\begin{array}{c}\text { Sueldo } \\
\text { mensual } \\
(\mathbf{S} / .)\end{array}$ & $\begin{array}{c}\text { CTS } \\
(\mathbf{5 , 5 5 \% )} \\
(\mathbf{S} / .)\end{array}$ & $\begin{array}{c}\text { Gratificación } \\
(\mathbf{8 , 3 3 \%}) \\
(\mathbf{S} / .)\end{array}$ & $\begin{array}{c}\text { Vacación } \\
\mathbf{( 4 , 1 7 \% )} \\
(\mathbf{S} / .)\end{array}$ & $\begin{array}{c}\text { Essalud } \\
(\mathbf{9 \%}) \\
(\mathbf{S} / .)\end{array}$ & $\begin{array}{c}\text { SVL } \\
(\mathbf{3 \%}) \\
(\mathbf{S} / \text {.) }\end{array}$ & $\begin{array}{c}\text { Bruto } \\
\text { mensual } \\
(\mathbf{S} / .)\end{array}$ & $\begin{array}{c}\text { Bruto } \\
\text { anual } \\
(\mathbf{S} / .)\end{array}$ \\
\hline $2016-2019$ & 4,00 & 2,00 & 850,00 & 47,18 & 70,81 & 35,45 & 76,50 & 0,00 & $8.639,40$ & $103.672,80$ \\
\hline 2020 & 4,00 & 2,00 & 850,00 & 47,18 & 70,81 & 35,45 & 76,50 & 25,50 & $8.843,40$ & $106.120,80$ \\
\hline $2021-2025$ & 4,00 & 3,00 & 850,00 & 47,18 & 70,81 & 35,45 & 76,50 & 25,50 & $1.3265,10$ & $159.181,20$ \\
\hline
\end{tabular}

Elaboración propia 


\subsubsection{Costos indirecto de fabricación (materiales indirectas, mano de obra indirecta y costos generales de planta)}

Son los costos relacionados indirectamente con la producción, como la mano de obra indirecta, energía eléctrica, agua potable y gas licuado de petróleo como se muestra desde la Tabla 7.23 hasta la Tabla 7.29.

El cálculo de mano de obra indirecta se subdivide en lo que se refiere al personal administrativo, algunos de planta, de vigilancia y al personal de limpieza. El cálculo de energía eléctrica se halló el costo de kilowatt hora en Acobamba, incluyendo el cargo fijo mensual. Asimismo, se encontró la tarifa de agua potable y desagüe en el mismo distrito, tomandose la tarifa por metro cúbico y los costos fijos asociados, cuyo suministro y administración está a cargo de la EPS Sierra Central. En cuanto al GLP, el costo fue hallado en base a información del OSINERGMIN.

Tabla 7.23

Costo de mano de obra indirecta y personal administrativo

\begin{tabular}{|c|c|c|c|c|c|c|c|c|}
\hline Cargo & $\begin{array}{c}\text { Sueldo } \\
\text { mensual } \\
(\mathbf{S} / .)\end{array}$ & $\begin{array}{c}\text { CTS } \\
(\mathbf{5 , 5 5 \%}) \\
(\mathbf{S} / .)\end{array}$ & $\begin{array}{c}\text { Gratificación } \\
\mathbf{( 8 , 3 3 \% )} \\
(\mathbf{S} / .)\end{array}$ & $\begin{array}{c}\text { Vacación } \\
(\mathbf{4 , 1 7 \%}) \\
(\mathbf{S} / .)\end{array}$ & $\begin{array}{c}\text { Essalud } \\
\mathbf{( 9 \% )} \\
(\mathbf{S} / .)\end{array}$ & $\begin{array}{c}\text { Bruto } \\
\text { mensual } \\
(\mathbf{S} / .)\end{array}$ & $\begin{array}{c}\text { Bruto anual } \\
\mathbf{( 2 0 1 6 - 2 0 1 9 )} \\
(\mathbf{S} / .)\end{array}$ & $\begin{array}{c}\text { Bruto anual } \\
(\mathbf{2 0 2 0 - 2 0 2 5}) \\
\mathbf{S V L}^{\mathbf{2 4}} \mathbf{( 3 \% )}(\mathbf{S} / .)\end{array}$ \\
\hline Gerente general & $4.011,50$ & 222,64 & 334,16 & 167,28 & 361,04 & $5.096,91$ & $61.159,33$ & $62.603,47$ \\
\hline Administrador & $3.051,00$ & 169,33 & 254,15 & 127,23 & 274,59 & $3.876,30$ & $46.515,55$ & $47.613,91$ \\
\hline Secretaria & $1.017,00$ & 56,44 & 84,72 & 42,41 & 91,53 & $1.292,10$ & $15.505,18$ & $15.871,30$ \\
\hline Jefe de planta & $2.373,00$ & 131,70 & 197,67 & 98,95 & 213,57 & $3.014,90$ & $36.178,76$ & $37.033,04$ \\
\hline $\begin{array}{c}\text { Encargado de } \\
\text { calidad }\end{array}$ & $1.921,00$ & 106,62 & 160,02 & 80,11 & 172,89 & $2.440,63$ & $29.287,57$ & $29.979,13$ \\
\hline
\end{tabular}

Elaboración propia

Tabla 7. 24

Costo de personal de limpieza

\begin{tabular}{|c|c|c|c|c|c|c|c|c|}
\hline Año & $\begin{array}{c}\text { Sueldo } \\
\text { mensual } \\
(\mathbf{S} / .)\end{array}$ & $\begin{array}{c}\text { CTS } \\
(\mathbf{5 , 5 5 \% )} \\
(\mathbf{S} / .)\end{array}$ & $\begin{array}{c}\text { Gratificación } \\
\mathbf{( 8 , 3 3 \% )} \\
(\mathbf{S} / \text {.) }\end{array}$ & $\begin{array}{c}\text { Vacación } \\
\mathbf{( 4 , 1 7 \% )} \\
(\mathbf{S} / .)\end{array}$ & $\begin{array}{c}\text { Essalud } \\
\mathbf{( 9 \% )} \\
(\mathbf{S} / .)\end{array}$ & $\begin{array}{c}\text { SVL } \\
\mathbf{( 3 \% )} \\
(\mathbf{S} / .)\end{array}$ & $\begin{array}{c}\text { Bruto } \\
\text { mensual } \\
(\mathbf{S} / .)\end{array}$ & $\begin{array}{c}\text { Bruto } \\
\text { anual } \\
(\mathbf{S} / .)\end{array}$ \\
\hline $2016-2019$ & 734,50 & 40,76 & 61,18 & 30,63 & 66,11 & 0,00 & 933,18 & $11.198,19$ \\
\hline $2020-2025$ & 734,50 & 40,76 & 61,18 & 30,63 & 66,11 & 22,04 & 955,22 & $11.462,61$ \\
\hline
\end{tabular}

Elaboración propia

\footnotetext{
${ }^{24}$ Seguro de Vida Ley, en base al artículo 1 del Decreto Legislativo $N^{\circ} 688$, donde se estipula que todo trabajador, empleado u obrero tiene derecho a un seguro de vida a cargo de su empleador, una vez cumplidos cuatro años de trabajo al servicio del mismo.
} 
Tabla 7. 25

Costo de personal de vigilancia

\begin{tabular}{|c|c|c|c|c|c|c|c|c|c|}
\hline Año & Cantidad & $\begin{array}{c}\text { Sueldo } \\
\text { mensual } \\
(\mathbf{S} / .)\end{array}$ & $\begin{array}{c}\text { CTS } \\
(\mathbf{5 , 5 5 \%}) \\
(\mathbf{S} / .)\end{array}$ & $\begin{array}{c}\text { Gratificación } \\
\mathbf{( 8 , 3 3 \% )} \\
(\mathbf{S} / .)\end{array}$ & $\begin{array}{c}\text { Vacación } \\
\mathbf{( 4 , 1 7 \% )} \\
(\mathbf{S} / .)\end{array}$ & $\begin{array}{c}\text { Essalud } \\
(\mathbf{9 \%}) \\
(\mathbf{S} / .)\end{array}$ & $\begin{array}{c}\text { SVL } \\
\mathbf{( 3 \% )} \\
(\mathbf{S} / .)\end{array}$ & $\begin{array}{c}\text { Bruto } \\
\text { mensual } \\
(\mathbf{S} / .)\end{array}$ & $\begin{array}{c}\text { Bruto } \\
\text { anual } \\
(\mathbf{S} / .)\end{array}$ \\
\hline $2016-2019$ & 2,00 & 960,50 & 53,31 & 80,01 & 40,05 & 86,45 & 0,00 & $2.440,63$ & $29.287,57$ \\
\hline $2020-2025$ & 2,00 & 960,50 & 53,31 & 80,01 & 40,05 & 86,45 & 28,82 & $2.498,26$ & $29.979,13$ \\
\hline
\end{tabular}

Elaboración propia

Tabla 7. 26

Costo de agua potable y desagüe

\begin{tabular}{|c|c|c|c|c|c|}
\hline Año & $\begin{array}{c}\text { Consumo de } \\
\text { agua para } \\
\text { lavadero }\left(\mathbf{m}^{\mathbf{3}}\right)\end{array}$ & $\begin{array}{c}\text { Consumo de } \\
\text { agua por } \\
\text { persona }\left(\mathbf{m}^{\mathbf{3}}\right)\end{array}$ & $\begin{array}{c}\text { Costo de agua } \\
\left(\mathbf{S} / . / \mathbf{m}^{\mathbf{3}}\right)\end{array}$ & $\begin{array}{c}\text { Costo fijo (S/. } \\
\text { /año) }\end{array}$ & $\begin{array}{c}\text { Costo total } \\
\text { de agua } \\
\mathbf{( S / . )}\end{array}$ \\
\hline $2016-2020$ & 135,63 & 1.200 & 1,413 & 19,20 & $1.906,44$ \\
\hline $2021-2025$ & 271,25 & 1.500 & 1,413 & 19,20 & $2.521,98$ \\
\hline
\end{tabular}

Elaboración propia

Tabla 7. 27

Costo de energía eléctrica

\begin{tabular}{|c|c|c|c|c|c|}
\hline Año & $\begin{array}{c}\text { Consumo de energía } \\
\text { eléctrica por } \\
\text { producción } \mathbf{( k W )}\end{array}$ & $\begin{array}{c}\text { Consumo de energía } \\
\text { eléctrica en otros } \\
\mathbf{( k W})\end{array}$ & $\begin{array}{c}\text { Costo de energía } \\
\text { activa }(\mathbf{S} / . / \mathbf{k W h})\end{array}$ & $\begin{array}{c}\text { Costo fijo de } \\
\text { energía eléctrica } \\
\mathbf{( S / . )}\end{array}$ & $\begin{array}{c}\text { Costo de energía } \\
\text { eléctrica (S/.) }\end{array}$ \\
\hline 2016 & $25.994,90$ & $7.336,80$ & 0,876 & 52,64 & $29.247,88$ \\
\hline 2017 & $26.088,49$ & $7.336,80$ & 0,876 & 53,24 & $29.330,45$ \\
\hline 2018 & $26.182,09$ & $7.336,80$ & 0,876 & 53,24 & $29.412,43$ \\
\hline 2019 & $26.273,00$ & $7.336,80$ & 0,876 & 53,24 & $29.492,07$ \\
\hline 2020 & $26.361,25$ & $7.336,80$ & 0,876 & 53,24 & $29.569,36$ \\
\hline 2021 & $26.449,49$ & $7.336,80$ & 0,876 & 53,24 & $29.646,66$ \\
\hline 2022 & $26.535,07$ & $7.336,80$ & 0,876 & 53,24 & $29.721,61$ \\
\hline 2023 & $26.617,96$ & $7.336,80$ & 0,876 & 53,24 & $29.794,22$ \\
\hline 2024 & $26.700,86$ & $7.336,80$ & 0,876 & 53,24 & $29.866,83$ \\
\hline 2025 & $26.781,08$ & $7.336,80$ & 0,876 & 53,24 & $29.937,09$ \\
\hline
\end{tabular}

Elaboración propia

Tabla 7. 28

Costo de gas licuado de petróleo (GLP)

\begin{tabular}{|c|c|c|c|}
\hline Año & $\begin{array}{c}\text { Consumo de } \\
\text { GLP } \\
\text { (Balones) }\end{array}$ & $\begin{array}{c}\text { Costo de GLP } \\
\text { (S/./Balón) }\end{array}$ & $\begin{array}{c}\text { Costo de GLP } \\
\text { (S/.) }\end{array}$ \\
\hline $2016-2025$ & 428,00 & 33,90 & $14.508,47$ \\
\hline
\end{tabular}

Elaboración propia 
Tabla 7. 29

Costo de telefonía fija

\begin{tabular}{|c|c|}
\hline Año & Costo (S/.) \\
\hline $2016-2025$ & $1.016,95$ \\
\hline
\end{tabular}

Elaboración propia

Finalmente, la Tabla 7.30 se muestran los servicios tercerizados.

Tabla 7.30

Costo de servicios de terceros

\begin{tabular}{|c|c|c|}
\hline Año & Descripción & Costo (S/.) \\
\hline $2016-2025$ & Servicio de transporte & $30.508,47$ \\
\hline $2016-2025$ & Servicio de calibración de balanza & $1.087,51$ \\
\hline $2016-2025$ & Servicio de análisis microbiológico & $14.764,00$ \\
\hline $2016-2025$ & Servicio de seguimiento de siembras & $25.200,00$ \\
\hline $2016-2025$ & Servicio de mantenimiento preventivo & $2.372,88$ \\
\hline
\end{tabular}

Elaboración propia

\subsection{Presupuestos operativos}

Los presupuestos operativos por lo general son tres:

El presupuesto de ingresos por ventas, se obtiene calculando el volumen de ventas anuales de ambos productos y sus respectivos valores de venta unitarios, como se ve en la Tabla 7.31.

El presupuesto operativo de costos abarca los costos ligados directamente a la producción, o sea, considera los costos de materia prima, de materiales y de mano de obra directa, como se ve desde la Tabla 7.32 hasta la 7.34.

El presupuesto operativo de gastos considera las inversiones a corto plazo en costos indirectos de fabricación como la mano de obra indirecta que abarca el costo del personal administrativo, del personal de limpieza y de vigilancia. También incluye los costos de los servicios básicos en la zona administrativa como la del agua potable, la de energía eléctrica. Adicionalmente, debido a la naturaleza del presente proyecto acá se incluye el costo del servicio de transporte de productos terminados, como se ve en la Tabla 7.35. Los siguientes puntos muestran directamente los presupuestos ya mencionados. 


\subsubsection{Presupuesto de ingreso por ventas}

Tabla 7.31

Presupuesto de ingreso por ventas

\begin{tabular}{|c|c|c|c|c|c|c|c|c|c|c|}
\hline Descripción & 2016 & 2017 & 2018 & 2019 & 2020 & 2021 & 2022 & 2023 & 2024 & 2025 \\
\hline $\begin{array}{l}\text { PT-PE } \\
\text { (kg) }\end{array}$ & $5.190,00$ & $5.470,00$ & $5.740,00$ & $6.010,00$ & $6.270,00$ & $6.530,00$ & $6.780,00$ & $7.030,00$ & $7.270,00$ & $7.510,00$ \\
\hline $\begin{array}{l}\text { PT-PE } \\
\text { (cajas) }\end{array}$ & $259.500,00$ & $273.500,00$ & $287.000,00$ & $300.500,00$ & $313.500,00$ & $326.500,00$ & $339.000,00$ & $351.500,00$ & $363.500,00$ & $375.500,00$ \\
\hline $\begin{array}{l}\text { Valor de venta } \\
\text { (S/./caja) }\end{array}$ & 1,87 & 1,87 & 1,87 & 1,87 & 1,87 & 1,87 & 1,87 & 1,87 & 1,87 & 1,87 \\
\hline $\begin{array}{c}\text { Ingreso por } \\
\text { ventas de PT-PE }\end{array}$ & $485.265,00$ & $511.445,00$ & $536.690,00$ & $561.935,00$ & $586.245,00$ & $610.555,00$ & $633.930,00$ & $657.305,00$ & $679.745,00$ & $702.185,00$ \\
\hline $\begin{array}{c}\text { PT-PF } \\
(\mathrm{kg})\end{array}$ & $1.400,00$ & $1.470,00$ & $1.550,00$ & $1.620,00$ & $1.690,00$ & $1.760,00$ & $1.830,00$ & $1.890,00$ & $1.960,00$ & $2.020,00$ \\
\hline $\begin{array}{l}\text { PT-PF } \\
\text { (cajas) }\end{array}$ & $93.333,00$ & $98.000,00$ & $103.333,00$ & $108.000,00$ & $112.666,00$ & $117.333,00$ & $122.000,00$ & $126.000,00$ & $130.666,00$ & $134.666,00$ \\
\hline $\begin{array}{c}\text { Valor de venta } \\
\text { (S/./caja) }\end{array}$ & 3,20 & 3,20 & 3,20 & 3,20 & 3,20 & 3,20 & 3,20 & 3,20 & 3,20 & 3,20 \\
\hline $\begin{array}{c}\text { Ingreso por } \\
\text { ventas de PT-F }\end{array}$ & $298.665,60$ & $313.600,00$ & $330.665,60$ & $345.600,00$ & $360.531,20$ & $375.465,60$ & $390.400,00$ & $403.200,00$ & $418.131,20$ & $430.931,20$ \\
\hline $\begin{array}{c}\text { Ingreso por } \\
\text { ventas de PT } \\
(\mathrm{S} / .)\end{array}$ & $783.930,60$ & $825.045,00$ & $867.355,60$ & $907.535,00$ & $946.776,20$ & $986.020,60$ & $1.024 .330,00$ & $1.060 .505,00$ & $1.097 .876,20$ & $1.133 .116,20$ \\
\hline
\end{tabular}

Nota: (PT-PE): Producto terminado de planta entera; (PT-F): Producto terminado de flores; (PT): Productos terminados.

Elaboración propia 


\subsubsection{Presupuesto operativo de costos}

Tabla 7. 32

Depreciación de activos tangibles

\begin{tabular}{|c|c|c|c|c|c|c|c|c|c|c|c|c|c|c|c|c|}
\hline AT & $\begin{array}{c}\text { Importe } \\
(\mathrm{S} / .)\end{array}$ & \begin{tabular}{|c} 
VU \\
(años)
\end{tabular} & 2016 & 2017 & 2018 & 2019 & 2020 & 2021 & 2022 & 2023 & 2024 & 2025 & $\begin{array}{l}\text { DT } \\
(\text { S/.) }\end{array}$ & $\begin{array}{c}\text { VR } \\
\text { (S/.) }\end{array}$ & $\begin{array}{l}\text { VM } \\
(\mathrm{S} / .)\end{array}$ & $\begin{array}{c}\text { VS } \\
(\mathrm{S} / .)\end{array}$ \\
\hline $\mathrm{T}$ & $20.930,00$ & - & - & - & - & - & - & 8 & - & - & - & - & - & $20.930,00$ & \multirow{5}{*}{0,50} & \multirow{5}{*}{$56.887,32$} \\
\hline $\mathrm{E}$ & $139.266,95$ & 30,00 & $4.642,23$ & $4.642,23$ & $4.642,23$ & $4.642,23$ & $4.642,23$ & $4.642,23$ & $4.642,23$ & $4.642,23$ & $4.642,23$ & $4.642,23$ & $46.422,32$ & $92.844,63$ & & \\
\hline MyE & $235.229,61$ & 5,00 & $47.045,92$ & \begin{tabular}{|l}
$47.045,92$ \\
\end{tabular} & $47.045,92$ & \begin{tabular}{|l|}
$47.045,92$ \\
\end{tabular} & $47.045,92$ & - & - & - & - & - & $235.229,61$ & 0,00 & & \\
\hline $\mathrm{EqC}$ & $32.396,54$ & 10,00 & $3.239,65$ & $3.239,65$ & $3.239,65$ & $3.239,65$ & $3.239,65$ & $3.239,65$ & $3.239,65$ & $3.239,65$ & $3.239,65$ & \begin{tabular}{|l|}
$3.239,65$ \\
\end{tabular} & $32.396,54$ & 0,00 & & \\
\hline $\mathrm{M}$ & $16.669,49$ & 10,00 & $1.666,95$ & $1.666,95$ & $1.666,95$ & $1.666,95$ & $1.666,95$ & $1.666,95$ & $1.666,95$ & $1.666,95$ & $1.666,95$ & \begin{tabular}{|l|}
$1.666,95$ \\
\end{tabular} & $16.669,49$ & 0,00 & & \\
\hline DF & - & - & $50.285,58$ & $50.285,58$ & $50.285,58$ & $50.285,58$ & $50.285,58$ & $3.239,65$ & $3.239,65$ & $3.239,65$ & $3.239,65$ & $3.239,65$ & $267.626,15$ & - & - & - \\
\hline DNF & - & - & $6.309,18$ & $6.309,18$ & $6.309,18$ & \begin{tabular}{|l|}
$6.309,18$ \\
\end{tabular} & $6.309,18$ & $6.309,18$ & \begin{tabular}{|l|}
$6.309,18$ \\
\end{tabular} & $6.309,18$ & $6.309,18$ & \begin{tabular}{|l|}
$6.309,18$ \\
\end{tabular} & $63.091,81$ & - & - & - \\
\hline
\end{tabular}

Nota: (AT): Activo tangible; (T): Terreno; (E): Edificio; (MyE): Maquinaria y equipo; (EqC): Equipos complementarios; (M): Mobiliario; (DF): Depreciación fabril; (DNF):

Depreciación no fabril; (VU): Vida útil; (DT): Depreciación total; (VR): Valor residual; (VM): Valor de mercado; (VS): Valor de salvamento.

Elaboración propia

Tabla 7.33

Depreciación de activos intangibles

\begin{tabular}{|c|c|c|c|c|c|c|c|c|c|c|c|c|c|c|c|c|}
\hline AI & $\begin{array}{c}\text { Importe } \\
\text { (S/.) }\end{array}$ & $\underset{\text { (años) }}{\text { VU }}$ & 2016 & 2017 & 2018 & 2019 & 2020 & 2021 & 2022 & 2023 & 2024 & 2025 & $\mathbf{A T}$ & VR & VM & VS \\
\hline EP & $13.559,32$ & 10,00 & $1.355,93$ & $1.355,93$ & $1.355,93$ & $1.355,93$ & $1.355,93$ & $1.355,93$ & $1.355,93$ & $1.355,93$ & $1.355,93$ & $1.355,93$ & $13.559,32$ & - & & \\
\hline $\mathrm{TL}$ & $3.389,83$ & 10,00 & 338,98 & 338,98 & 338,98 & 338,98 & 338,98 & 338,98 & 338,98 & 338,98 & 338,98 & 338,98 & $3.389,83$ & - & & \\
\hline $\mathrm{CP}$ & $7.542,37$ & 10,00 & 754,24 & 754,24 & 754,24 & 754,24 & 754,24 & 754,24 & 754,24 & 754,24 & 754,24 & 754,24 & $7.542,37$ & - & & \\
\hline $\mathrm{C}$ & $11.960,76$ & 10,00 & $1.196,08$ & $1.196,08$ & $1.196,08$ & $1.196,08$ & $1.196,08$ & $1.196,08$ & $1.196,08$ & $1.196,08$ & $1.196,08$ & $1.196,08$ & $11.960,76$ & - & & \\
\hline AT & - & - & $3.645,23$ & $3.645,23$ & $3.645,23$ & $3.645,23$ & $3.645,23$ & $3.645,23$ & $3.645,23$ & $3.645,23$ & $3.645,23$ & $3.645,23$ & $36.452,29$ & - & & \\
\hline
\end{tabular}

Nota: (AI): Activo intangible; (EP): Estudios previos; (TL): Trámites legales; (CP): Capacoitación de personal; (C): Contingencias; (AT): Amortización total; (VU): Vida útil (VR): Valor residual; (VM): Valor de mercado; (VS): Valor de salvamento.

Elaboración propia 
Tabla 7.34

Presupuesto operativo de costos

\begin{tabular}{|c|c|c|c|c|c|c|c|c|c|c|}
\hline Descripción & 2016 & 2017 & 2018 & 2019 & 2020 & 2021 & 2022 & 2023 & 2024 & 2025 \\
\hline Materia prima & $24.013,81$ & $25.289,20$ & $26.564,59$ & $27.803,54$ & $29.006,05$ & $30.208,57$ & $31.374,64$ & $32.504,27$ & $33.633,90$ & $34.727,10$ \\
\hline Materiales & $140.140,09$ & $147.366,76$ & $154.749,94$ & $161.836,69$ & $168.872,26$ & $176.818,22$ & $183.569,23$ & $189.952,59$ & $196.778,03$ & $203.001,03$ \\
\hline $\begin{array}{c}\text { Mano de obra } \\
\text { directa }\end{array}$ & $103.672,80$ & $103.672,80$ & $103.672,80$ & $103.672,80$ & $106.120,80$ & $159.181,20$ & $159.181,20$ & $159.181,20$ & $159.181,20$ & $159.181,20$ \\
\hline $\begin{array}{l}\text { Mano de obra } \\
\text { indirecta }\end{array}$ & $65.466,32$ & $65.466,32$ & $65.466,32$ & $65.466,32$ & $67.012,16$ & $67.012,16$ & $67.012,16$ & $67.012,16$ & $67.012,16$ & $67.012,16$ \\
\hline $\begin{array}{l}\text { Servicios para } \\
\text { operación (Luz, } \\
\text { agua y GLP) }\end{array}$ & $37.504,97$ & $37.586,95$ & $37.668,92$ & $37.748,56$ & $37.825,85$ & $38.094,79$ & $38.169,74$ & $38.242,35$ & $38.314,96$ & $38.385,22$ \\
\hline Depreciación fabril & $50.285,58$ & $50.285,58$ & $50.285,58$ & $50.285,58$ & $50.285,58$ & $3.239,66$ & $3.239,66$ & $3.239,66$ & $3.239,66$ & $3.239,66$ \\
\hline $\begin{array}{c}\text { Total costo } \\
\text { operativo }\end{array}$ & $421.083,56$ & $429.667,61$ & $438.408,15$ & $446.813,49$ & $459.122,71$ & $474.554,59$ & $482.546,63$ & $490.132,23$ & $498.159,91$ & $505.546,37$ \\
\hline
\end{tabular}

Elaboración propia
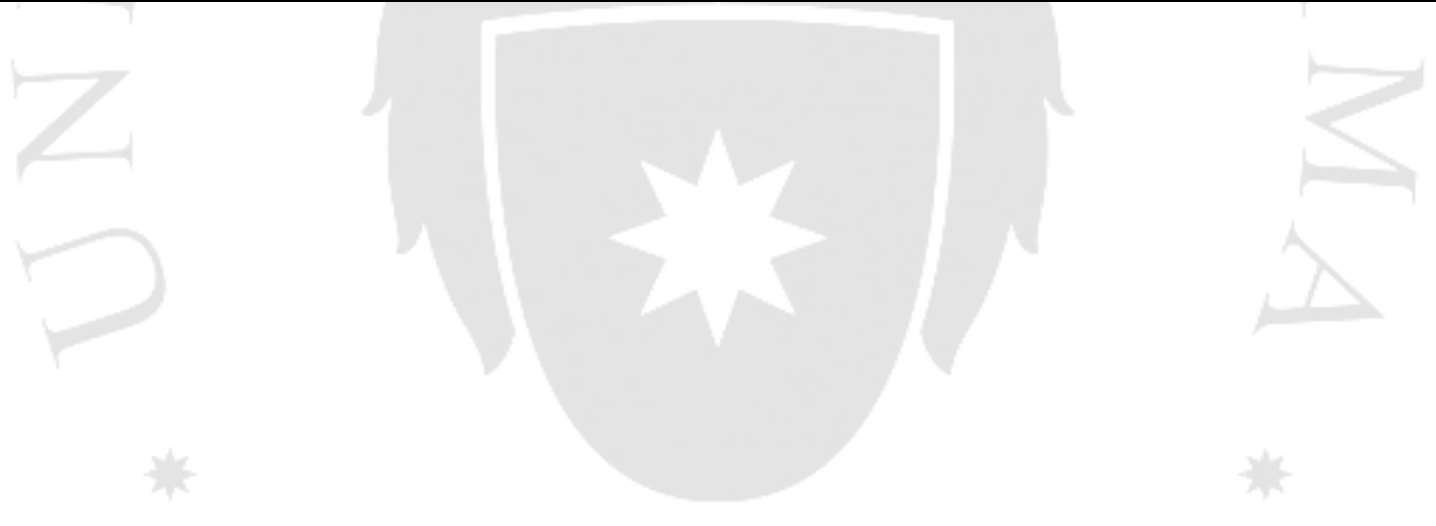


\subsubsection{Presupuesto operativo de gastos}

Tabla 7. 35

Presupuesto operativo de gastos

\begin{tabular}{|c|c|c|c|c|c|c|c|c|c|c|}
\hline Descripción & 2016 & 2017 & 2018 & 2019 & 2020 & 2021 & 2022 & 2023 & 2024 & 2025 \\
\hline Personal administrativo & $123.180,06$ & $123.180,06$ & $123.180,06$ & $123.180,06$ & $126.088,68$ & $126.088,68$ & $126.088,68$ & $126.088,68$ & $126.088,68$ & $126.088,68$ \\
\hline $\begin{array}{l}\text { Servicios administrativos (luz, } \\
\text { agua y teléfono) }\end{array}$ & $9.174,77$ & $9.174,77$ & $9.174,77$ & $9.174,77$ & $9.174,77$ & $9.598,67$ & $9.598,67$ & $9.598,67$ & $9.598,67$ & $9.598,67$ \\
\hline $\begin{array}{c}\text { Otros servicios (limpieza y } \\
\text { seguridad) }\end{array}$ & $40.485,75$ & $40.485,75$ & $40.485,75$ & $40.485,75$ & $41.441,73$ & $41.441,73$ & $41.441,73$ & $41.441,73$ & $41.441,73$ & $41.441,73$ \\
\hline Gastos de publicidad & $21.054,18$ & $21.054,18$ & $21.054,18$ & $21.054,18$ & $21.054,18$ & $21.054,18$ & $21.054,18$ & $21.054,18$ & $21.054,18$ & $21.054,18$ \\
\hline Gastos de distribución & $30.508,47$ & $30.508,47$ & $30.508,47$ & $30.508,47$ & $30.508,47$ & $30.508,47$ & $30.508,47$ & $30.508,47$ & $30.508,47$ & $30.508,47$ \\
\hline Depreciación no fabril & $6.309,17$ & $6.309,17$ & $6.309,17$ & $6.309,17$ & $6.309,17$ & $6.309,17$ & $6.309,17$ & $6.309,17$ & $6.309,17$ & $6.309,17$ \\
\hline Amortización de intangibles & $3.645,23$ & $3.645,23$ & $3.645,23$ & $3.645,23$ & $3.645,23$ & $3.645,23$ & $3.645,23$ & $3.645,23$ & $3.645,23$ & $3.645,23$ \\
\hline $\begin{array}{l}\text { Servicio de calibración de } \\
\text { balanzas }\end{array}$ & $1.087,51$ & $1.087,51$ & $1.087,51$ & $1.087,51$ & $1.087,51$ & $1.087,51$ & $1.087,51$ & $1.087,51$ & $1.087,51$ & $1.087,51$ \\
\hline $\begin{array}{l}\text { Servicio de análisis } \\
\text { microbiologico }\end{array}$ & $14.764,00$ & $14.764,00$ & $14.764,00$ & $14.764,00$ & $14.764,00$ & $14.764,00$ & $14.764,00$ & $14.764,00$ & $14.764,00$ & $14.764,00$ \\
\hline $\begin{array}{l}\text { Servicio de seguimiento de } \\
\text { sembríos }\end{array}$ & $25.200,00$ & $25.200,00$ & $25.200,00$ & $25.200,00$ & $25.200,00$ & $25.200,00$ & $25.200,00$ & $25.200,00$ & $25.200,00$ & $25.200,00$ \\
\hline $\begin{array}{l}\text { Servicio de mantenimiento } \\
\text { preventivo }\end{array}$ & $2.372,88$ & $2.372,88$ & $2.372,88$ & $2.372,88$ & $2.372,88$ & $2.372,88$ & $2.372,88$ & $2.372,88$ & $2.372,88$ & $2.372,88$ \\
\hline Implementos de seguridad & $2.370,17$ & $2.370,17$ & $2.370,17$ & $2.370,17$ & $2.370,17$ & $3.555,25$ & $3.555,25$ & $3.555,25$ & $3.555,25$ & $3.555,25$ \\
\hline Total & $280.152,19$ & $280.152,19$ & $280.152,19$ & $280.152,19$ & $284.016,79$ & $285.625,78$ & $285.625,78$ & $285.625,78$ & $285.625,78$ & $285.625,78$ \\
\hline
\end{tabular}

Elaboración propia

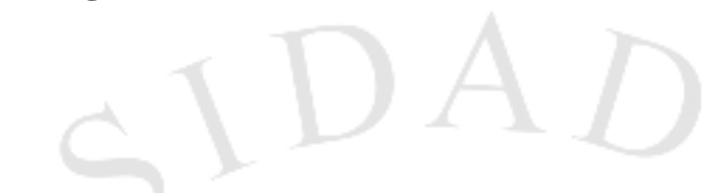




\subsection{Presupuestos financieros}

\subsubsection{Presupuesto de servicio de deuda}

El 46\% del proyecto se financiará por el COFIDE (Corporación Financiera de Desarrollo) con una tasa efectiva anual (TEA) del $15 \%$ mediante el programa de financiamiento PROBID; con gracia parcial para el primer año y 5 años de cuotas crecientes según muestran las tablas 7.36 y 7.37 .

Tabla 7. 36

Estructura de financiamiento del proyecto

\begin{tabular}{|c|c|c|c|c|}
\hline Rubro & Monto (S/.) & \%Participación & Interés & Tasa \\
\hline Aporte propio & $355.136,00$ & $55,54 \%$ & COK 16,93\% & $9,40 \%$ \\
\hline Préstamo & $284.295,66$ & $44,46 \%$ & TEA 15\% & $6,67 \%$ \\
\hline Inversión total & $639.431,66$ & $100,00 \%$ & WAAC (CPPC) & $16,07 \%$ \\
\hline
\end{tabular}

Elaboración propia

Tabla 7. 37

Servicio de deuda del proyecto

\begin{tabular}{|c|c|c|c|c|c|c|}
\hline Años & $\mathbf{2 0 1 6}$ & $\mathbf{2 0 1 7}$ & $\mathbf{2 0 1 8}$ & $\mathbf{2 0 1 9}$ & $\mathbf{2 0 2 0}$ & $\mathbf{2 0 2 1}$ \\
\hline Deuda inicial & $284.295,66$ & $284.295,66$ & $265.342,61$ & $227.436,53$ & $170.577,39$ & $94.765,22$ \\
\hline Intereses & $42.644,35$ & $42.644,35$ & $39.801,39$ & $34.115,48$ & $25.586,61$ & $14.214,78$ \\
\hline Factor & - & 0,067 & 0,133 & 0,200 & 0,267 & 0,333 \\
\hline Amortización & - & $18.953,04$ & $37.906,09$ & $56.859,13$ & $75.812,18$ & $94.765,22$ \\
\hline Cuota & $42.644,35$ & $61.597,39$ & $77.707,48$ & $90.974,61$ & $101.398,78$ & $108.980,00$ \\
\hline Saldo & $284.295,66$ & $265.342,61$ & $227.436,53$ & $170.577,39$ & $94.765,22$ & - \\
\hline Escudo fiscal* & $12.793,30$ & $12.793,30$ & $11.940,42$ & $10.234,64$ & $7.675,98$ & $4.264,43$ \\
\hline
\end{tabular}

Nota: * Escudo fiscal sólo para fines tributarios, igual al $30 \%$ del interés de la deuda hasta que dure la deuda Elaboración propia

\subsubsection{Presupuesto de estado de resultados}

La Tabla 7.38 muestra el presupuesto de estado de resultados, el que indica la utilidad disponible antes de reserva legal para el proyecto. 
Tabla 7.38

Presupuesto de estado de resultados del proyecto

\begin{tabular}{|c|c|c|c|c|c|c|c|c|c|c|}
\hline Rubro & 2016 & 2017 & 2018 & 2019 & 2020 & 2021 & 2022 & 2023 & 2024 & 2025 \\
\hline Ingresos por ventas & $783.930,60$ & $825.045,00$ & $867.355,60$ & $907.535,00$ & $946.776,20$ & $986.020,60$ & $1.024 .330,00$ & $1.060 .505,00$ & $1.097 .876,20$ & $1.133 .116,20$ \\
\hline $\begin{array}{l}\text { (-) Costo de } \\
\text { producción }\end{array}$ & $421.083,56$ & $429.667,61$ & $438.408,15$ & $446.813,49$ & $459.122,71$ & $474.554,59$ & $482.546,63$ & $490.132,23$ & $498.159,91$ & $505.546,37$ \\
\hline (=) Utilidad bruta & $362.847,04$ & $395.377,39$ & $428.947,45$ & $460.721,51$ & $487.653,49$ & $511.466,01$ & $541.783,37$ & $570.372,77$ & $599.716,29$ & $627.569,83$ \\
\hline (-) Gastos generales & $280.152,19$ & $280.152,19$ & $280.152,19$ & $280.152,19$ & $284.016,79$ & $285.625,78$ & $285.625,78$ & $285.625,78$ & $285.625,78$ & $285.625,78$ \\
\hline $\begin{array}{c}\text { (-) Gastos } \\
\text { financieros }\end{array}$ & $42.644,35$ & $42.644,35$ & $39.801,39$ & $34.115,48$ & $25.586,61$ & $14.214,78$ & 0,00 & 0,00 & 0,00 & 0,00 \\
\hline $\begin{array}{c}\text { (=) Utilidad antes } \\
\text { de impuestos }\end{array}$ & $40.050,50$ & $72.580,85$ & $108.993,87$ & $146.453,84$ & $178.050,09$ & $211.625,45$ & $256.157,59$ & $284.746,99$ & $314.090,51$ & $341.944,05$ \\
\hline $\begin{array}{c}\text { (-) Participación } \\
(10 \%)\end{array}$ & $4.005,05$ & $7.258,09$ & $10.899,39$ & $14.645,38$ & $17.805,01$ & $21.162,54$ & $25.615,76$ & $28.474,70$ & $31.409,05$ & $34.194,41$ \\
\hline $\begin{array}{l}\text { (-) Impuesto a la } \\
\text { renta }(30 \%)\end{array}$ & 0,00 & 0,00 & 0,00 & 0,00 & $53.415,03$ & $63.487,63$ & $76.847,28$ & $85.424,10$ & $94.227,15$ & $102.583,22$ \\
\hline $\begin{array}{c}\text { (=) Utilidad antes } \\
\text { de reserva legal }\end{array}$ & $36.045,45$ & $65.322,77$ & $98.094,48$ & $131.808,46$ & $106.830,06$ & $126.975,27$ & $153.694,56$ & $170.848,20$ & $188.454,31$ & $205.166,43$ \\
\hline $\begin{array}{c}\text { (-) Reserva legal } \\
(10 \%)\end{array}$ & $3.604,54$ & $6.532,28$ & $9.809,45$ & $13.180,85$ & $10.683,01$ & $12.697,53$ & $14.519,55$ & 0,00 & 0,00 & 0,00 \\
\hline $\begin{array}{l}(=) \text { Utilidad } \\
\text { disponible }\end{array}$ & $32.440,90$ & $58.790,49$ & $88.285,03$ & $118.627,61$ & $96.147,05$ & $114.277,74$ & $139.175,00$ & $170.848,20$ & $188.454,31$ & $205.166,43$ \\
\hline
\end{tabular}

Elaboración propia 


\subsubsection{Presupuesto de estado de situación financiera}

La Tabla 7.39 muestra el presupuesto de estado de situación financiera (Balance General), al finalizar el primer año. Asimismo, las tablas 7.40, 7.41 y 7.42 muestran los flujos de corto plazo, de fondo económico y financiero, respectivamente.

Tabla 7. 39

Presupuesto de estado de situación financiera

\begin{tabular}{|c|c|c|c|c|c|}
\hline Descripción/Año & $\mathbf{0}$ & 2016 & Descripción/Año & $\mathbf{0}$ & 2016 \\
\hline Caja & $153.545,99$ & $135.974,67$ & Cuentas por pagar comerciales & $70.070,04$ & $73.683,38$ \\
\hline Cuentas por cobrar & 0,00 & $130.655,10$ & Otras cuentas por pagar & 0,00 & $7.852,18$ \\
\hline Existencias & $70.070,04$ & $73.683,38$ & Participación por pagar $(10 \%)$ & 0,00 & $4.005,05$ \\
\hline Total Activo Corriente & $223.616,04$ & $340.313,15$ & Total Pasivo corriente & $70.070,04$ & $85.540,61$ \\
\hline Activos tangibles & $444.492,26$ & $444.492,26$ & Obligaciones Financieras & $284.295,66$ & $284.295,66$ \\
\hline $\begin{array}{l}\text { (-) Depreciación } \\
\text { Acumulada }\end{array}$ & 0,00 & $56.594,75$ & Total Pasivo No Corriente & $284.295,66$ & $284.295,66$ \\
\hline Activos intangibles & $41.393,42$ & $36.452,29$ & Total Pasivos & $354.365,70$ & $369.836,27$ \\
\hline $\begin{array}{l}\text { (-) Amortización } \\
\text { Acumulada }\end{array}$ & 0,00 & $3.645,23$ & Aporte Propio & $355.136,00$ & $355.136,00$ \\
\hline Total Activo No Corriente & $485.885,67$ & $420.704,57$ & Utilidad del Ejercicio Anterior & 0,00 & $32.440,90$ \\
\hline & & & Reserva Legal & 0,00 & $3.604,54$ \\
\hline+ & & & Total Patrimonio & $355.136,00$ & $391.181,45$ \\
\hline Total Activos & $709.501,71$ & $761.017,72$ & Total Pasivo y Patrimonio & $709.501,71$ & $761.017,72$ \\
\hline
\end{tabular}

Elaboración propia

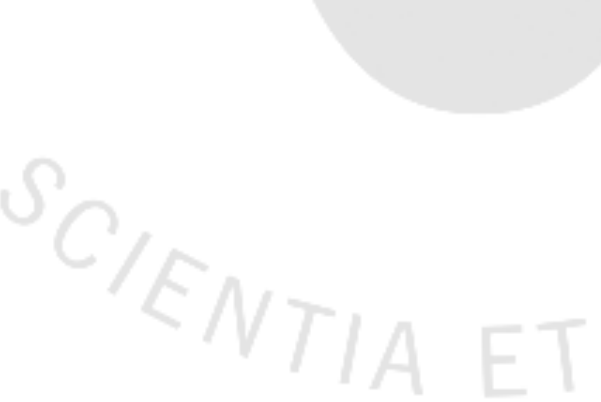




\subsubsection{Flujo de caja de corto plazo}

Tabla 7.40

Flujo de caja de corto plazo

\begin{tabular}{|c|c|c|c|c|c|c|c|c|c|c|c|c|c|}
\hline 2016 & $\mathbf{0}$ & $\mathbf{E}$ & $\mathbf{F}$ & $\mathbf{M}$ & $\mathbf{A}$ & M & $\mathbf{J}$ & JL & $\mathbf{A}$ & $\mathbf{S}$ & $\mathbf{O}$ & $\mathbf{N}$ & D \\
\hline$+\mathrm{IE}$ & & & & $65.327,55$ & $65.327,55$ & $65.327,55$ & $65.327,55$ & $65.327,55$ & $65.327,55$ & $65.327,55$ & $65.327,55$ & $65.327,55$ & $65.327,55$ \\
\hline$+\mathrm{AP}$ & $355.136,00$ & & & $x$ & 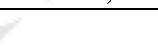 & & & & 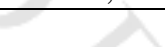 & & & & \\
\hline$+\mathrm{D}$ & $284.295,66$ & & & 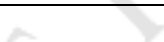 & & & & & 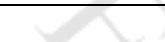 & & & & \\
\hline -CMP & & $2.001,15$ & $2.001,15$ & $2.001,15$ & $2.001,15$ & $2.001,15$ & $2.001,15$ & $2.001,15$ & $2.001,15$ & $2.001,15$ & $2.001,15$ & $2.001,15$ & $2.001,15$ \\
\hline$-\mathrm{CM}$ & & $70.070,04$ & & 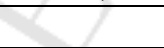 & & & & $70.070,04$ & & & & & \\
\hline -MOD & & $8.639,40$ & $8.639,40$ & $8.639,40$ & $8.639,40$ & $8.639,40$ & $8.639,40$ & $8.639,40$ & $8.639,40$ & $8.639,40$ & $8.639,40$ & $8.639,40$ & $8.639,40$ \\
\hline -MOI & & $5.455,53$ & $5.455,53$ & $5.455,53$ & $5.455,53$ & $5.455,53$ & $5.455,53$ & $5.455,53$ & $5.455,53$ & $5.455,53$ & $5.455,53$ & $5.455,53$ & $5.455,53$ \\
\hline -SBO & & $3.125,41$ & $3.125,41$ & $3.125,41$ & $3.125,41$ & $3.125,41$ & $3.125,41$ & $3.125,41$ & $3.125,41$ & $3.125,41$ & $3.125,41$ & $3.125,41$ & $3.125,41$ \\
\hline -PA & & $10.265,00$ & $10.265,00$ & $10.265,00$ & $10.265,00$ & $10.265,00$ & $10.265,00$ & $10.265,00$ & $10.265,00$ & $10.265,00$ & $10.265,00$ & $10.265,00$ & $10.265,00$ \\
\hline -SBA & & 764,56 & 764,56 & 764,56 & 764,56 & 764,56 & 764,56 & 764,56 & 764,56 & 764,56 & 764,56 & 764,56 & 764,56 \\
\hline$-\mathrm{OS}$ & & $3.373,81$ & $3.373,81$ & $3.373,81$ & $3.373,81$ & $3.373,81$ & $3.373,81$ & $3.373,81$ & $3.373,81$ & $3.373,81$ & $3.373,81$ & $3.373,81$ & $3.373,81$ \\
\hline$-G P$ & & $1.754,51$ & $1.754,51$ & $1.754,51$ & $1.754,51$ & $1.754,51$ & $1.754,51$ & $1.754,51$ & $1.754,51$ & $1.754,51$ & $1.754,51$ & $1.754,51$ & $1.754,51$ \\
\hline$-G D$ & & $2.542,37$ & $2.542,37$ & $2.542,37$ & $2.542,37$ & $2.542,37$ & $2.542,37$ & $2.542,37$ & $2.542,37$ & $2.542,37$ & $2.542,37$ & $2.542,37$ & $2.542,37$ \\
\hline$-\mathrm{ST}$ & & $3.618,70$ & $3.618,70$ & $3.618,70$ & $3.618,70$ & $3.618,70$ & $3.618,70$ & $3.618,70$ & $3.618,70$ & $3.618,70$ & $3.618,70$ & $3.618,70$ & $3.618,70$ \\
\hline -ISH & & 197,51 & 197,51 & 197,51 & 197,51 & 197,51 & 197,51 & 197,51 & 197,51 & 197,51 & 197,51 & 197,51 & 197,51 \\
\hline -IR & & - & - & - & - & - & - & - & - & - & - & - & - \\
\hline$-\mathrm{AD}$ & & - & - & - & - & - & - & - & - & - & - & - & - \\
\hline$-\mathrm{GF}$ & & & & $4.264,43$ & $4.264,43$ & $4.264,43$ & $4.264,43$ & $4.264,43$ & $4.264,43$ & $4.264,43$ & $4.264,43$ & $4.264,43$ & $4.264,43$ \\
\hline$+\mathrm{EF}$ & & & 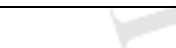 & $1.279,33$ & $1.279,33$ & $1.279,33$ & $1.279,33$ & $1.279,33$ & $1.279,33$ & $1.279,33$ & $1.279,33$ & $1.279,33$ & $1.279,33$ \\
\hline$-\mathrm{MI}$ & $485.885,67$ & & & & & & & & & & & & \\
\hline SN & $153.545,99$ & $-111.808,02$ & $-41.737,97$ & $20.604,47$ & $20.604,47$ & $20.604,47$ & $20.604,47$ & $-49.465,57$ & $20.604,47$ & $20.604,47$ & $20.604,47$ & $20.604,47$ & $20.604,47$ \\
\hline SI & 0 & $153.545,99$ & $41.737,97$ & 0,00 & $20.604,47$ & $41.208,94$ & $61.813,41$ & $82.417,89$ & $32.952,31$ & $53.556,78$ & $74.161,26$ & $94.765,73$ & $115.370,20$ \\
\hline SF & $153.545,99$ & $41.737,97$ & 0,00 & $20.604,47$ & $41.208,94$ & $61.813,41$ & $82.417,89$ & $32.952,31$ & $53.556,78$ & $74.161,26$ & $94.765,73$ & $115.370,20$ & $135.974,67$ \\
\hline
\end{tabular}

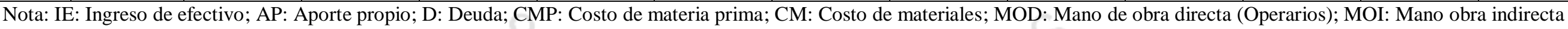

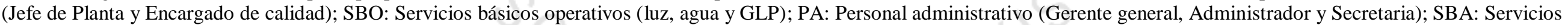

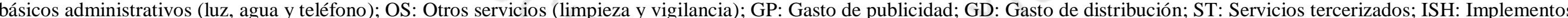

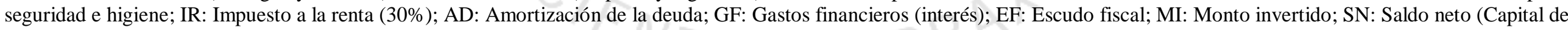
trabajo); SI: Saldo inicial; SF: Saldo final.

Elaboración propia 


\subsection{Flujo de fondos netos}

\subsubsection{Flujo de fondos económicos}

Tabla 7.41

Flujo de fondos económicos

\begin{tabular}{|c|c|c|c|c|c|c|c|c|c|c|c|}
\hline Descripción & $\mathbf{0}$ & $\mathbf{2 0 1 6}$ & $\mathbf{2 0 1 7}$ & $\mathbf{2 0 1 8}$ & $\mathbf{2 0 1 9}$ & $\mathbf{2 0 2 0}$ & $\mathbf{2 0 2 1}$ & $\mathbf{2 0 2 2}$ & $\mathbf{2 0 2 3}$ & $\mathbf{2 0 2 4}$ & $\mathbf{2 0 2 5}$ \\
\hline (-) Inversión & $-485.885,67$ & - & - & - & - & - & - & - & - \\
\hline (+) Ingreso de efectivo & - & $653.275,50$ & $818.192,60$ & $860.303,83$ & $900.838,43$ & $940.236,00$ & $979.479,87$ & $1.017 .945,10$ & $1.054 .475,83$ & $1.091 .647,67$ & $1.316 .095,57$ \\
\hline (-) Costos de operación & - & $370.797,98$ & $379.382,03$ & $388.122,57$ & $396.527,91$ & $408.837,13$ & $471.314,93$ & $479.306,97$ & $486.892,57$ & $494.920,26$ & $502.306,72$ \\
\hline (-) Gastos generales & - & $270.197,79$ & $270.197,79$ & $270.197,79$ & $270.197,79$ & $274.062,39$ & $275.671,38$ & $275.671,38$ & $275.671,38$ & $275.671,38$ & $275.671,38$ \\
\hline $\begin{array}{c}\text { (-) Impuesto a la renta } \\
\text { (30\%) }\end{array}$ & - & 0,00 & 0,00 & 0,00 & 0,00 & $61.091,01$ & $67.752,07$ & $76.847,28$ & $85.424,10$ & $94.227,15$ & $102.583,22$ \\
\hline Flujo caja económico & - & $12.279,72$ & $168.612,77$ & $201.983,47$ & $234.112,73$ & $196.245,47$ & $164.741,48$ & $186.119,47$ & $206.487,78$ & $226.828,88$ & $435.534,26$ \\
\hline (+) Valor residual & - & - & - & - & - & - & - & - & - & - & $113.774,40$ \\
\hline (+) Capital de trabajo & $-153.545,99$ & - & - & - & - & - & - & - & - & - & $153.545,99$ \\
\hline Flujo fondo económico & $-639.431,66$ & $12.279,72$ & $168.612,77$ & $201.983,47$ & $234.112,73$ & $196.245,47$ & $164.741,48$ & $186.119,47$ & $206.487,78$ & $226.828,88$ & $702.854,65$ \\
\hline
\end{tabular}

Elaboración propia

\subsubsection{Flujo de fondos financieros}

Tabla 7.42

Flujo de fondo financiero

\begin{tabular}{|c|c|c|c|c|c|c|c|c|c|c|c|}
\hline Descripción & $\mathbf{0}$ & 2016 & 2017 & 2018 & 2019 & 2020 & 2021 & 2022 & 2023 & 2024 & 2025 \\
\hline Flujo fondo económico & $-639.431,66$ & $12.279,72$ & $168.612,77$ & $201.983,47$ & $234.112,73$ & $196.245,47$ & $164.741,48$ & $186.119,47$ & $206.487,78$ & $226.828,88$ & $702.854,65$ \\
\hline (+) Deuda & $284.295,66$ & - & -1 & - & - & - & 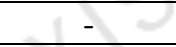 & - & - & - & - \\
\hline (-) Amortización & - & - & $18.953,04$ & $37.906,09$ & $56.859,13$ & $75.812,18$ & $94.765,22$ & - & - & - & - \\
\hline (-) Interés & - & $42.644,35$ & $42.644,35$ & $39.801,39$ & $34.115,48$ & $25.586,61$ & $14.214,78$ & - & - & - & - \\
\hline (+) Escudo fiscal & - & $12.793,30$ & $12.793,30$ & $11.940,42$ & $10.234,64$ & $7.675,98$ & $4.264,43$ & - & - & - & - \\
\hline Flujo fondo financiero & $-355.136,00$ & $-17.571,32$ & $119.808,69$ & $136.216,40$ & $153.372,76$ & $102.522,67$ & $60.025,92$ & $186.119,47$ & $206.487,78$ & $226.828,88$ & $702.854,65$ \\
\hline
\end{tabular}

Elaboración propia 


\section{CAPÍTULO VIII: EVALUACIÓN ECONÓMICA Y FINANCIERA DEL PROYECTO}

\subsection{Evaluación económica: VAN, TIR, B/C, PR}

La evaluación del flujo económico, determinado anteriormente en la Tabla 7.41, será en base a los ratios de VAN (valor actual neto), TIR (tasa interna de retorno), B/C (beneficio/costo) y periodo de recupero. Se considera un COK de 16,93\%, los resultados se muestran en la Tabla 8.1.

Tabla 8.1

Evaluación económica

\begin{tabular}{|c|c|}
\hline CPCC & $16,93 \%$ \\
\hline VANE & S/. 224.097,33 \\
\hline TIRE & $23,63 \%$ \\
\hline B/C & 1,35 \\
\hline Periodo de recupero & 4 años y 2 meses \\
\hline
\end{tabular}

Elaboración propia

\subsection{Evaluación financiera: VAN, TIR, B/C, PR}

La evaluación de los flujos financieros será desarrollada mediante los mismos ratios de VAN, TIR, B/C y periodo de recupero, se utiliza el flujo financiero de la Tabla 7.42. Se considera el mismo COK de 16,93\%, los resultados se mostrarán en la tabla 8.2.

Tabla 8. 2

Evaluación financiera

\begin{tabular}{|c|c|}
\hline COK & $16,93 \%$ \\
\hline VANF & S/. 279.008,83 \\
\hline TIR & $29,00 \%$ \\
\hline B/C & 1,79 \\
\hline Periodo de recupero & 3 años y 10 meses \\
\hline
\end{tabular}

Elaboración propia 


\subsection{Análisis de ratios (liquidez, solvencia, rentabilidad e indicadores económicos y financieros del proyecto)}

\section{Análisis del resultado económico}

Los indicadores económicos demuestran que el proyecto es viable. El valor actual neto del flujo de fondos económicos otorga un valor positivo de S/. 224.097,33, lo que significa que existe retorno y ganancia si el proyecto se traslada al presente.

El TIR económico otorga un valor porcentual de $23,63 \%$, que es mayor al COK $(16,930 \%)$, lo que reafirma la conveniencia del proyecto.

En cuanto al beneficio/costo, esta relación es de 1,35, lo que significa que el proyecto otorga más beneficios económicos que los costos del proyecto.

Finalmente, el periodo de recupero es de 4 años y 2 meses, este indicador señala que el monto de la inversión se recuperaría en ese lapso de periodo. A partir de esa fecha el proyecto solventa su funcionamiento y además genera utilidades.

\section{Análisis del resultado financiero}

Los indicadores financieros indican que si el proyecto es financiado es incluso más rentable. El valor actual neto del flujo de fondos financieros otorga un valor positivo de S/. $279.008,83$, o sea un mayor retorno y ganancia llevando a valor presente los flujos del fonfo financiero.

El TIR financiero otorga un valor porcentual de $29,00 \%$, el que es muy superior al $\operatorname{COK}(16,93 \%)$, otro ratio que corrobora la rentabilidad del proyecto.

En cuanto al beneficio/costo, esta relación es de 1,79, lo que indica que el proyecto otorga más beneficios económicos sobre los costos del proyecto.

Por último en este caso el periodo de recupero es de 3 años y 10 meses, esto señala que el monto de la inversión se empieza a recuperar después de ese periodo ya que desde esa fecha el proyecto solventa su funcionamiento y además genera utilidades. 


\subsection{Análisis de sensibilidad del proyecto}

Mediante este análisis se evalúa cómo se afecta al proyecto si van cambiando variables como son el costo de la materia prima, materiales y el valor de venta de ambos productos. Asimismo, se usó el VANF (valor actual neto financiero) del proyecto y el cambio de las variables fue en base:

- Variación del valor de venta de los productos: $\pm 15 \%, \pm 10 \%$ y $\pm 5 \%$.

- Variación en los costos de materia prima y materiales: $\pm 20 \%, \pm 15 \%, \pm 10 \%$ y $\pm 5 \%$.

La Tabla 8.3 muestra el análisis económico de sensibilidad del proyecto

Tabla 8. 3

Análisis económico de sensibilidad del proyecto

\begin{tabular}{|c|c|c|c|c|c|c|c|c|}
\hline \multirow{2}{*}{ VANF } & \multirow{2}{*}{$\begin{array}{c}\text { S/. } \\
279.008,83\end{array}$} & \multicolumn{7}{|c|}{ Valor de venta de ambos producto (s/./caja) } \\
\hline & & $-15,00 \%$ & $-10,00 \%$ & $-5,00 \%$ & $0 \%$ & $5,00 \%$ & $10,00 \%$ & $15,00 \%$ \\
\hline \multirow{9}{*}{$\begin{array}{c}\text { Costo } \\
\text { de } \\
\text { materia } \\
\text { prima y } \\
\text { material } \\
\text { (S/.) }\end{array}$} & $-20 \%$ & $-97.486,07$ & $81.708,47$ & $260.903,01$ & $440.097,55$ & $619.292,09$ & $798.486,63$ & $977.681,17$ \\
\hline & $-15 \%$ & $-137.758,32$ & $41.436,22$ & $220.630,76$ & $399.825,30$ & $579.019,84$ & $758.214,38$ & $937.408,92$ \\
\hline & $-10 \%$ & $-178.030,58$ & $1.163,96$ & $180.358,51$ & $359.553,05$ & $538.747,54$ & $717.942,13$ & $897.136,67$ \\
\hline & $-5 \%$ & $-218.302,83$ & $-39.108,29$ & $140.086,25$ & $319.280,79$ & $498.475,33$ & $677.669,87$ & $856.864,41$ \\
\hline & 0\% & $-258.575,08$ & $-79.380,54$ & $99.814,00$ & $279.008,54$ & $458.203,08$ & $637.397,62$ & $816.592,16$ \\
\hline & $+5 \%$ & $-298.847,33$ & $-119.652,79$ & $59.541,75$ & $238.736,29$ & $417.930,83$ & $597.125,37$ & $776.319,91$ \\
\hline & $+10 \%$ & $-339.119,58$ & $-159.925,04$ & $192.169,50$ & $198.464,04$ & $377.658,58$ & $556.853,12$ & $736.047,66$ \\
\hline & $+15 \%$ & $-379.391,83$ & $-200.197,29$ & $-21.002,75$ & $158.191,79$ & $337.386,33$ & $516.580,87$ & $695.775,91$ \\
\hline & $+20 \%$ & $-419.664,98$ & $-240.469,54$ & $-61.275,00$ & $117.919,54$ & $297.114,08$ & $476.308,62$ & $655.503,16$ \\
\hline
\end{tabular}

Elaboración propia

Como resultado de la simulación se puede afirmar que el proyecto tendría un VANF positivo de S/. 1.163,96 incluso cuando los costos de materia prima e insumos aumentasen en un $10 \%$ y el valor de venta de los productos disminuyesen en un $10 \%$. Culquier escenario desfavorable sobre esos límites haría que el VANF sea negativo, y en consecuencia que en esas crcusntancias el proyecto no sea rentable. 


\section{CAPÍTULO IX: EVALUACIÓN SOCIAL DEL PROYECTO}

\subsection{Identificación de las zonas y comunidades de influencia del proyecto}

Los principales factores que aportan beneficios al instalarse una planta de producción de bolsas filtrantes de manzanilla común en Acobamba, provincia de Tarma, región Junín son:

\section{Generación de empleo}

Favorece a la localidad, en el sentido que a medida que se incrementa la producción se da una mayor oportunidad de contratación ya sea como mano de obra directa o indirecta, o también como posible proveedor de materia prima. Estimulando así, a los distintos agricultores de la localidad, y de los alrededores a que se siembre más manzanilla común.

\section{Generación de arbitrios municipales}

La instalación de la planta contribuirá con el gobierno municipal de su jurisdicción, ya que toda actividad comercial, industrial o de servicio le generará rentas.

\subsubsection{Análisis de indicadores sociales (valor agregado, densidad de capital, intensidad de capital, generación de divisas)}

El valor agregado representa el valor global en términos monetarios que aporta el proyecto durante un periodo evaluado. La Tabla 9.1 muestra este valor global.

Tabla 9. 1

Valor agregado acumulado del proyecto

\begin{tabular}{|c|c|c|c|c|c|c|c|c|c|c|}
\hline Ítem & 2016 & 2017 & 2018 & 2019 & 2020 & 2021 & 2022 & 2023 & 2024 & 2025 \\
\hline$S$ & $332,804.93$ & $332,804.93$ & $332,804.93$ & $332,804.93$ & $340,663.37$ & $393,723.77$ & $393,723.77$ & $393,723.77$ & $393,723.77$ & $393,723.77$ \\
\hline $\mathrm{D}$ & $56,594.75$ & $56,594.75$ & $56,594.75$ & $56,594.75$ & $56,594.75$ & $9,548.83$ & $9,548.83$ & $9,548.83$ & $9,548.83$ & $9,548.83$ \\
\hline SE & $46,679.74$ & $46,761.72$ & $46,843.70$ & $46,923.33$ & $47,000.63$ & $47,693.46$ & $47,768.41$ & $47,841.02$ & $47,913.63$ & $47,983.90$ \\
\hline OS & $97,357.21$ & $97,357.21$ & $97,357.21$ & $97,357.21$ & $97,357.21$ & $98,542.30$ & $98,542.30$ & $98,542.30$ & $98,542.30$ & $98,542.30$ \\
\hline A & $3,645.23$ & $3,645.23$ & $3,645.23$ & $3,645.23$ & $3,645.23$ & $3,645.23$ & $3,645.23$ & $3,645.23$ & $3,645.23$ & $3,645.23$ \\
\hline GF & $42,644.35$ & $42,644.35$ & $39,801.39$ & $34,115.48$ & 25,58 & 14,2 & 0.00 & 0.00 & 0.00 & 0.00 \\
\hline I & 0.00 & 0.00 & 0.00 & 0.00 & $61,091.01$ & $67,752.07$ & $76,847.28$ & $85,424.10$ & $94,227.15$ & $102,583.22$ \\
\hline UDI & $12,279.72$ & $168,612.77$ & $201,983.47$ & $234,112.73$ & $196,245.47$ & $164,741.48$ & $186,119.47$ & $206,487.78$ & $226,828.88$ & $435,534.26$ \\
\hline VA & $592,005.93$ & $748,420.96$ & $779,030.68$ & $805,553.66$ & 828,1 & 799,8 & 816,1 & $845,213.03$ & $874,429.79$ & $1,091,561.49$ \\
\hline VAA & $533,338.68$ & $607,435.24$ & $569,620.52$ & $530,643.15$ & $491,487.06$ & $427,638.85$ & $393,127.32$ & $366,760.33$ & $341,836.26$ & $384,431.02$ \\
\hline VAC & $533,338.68$ & $1,140,773.92$ & $1,710,394.44$ & $2,241,037.58$ & $2,732,524.64$ & $3,160,163.49$ & $3,553,290.81$ & $3,920,051.14$ & $4,261,887.40$ & $4,646,318.42$ \\
\hline
\end{tabular}

Nota: S: Sueldos; D: Depreciación; SE: Servicios (Electricidad, agua potable, GLP y teléfono); OS: Otros servicios; A:

Amortización; GF: Gastos financieros (intereses); I: Impuesto a la renta; UDI: Utilidad después de impuesto; VA: Valor agregado; VAA: Valor actual agregado (descontando a una tasa de 11\%); VAC: Valor agregado acumulado. 
El valor agregado actual fue hallado usando una tasa de descuento social de $11 \%$, según el informe del Ministerio de Economía y Finanzas. Este valor agregado acumulado en 10 años evaluados es de S/. 4.646.318,42.

Asimismo, se procedió a obtener otros indicadores sociales como son: productocapital, densidad de capital e intensidad de capital. La Tabla 9.2 muestra el indicador producto-capital. Según este, el proyecto es viable porque la relación es mayor a 1. Es decir por cada sol invertido se obtiene 7,27 soles de valor agregado.

Tabla 9. 2

Indicador producto-capital

\begin{tabular}{|c|c|}
\hline \multicolumn{2}{|c|}{ Relación producto-capital } \\
\hline Valor agregado & S/. 4.646.318,42 \\
\hline Inversión total & S/. 639.431,66 \\
\hline P/C & 7,27 \\
\hline
\end{tabular}

Elaboración propia

La Tabla 9.3 muestra el indicador densidad de capital. Este indica que para generar un puesto de trabajo se debe invertir en promedio S/. 31.971,58.

Tabla 9.3

Indicador densidad de capital

\begin{tabular}{|l|c|}
\hline \multicolumn{2}{|c|}{ Densidad de capital } \\
\hline Inversión total & S/. 639.431,66 \\
\hline Número de trabajadores & 20,00 \\
\hline Inversión/trabajadores & S/. 31.971,58 \\
\hline
\end{tabular}

Elaboración propia

Finalmente, la Tabla 9.4 muestra la relación intensidad de capital. Indica que para generar S/.1, 00 sol de valor agregado se requiere S/. 0,14 soles de inversión.

Tabla 9.4

Indicador intensidad de capital

\begin{tabular}{|l|c|}
\hline \multicolumn{2}{|c|}{ Intensidad de capital } \\
\hline Valor agregado & S/. 4.646.318,42 \\
\hline Inversión total & S/. 639.431,66 \\
\hline Intensidad de capital & S/. 0,14 \\
\hline
\end{tabular}

Elaboración propia 


\section{CONCLUSIONES}

- La instalación de una planta de bolsas filtrantes de manzanilla común presenta un viabilidad de mercado, tecnológica, económica, financiera y social. Además, se prevé una demanda en aumento para los productos.

- Se estimó una demanda para los productos en estudio de 6,59 toneladas y 9,53 toneladas para el primer y último año del proyecto, respectivamente.

- La planta será instalada en Acobamba, provincia de Tarma y región de Junín. Los factores de mayor importancia para la macrolocalización fueron la disponibilidad de materia prima y cercanía al mercado meta. Para la microlocalización fueron la disponibilidad de materia prima y el costo de energía eléctrica.

- El seguimiento de los sembríos de la materia prima es la actividad más importante para garantizar la inocuidad de los productos.

- El presente estudio prevé un financiamiento de aproximadamente el 44\% de la inversión total para la adquisición de activos fijos.

- A lo largo del proceso de producción se identificó un impacto moderadamente significativo hacia el medio ambiente en la operación de deshidratado debido a la emisión de gases de combustión.

- Los indicadores sociales demuestran un impacto favorable en la zona donde se prevé instalar la planta de producción. 


\section{RECOMENDACIONES}

- Evaluar la posibilidad de exportar el producto de flores en bolsas filtrantes.

- Aprovechar el canal de ventas tradicional por bodegas para vender el producto de planta entera, cubriendo los distritos con mayor poder adquisitivo, sabiendo que este canal posee alrededor del $60 \%$ de ventas de infusiones en Lima Metropolitana.

- Analizar la posibilidad de diversificar la producción de filtrantes usando otras hierbas aromáticas existentes en la zona donde se instalará la planta de producción, tales como cedrón, menta, toronjil y hierba luisa.

- Evaluar la aceptación de comercializar, en supermercados, productos de bolsas filtrantes sin sobres de envoltura, prescindiendo del costo de este material.

- Como estrategia de marketing realizar ofertas con otros productos complementarios para incrementar las ventas. 


\section{REFERENCIAS}

Agencia Agraria de Tarma. (2008). Estudio de mercado de manzanilla en la provincia de Tarma.

Amadeo, J. J., y Campodónico, L. C. (1979). Cultivo de la manzanilla. (Tésis para optar el título de Ingeniero Agrónomo). Universidad de Buenos Aires, Argentina.

Celiz Castillo, H. (1991). Estudio de Factibilidad para la instalación de una fábrica de bolsistas filtrantes de Plantas Medicinales. (Tesis para optar el título de Ingeniero Industrial). Universidad de Lima. Perú.

Centro de Innovación y Desarrollo Rural (Cender). (2012). Siembra de manzanilla de exportación en Incahuasi. Recuperado de https://www.youtube.com/watch?v=VCS_410X5k8.

Centro de Innovación y Desarrollo Rural (Cender). (2013). Cultivo de Manzanilla con apoyo de PROFONANPE. Recuperado de https://www.youtube.com/watch?v=IGezLwqLUBw.

Centro Nacional de Salud Intercultural. (2015). Inventario Nacional de Plantas Medicinales. Recuperado de http://www.portal.ins.gob.pe/es/censi/censi-c4/plantasmedicinales/inventario-nacional-de-plantas-medicinales.

Compañia de Investigación de Mercado CCR. (2003). El mercado de bebidas filtrantes: En franco crecimiento. Medio Empresarial, 34.

Consejo Nacional de Competitividad (CNC). (2014). Índice de Competitividad Regional del Perú. Recuperado de http://www.cnc.gob.pe/indicexregiones/ranking.php.

Diaz, B., Jarufe, B., y Noriega, M. (2007). Disposición de Planta. Lima: Universidad de Lima.

Euromonitor International. (2015). Hot Drinks in Peru-Industry Overview.

Filtrantes para calentar tu negocio. (2012). Revista Don Bodega. Edición 30, 22-25. Recuperado de Issuu-Digital Publishing Platform for Magazines, Catalogs, and more: https://issuu.com/donbodega/docs/revista_don_bodega_edicion_30. 
Fito Maupoey, P., Andrés Grau, A., Albors Sorolla, A. M., y Barat Baviera, J. M. (2001). Introducción al secado de alimentos por aire caliente. Universitat Politécnica de Valéncia.

Franke, R., y Schilcher, H. (2005). Chamomile: Industrial Profiles. (R. Franke, \& H. Schilcher, Edits.) United States of America: Taylor \& Francis Group.

Gupta, M. P., Handa, S. S., Longo, G., y Rakesh, D. D. (2013). Compendium of Medicinal and Aromatic Plants: The Americas.

Handa, S. S., Singh Khanuja, S. P., Longo, G., y Rakesh, D. D. (2008). Extraction technologies for medicinal and aromatic plants. Trieste, Italy: ICS-UNIDO.

Instituto Nacional de Estadística e Informática (INEI). (2010). Perú: Estimaciones y Proyecciones de Población Departamental por Años Calendario y Edades Simples 1995-2025. Recuperado de http://proyectos.inei.gob.pe/web/biblioineipub/bancopub/Est/Lib1039/index.htm.

Instituto Nacional de Estadística e Informática (INEI). (2015). Población peruana entre los años 2000 y 2015. Recuperado de http://proyectos.inei.gob.pe/web/poblacion/.

Ipsos Perú. (2012). Liderazgo de productos comestibles. Lima Metropolitana.

Ipsos Perú. (2014). Liderazgo de productos comestibles. Lima Metropolitana.

Ipsos Perú. (2014). Perfiles Socioeconómicos. Lima Metropolitana.

Keat, P. G., y Young, P. (2004). Economía de la empresa. México.

Kotler, P., \& Armstrong, G. (2013). Fundamentos de marketing. México: Pearson Education.

Lopez Fierro, J.F., Meneses Florián, E.M., Ortíz Rodríguez, P.B., y Vásquez Valverde, N.Y. (1997). Elaboración de un manual de calidad para la empresa Tecno Food S.A. y una propuesta de un plan HACCP para la línea de infusiones a base de té, canela y clavo de olor. (Tesis para optar el título de Ingeniero en Industrias Alimentarias). Universidad Nacional Agraria La Molina. Perú.

Martínez M., A. (2003). Aceites esenciales. Medellin, Colombia: Universidad de Antioquia. Recuperado de http://www.medinformatica.com/OBSERVAMED/Descripciones/AceitesEsencialesUdeA_esencias 2001b.pdf. 
McCabe, W., Smith, J., y Harriot, P. (2007). Operaciones unitarias en ingeniería química. México: McGraw-Hill.

Mckay, D. L., y Blumberg, J. B. (2006). A Review of the Bioactivity and Potencial Health Benefits of Chamomile Tea (Matricaria recutita L.). Phytotherapy Research.

Ministerio de Agricultura y Riego (Minagri). (2006). Problemas en la agricultura Peruana. Recuperado de http://minagri.gob.pe/portal/objetivos/22-sector-agrario/visiongeneral/190-problemas-en-la-agricultura-peruana?limitstart=0.

Organismo Supervisor de la Inversión en Energía y Minería (OSINERGMIN). (2015). Diferencias Físico - Químicas del Gas Natural (GN) y el GLP. Recuperado de http://srvgart07.osinerg.gob.pe/webdgn/contenido/diferencias-fisico-quimicas-gnglp.html.

Páez, C. J. (1943). El cultivo de la manzanilla común (Matricaria chamomilla L.). Estación experimental de la Molina. Lima (Perú).

Pérez Castro, M. A. (2010). Estudio de prefactibilidad para la instalación de una planta de producción de bolsitas filtrantes a base de orégano, llantén y hierba buena. (Tesis para optar el título de Ingeniero Industrial). Universidad de Lima, Perú.

Pindyck, R. L., y Rubinfeld, D. L. (2009). Microeconomía. Madrid: Pearson.

Sierra Exportadora. (2014). 35 proyectos de inversión productiva en las regiones andinas.

Sierra Exportadora. (2014). El té huyro. Recuperado de YouTube: https://www.youtube.com/watch?v=XLtTumu34F0.

Silva Jaimes, M. I. (1985). Determinación de los parámetros de procesamiento para la obtención de la manzanilla Común (Matricaria chamomilla L.) deshidratada por el método del Aire Caliente. (Tesis para optar el título de Ingeniero en Industrias Alimentarias). Universidad Nacional Agraria La Molina. Perú.

Tabernaemontanus, J.T. (1664). New vollkommenlich Kräuter-Buch, Jacob Werenfels, Basel, 1529 pp.

United States Department of Agriculture (USDA). (2011). Chilean Tea and Herbal Tea Market Has Grown 48 Percent. Recuperado de Global Agricultural Information Network:

http://gain.fas.usda.gov/Recent\%20GAIN\%20Publications/Chilean\%20Tea\%20and \%20Herbal\%20Tea\%20Market\%20Has\%20Grown\%2048\%20Percent_Santiago_C hile_7-25-2011.pdf. 


\section{BIBLIOGRAFÍA}

Arroyo Gordillo, P., y Vásquez, R. (2016). Ingeniería económica: ¿cómo medir la rentabilidad de un proyecto? Universidad de Lima.

Brennan, J., Butters, Cowell, y Lilly. (1980). Las operaciones de la ingeniería de los alimentos. Zaragoza (España): Segunda edición Acribia.

Çengel, Y., y Boler, M. (2011). Termodinámica. México: Mc Graw Hill.

Felder, R., y Rousseau, R. (2004). Principios elementales de los procesos químicos. Limusa Willey.

Goñi Delión, J. (2009). Máquinas hidráulicas y térmicas. Universidad de Lima.

Instituto Nacional de Estadística e Informática (INEI). (2013). Superficie, población, densidad poblacional y altitud de las provincias del Perú. Recuperado de http://webcache.googleusercontent.com/search?q=cache:m5rA_8RMP9EJ:www.ine i.gob.pe/media/MenuRecursivo/publicaciones_digitales/Est/Lib1173/cap01/cap010 12.xls $+\& \mathrm{~cd}=1 \& \mathrm{hl}=\mathrm{es} \& \mathrm{ct}=\mathrm{clnk} \& \mathrm{gl}=\mathrm{pe}$

Lozano Venegas, W. A. (2002). Obtención de la dosis óptima de radiación de filtrantes de anís (Pimpinella anisum) y hierba luisa (Cymbopogon citratus). (Tesis para optar el título de Ingeniero en Industrias Alimentarias). Universidad Nacional Agraria La Molina. Perú.

Perry, R., y Green, D. (1997). Perry's Chemical Engineers' Handbook. New York:

McGraw Hill.

Porter, M. (2009). Estrategia competitiva : técnicas para el análisis de los sectores industriales y de la competencia. México: Pirámide.

Porter, M. (2010). Ventaja competitiva: creación y sostenibilidad de un desempeño superior. México: Pirámide.

Tello Rojas, C.C., Palomino Onsihuay, J.A., Tenorio Ramos, M.R., y Paz Villalobos, R.H. (1985). Estudio de Prefactibilidad para la Elaboración de Infusiones Filtrantes de Uña de Gato (Uncaria tomentosa), mezclado con Manzanilla (Matricaria chamomilla) y Hierba Luisa (Cymbopogum citratus) destinados al Mercado Japonés. Universidad Nacional Agraria La Molina. Perú. 


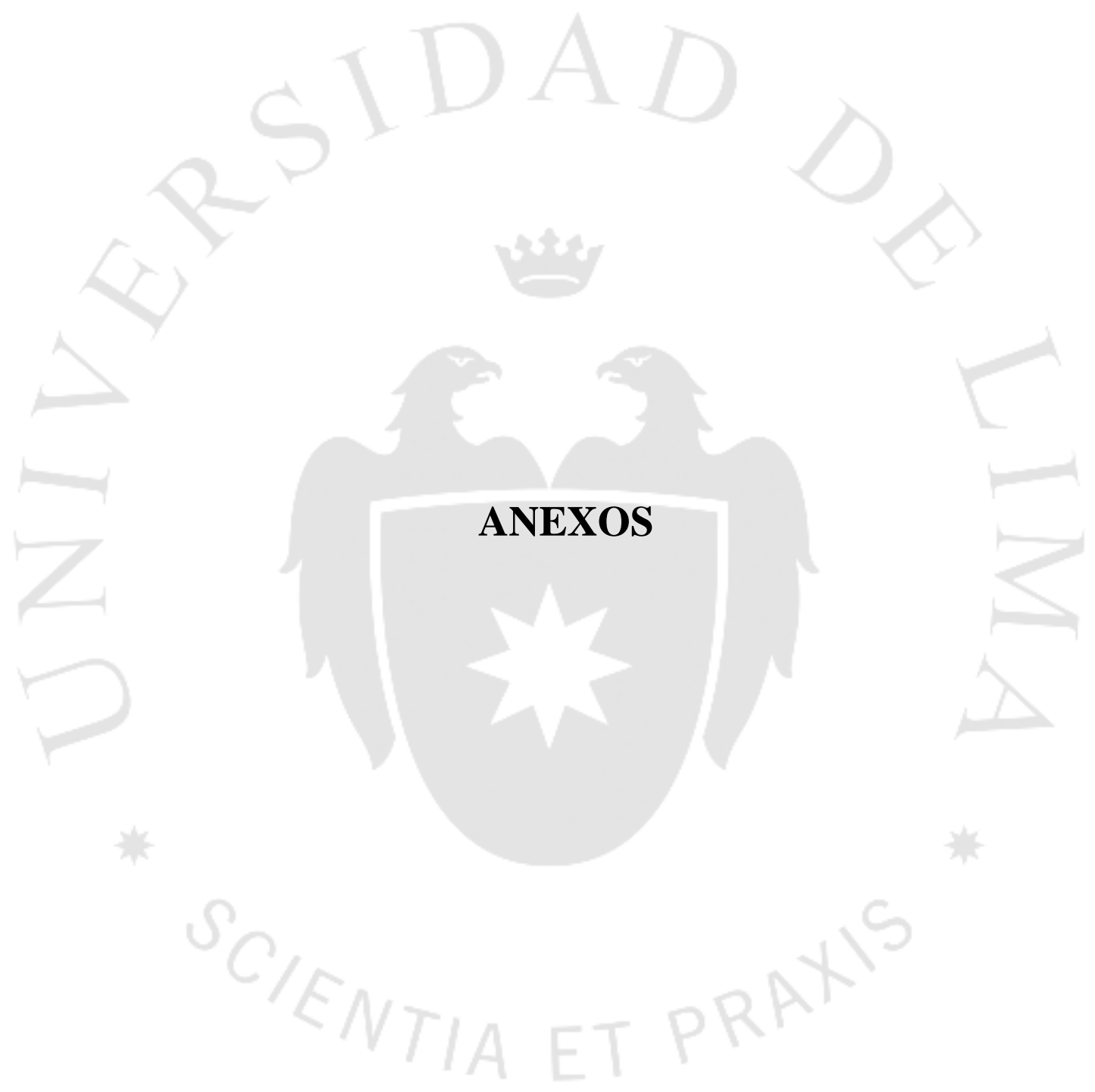




\section{ANEXO 1: Producción materia prima y diseño de producto}

\section{A.2. Producción de manzanilla común según la Agencia Agraria de Tarma}

\begin{tabular}{|c|c|c|c|}
\hline Año & Producción (TM) & Superficie cosechada (ha) & Rendimiento (TM/ha) \\
\hline 2001 & $3.620,46$ & 97,72 & 37,05 \\
\hline 2002 & $3.474,87$ & 98,99 & 35,10 \\
\hline 2003 & $3.436,66$ & 92,76 & 37,05 \\
\hline 2004 & $3.809,57$ & 93,03 & 40,95 \\
\hline 2005 & $4.054,90$ & 103,97 & 39,00 \\
\hline 2006 & $4.229,29$ & 98,59 & 42,90 \\
\hline 2007 & $4.672,89$ & 99,85 & 46,80 \\
\hline
\end{tabular}

\section{A.5. Diseño de cajas, sobres de envoltura y etiquetas de producto de flores de manzanilla común}

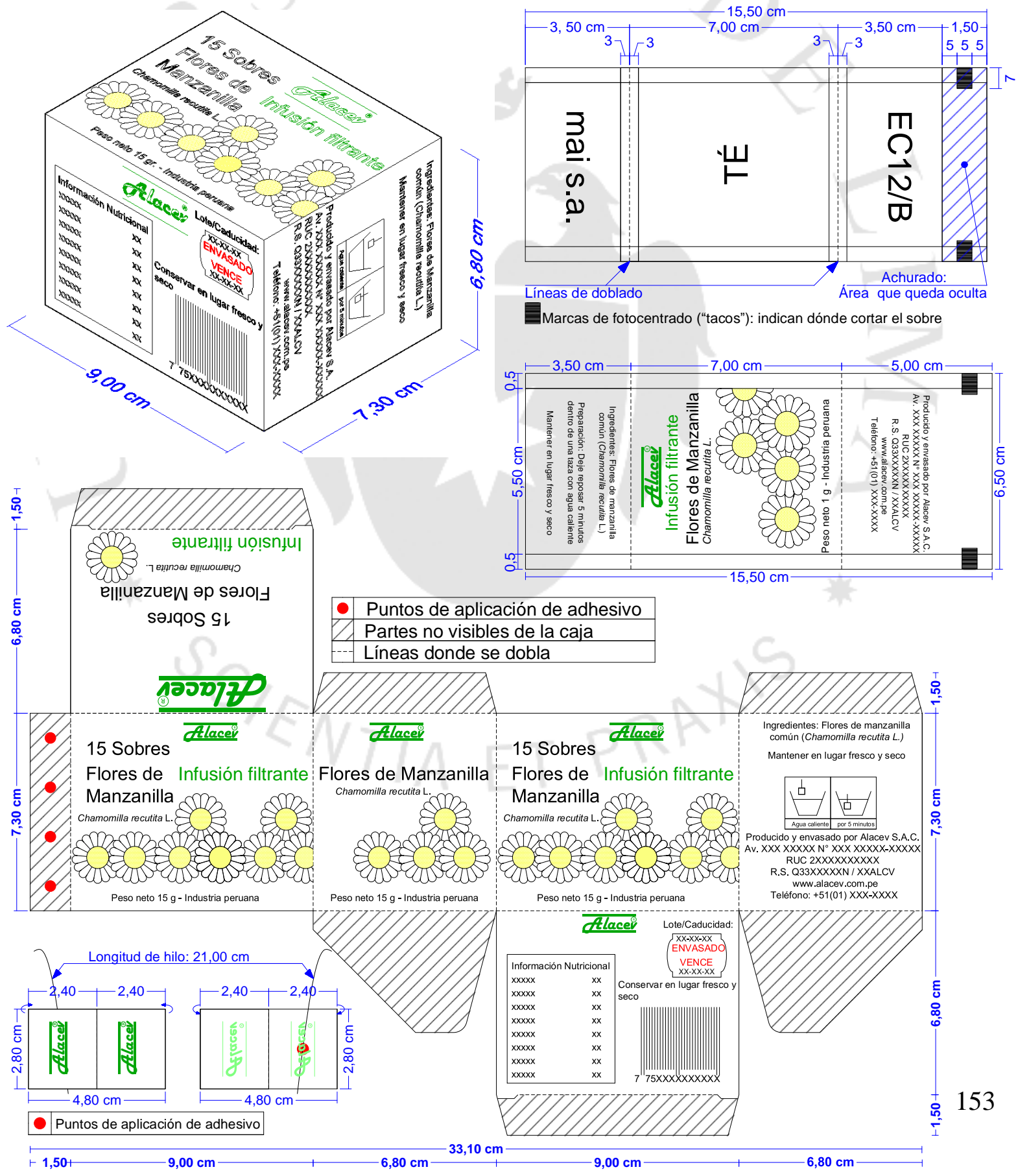




\section{ANEXO 2: Degustaciones y encuestas}

\section{A.11. Clasificación de pruebas, pautas de análisis sensorial, ensayo triangular y resultados}

Análisis

Análisis sensorial triangular entre filtrantes de planta entera y flores de manzanilla común

Fecha:

\begin{tabular}{|l|l|l|l|}
\multicolumn{1}{c}{ Hora } & Méa & Año \\
\hline & & & \\
\hline
\end{tabular}

1. Género

Femenino 1 Masculino

2. Edad

\begin{tabular}{|l|l|l|l|l|}
\hline $18-29$ & $30-39$ & $40-49$ & $50-59$ & 60 -más \\
\hline
\end{tabular}

3. ¿En qué distrito vive?

4. Procedimiento

Solo se evalua a personas que hayan consumido alguna infusión filtrante a base de manzanilla común.

- Verter aproximadamente $250 \mathrm{ml}$ de agua caliente en cada una de las tres tazas.

Dejar reposar por cinco minutos hasta que empieze la degustación.

La temperatura a la que se degusta cada muestra debe ser, en lo posible, la misma.

No agregar azúcar ni cualquier otra sustancia a ninguna muestra.

El evaluador puede tomar varios sorbos de una muestra, siempre que sea igual en las otras muestras.

Si se lleva a cabo la prueba con más de un evaluador se debe evitar la comunicación entre estos durante la misma.

Se recuerda que una vez usada una bolsa filtrante esta debe desecharse.

5. Instrucciones

- Probar las muestras de izquierda a derecha. Dos son iguales y una es diferente. Escribir el número de la muestra diferente en el espacio en blanco.

6. Prueba Triangular
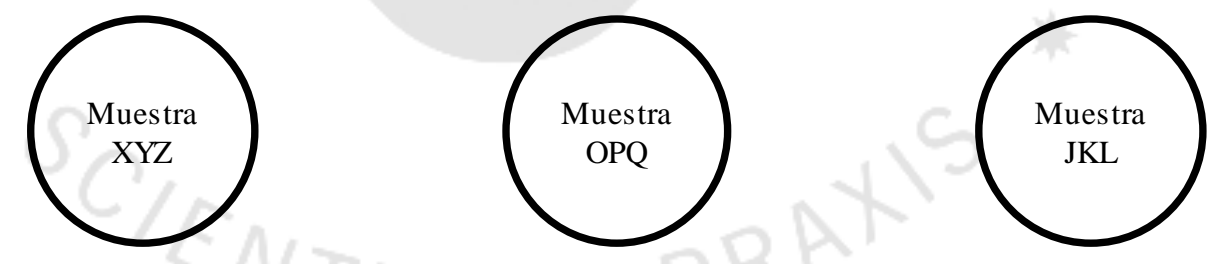

La muestra que difiere de las otras dos es: 

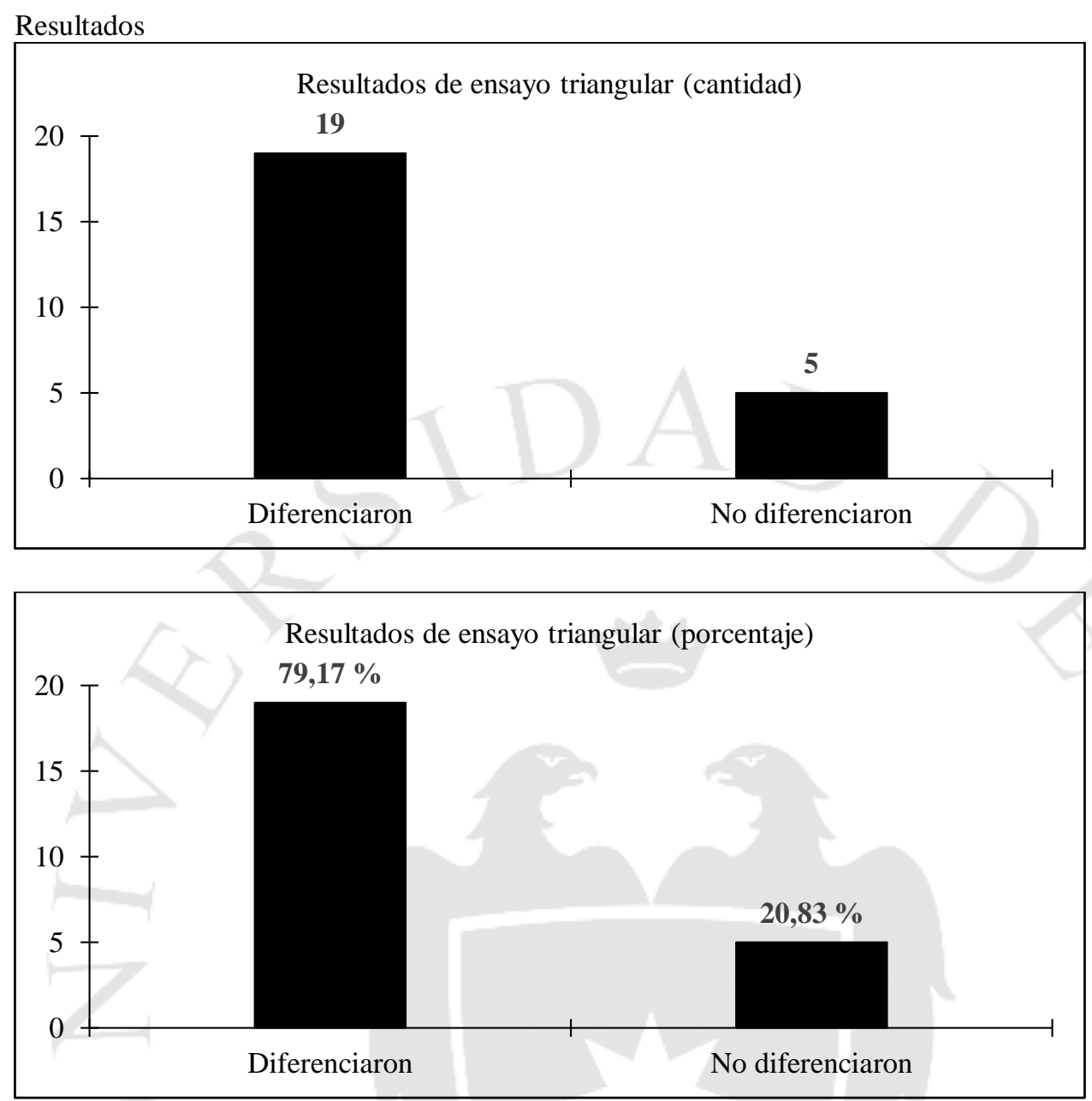

\section{A.12. Cantidad de encuestas a realizar}

Coeficiente de confianza

\begin{tabular}{|c|c|c|}
\hline $\begin{array}{c}\text { Intervalo de confianza } \\
\mathbf{1}-\boldsymbol{\alpha}\end{array}$ & $\begin{array}{c}\text { Nivel de significación } \\
\boldsymbol{\alpha} / \mathbf{2}\end{array}$ & $\begin{array}{c}\text { Coeficiente de confianza } \\
\mathbf{z}_{\boldsymbol{\alpha} / \mathbf{2}}\end{array}$ \\
\hline 0.90 & 0.05 & 1.645 \\
\hline 0.95 & 0.025 & 1.96 \\
\hline 0.99 & 0.005 & 2.575 \\
\hline
\end{tabular}

Tamaño de muestra para poblaciones finitas

$$
n=\frac{N \times Z^{2} \times p \times q}{(N-1) \times e^{2}+p \times q \times Z^{2}}
$$

Tamaño de muestrapara poblaciones infinitas (mayor a 100.000)

n: Cantidad de muestras

$$
n=\frac{Z^{2} \times p \times q}{e^{2}}
$$

N: Tamaño de la población

Z: Coeficiente de confianza

p: Probabilidad a favor

q: Probabilidad en contra

e: Error admisible 


\section{A.13. Encuesta de consumo de infusiones filtrantes}

Preguntas

Consumo de infusiones filtrantes a base de Manzanilla-Lima Metropolitana

Fecha:

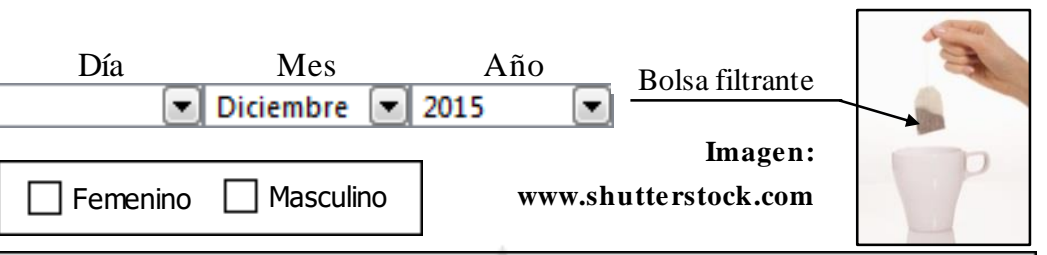

1. Género

\begin{tabular}{|llll|}
\hline 18-29 & $\square$ 30-39 $\square$ 40-49 $\square$ 50-59 $\square$ 60-más \\
\hline
\end{tabular}

2. Edad

3. ¿En qué distrito vive?

4. ¿Consume infusiones filtrantes?

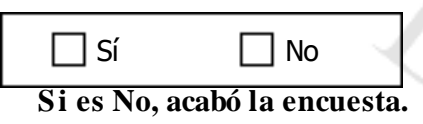

5. ¿Con qué frecuencia las consume?

\begin{tabular}{|l|l}
$\square$ a & Todos los días \\
$\square$ b & Al menos una vez por semana \\
$\square$ c & Dos o más veces por semana \\
$\square$ d & Una vez al mes \\
$\square$ e & Otro
\end{tabular}

6. ¿Generalmente dónde son adquiridas las infusiones filtrantes que consume?

$\square$ a
$\square$ b
$\square$ c
$\square$ d
$\square$ e

Bodegas

Supermercados o hipermercados

Tiendas naturistas

Puestos de mercado

Otro

7. Si marcó b en la pregunta anterior, ¿En qué supermercado o hipermercado son adquiridas las infusiones filtrantes que consume? (puede haber más de una respuesta).

\begin{tabular}{|l|l}
\hline$\square$ a & Metro \\
$\square$ b & Wong \\
$\square$ c & Plaza Vea \\
$\square$ d & Vivanda \\
$\square$ e & Makro \\
$\square$ f & Tottus \\
$\square$ g & Otro(s)
\end{tabular}

8. ¿Qué marca de infusión filtrante consume? (puede haber más de una respuesta).

\begin{tabular}{|l|l}
\hline$\square$ a & Herbi \\
$\square$ b & McColin's \\
$\square$ c & Lipton \\
$\square$ d & Hornimans \\
$\square$ e & Zurit \\
$\square$ f & Wawasana \\
$\square$ g & Sunka \\
$\square$ h & Otro(s)
\end{tabular}


9. ¿ Qué tipo de infusión filtrante consume? (puede haber más de una respuesta).

\begin{tabular}{|l|l}
\hline$\square$ a & Té \\
$\square$ b & Manzanilla \\
$\square$ c & Anís \\
$\square$ d & Boldo \\
$\square$ e & Hierbabuena \\
$\square$ f & Otro(s) \\
\hline
\end{tabular}

10. Si marcó b en la pregunta anterior, ¿Con qué fin consume infusiones filtrantes de manzanilla? (puede haber más de una respuesta).

\begin{tabular}{|l|l}
\hline$\square$ a \\
$\square$ b & Medicinal \\
$\square$ celajante \\
$\square$ d & Acompañante digestivo \\
$\square$ e & Estimulante contra el frío \\
\hline
\end{tabular}

11. ¿Pagaría usted S/. $\underline{3,50}$ por una nueva marca, en caja de 20 bolsas filtrantes de 1 gr cada una de manzanilla, es decir cada bolsa filtrante a $\underline{\mathbf{S} / .} \underline{\mathbf{0 , 1 7 5}}$ teniendo en cuenta que tiene sabor y aroma más intensos que otras marcas?

\begin{tabular}{|l|l}
\hline$\square$ a & Sí \\
$\square$ b & No
\end{tabular}

12. Si respondió afirmativamente a la pregunta anterior, en una escala del 1 al 10 ¿Con qué seguridad compraría esta nueva marca? Siendo el 10 muy seguro y el 1 probablemente no.

$$
\square 1 \square 2 \square 3 \square 4 \square 5 \square 6 \square 7 \square 8 \square 9 \square 10
$$

13. ¿Pagaría usted S/. 5,99 por un nuevo producto, en caja de 15 bolsas filtrantes de 1 gr cada una de

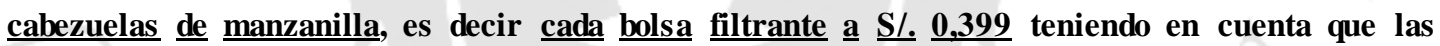
cabezuelas concentran la mayor proporción de propiedades atribuidas a esta planta?

\begin{tabular}{ll}
\hline $\mathrm{a}$ & Sí \\
$\square \mathrm{b}$ & No
\end{tabular}

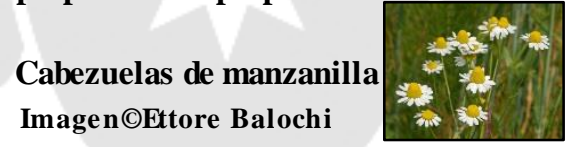

14. Si respondió afirmativamente a la pregunta anterior, en una escala del 1 al 10 ¿Con qué seguridad compraría este producto? Siendo el 10 muy seguro y el 1 probablemente no.
$\square 1$
$1 \square 2$
$\square 3$
4
$5 \square 6$
7
$8 \square 9$
$\square 10$

\section{$\underline{\text { Resultados }}$}

1.

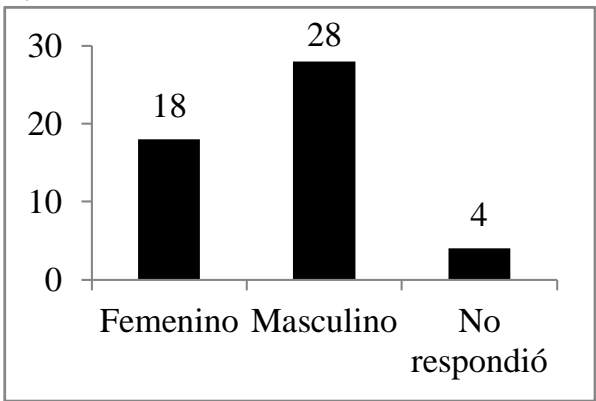

2.

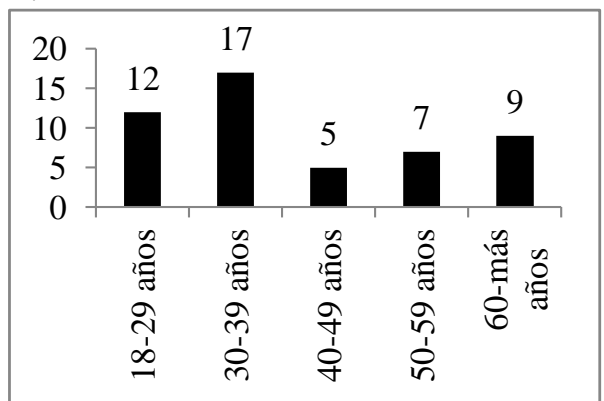



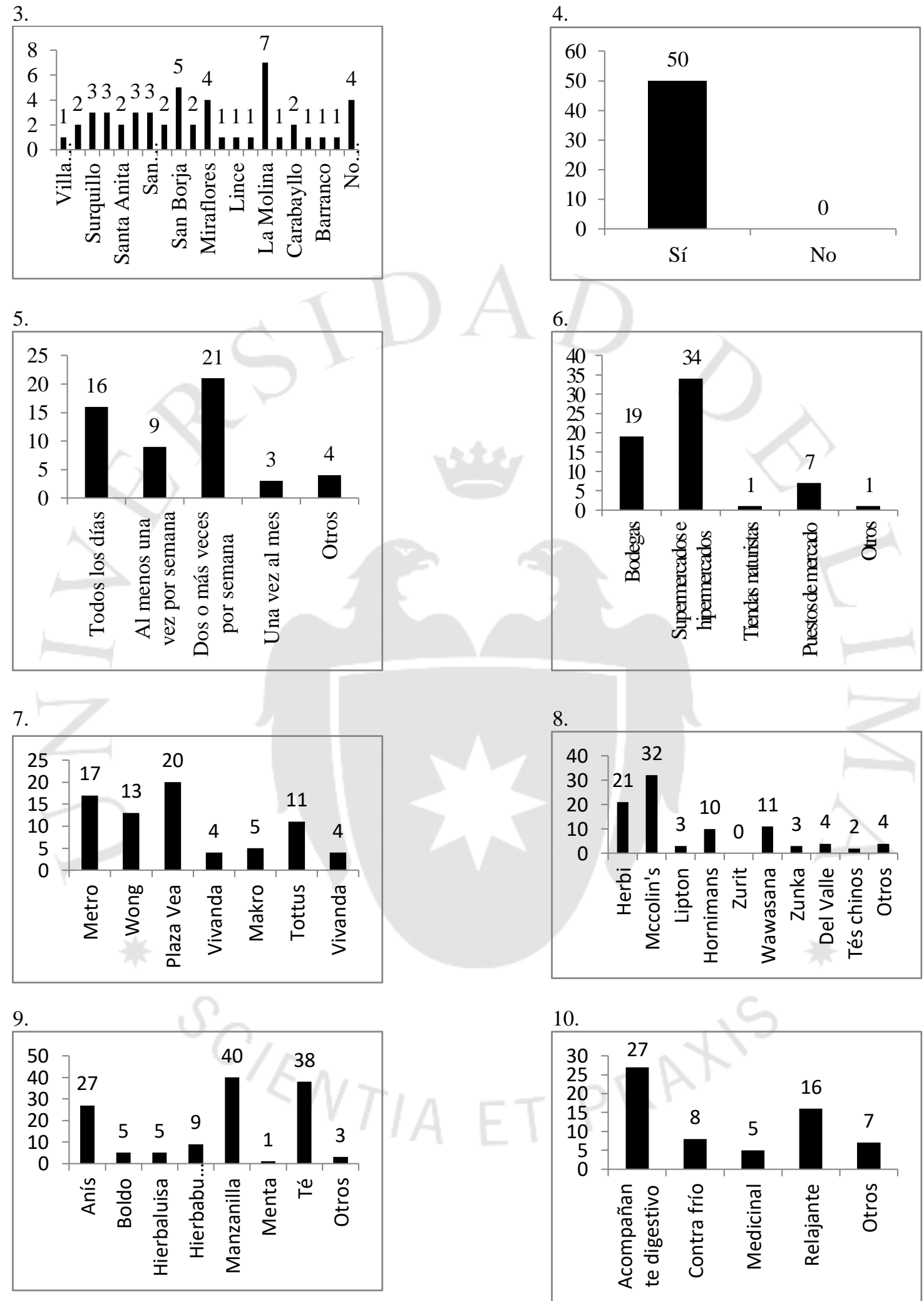
11.

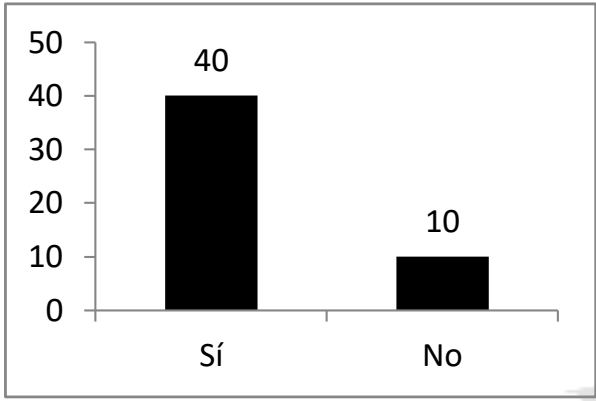

13.

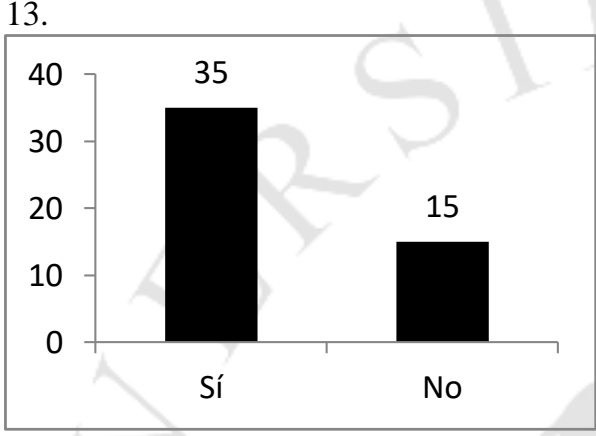

12.

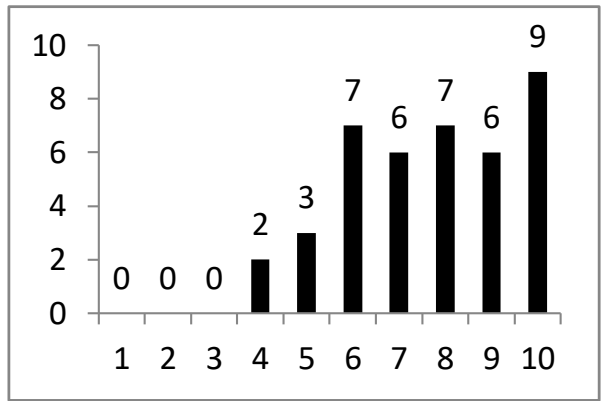

14.

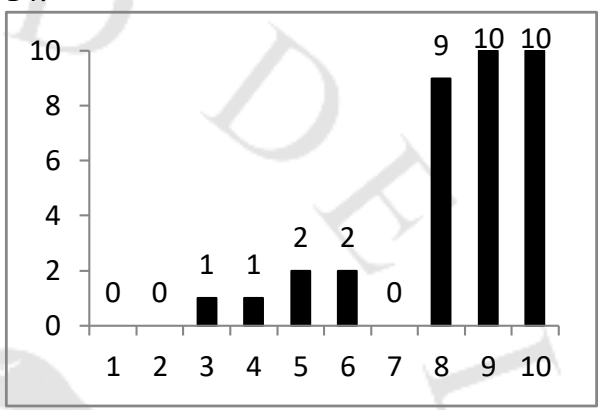

A.14. Cálculo de intención de compra porcentual de productos a base de manzanilla común

\begin{tabular}{|c|c|c|c|c|c|c|c|c|c|c|c|c|c|c|c|c|c|c|c|c|c|}
\hline \multicolumn{10}{|c|}{ Producto de planta entera } & \multicolumn{10}{|c|}{ Producto de sólo flores } \\
\hline Intensidad (I) & 1 & 2 & 3 & 4 & 5 & 6 & 7 & 8 & 9 & 10 & Intensidad (I) & 1 & 2 & 3 & 4 & 5 & 6 & 7 & 8 & 9 & 10 \\
\hline & & & & $\mathrm{x}$ & $\mathrm{x}$ & $\mathrm{x}$ & $\mathrm{x}$ & $\mathrm{x}$ & $\mathrm{x}$ & $\mathrm{x}$ & & & & $\mathrm{x}$ & $\mathrm{x}$ & $\mathrm{x}$ & $\mathrm{x}$ & & $\mathrm{x}$ & $\mathrm{x}$ & $\mathrm{x}$ \\
\hline & & & & $\mathrm{x}$ & $\mathrm{x}$ & $\mathrm{x}$ & $\mathrm{x}$ & $\mathrm{x}$ & $\mathrm{x}$ & $\mathrm{x}$ & & & & & & $\mathrm{x}$ & $\mathrm{x}$ & & $\mathrm{x}$ & $\mathrm{x}$ & $\mathrm{x}$ \\
\hline & & & & $\mathrm{x}$ & $\mathrm{x}$ & $\mathrm{x}$ & $\mathrm{x}$ & $\mathrm{x}$ & $\mathrm{x}$ & & & & & & & & & $\mathrm{x}$ & $\mathrm{x}$ & $\mathrm{x}$ \\
\hline & & & & & & $\mathrm{x}$ & $\mathrm{x}$ & $\mathrm{x}$ & $\mathrm{x}$ & $\mathrm{x}$ & & & & & & & & & $\mathrm{x}$ & $\mathrm{x}$ & $\mathrm{x}$ \\
\hline & & & & & $\mathrm{x}$ & $\mathrm{x}$ & $\mathrm{x}$ & $\mathrm{x}$ & $\mathrm{x}$ & & & & & & & & & $\mathrm{x}$ & $\mathrm{x}$ & $\mathrm{x}$ \\
\hline & & & & & $\mathrm{x}$ & $\mathrm{x}$ & $\mathrm{x}$ & $\mathrm{x}$ & $\mathrm{x}$ & & & & & & & & $\mathrm{x}$ & $\mathrm{x}$ & $\mathrm{x}$ \\
\hline & & & & & $\mathrm{x}$ & & $\mathrm{x}$ & & $\mathrm{x}$ & & & & & & & & $\mathrm{x}$ & $\mathrm{x}$ & $\mathrm{x}$ \\
\hline & & & & & & & & & $\mathrm{x}$ & & & & & & & & $\mathrm{x}$ & $\mathrm{x}$ & $\mathrm{x}$ \\
\hline & & & & & & & & & $\mathrm{x}$ & & & & & & & & $\mathrm{x}$ & $\mathrm{x}$ & $\mathrm{x}$ \\
\hline & & & & & & & & & & & & & & & & & & & $\mathrm{x}$ & $\mathrm{x}$ \\
\hline & & & & & & & & & & & & & & & & & & & & \\
\hline & & & & & & & & & & & & & & & & & & & & & \\
\hline
\end{tabular}

Elaboración propia 


\section{ANEXO 3: Participación y margen de filtrantes en supermercados}

\section{A.18. El mercado de las bebidas filtrantes en Perú}

"La venta de las infusiones está concentrada en la ciudad de Lima, en donde se encontramos el $70 \%$ de las ventas totales del país".

Fuente: Revista Medio Empresarial, Marzo 2003, página 34.

A.19. Venta mensual de infusiones en hipermercados Tottus en Lima Metropolitana 2015

\begin{tabular}{|c|c|c|c|}
\hline F & & Infusiónes filtrantes & $59,15 \%$ \\
\hline & A & Anís & $12,41 \%$ \\
\hline & M & Manzanilla & $23,83 \%$ \\
\hline & OH & Otras hierbas & $18,13 \%$ \\
\hline & T & Té & $36,45 \%$ \\
\hline & TV & Té verde & $9,18 \%$ \\
\hline
\end{tabular}

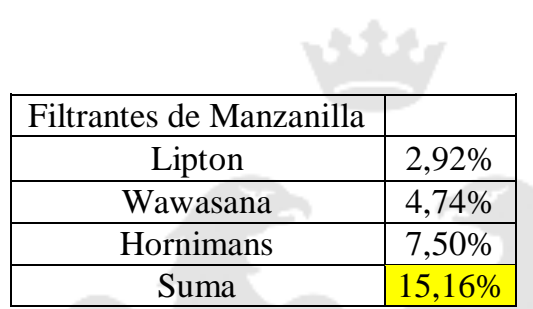

\begin{tabular}{|c|c|c|c|c|}
\hline S & & $\begin{array}{c}\text { Infusiónes en hojas } \\
\text { sueltas }\end{array}$ & $40,85 \%$ & \\
\hline & A & Anís & & $0,56 \%$ \\
\hline & M & Manzanilla & & $0,25 \%$ \\
\hline & T & Té & & $0,00 \%$ \\
\hline & OH & Otras hierbas & & $94,71 \%$ \\
\hline & TV & Té verde & & $4,48 \%$ \\
\hline
\end{tabular}

Fuente: Supermercado Tottus (2015).

A.1.20. Precio y margen bruto de ganancia de infusiones filtrantes de manzanilla común en supermercados Tottus

\begin{tabular}{|c|c|c|c|c|c|c|c|c|}
\hline Descripción & Cantidad & $\begin{array}{c}\text { Peso/Sobre } \\
\text { (g) }\end{array}$ & $\begin{array}{c}\text { Peso/Caja } \\
\text { (g) }\end{array}$ & Marca & Costo $\left(\mathrm{C}_{0}\right)$ & \begin{tabular}{|l|} 
Precio \\
Regular
\end{tabular} & $\begin{array}{c}\text { Margen bruto } \\
\left(C_{1}-C_{0}\right) / C_{1}\end{array}$ & $\begin{array}{c}\text { Margen bruto } \\
\text { promedio }\end{array}$ \\
\hline Manzanilla lipton x 20 unidades & 20,00 & 1,00 & 20,00 & Lipton & 1,89 & 3,59 & 0,47 & \multirow{7}{*}{0,44} \\
\hline Manzanilla wawasana x 20 unidades & 20,00 & 1,00 & 20,00 & Wawasana & 1,30 & 2,95 & 0,56 & \\
\hline Mc collins manzanilla x100 unidades & 100,00 & 1,00 & 100,00 & Mc colins & 5,02 & 8,39 & 0,40 & \\
\hline Manzanilla herbi caja x 25 sobres & 25,00 & 1,00 & 25,00 & Herbi & 1,12 & 1,99 & 0,44 & \\
\hline Manzanilla herbi caja x 100 sobres & 100,00 & 1,00 & 100,00 & Herbi & 3,91 & 6,99 & 0,44 & \\
\hline Infusion mc coli ns manzani x 25 sobres & 25,00 & 1,00 & 25,00 & Mc colins & 1,51 & 2,39 & 0,37 & \\
\hline Manzanilla horni mans x 25 bolsas & 25,00 & 1,00 & 25,00 & Hornimans & 1,30 & 2,29 & 0,43 & \\
\hline
\end{tabular}

Fuente: Supermercados Tottus (2015).

\section{A.50. Supermercados en Lima Metropolitana}

\begin{tabular}{|c|c|c|c|c|c|}
\hline Supermercado & Metro & Wong & Plaza Vea & Vivanda & Tottus \\
\hline Locales & 45,00 & 14,00 & 55,00 & 8,00 & 26,00 \\
\hline
\end{tabular}

Elaboración propia 


\section{ANEXO 4: Cálculos para el capítulo de ingeniería}

\section{A.28. Magnitudes de planta entera, flores y partes verdes de manzanilla común de Tarma}

Prueba de densidad de planta entera fresca

\begin{tabular}{|c|c|}
\hline Peso de atado $(\mathrm{kg})$ & 1,2020 \\
\hline Diámetro de atado $(\mathrm{m})$ & 0,2000 \\
\hline Largo de atado $(\mathrm{m})$ & 0,6000 \\
\hline Volumen atado $\left(\mathrm{m}^{3}\right)$ & 0,018850 \\
\hline Densidad $\left(\mathrm{kg} / \mathrm{m}^{3}\right)$ & 63,77 \\
\hline
\end{tabular}

Prueba de densidad de partes verdes frescas picadas de $01 \mathrm{~cm}$

\begin{tabular}{|c|c|c|}
\hline 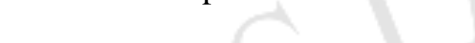 & \multicolumn{2}{|c|}{ Prueba 1} \\
\hline Largo de caja & 18,5 & $\mathrm{~cm}$ \\
\hline Profundidad de caja & 7,50 & $\mathrm{~cm}$ \\
\hline Altura de caja & 3,50 & $\mathrm{~cm}$ \\
\hline 1. Volumen caja & 485,63 & $\mathrm{~cm}^{3}$ \\
\hline 2. Peso de caja vacía & 31,00 & $\mathrm{~g}$ \\
\hline 3. Peso de caja llena con carga & 219,00 & $\mathrm{~g}$ \\
\hline 4. Peso de carga & 188,00 & $\mathrm{~g}$ \\
\hline 5. Densidad $\left(\mathrm{g} / \mathrm{cm}^{3}\right)$ & $\frac{188,00}{485,63}$ & $\begin{array}{c}\mathrm{g} \\
\mathrm{cm}^{3}\end{array}$ \\
\hline 6. Densidad $\left(\mathrm{kg} / \mathrm{m}^{3}\right)$ & 387,1300 & $\mathrm{~kg} / \mathrm{m}^{3}$ \\
\hline
\end{tabular}

Prueba de aumento de peso de partes verdes frescas picadas y lavadas

\begin{tabular}{|c|c|c|}
\hline \multicolumn{1}{|c|}{ 1. Peso de carga inicial } & 54,00 & $\mathrm{~g}$ \\
\hline 2. Tiempo de remojo & 10,00 & $\mathrm{~min}$ \\
\hline 3. Peso después de remojo & 79,00 & $\mathrm{~g}$ \\
\hline 4. Aumento de peso & $46 \%$ & \\
\hline 5. Tiempo de oreado & 30,00 & $\mathrm{~min}$ \\
\hline 6. Peso después de oreado & 74,00 & $\mathrm{~g}$ \\
\hline 7. Aumento de peso en & $37 \%$ & \\
\hline 8. Peso después de secado en Microondas por 5 min & 27,00 & $\mathrm{~g}$ \\
\hline 9. Peso después de secado en Microondas por 3 min & 10,00 & $\mathrm{~g}$ \\
\hline 10. Peso después de secado en Microondas por 2 min & 8,00 & $\mathrm{~g}$ \\
\hline
\end{tabular}

Prueba de densidad de flores frescas de manzanilla común de Tarma

\begin{tabular}{|c|c|c|c|c|}
\cline { 2 - 5 } \multicolumn{1}{c|}{} & \multicolumn{2}{c|}{ Prueba 1} & \multicolumn{2}{c|}{ Prueba 2} \\
\hline Largo de caja & 10,00 & $\mathrm{~cm}$ & 7,80 & $\mathrm{~cm}$ \\
\hline Profundidad de caja & 8,00 & $\mathrm{~cm}$ & 2,50 & $\mathrm{~cm}$ \\
\hline Altura de caja & 3,00 & $\mathrm{~cm}$ & 7,50 & $\mathrm{~cm}$ \\
\hline 1. Volumen caja & 240,00 & $\mathrm{~cm}^{3}$ & 146,25 & $\mathrm{~cm}^{3}$ \\
\hline 2. Peso de caja vacía & 24,00 & $\mathrm{~g}$ & 7,00 & $\mathrm{~g}$ \\
\hline 3. Peso de caja llena con carga & 79,00 & $\mathrm{~g}$ & 40,00 & $\mathrm{~g}$ \\
\hline 4. Peso de carga & 55,00 & $\mathrm{~g}$ & 33,00 & $\mathrm{~g}$ \\
\hline 5. Densidad $\left(\mathrm{g} / \mathrm{cm}^{3}\right)$ & $\underline{55,00}$ & $\mathrm{~g}$ & $\underline{33,00}$ & $\mathrm{~g}$ \\
$\mathrm{~cm}^{3}$ & 146,25 & $\mathrm{~cm}^{3}$ \\
\hline 6. Densidad $\left(\mathrm{kg} / \mathrm{m}^{3}\right)$ & 240,00 & $\mathrm{~kg} / \mathrm{m}^{3}$ & 225,6410 & $\mathrm{~kg} / \mathrm{m}^{3}$ \\
\hline Promedio de densidad según \\
pruebas 1 y 2 $\left(\mathrm{kg} / \mathrm{m}^{3}\right)$
\end{tabular}


Prueba de aumento de peso de flores frescas

\begin{tabular}{|c|c|c|}
\hline \multicolumn{1}{|c|}{$1 . \quad$ Peso de carga inicial } & 54,00 & $\mathrm{~g}$ \\
\hline 2. Tiempo de remojo & 10,00 & $\mathrm{~min}$ \\
\hline 3. Peso después de remojo & 80,00 & $\mathrm{~g}$ \\
\hline 4. Aumento de peso & $48 \%$ & \\
\hline 5. Tiempo de oreado & 30,00 & $\mathrm{~min}$ \\
\hline 6. Peso después de oreado & 75,00 & $\mathrm{~g}$ \\
\hline 7. Aumento de peso en & $39 \%$ & \\
\hline 8. Peso después de secado en Microondas por 5 min & 32,00 & $\mathrm{~g}$ \\
\hline 9. Peso después de secado en Microondas por 3 min & 13,00 & $\mathrm{~g}$ \\
\hline 10. Peso después de secado en Microondas por 2 min & 10,00 & $\mathrm{~g}$ \\
\hline
\end{tabular}

Prueba de tamaño de pedicelo luego de la operación de selección con peine

\begin{tabular}{|c|c|c|c|c|c|c|c|c|c|c|c|}
\hline Muestras & 1 & 2 & 3 & 4 & 5 & 6 & 7 & 8 & 9 & 10 & Promedio \\
\hline Tamaño $(\mathrm{cm})$ & 1,50 & 3,50 & 0,50 & 0,60 & 2,50 & 3,00 & 1,80 & 1,70 & 0,40 & 0,50 & 1,60 \\
\hline
\end{tabular}

\section{A.29. Tiempo promedio u observado de la operación de selección de manzanilla común de Tarma}

Tiempo observado en selección* de atados

\begin{tabular}{|c|c|c|c|c|c|c|c|}
\hline Descripción & Atado 1 & Atado 2 & Atado 3 & Atado 4 & $\%$ & Promedio & Suma \\
\hline Tiempo selección (min) & 0,44 & 0,38 & 0,39 & 0,42 & - & 0,4075 & - \\
\hline Peso planta entera $(\mathrm{g})$ & 44,00 & 59,00 & 50,00 & 52,00 & - & - & 205,00 \\
\hline Peso partes verdes $(\mathrm{g})$ & 29,00 & 45,00 & 36,00 & 35,00 & 0,71 & - & 145,00 \\
\hline Peso de flores $(\mathrm{g})$ & 15,00 & 14,00 & 14,00 & 17,00 & 0,29 & - & 60,00 \\
\hline
\end{tabular}

Tiempo estimado en selección por lote

\begin{tabular}{|cccccccc|}
\hline Tiempo de selección & $\frac{0,4075}{205,00} \frac{\min }{\mathrm{g}}$ & $=0,001988$ & $\frac{\mathrm{min}}{\mathrm{g}}$ & & \\
& $=0,033130$ & $\frac{\text { hora }}{\mathrm{kg}}$ & $\times$ & 85,00 & $\frac{\mathrm{kg}}{\mathrm{Lg}}$ \\
& $=$ & 2,82 & $\frac{\text { Horas }}{\text { Lote }}$ & & \\
& $=168,96$ & $\frac{\text { min }}{\text { Lote }}$ & & \\
\hline
\end{tabular}

*La selección se realizó con un peine de plástico de $5 \mathrm{~mm}$ de luz.

\section{A.30. Cálculo de cantidad de envases requeridos y composición de productos}

Tabla 30-1: Cantidad de cestos requeridos

\begin{tabular}{|c|c|c|c|}
\hline $\begin{array}{c}\text { Partes verdes frescas picadas }(1 \mathrm{~cm}) \text { de manzanilla } \\
\text { común de Tarma }\end{array}$ & Cantidad & $\begin{array}{c}\text { Flores frescas de manzanilla común de } \\
\text { Tarma }\end{array}$ & Cantidad \\
\hline Densidad $\left(\mathrm{kg} / \mathrm{m}^{3}\right)$ & 387,1300 & Densidad $\left(\mathrm{kg} / \mathrm{m}^{3}\right)$ & 227,4039 \\
\hline Partes verdes a lavar por lote el año 10 $(\mathrm{kg})$ & $\mathbf{5 5 , 3 7}$ & Flores a lavar por lote el año $10(\mathrm{~kg})$ & $\mathbf{2 3 , 9 7}$ \\
\hline Diámetro de cesto $(\mathrm{m})$ & 0,400 & Diámetro de cesto $(\mathrm{m})$ & 0,400 \\
\hline Altura de cesto $(\mathrm{m})$ & 0,300 & Altura de cesto $(\mathrm{m})$ & 0,300 \\
\hline Volumen cesto $\left(\mathrm{m}^{3}\right)$ & 0,037699 & Volumen cesto $\left(\mathrm{m}^{3}\right)$ & 0,037699 \\
\hline Volumen cesto $(\mathrm{L})$ & 37,70 & Volumen cesto $(\mathrm{L})$ & 37,70 \\
\hline Partes verdes al 100\% del cesto $(\mathrm{kg})$ & 14,5945 & Flores al 100\% del cesto $(\mathrm{kg})$ & 8,57 \\
\hline Cantidad de cargas teóricas & 3,79 & Cantidad de cargas teóricas & 2,80 \\
\hline Cantidad de cargas reales & 4,00 & Cantidad de cargas reales & 3,00 \\
\hline Partes verdes/carga $(\mathrm{kg})$ & 13,84 & Flores/carga $(\mathrm{kg})$ & 7,99 \\
\hline Porcentaje de cesto llenado & $95 \%$ & Porcentaje de cesto llenado & $93 \%$ \\
\hline
\end{tabular}

Elaboración propia 
Cantidad de tinas requeridas

Tabla 30-2

\begin{tabular}{|c|c|c|c|}
\hline $\begin{array}{l}\text { Partes verdes molidas (Tamiz } \mathrm{N}^{\circ} 30 \text { ASTM) de } \\
\text { manzanilla común de Tarma }\end{array}$ & Cantidad & $\begin{array}{l}\text { Flores molidas (Tamiz No30 ASTM) de } \\
\text { manzanilla común de Tarma }\end{array}$ & Cantidad \\
\hline Densidad $\left(\mathrm{kg} / \mathrm{m}^{3}\right)$ & 215,2266 & Densidad $\left(\mathrm{kg} / \mathrm{m}^{3}\right)$ & 215,2266 \\
\hline Partes verdes a envasar por lote el año $10(\mathrm{~kg})$ & 12,87 & Flores a envasar por lote el año $10(\mathrm{~kg})$ & 3,46 \\
\hline Diámetro mayor de tina $(\mathrm{m})$ & 0,450 & Diámetro mayor de tina $(\mathrm{m})$ & 0,450 \\
\hline Altura de tina $(\mathrm{m})$ & 0,250 & Altura de tina $(\mathrm{m})$ & 0,250 \\
\hline Diámetro menor de tina (m) & 0,380 & Diámetro menor de tina (m) & 0,380 \\
\hline Volumen $\left(\mathrm{m}^{3}\right)$ & 0,033897 & Volumen $\left(\mathrm{m}^{3}\right)$ & 0,033897 \\
\hline Volumen (L) & 33,90 & Volumen (L) & 33,90 \\
\hline Flores al $100 \%$ de la tina $(\mathrm{kg})$ & 7,30 & Flores al $100 \%$ de la tina $(\mathrm{kg})$ & 7,30 \\
\hline Cantidad de cargas teóricas & 1,7638 & Cantidad de cargas teóricas & 0,4744 \\
\hline Cantidad de cargas reales & 2,00 & Cantidad de cargas reales & 1,00 \\
\hline Cantidad total de tinas requeridas & & 2,00 & \\
\hline
\end{tabular}

Cantidad de jarras de medida

Tabla 30-3

\begin{tabular}{|c|c|}
\hline Flores molidas de manzanilla común de Tarma & Cantidad \\
\hline Densidad $\left(\mathrm{kg} / \mathrm{m}^{3}\right)$ & 215,2266 \\
\hline Flores molidas a separar por lote el año $10(\mathrm{~kg})$ & $\mathbf{1 , 4 7}$ \\
\hline Diámetro de jarra de medida $(\mathrm{m})$ & 0,170 \\
\hline Altura de jarra de medida $(\mathrm{m})$ & 0,225 \\
\hline Volumen $\left(\mathrm{m}^{3}\right)$ & 0,005107 \\
\hline Volumen $(\mathrm{L})$ & 5,1071 \\
\hline Flores molidas al 100\% de la jarra de medida $(\mathrm{kg})$ & 1,0992 \\
\hline Cantidad de cargas teóricas & 1,3392 \\
\hline Cantidad de cargas reales & 2,00 \\
\hline
\end{tabular}

Composición de partes en productos

Tabla 30-4

\begin{tabular}{|c|c|c|cc|cc|cc|cc|}
\hline Descripción & \multicolumn{2}{|c|}{ Partes } & \multicolumn{3}{|c|}{ Producto flores } & \multicolumn{3}{c|}{ Producto planta entera } \\
\hline Insumo & Flores & $\begin{array}{c}\text { Planta } \\
\text { entera }\end{array}$ & \multicolumn{2}{|c|}{ Agua } & Material seco & \multicolumn{2}{c|}{ Agua } & \multicolumn{2}{|c|}{ Material seco } \\
\hline Partes & $\mathbf{k g}$ & $\mathbf{k g}$ & $\mathbf{\%}$ & $\mathbf{k g}$ & $\mathbf{\%}$ & $\mathbf{k g}$ & $\mathbf{\%}$ & $\mathbf{k g}$ & $\mathbf{\%}$ & $\mathbf{k g}$ \\
\hline $\begin{array}{c}\text { Verdes de manzanilla } \\
\text { común }\end{array}$ & - & 11,40 & - & - & - & - & 6,5 & 0,74 & 93,50 & $\mathbf{1 0 , 6 6}$ \\
\hline $\begin{array}{c}\text { Flores de manzanilla } \\
\text { común }\end{array}$ & 3,46 & 1,47 & 6,50 & 0,22 & 93,50 & $\mathbf{3 , 2 4}$ & 6,5 & 0,10 & 93,50 & $\mathbf{1 , 3 7}$ \\
\hline Total & 3,46 & 12,87 & 6,50 & $\mathbf{0 , 2 2}$ & 93,50 & 3,24 & 6,5 & $\mathbf{0 , 8 4}$ & 93,50 & 12,03 \\
\hline
\end{tabular}

Composición de productos

Tabla 30-5

\begin{tabular}{|c|c|c|c|c|}
\hline & \multicolumn{2}{|c|}{ Producto flores } & \multicolumn{2}{c|}{ Producto planta entera } \\
\hline Componente & kg & $\mathbf{\%}$ & kg & \% \\
\hline Partes verdes & 0,22 & 6,50 & 10,66 & 82,83 \\
\hline Flores & - & - & 1,37 & 10,64 \\
\hline Agua & 3,24 & 93,50 & 0,84 & 6,50 \\
\hline Total & 3,46 & 100,00 & 12,87 & 100,00 \\
\hline
\end{tabular}




\section{A.31. Cálculo de carga a envasadora}

Volumen de tolva envasadora Maisa-EC12BE

Tabla 31-1

\begin{tabular}{|c|c|c|c|c|}
\hline Capacidad de tolva envasadora: & 12,00 & kg de Té Negro Fannings & & \\
\hline \multirow[t]{3}{*}{ Prueba de densidad de Fannings*: } & $\frac{2,00}{4,60}$ & $\frac{\mathrm{g} \text { de Té Negro Fannings }}{\mathrm{mL}}$ & & \\
\hline & 0,43 & $\frac{\mathrm{g} \text { de Té Negro Fannings }}{\mathrm{mL}}$ & & \\
\hline & 0,43 & $\frac{\text { kg de Té Negro Fannings }}{\mathrm{L}}$ & & \\
\hline Densidad: & 434,78 & $\frac{\text { kg de Té Negro Fannings }}{\mathrm{m}^{3}}$ & & \\
\hline Volumen de tolva de envasadora: & $\frac{1,00}{434,78}$ & $\frac{\mathrm{m}^{3}}{\text { kg de Té Negro Fannings }}$ & $\mathrm{x} \quad 12,00$ & kg de Té Negro Fannings \\
\hline
\end{tabular}

Fuente: Maisa (2015).

Carga a tolva envasadora Maisa-EC12BE por tipo de producto

Tabla 31-2

\begin{tabular}{|c|c|c|c|}
\hline $\begin{array}{c}\text { Partes verdes molidas (Tamiz N } \\
\text { manzanilla común de Tarma }\end{array}$ & Cantidad & $\begin{array}{c}\text { Flores molidas (Tamiz No30 ASTM) de } \\
\text { manzanilla común de Tarma }\end{array}$ & Cantidad \\
\hline Densidad $\left(\mathrm{kg} / \mathrm{m}^{3}\right)$ & 215,2266 & Densidad $\left(\mathrm{kg} / \mathrm{m}^{3}\right)$ & 215,2266 \\
\hline Carga a envasadora EC12BE $(\mathrm{kg})$ & 5,94 & Carga a envasadora EC12BE $(\mathrm{kg})$ & 5,94 \\
\hline Partes verdes a envasar por lote el año $10(\mathrm{~kg})$ & $\mathbf{1 2 , 8 7}$ & Flores a envasar por lote el año $10(\mathrm{~kg})$ & $\mathbf{3 , 4 6}$ \\
\hline Cantidad de cargas teóricas por lote & 2,17 & Cantidad de cargas teóricas por lote & 0,58 \\
\hline Cantidad de cargas reales por lote & 3,00 & Cantidad de cargas reales por lote & 1,00 \\
\hline
\end{tabular}

Fuente: Maisa (2015).

Volumen de contenido de bolsa filtrante según tipo de producto

Tabla 31-3

\begin{tabular}{|c|c|c|c|}
\hline $\begin{array}{c}\text { Partes verdes molidas (Tamiz } N^{\circ} \text { 30 ASTM) de } \\
\text { manzanilla común de Tarma }\end{array}$ & Cantidad & $\begin{array}{c}\text { Flores molidas (Tamiz No30 ASTM) de } \\
\text { manzanilla común de Tarma }\end{array}$ & Cantidad \\
\hline Densidad $\left(\mathrm{g} / \mathrm{cm}^{3}\right)$ & 0,2152 & Carga a envasadora EC12BE $(\mathrm{kg})$ & 0,2152 \\
\hline Volumen de 1 gramo $\left(\mathrm{cm}^{3}\right)$ & 4,6468 & Flores a envasar por lote el año $10(\mathrm{~kg})$ & 4,6468 \\
\hline Volumen de bolsa filtrante $\left(\mathrm{cm}^{3}\right)$ & $\mathbf{4 , 6 4 6 8}$ & Volumen de bolsa filtrante $\left(\mathrm{cm}^{3}\right)$ & $\mathbf{4 , 6 4 6 8}$ \\
\hline
\end{tabular}

Fuente: Maisa (2015).

"Tipo de té negro especialmente molido para ser envasado en bolsas filtrantes. 


\section{A.37. Valoración y suplementos de las operaciones}

Tabla 37-1

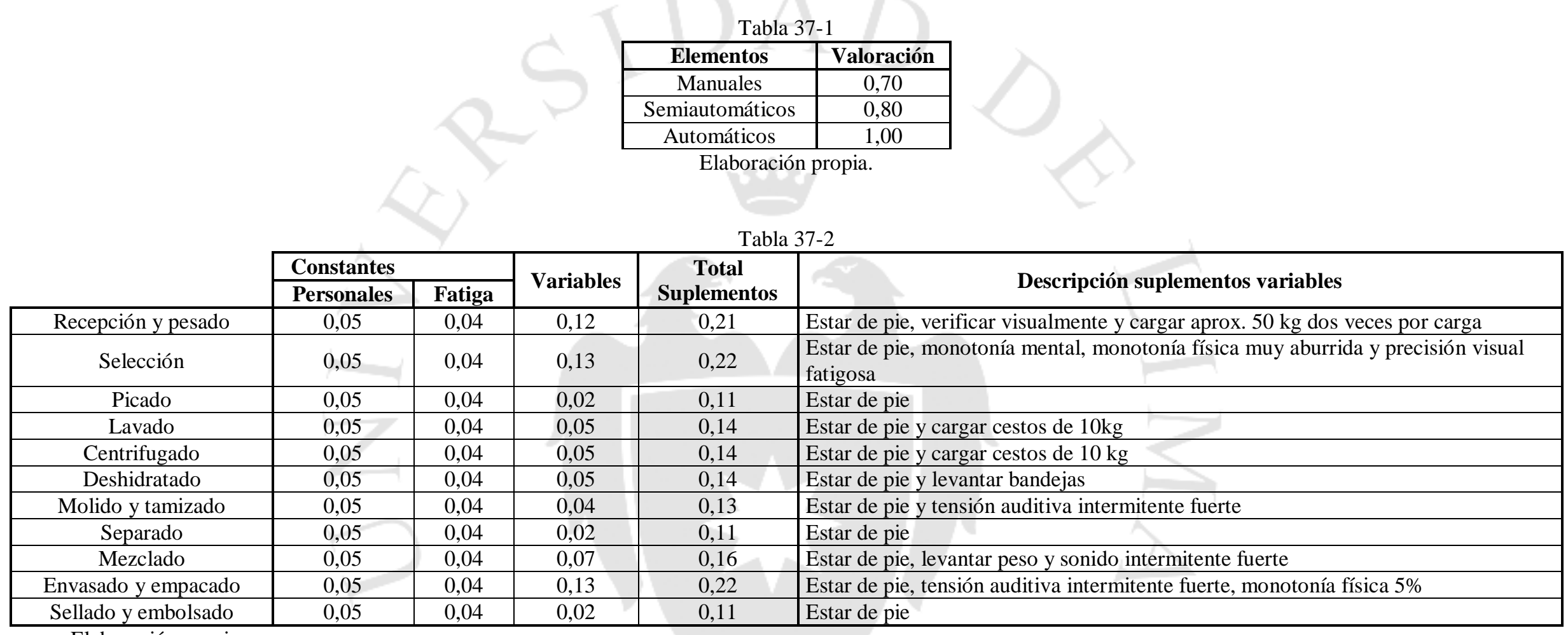

Elaboración propia 
A.38. Tiempo por lote $\mathrm{v}$ estándar de operaciones asociadas a partes verdes

\begin{tabular}{|c|c|c|c|c|c|c|c|c|}
\hline Operación & Elemento & $\begin{array}{c}\text { Tiempo } \\
\text { Promedio } \\
\text { (min/lote) }\end{array}$ & $\begin{array}{c}\% \\
\text { Valoración }\end{array}$ & $\begin{array}{c}\% \\
\text { Suplemento }\end{array}$ & $\begin{array}{c}\text { Tiempo } \\
\text { Estándar } \\
\text { (min/lote) }\end{array}$ & $\begin{array}{l}\text { Tiempo } \\
\text { Estándar } \\
\text { (min/lote) }\end{array}$ & $\begin{array}{l}\text { Factor de } \\
\text { Eficiencia }\end{array}$ & $\begin{array}{l}\text { Tiempo } \\
\text { Estándar } \\
\text { (h/kgMP) }\end{array}$ \\
\hline \multirow{3}{*}{$\begin{array}{c}\text { Recepción y } \\
\text { pesado }\end{array}$} & Recibir carga, verificar y llevar a balanza & 4,00 & 0,70 & 1,21 & 3,39 & \multirow{3}{*}{4,40} & \multirow{3}{*}{0,8470} & \multirow{3}{*}{0,000864} \\
\hline & Pesar carga & 0,53 & 0,70 & 1,21 & 0,45 & & & \\
\hline & Registrar carga & 0,67 & 0,70 & 1,21 & 0,56 & & & \\
\hline \multirow{2}{*}{ Selección } & Llevar carga a mesa de selección & 0,15 & 0,70 & 1,22 & 0,13 & \multirow{2}{*}{144,42} & \multirow{2}{*}{0,8540} & \multirow{2}{*}{0,028318} \\
\hline & Seleccionar y cortar partes & 168,96 & 0,70 & 1,22 & 144,29 & & & \\
\hline \multirow{2}{*}{ Picado } & Llevar partes verdes en cestos a picadora & 1,00 & 0,70 & 1,11 & 0,78 & \multirow{2}{*}{90,27} & \multirow{2}{*}{0,7998} & \multirow{2}{*}{0,026898} \\
\hline & Picar partes verdes con avance manual & 111,86 & 0,80 & 1,00 & 89,49 & & & \\
\hline \multirow{3}{*}{ Lavado } & Llevar carga en cestos a lavadero & 1,00 & 0,70 & 1,14 & 0,80 & \multirow{3}{*}{16,38} & \multirow{3}{*}{0,9102} & \multirow{3}{*}{0,004932} \\
\hline & Agregar desinfectante y dejar reposar & 10,00 & 1,00 & 1,00 & 10,00 & & & \\
\hline & Lavar y enjuagar manualmente la carga & 7,00 & 0,70 & 1,14 & 5,59 & & & \\
\hline \multirow{3}{*}{ Centrifugado } & Cargar cestos a centrífuga & 0,29 & 0,70 & 1,14 & 0,23 & \multirow{3}{*}{24,57} & \multirow{3}{*}{0,9941} & \multirow{3}{*}{0,007396} \\
\hline & Dejar centrifugar & 24,00 & 1,00 & 1,00 & 24,00 & & & \\
\hline & Descargar cestos & 0,43 & 0,70 & 1,14 & 0,34 & & & \\
\hline \multirow{3}{*}{ Deshidratado } & Colocar cargas en bandejas & 22,00 & 0,70 & 1,14 & 17,56 & \multirow{3}{*}{690,32} & \multirow{3}{*}{0,9890} & \multirow{3}{*}{0,147770} \\
\hline & Deshidratar bajo supervisión periódica & 660,00 & 1,00 & 1,00 & 660,00 & & & \\
\hline & Retirar bandejas del deshidratador & 16,00 & 0,70 & 1,14 & 12,77 & & & \\
\hline \multirow{3}{*}{$\begin{array}{l}\text { Molido y } \\
\text { tamizado }\end{array}$} & Llevar carga seca a molino & 0,50 & 0,70 & 1,13 & 0,40 & \multirow{3}{*}{38,00} & \multirow{3}{*}{0,7998} & \multirow{3}{*}{0,054467} \\
\hline & Moler con avance manual & 46,51 & 0,80 & 1,00 & 37,21 & & & \\
\hline & Recoger molido & 0,50 & 0,70 & 1,13 & 0,40 & & & \\
\hline \multirow{2}{*}{ Mezclado } & Llevar carga de flores y partes verdes & 1,50 & 0,70 & 1,16 & 1,22 & \multirow{2}{*}{16,22} & \multirow{2}{*}{0,9829} & \multirow{2}{*}{0,021007} \\
\hline & Dejar mezclar & 15,00 & 1,00 & 1,00 & 15,00 & & & \\
\hline Envasado y & Cargar manualmente la tolva del envasador & 0,51 & 0,70 & 1,22 & 0,44 & 10766 & 09093 & 0139453 \\
\hline empacado & Dejar envasar. Cerrar cajas manualmente & 107,23 & 1,00 & 1,00 & 107,23 & $10 /, 00$ & 0,9995 & 0,159455 \\
\hline Sellado y & Llevar cajas a selladora & 0,14 & 0,70 & 1,11 & 0,11 & 2600 & م 7000 & 3678 \\
\hline embolsado & Sellar cajas y colocarlas en bolsa & 32,37 & 0,80 & 1,00 & 25,89 & 20,00 & 0,1999 & $0,0350 / 8$ \\
\hline
\end{tabular}

Elaboración propia 
A.39. Tiempo por lote v estándar de operaciones asociadas a flores

\begin{tabular}{|c|c|c|c|c|c|c|c|c|}
\hline Operación & Elemento & $\begin{array}{c}\text { Tiempo } \\
\text { Promedio } \\
\text { (min/lote) }\end{array}$ & \begin{tabular}{|c|}
$\%$ \\
Valoración
\end{tabular} & $\begin{array}{c}\% \\
\text { Suplemento }\end{array}$ & $\begin{array}{c}\text { Tiempo } \\
\text { Estándar } \\
\text { (min/lote) }\end{array}$ & $\begin{array}{c}\text { Tiempo } \\
\text { Estándar } \\
\text { (min/lote) }\end{array}$ & $\begin{array}{l}\text { Factor de } \\
\text { Eficiencia }\end{array}$ & $\begin{array}{c}\text { Tiempo } \\
\text { Estándar } \\
(\text { h/kgMP })\end{array}$ \\
\hline \multirow{3}{*}{$\begin{array}{c}\text { Recepción y } \\
\text { pesado }\end{array}$} & Recibir carga, verificar y llevar a balanza & 4,00 & 0,70 & 1,21 & 3,39 & \multirow{3}{*}{4,40} & \multirow{3}{*}{0,8470} & \multirow{3}{*}{0,000864} \\
\hline & Pesar carga & 0,53 & 0,70 & 1,21 & 0,45 & & & \\
\hline & Registrar carga & 0,67 & 0,70 & 1,21 & 0,56 & & & \\
\hline \multirow{2}{*}{ Selección } & Llevar carga a mesa de selección & 0,15 & 0,70 & 1,22 & 0,13 & \multirow{2}{*}{144,42} & \multirow{2}{*}{0,8540} & \multirow{2}{*}{0,028318} \\
\hline & Seleccionar y cortar partes & 168,96 & 0,70 & 1,22 & 144,29 & & & \\
\hline \multirow{3}{*}{ Lavado } & Llevar carga en cestos a lavadero & 0,55 & 0,70 & 1,14 & 0,44 & \multirow{3}{*}{12,83} & \multirow{3}{*}{0,9471} & \multirow{3}{*}{0,008923} \\
\hline & Agregar desinfectante y dejar reposar & 10,00 & 1,00 & 1,00 & 10,00 & & & \\
\hline & Lavar y enjuagar manualmente la carga & 3,00 & 0,70 & 1,14 & 2,39 & & & \\
\hline \multirow{3}{*}{ Centrifugado } & Cargar cestos a centrífuga & 0,22 & 0,70 & 1,14 & 0,17 & \multirow{3}{*}{12,34} & \multirow{3}{*}{0,9930} & \multirow{3}{*}{0,008582} \\
\hline & Dejar centrifugar & 12,00 & 1,00 & 1,00 & 12,00 & & & \\
\hline & Descargar cestos & 0,22 & 0,70 & 1,14 & 0,17 & & & \\
\hline \multirow{3}{*}{ Deshidratado } & Colocar cargas en bandejas & 17,00 & 0,70 & 1,14 & 13,57 & \multirow{3}{*}{682,34} & \multirow{3}{*}{0,9918} & \multirow{3}{*}{0,154179} \\
\hline & Deshidratar bajo supervisión periódica & 660,00 & 1,00 & 1,00 & 660,00 & & & \\
\hline & Retirar bandejas del deshidratador & 11,00 & 0,70 & 1,14 & 8,78 & & & \\
\hline \multirow{3}{*}{$\begin{array}{l}\text { Molido y } \\
\text { tamizado }\end{array}$} & Llevar carga seca a molino & 0,22 & 0,70 & 1,13 & 0,17 & \multirow{3}{*}{16,46} & \multirow{3}{*}{0,7998} & \multirow{3}{*}{0,054486} \\
\hline & Moler con avance manual & 20,13 & 0,80 & 1,00 & 16,11 & & & \\
\hline & Recoger molido & 0,22 & 0,70 & 1,13 & 0,17 & & & \\
\hline \multirow{2}{*}{ Separado } & Pesar carga de flores molidas a mezclar & 0,10 & 0,70 & 1,11 & 0,08 & \multirow{2}{*}{0,85} & \multirow{2}{*}{0,7770} & \multirow{2}{*}{0,002888} \\
\hline & Separar carga de flores a mezclar & 1,00 & 0,70 & 1,11 & 0,78 & & & \\
\hline \multirow{2}{*}{$\begin{array}{c}\text { Envasado y } \\
\text { empacado }\end{array}$} & Cargar manualmente la tolva del envasador & 0,17 & 0,70 & 1,22 & 0,15 & \multirow{2}{*}{28,99} & \multirow{2}{*}{0,9991} & \multirow{2}{*}{0,139588} \\
\hline & Dejar envasar. Cerrar cajas manualmente & 28,84 & 1,00 & 1,00 & 28,84 & & & \\
\hline \multirow{2}{*}{$\begin{array}{l}\text { Sellado y } \\
\text { embolsado }\end{array}$} & Llevar cajas a selladora & 0,14 & 0,70 & 1,11 & 0,11 & 0 & & \\
\hline & Sellar cajas y colocarlas en bolsa & 11,61 & 0,80 & 1,00 & 9,29 & 9,39 & 0,199 & $0,045<40$ \\
\hline
\end{tabular}

Elaboración propia

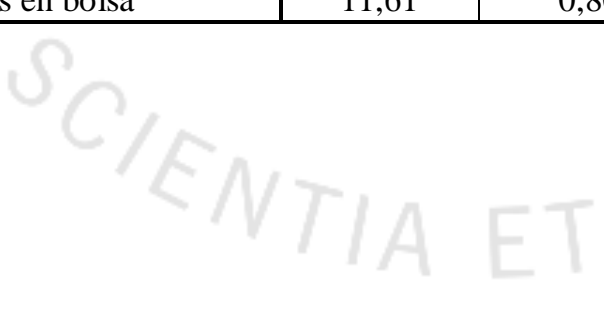




\section{$\underline{\text { A.40. Tiempo de ciclo del proceso productivo }}$}

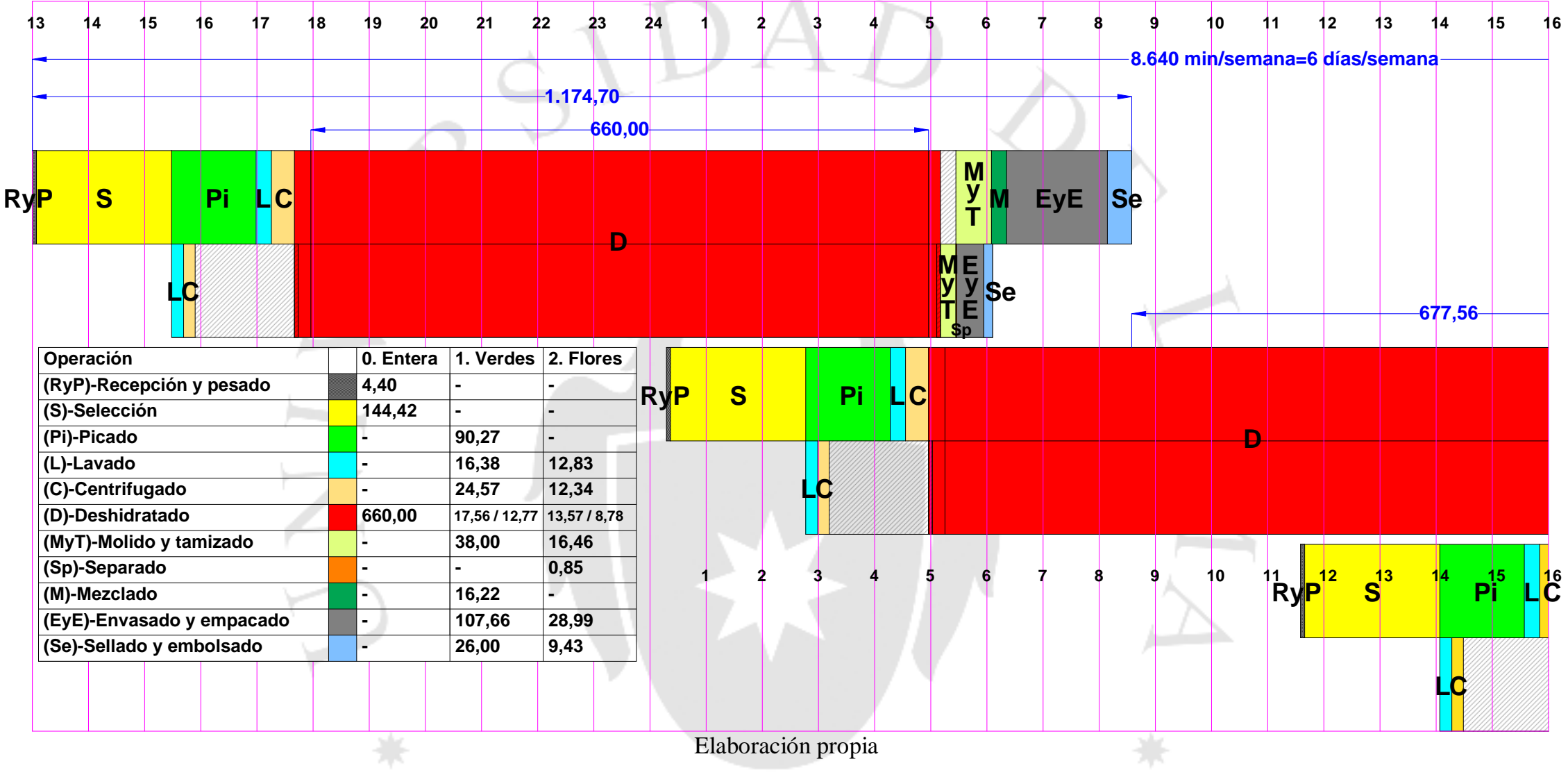

\begin{tabular}{|c|c|}
\hline Descripción & Tiempo (minutos) \\
\hline Duración del primer ciclo & $1.174,70$ \\
\hline Duración a partir del segundo ciclo & 677,56 \\
\hline Duración teórica a la semana (8x3x6x60) & $8.640,00$ \\
\hline Duración real a la semana (1,174.70+11x677,56) & 8.627 .86 \\
\hline Factor de Utilización & 0,9986 \\
\hline
\end{tabular}

Elaboración propia

के 


\section{A.42. Cálculo de carga por bandeja y número de bandejas}

Cálculo de carga por bandeja según producto a deshidratar

Tabla 42-1

\begin{tabular}{|c|c|c|c|c|c|}
\hline Carga de partes verdes por bandeja & Cantidad & Unidad & Carga de flores por bandeja & Cantidad & Unidad \\
\hline Largo de bandeja & 0,50 & $\mathrm{~m}$ & Largo de bandeja & 0,50 & $\mathrm{~m}$ \\
\hline Ancho de bandeja & 0,50 & $\mathrm{~m}$ & Ancho de bandeja & 0,50 & $\mathrm{~m}$ \\
\hline Altura de bandeja & 0,02 & $\mathrm{~m}$ & Altura de bandeja & 0,02 & $\mathrm{~m}$ \\
\hline Porcentaje llenado & 97,5 & $\%$ & Porcentaje llenado & 100 & $\%$ \\
\hline Volumen de bandeja & 0,0049 & $\mathrm{~m}^{3}$ & Volumen de bandeja & 0,0050 & $\mathrm{~m}^{3}$ \\
\hline Altura llenada & 1,95 & $\mathrm{~cm}$ & Altura llenada & 2,00 & $\mathrm{~cm}$ \\
\hline Densidad de partes verdes a secar & 387,1300 & $\mathrm{~kg} / \mathrm{m}^{3}$ & Densidad de flores a secar & 227,4039 & $\mathrm{~kg} / \mathrm{m}^{3}$ \\
\hline Carga por bandeja & 1,8873 & $\mathrm{~kg}$ & Carga por bandeja & 1,1370 & $\mathrm{~kg}$ \\
\hline Carga por área & 7,5490 & $\mathrm{~kg} / \mathrm{m}^{2}$ & Carga por área & 4,5481 & $\mathrm{~kg} / \mathrm{m}^{2}$ \\
\hline
\end{tabular}
Elaboración propia

Cálculo de número de bandejas según producto a deshidratar

Tabla 42-2

\begin{tabular}{|c|c|c|c|c|c|}
\hline Número de bandejas para partes verdes & Cantidad & Unidad & Número de bandejas para flores & Cantidad & Unidad \\
\hline Carga por lote a secar el último año & 55,3707 & $\mathrm{~kg}$ & Carga por lote a secar el último año & 23,9700 & $\mathrm{~kg}$ \\
\hline Carga por bandeja & 1,8873 & $\mathrm{~kg}$ & Carga por bandeja & 1,1370 & $\mathrm{~kg}$ \\
\hline Número teórico de bandejas & 29,3392 & bandejas & Número teórico de bandejas & 21,0814 & bandejas \\
\hline Número real de bandejas & 30,00 & bandejas & Número real de bandejas & 22,00 & bandejas \\
\hline
\end{tabular}

Elaboración propia

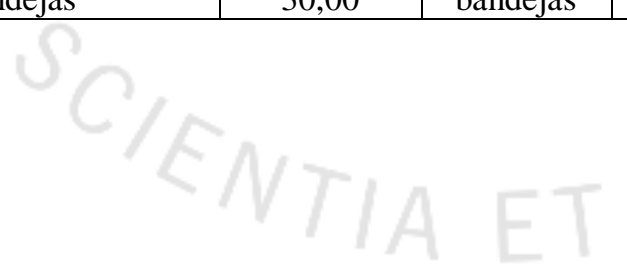




\section{ANEXO 5: Cálculo de consumo de GLP}

A.46. Características físico-químicas del GLP

\begin{tabular}{|c|c|c|c|c|}
\hline Propiedades & & Propano & GLP & Butano \\
\hline Composición volumétrica & & & & \\
\hline Propano & $\%$ & 100,00 & 60,00 & 0,00 \\
\hline Butano & $\%$ & 0,00 & 40,00 & 100,00 \\
\hline Propiedades fisicoquímicas & & & & \\
\hline Presión de vapor a 37,8 ${ }^{\circ} \mathrm{C}$ & $\mathrm{psig}$ & 208 & 160 & 70 \\
\hline Presión de vapor a 0,0 ${ }^{\circ} \mathrm{C}$ & $\mathrm{psig}$ & 70 & 48 & 15 \\
\hline Punto de ebullición @ 1 atm & ${ }^{\circ} \mathrm{C}$ & $-42,10$ & $-25,50$ & $-0,50$ \\
\hline Líquido & & & & \\
\hline Gravedad específica @ 60/60 ${ }^{\circ} \mathrm{F}($ Agua=1) & - & 0,5083 & 0,5389 & 0,5847 \\
\hline Densidad @ 15 ${ }^{\circ} \mathrm{C}$ & $\mathrm{kg} / \mathrm{gal}$ & 1,9220 & 2,0380 & 2,2110 \\
\hline Vapor: & & & & \\
\hline Densidad relativa (Aire=1) & - & 1,5225 & 1,7162 & 2,0068 \\
\hline Inflamabilidad & & & & \\
\hline Límite inferior (LEL) \% volumen de aire & $\%$ & 2,00 & 1,80 & 1,50 \\
\hline Límite superior (UEL) \% volumen de aire & $\%$ & 9,50 & 9,30 & 9,00 \\
\hline Combustión & & & & \\
\hline Volumen aire/gas para combustión (ideal) & & 23,86 & 26,72 & 31,02 \\
\hline Poder calorífico & $\mathrm{BTU} / \mathrm{kg}$ & 47.375 & 47.063 & 46.596 \\
\hline Poder calorífico (Vapor @ 15 ${ }^{\circ} \mathrm{C}$ ) & $\mathrm{BTU} / \mathrm{m}^{3}$ & 88.353 & 98.940 & 114.544 \\
\hline Poder calorífico (Líquido @ 60 ${ }^{\circ} \mathrm{F}$ ) & $\mathrm{BTU} / \mathrm{gal}$ & 90.823 & 95.657 & 102.909 \\
\hline
\end{tabular}

Fuente: OSINERGMIN (2016).

A.47. Parámetros medioambientales en la ubicación de la planta de producción

\begin{tabular}{|c|c|c|c|}
\hline Código & Descripción & Valor & Unidad \\
\hline T1 & Temperatura promedio en Acobamba & 11,40 & ${ }^{\circ} \mathrm{C}$ \\
\hline HR1 & Humedad relativa en Acobamba & 72,00 & $\%$ \\
\hline Altitud & Altitud en Acobamba & $3.059,00$ & $\mathrm{~m} . s . n . m$. \\
\hline P1 & Presión atmosférica en Acobamba & 69,60 & $\mathrm{kPa}$ \\
\hline H1 & Humedad en Acobamba & 0,0088 & $\mathrm{~kg} \mathrm{H} 2 \mathrm{O} / \mathrm{kg}$ Aire Seco \\
\hline T2 & Temperatura en cámara de secado & 45,00 & ${ }^{\circ} \mathrm{C}$ \\
\hline
\end{tabular}

Fuente: Instituto Geofísico del Perú (2016).

A.47. Cálculos del consumo de GLP

\begin{tabular}{|c|c|c|c|c|c|}
\hline GLP en Perú & & $\%$ Volumen & Moles & Masa molar $(\overline{\mathbf{M}})$ & $\begin{array}{c}\text { Entalpía de } \\
\text { combustión }(\mathrm{kJ} / \mathrm{mol})\end{array}$ \\
\hline Propano & C3H8 & 60,00 & 60 & 44,09 & $2.220,00$ \\
\hline Butano & $\mathrm{C} 4 \mathrm{H} 10$ & 40,00 & 40 & 58,12 & $2.878,50$ \\
\hline Elemento & Símbolo & Peso atómico & & & \\
\hline \multicolumn{6}{|l|}{ Por moles: } \\
\hline m GLP & $=$ & $\mathrm{m}$ C $3 \mathrm{H} 8$ & + & $\stackrel{\mathrm{m}}{\mathrm{C} 4 \mathrm{H} 10}$ & \\
\hline Q̊ GLP & $=$ & Q̊ C3H8 & + & Q C4H10 & \\
\hline 7,31 & $=$ & $2.220,00(\mathrm{X})$ & + & $2.878,00(\mathrm{Y})$ & $\ldots$ i \\
\hline$\underline{X}$ & $=$ & $\underline{60,00}$ & & & ...ii \\
\hline $\mathrm{Y}$ & & 40,00 & & & \\
\hline
\end{tabular}




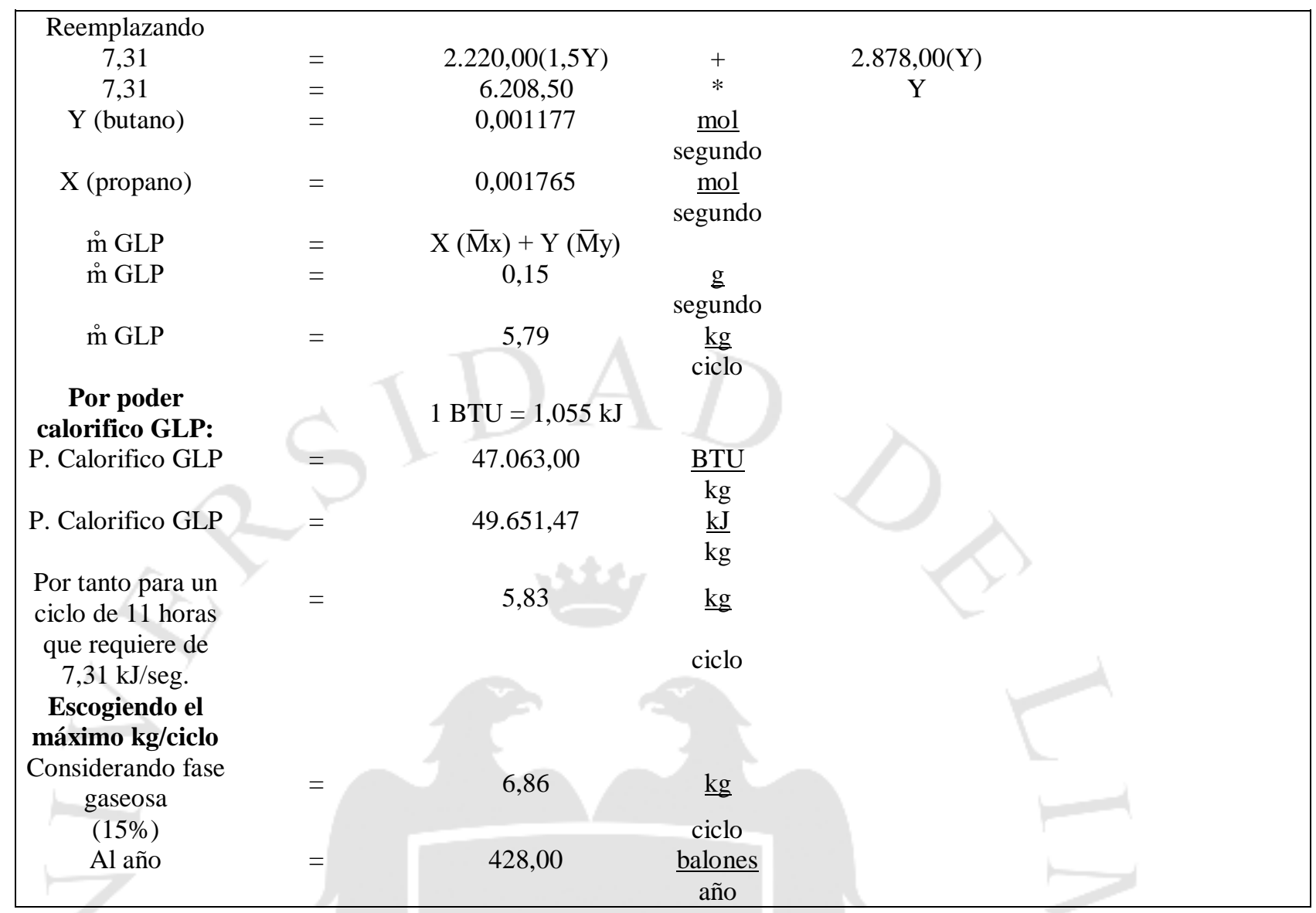

Elaboracion propia

\section{A.48. Plano isométrico del tanque estacionario de GLP y conexiones internas}

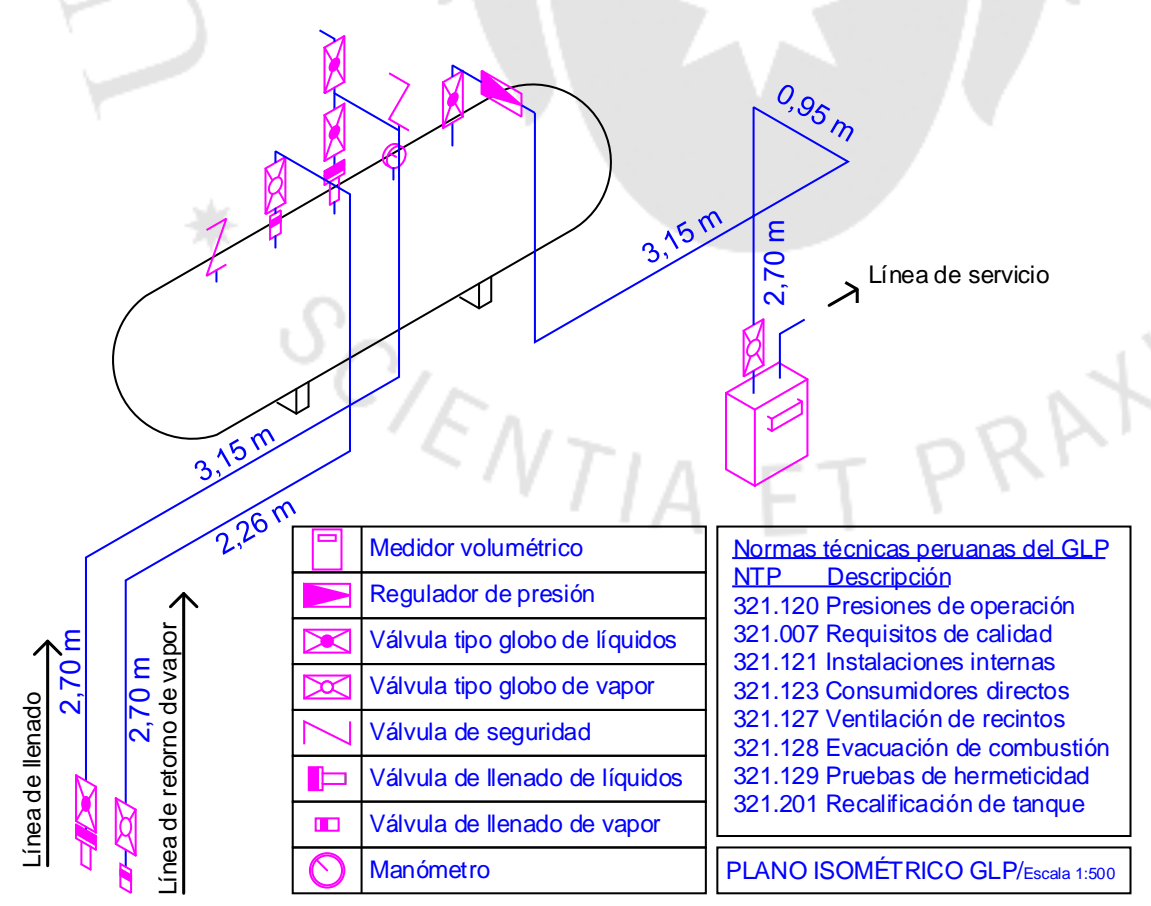

Elaboración propia 